Portland State University

PDXScholar

$1-1-1985$

\title{
The life history strategy of the saxicolous desert lizard, Sauromalus obesus
}

Marvin Lynn Abts

Portland State University

Follow this and additional works at: https://pdxscholar.library.pdx.edu/open_access_etds Let us know how access to this document benefits you.

Recommended Citation

Abts, Marvin Lynn, "The life history strategy of the saxicolous desert lizard, Sauromalus obesus" (1985). Dissertations and Theses. Paper 8.

https://doi.org/10.15760/etd.8

This Dissertation is brought to you for free and open access. It has been accepted for inclusion in Dissertations and Theses by an authorized administrator of PDXScholar. Please contact us if we can make this document more accessible: pdxscholar@pdx.edu. 
THE LIFE HISTORY STRATEGY OF THE SAXICOLOUS

DESERT LIZARD, Sauromalus obesus

by

MARVIN LYNN ABTS

A dissertation submitted in partial fulfillment of the requirements for the degree of

DOCTOR OF PHILOSOPHY

in

ENVIRONMENTAL SCIENCES AND RESOURCES:BIOLOGY

Portland State University

1985 
TO THE OFFICE OF GRADUATE STUDIES AND RESEARCH:

The members of the Committee approve the dissertation of Marvin Lynn Abts presented June 3. 1985.

PhillipVC. Withers, Chairman

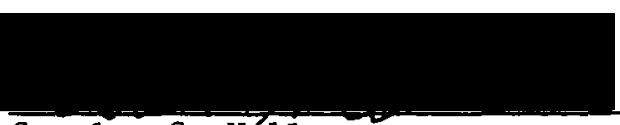

Stanley S. HIIIman

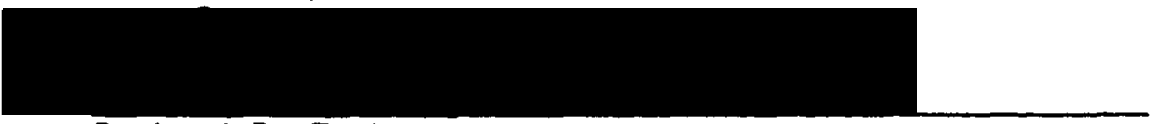

Richard B. Forbes

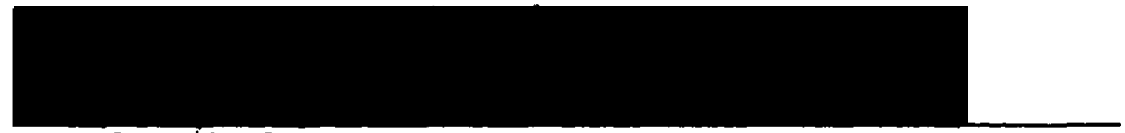

Alfred S. Levinson

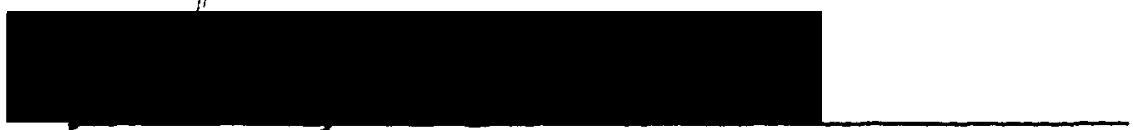

Richard E. Thoms

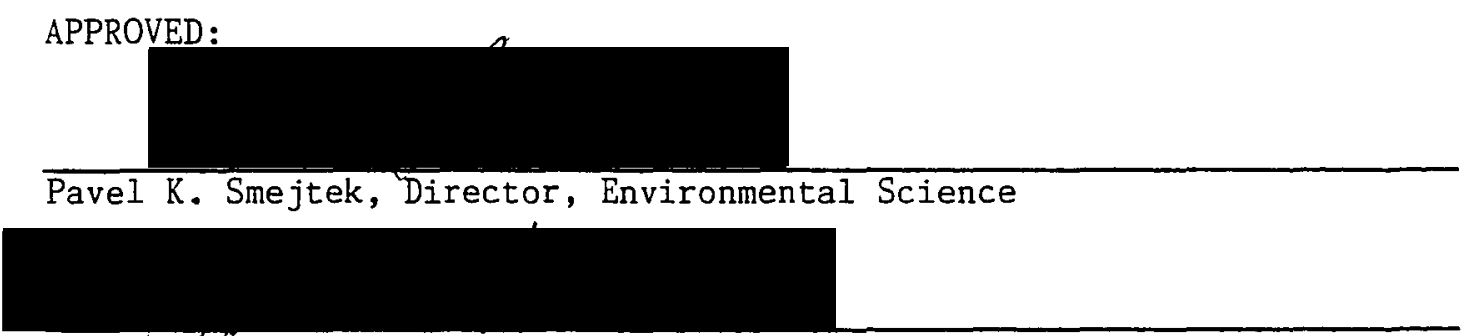

Jame E.J Heath, Dean of Graduate Studies and Research 


\section{ABSTRACT}

Studies of life histories of lizards have usually failed to address appropriate questions and/or were not of sufficient duration to test current life history theory. Also, studies of insectivorous lizards far outnumber studies of herbivorous species, and the life history of the western chuckwalla (Sauromalus obesus Baird), an important desert herbivore, is scarcely known. I chose to study the life history of S. obesus over a sufficient period to provide an adequate test of current life history theory. In addition, I attempted to model population parameters for $\underline{S}$. obesus from environmental variables.

This investigation of $\underline{\mathrm{S}}$. obesus was conducted from $1977-1983$ in the Colorado Desert of southeastern California and incorporated 4 segments of data: 1) environmental and general ecology; 2) reproductive cycle and synchrony; 3) life history and demography; and 4) population dynamics.

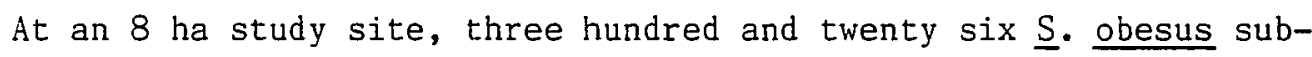
jected to capture-recapture and observation during 1250 hours of investigation provided data for determining most life history and demographic attributes. About $500 \underline{\mathrm{S}}$. obesus (approximately equal numbers of the sexes) were collected for autopsy from localities within a $15 \mathrm{~km}$ radius of the study site. A combination of gross morphological and histological measurements enabled the determination of a number of reproductive traits and provided additional life history and demographic information.

The main activity period of Colorado Desert $\underline{S}$. obesus is about 8 months, but episodes of feeding occurred throughout the year. Coyotes 
appeared to be this species' primary predator. Home range sizes of males and females were correlated with adult female activity and nutrient requirements, respectively. Territoriality occurred throughout the activity season, but episodes of high level aggression were rare. Sharing of rock crevices between sexes year round solidified pair-bonding for future reproductions.

Determination of 4 types of ovarian follicles in adult females contributed to understanding breeding synchrony. Pre-ovulatory follicles and corpora lutea contributed to estimates of clutch size. The breeding status of males was best determined by the presence of sperm in the vas deferens and by levels of spermatogenic activity. Adult males displayed a type II testicular cycle. The corpora adiposa of males and females largely served as an energy source for reproduction. Adult females always oviposited during the first half of July. Eggs required about 3 months for incubation.

Size at reproductive maturity for both sexes was about $125 \mathrm{~mm}$ SVL. Age at maturity for males and females was 2 and 3 years, respectively. Mean clutch size was 6.9 eggs. Reproduction occurred in 6 of 7 years. Mean annual reproductive frequency was $51 \%$. Mean egg weight was $8.4 \mathrm{~g}$. Clutch weights averaged $34.3 \%$ of the total body weight. Egg weights averaged $5.3 \%$ of the total body weight. For a given body size, there was no annual variation in clutch size, egg size or reproductive effort. The consistency of these traits indicates adaptation to a predictable environment. Relatively high egg weights are an adaptation to counter the harsh environment. Fecundity was highly correlated with body size (age); annual variation was attributable to changes in reproductive 
frequency. First year and subsequent annual survivorship rates were $38 \%$ and $75 \%$, respectively.

The adult sex ratio was $1: 1$. Annual recruitment was about $20 \%$, almost exclusively due to reproduction. Annual tail-break frequency was generally higher in adult males, but greatiy increased in individuals larger than $165 \mathrm{~mm}$ SVL. The mean population density was 23 per ha. Most individuals lived no longer than 10 years.

Compared with Mojave Desert populations, Colorado Desert $\underline{S}$. obesus demonstrated earlier maturity, higher reproductive rates, higher first year survival and lower adult survivorship. High reproductive rates and first year survival were attributable to the predictability of mild winters and summer rainfall. Such conditions promoted lower adult survivorship because of associated costs of reproduction and predation. The population I studied demonstrated considerable growth $\left(R_{0}=1.54\right)$. However, because occasional periods of drought cause rapid population decline, over the long run population stability is maintained. Attempts were made to predict population age class structure from winter precipitation regression models. Such a procedure appears reliable for predicting age-specific fecundity and therefore is a useful tool for management practices. 


\section{ACKNOWLEDGEMENTS}

Dr. Kristin Berry directed my attention to considering the relationship of environment and life history tactics. Dan Birchfield, Neal Mettler, Richard Chacon, Roger Anderson, Robert Lehmann, Laura O'Brien and Jim Campbell assisted in the location and capture of lizards. Robert Lehmann made a major contribution in lizard observation and plant collection. Oscar Clark was instrumental in the identification of desert flora. John Hough permitted the use of the biomedical facility at the University of California, Riverside and provided indepth assistance in histological preparations. Dr. Phillip Withers was responsible for all computer programming. Dr. Phillip Withers, Dr. Stanley Hillman, and Dr. Richard Forbes offered helpful criticism in the construction of the thesis. Debbie Latham, Margaret Johnson, and Ginger Abts typed the thesis.

I'm deeply indebted to these people and sincerely thank them for devoting considerable time and effort to the undertaking of this project. In addition, I wish to thank my parents, Marge and Wes Abts, for supporting my childhood herpetological interests and giving me the opportunity to pursue higher education. Lastly, I thank my dear wife Ginger. Her patience and understanding were critical to the success of the project. 
ACKNOWLEDGEMENTS . . . . . . . . . . . . . . . iii

LIST OF TABLES ..................... . . vi

LIST OF FIGURES . . . . . . . . . . . . . . . xi

INTRODUCTION . . . . . . . . . . . . . . . . 1

MATERIALS AND METHODS ..................... 6 CHAPTER

I CLIMATE AND VEGETATION . . . . . . . . . 16

II GENERAL ECOLOGY

Annual Activity of Chuckwallas ........ 49

Feeding Habits ............ . . 51

Competitors and Predators . . . . . . . 58

Movement and Spacing Patterns ........ 64

Social Behavior............. 83

III REPRODUCTION

Female Reproductive Cycle . . . . . . . . 112

Male Reproductive Cycle . . . . . . . . . 162

Synchrony of the Breeding Season ........ 246

Incubation and Appearence of Hatchlings . . . . 251

IV LIFE HISTORY: REPRODUCTION

Size and Age at Reproductive Maturity . . . . 258

Clutch Size ............... 266

Frequency of Reproduction ............ 275

Reproductive Effort .............. 293

Annual Reproductive Output and Fecundity . . . . 307

V LIFE HISTORY: POPULATION DYNAMICS

Survivorship . . . . . . . . . . 321

Sex Ratio ................. 340

Recruitment and Predation Intensity . . . . . 352 
PAGE

Density . . . . . . . . . . 381

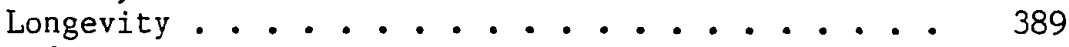

Life Tables............... 400

Leslie Matrix . . . . . . . . . 424

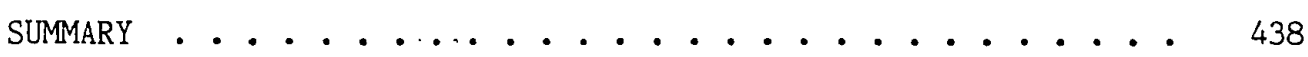

REFERENCES ....................... 466 
I Mean Monthly Temperatures for Julian Hinds Pumping Station ..................

II Mean Monthly Precipitation for Julian Hinds Pumping Station ................

III Comparison of various Precipitation Categories during Different Periods for Julian Hinds Pumping Station. •

IV 7-Year Precipitation Categories for Julian Hinds Pumping Station............... . . 25

V Warm Season Precipitation for Julina Hinds Pumping Station . . . . . . . . . . . 25

VI Mean Monthly Standing Crop of Winter Annuals at the Red Cloud Road Study Site............ 32

VII Linear Regression Analysis of Vegetation Growth with an Assortment of Climatic Parameters . . . . . . 44

VIII Multiple Regression Analysis of Vegetation with an Assortment of Climatic Parameters ...... . 48

IX Monthly Sighting Frequency of $\underline{S}$. obesus at the Red Cloud Road Study Site .......... 50

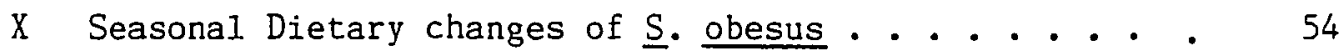

XI Lizard Species Inhabiting the Red Cloud Road Study Site. 61

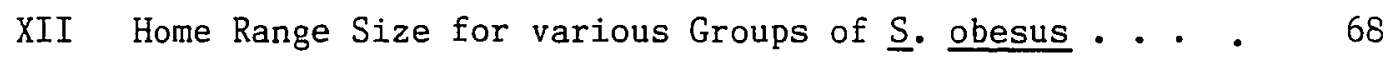

XIII The Body Sizes of Tyrant Males . . . . . . . 70

XIV Home Range Size Comparison for various Groups of $\underline{\mathrm{S}}$.

XV The Number of Adult Females Observed within the Home Ranges of Tyrant Adult Males .......... 76

XVI Stereotyped Behaviors Associated with Territoriality and Courtship ...............

XVII The Acts and Act Systems Integral in Threat, Challenge and Chase ............... 88

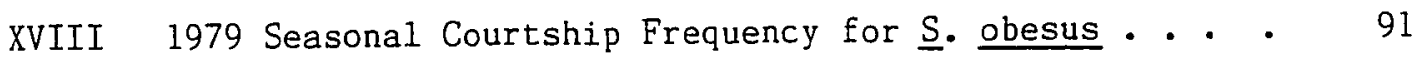


vii

TABLE

PAGE

XIX 1979 Relationship Between Courtship Frequency and Body Size for Adult Males . . . . . . . . .

XX 1979 Relationship Between Courtship Frequency and Body Size for Adult Females . . . . . . . . .

XXI Seasonal Change in Number of Ovarian Follicles in Adult Females . . . . . . . . . . . .

XXII Seasonal Change in Number of Previtellogenic Ovarian Follicles in Adult Females. . . . . . . . . .

XXIII Seasonal Change in Number of Vitellogenic Ovarian Follicles in Adult Females. . . . . . . . .

XXIV Seasonal Change in Number of Atretic Ovarian Follicles in Adult Females . . . . . . . . . . 124

XXV Seasonal Change in Number of Preovulatory Ovarian Follicles in Adult Females . . . . . . . . 130

XXVI Seasonal Change in Diameter of Preovulatory Ovarian Follicles in Adult Females . . . . . . . .

XXVII Seasonal Change in Diameter of Corpora Lutea in Adult Females . . . . . . . . . . . 137

XXVIII Seasonal Change in Ovarian Volume in Adult Females . . 139

XXIX Seasonal Change in Number of Ovarian Follicles of Immature Females. . . . . . . . . . .

XXX Seasonal Change in Ovarian Volume in Innature Females.

XXXI Seasonal Change in Uterine Tubular Gland Epithelial Thickness in Adult Females. . . . . . . . 149

XXXII Eight Stages of Spermatogenesis for Adult Males. . . . 175

XXXIII Bimonthly Spermatogenic Activity in Adult Males. •. . 189

XXXIV Relationship of Stages of Spermatogenic Cycle with Seminiferous Tubule Diameter and Seminiferous Epithelial Height in Adult Males. . . . . . .

XXXV Sighting Frequency of Hatchling $\underline{S}$. obesus at the Red Cloud Road Study Site.......... 
XXXVI Population Breeding Frequency of Adult Fenales during 5 Consecutive Years ..........

XXXVII Range in Body Size for 7 Age Classes of Male and Female $\underline{S}$ obesus . . . . . . . . . 265

XXXVIII Mean Clutch Size and Mean Body Size for Adult Females.............. 268

XXXIX Regression Analysis of the Relationship of Climatic Factors and Clutch Size. . . . . . . . 273

XXXX Frequency of Reproduction for Adult Females Captured during 4 Consecutive Years. . . . . . .

XXXXI Body Mass Fluctuation for Red Cloud Road Study Site Adult Females . . . . . . . . . 285

XXXXII Spring Growth and Frequency of Reproduction for Adult Females of SVL Range $150-170 \mathrm{~mm}$. . . . 288

XXXXIII Regression Analysis of the Relationship of Climatic Factors and Reproductive Frequency . . . . . . 290

XXXXIV Egg and Clutch Data for Adult Females . . . . . 295

XXXXV Regression Analysis of Egg and Clutch Data for Adult Females ........... 296

XXXXVI Comparison of Relative Morphological Measurements Between Platynotus Semitaeniatus and $\underline{\text { S. obesus . }} 301$

XXXXVII Comparison of Reproductive Parameters for 12 Species of Iguanines . . . . . . . . . . 305

XXXXVIII 5-Year Annual Reproductive Output for Adult Females • 310

XXXXIX Age-Specific Fecundity for Adult Females. . . . . 312

L Linear Regression Analysis showing the Correlation of Fecundity with Age for Adult Females. . . . 313

LI Linear Regression Analysis Showing the Correlation of Fecundity with 3 Important Climatic and Vegetation Parameters ......... 315

LII Age-Specific Fecundity for 5 Species of Iguanid Lizards . . . . . . . . . . . . 
LIII Age Class 0 to Age Class 1 Survivorship . . . . . 323

LIV Annual Survivorship of Females Greater than 1 Year 01d. 329

LV Annual Survivorship of Males Greater that 1 Year 01d. . 332

LVI Comparison of Annual Survivorship for Iguanid Lizards . 336

LVII The Population Sex Ratio at the Red Cloud Road Study Site............. . . 343

LVIII Cohort Sex Ratios at the Red Cloud Road Study Site. . . 345

LIX A Comparison of Adult Sex Ratios for 6 Populations of S. obesus ............ . . 347

LX A Comparison of Adult Sex Ratios for 2 Populations of S. obesus ............. 349

LXI Total Annual Recruitment Rate . . . . . . . . 355

LXII Annual Recruitment of Yearlings and Older Age Classes • 356

LXIII The Relationship of Tail Break Frequency with Several

Parameters ............ 363

LXIV Tail Break Frequency Comparison Between Adult Sexes . • 365

LXV Linear Regression Analysis of Tail Break Frequency and Selected Population Parameters ....... 375

LXVI The Relationship Between Tail Break Frequency and 2 Body Size Parameters for Northern Desert Populations ............. . . 377

LXVII Annual Population Density at the Red Cloud Road Study Site............. . . 383

LXVIII Comparison of Density and Biomass Between Mojave Desert and Red Cloud Road S. obesus . . . . . 387

LXIX Body Sizes of Known-Age $\underline{S}$. obesus during the First 10 Years . . . . . . . . . . .

LXX Annual Growth Rates for Different Body Size Categories of Males................ 
TABLE

LXXI Annual Growth Rates for Different Body Size Categories of Females ............. . 394

LXXII Mean Annual Growth Rates for Different Body Size Categories of S. obesus at Lone Butte . . . . . 397

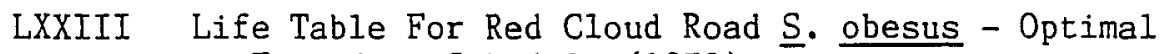
Fecundity Schedule (1979) ........ 405

LXXIV Life Table - Average Fecundity Schedule (1980). . . . 406

LXXV Life Table - 5-Year Average Fecundity Schedule. . . . 408

LXXVI Life Table - Depicting a Stable Population . . . . . 409

LXXVII Life Table - Predicted for 1961 - 1977 from FecundityPrecipitation Regression Equation ....... 411

LXXVIII Chi-Square Test for Goodness of Fit for Observed and Predicted (Leslie Matrix) Population Characteristics of Red Cloud Road S. obesus .......... 434 
LIST OF FIGURES

FIGURE

PAGE

1. The Colorado Desert Study Area ... . . . . . . 7

2. The Red Cloud Road Study Site ... . . . . . . . 9

3. Monthly Precipitation Amounts during the 7-Year Study . . 21

4. Growing Season during the 7-Year Study . . . . . . . . 27

5. Map of the Red Cloud Road Study Site . . . . . . . . 29

6. Monthly Dry Weights of Winter Annuals . . . . . . . . 34

7. Average Daily Rate of Change of Winter Annual Standing Crop ................... 37

8. Mean April (Peak) Winter Annual Standing Crop . . . . 39

9. Yearly Analysis of Perennial Stem Elongation . . . . . 41

10. 4-Year Home Ranges of the 36 Most Frequently Observed

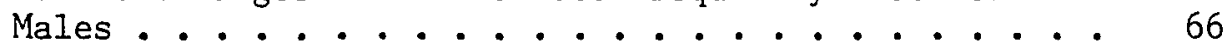

11. Annual Variation of Home Range Sizes for Adult Males . . 72

12. 4-Year Home Ranges of the 46 Most Frequently Observed Females ................. 78

13. Annual Variation of Home Range Sizes for Adult Females . - 81

14. The Relationship of Body Size and Courtship Frequency for Adult Males ................. 93

15. The Relationship of Body Size and Courtship Frequency For Adult Females . . . . . . . . . . . . 93

16. The Response of Adult Females to Courtship Frequency for Adult Females . . . . . . . . . . 102

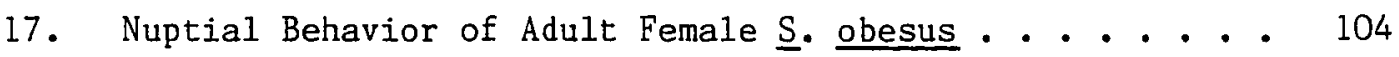

18. 3 Forms of Enticement Behavior Elicited by Adult Females • 107

19. Types of Ovarian Follicles in Adult Females . . . . . 113

20. Percent Frequency of the Types of Ovarian Follicles for
Adult Females . . . . . . . . . . 125 
21. The Corpus Luteum of an Adult Female . . . . . . . 134

22. The Uterus of Adult Females with Seasonal Changes in Branched Tubular Glands .............. 143

23. Seasonal Changes in Uterine Epithelial Thickness for Adult Females . . . . . . . . . . . 147

24. The Relationship of Seasonal Changes in Ovarian and Uterine Structures for Adult Females . . . . . . 152

25. Seasonal Changes in Mean Fat Body Weight/Body Weight of Adult Females ............. 154

26. Seasonal Change in Reproductive Characteristics of Adult Males .................. 164

27. The Correlation of Testis Volume and Body Size . . . . 168

28. Seasonal Changes in Mean Testis Volume of Adult Males • 170

29. Seminiferous Tubule Cross Section - 8 Stages of Spermatogenic Activity in Adult Males ....... 176

30. Seasonal Changes in Mean Seminiferous Tubule diameter and Seminiferous Tubule Epithelial Height in Adult Males .................

31. Seasonal Change in Mean Interstitial Cell Diameter of Adult Males ............. 203

32. Seasonal Change in Mean Epididymal Epithelial Height of Adult Males .............. 209

33. Cross Sections of Epididymis, Vas Deferens and Kidney Sexual Segment for Adult Males ......... 213

34. Seasonal Changes in Vas Deferens Epithelial Height of Adult Males . . . . . . . . . . . . 226

35. Seasonal Changes in Sexual Segment Epithelial Height of Adult Males . . . . . . . . . . . . .

36. The Relationship of Seasonal Changes in Testicular and Reproductive Tract Structures for Adult Males . . . .

37. Seasonal Changes in Mean Fat Body Weight/Body Weight Ratios of Adult Females.............. 
38. The Relationship of Key Reproductive Cycle Events for Adult Males . . . . . . . . . . . 247

39. The Relationship of Key Reproductive Cycle Events for Adult Females . . . . . . . . . . . 249

40. The Relationship of Key Male and Female Reproductive Cycle Events . . . . . . . . . . . 252

41. Growth Rates of a Cohort at the Red Cloud Road Study Site over a 7-Year Period ........... 263

42. Clutch Size Body Size Relationship for Adult Females Captured during 6 Consecutive Years . . . . . . 270

43. Annual Reproductive Frequency for Colorado Desert Adult Females . . . . . . . . . . 277

44. Annual Tail Break Frequency for a Cohort (1) at the Red Cloud Road Study Site............ 366

45. Annual Tail Break Frequency for a Cohort (2) at the Red Cloud road Study Site............ 368

46. Tail Break Frequency of Specific Ages at the Red Cloud Road Study Site............... 371

47. Estimation of Stable Age Population Conditions for Red Cloud Road S. obesus ............ 420

48. 1977 Age Class Distribution - Prediction from Leslie Analysis .............. 425

49. 1978 Age Class Distribution - Prediction from Leslie Analysis . . . . . . . . . . . 427

50. 1979 Age Class Distribution - Prediction from Leslie Analysis .................

51. 1980 Age Class Distribution - Prediction from Leslie Analysis ................ 


\section{INTRODUCTION}

There are extensive reproductive studies of Reptilia, particularly lizards (see Mayhew, 1968; Fitch, 1970; Porter, 1972; Fox, 1977; Trauth, 1970), but, most are inadequate in explaining the evolution of lizard life histories (Tinkle, 1969; Tinkle et al., 1970). Tinkle and colleagues urged the collection of specific kinds of data that would answer basic questions about life histories: 1) age at maturity; 2) clutch size; 3) clutch frequency within a single season; 4) absolute size of eggs; 5) egg size relative to weight of female; 6) adult reproductive life expectancy; 7) age-specific fecundities and mortalitities; and 8 ) the survivorship of juveniles to sexual maturity. The available data enabled Tinkle (1969) to formulate a general theory for the dichotomous evolution of life history types in lizards. Lizards are either early maturing (in one year), have short adult life expectancies, are almost always multiple-brooded, and produce relatively small clutches, or they are late-maturing (longer than one year), have long adult life expectancies, are usually single-brooded, and produce relatively large clutches. Numerous investigators have since described how various lizard species conform to this general theory (Pianka, 1970b: Turner et al., 1970; Tinkle, 1972; Ballinger and Shrank, 1972; Ballinger et al., 1972; Tinkle and Ballinger, 1972; Ballinger, 1973; Gennaro, 1974; Vinegar, 1975; Ballinger, 1976; Parker and Pianka, 1976; Ballinger, 1977; Martin, 1977; Smith, 1977; Vitt, 1977; Vitt and Ohmart, 1977 a \& b; Schall, 1978; Vitt et al., 1978; Ferguson et al., 1980; Dunham, 1982).

Two major selective factors - resource availability (i.e., food) and the demongraphic environment (i.e., juvenile and adult survivorship)- 
have been implicated as being important to current life history theory (see Stearns, $1976 \& 1977$ ). The deterministic model of MacArthur and Wilson (1967) argued that life history traits such as early maturity, high age-specific fecundity, small offspring, high age-specific reproductive effort, and short life expectancy evolve in organisms inhabiting environments with a high ratio of resource supply to demand. The traits are called "r-selected", since this set of life history traits leads to high intrinsic rates of increase. Life history traits such as delayed maturity, low individual growth rates, low age-specific fecundity and reproductive effort, large offspring and longer life expectancy evolve in organisms inhabiting highly competitive environments with low ratios of resource supply to demand. Such "K-selected" organisms would normally be at or near carrying capacity. The theory of $\mathrm{r}$ - and $\mathrm{K}$-selection has received considerable attention in the meantime (Pianka, 1970a, 1972; Roughgarden, 1971; Gadgil and Solbrig, 1972; Abrahamson and Gadgil, 1973; Southwood et a1., 1974).

Several stochastic models predict evolution of the above combinations of life history traits from the demographic environment (Williams, 1966 a \& b; Murphy, 1968; Schaffer, 1974; Hirshfield and Tinkle, 1975; Stearns 1976, 1977). Selection can favor life history traits such as delayed maturity, low age-specific reproductive effort and high adult survivorship, if there is a trade-off between age-specific reproductive effort and probability of surviving to the next reproductive opportunity, in environments where juvenile survivorship is unpredictable, with occasional very low values. These life history traits are exactly those favored by "K-selection". In contrast, environments characterized by high ex- 
trinsic mortality of adults should favor evolution of rapid maturity, large numbers of small offspring, and high age-specific reproductive effort. These life history characteristics are those expected for "rselection". In addition, selection should favor individuals exhibiting high levels of reproductive effort during periods that are favorable for juvenile survivorship and lower levels of reproductive effort during unfavorable periods, for those environments in which juvenile survivorship is variable but predictable (Hirshfield and Tinkle, 1975).

To date, few studies have assessed the roles of resource availability and demographic environment in the evolution of lizard life histories. Resource abundance should be measured simultaneously with demographic and life history studies in order to assess the impact of the former. Similar methods of estimating resource abundance should be employed by different studies to insure reliability of comparison, but this has not been done (Dunham, 1982). Comparable data concerning temporal variation in such demographic characteristics as age-specific survivorship of juveniles and adults are required to test theories of life history evolution based on selection arising from the demographic environment. Adequate quantification of such temporal variation requires long-term capture-recapture studies of individual populations. There are few long-term capture-recapture studies of lizard populations in which variation in demographic characteristics and resource abundance were simultaneously monitored (Dunham, 1982).

Previous studies on lizard life histories have largely been concerned with insectivorous species. The subfamily Iguaninae, however, includes herbivorous lizards that are widely distributed in the New World (Etheridge, 1982). Iguanines are relatively large, long-lived 
and have fairly complex social behaviors (Wiewandt, 1982). A few species have been hunted and trapped excessively; in some areas they can no longer withstand such exploitation (Fitch et al., 1982). Life history studies are sorely needed for iguanines because of a sometimes urgent need for their conservation. Most iguanine species inhabit tropical and subtropical island and continental regions. The available life history studies of several of these species (Iverson, 1979; Harris, 1982; Van Devender, 1982b and Werner, 1983) are not long-term in nature. Life history studies of temperate region iguanines are fragmentary. Furthermore, no life history study of an iguanine has simultaneously investigated the respective roles of climate and resource abundance. The western chuck:walla, Sauromalus obesus (Baird), is a large temperate region iguanine. $\underline{S}$. obesus is widely distributed in the rocky habitats of deserts of the southwestern United States and northern Mexico (Stebbins, 1966). Previous investigators have paid limited attention to the life history of this species (Johnson, 1965; Nagy, 1973; Berry, 1974). Life history patterns observed, but scantily quantified for $\underline{\text { S. }}$ obesus, include delayed maturity, low annual reproductive frequency, low recruitment rate, and high adult survivorship. The primary objectives of this investigation are the thorough quantification of these and other life history traits, and a determination of the influence of environmental parameters (climate, resource abundance, etc.) on the life history strategy of the chuckwalla. The life history parameters of a population of $\underline{S}$. obesus were determined by a long-term investigation that collected information on reproduction, demography and population dynamics. Simultaneous collection of climatic and vegetational data allowed the construction of predictive models for various life 
history traits. This study is the first of its kind for an iguanine species. It will hopefully serve as a basis for comparison with similar tests of theories of life history evolution for insectivorous species and, more importantly, for future population modeling studies of lizard species for which appropriate management practices are required. 
MATERIALS AND METHODS

This study of the western chuckwalla, was conducted over a 7year period (1977 - 1983) in the Colorado Desert of southeastern California. The study area, situated about halfway between Indio and Blythe, encompassed portions of the Eagle, Orocopia, and Chuckwalla Mountains (Figure 1). This is a typical creosote bush community (Munz, 1968); conspicuous plant species include desert ironwood (으eya tesota), ocotillo (Fouquieria spendins), bigelow cholla (Opuntia bigelovii) and barrel cactus (Ferrocactus acanthodes). Specific localities typically favored by $\underline{S}$. obesus were exfoliated granitic outcrops separated by talus slopes, washes and gravel alluvial flats (Figure 2). The elevation of these localities was $450-650 \mathrm{~m}$ above sea level.

The research protocol for this study was two-fold. A capturerecapture and observation study was undertaken in the Chuckwalla Mountains at the Red Cloud Road study site, about $12 \mathrm{~km}$ south of highway 10. Lizards were also collected periodically at 6 localities within a $15 \mathrm{~km}$ radius of the capture-recapture site; Orocopia Mountains - Hayfield Road, Eagle Mountains - Juliam Hinds Pumping Station, and Chuckwalla Mountains - Corn Springs, Lost Pony Mine, Gas Line Road, and Red Cloud Wash.

Meteorologic al data for various Mojave Desert localities and the Colorado Desert study area were provided by the National Weather Service and Julian Hinds Pumping Station, respectively. The Julian Hinds Pumping Station was located about $15 \mathrm{~km}$ north of the Red Cloud Road study site. Specific climatic parameters recorded included daily precipitation amounts and minimum and maximum temperatures. 
Figure 1. The Colorado Desert study area for investigation of the life history strategy of $\underline{\mathrm{S}}$. obesus. Solid irregular lines indicate gravel roads. Broken lines indicate major washes (i.e., Red Cloud and Corn springs). $\mathrm{RC}=$ Red Cloud Road study site; LP = Lost Pony Mine; $\mathrm{RW}=$ Red Cloud Wash; GL = Gas Line Road; CS = Corn Springs; HR = Hayfield Road; JH = Julian Hinds Pumping Station. 

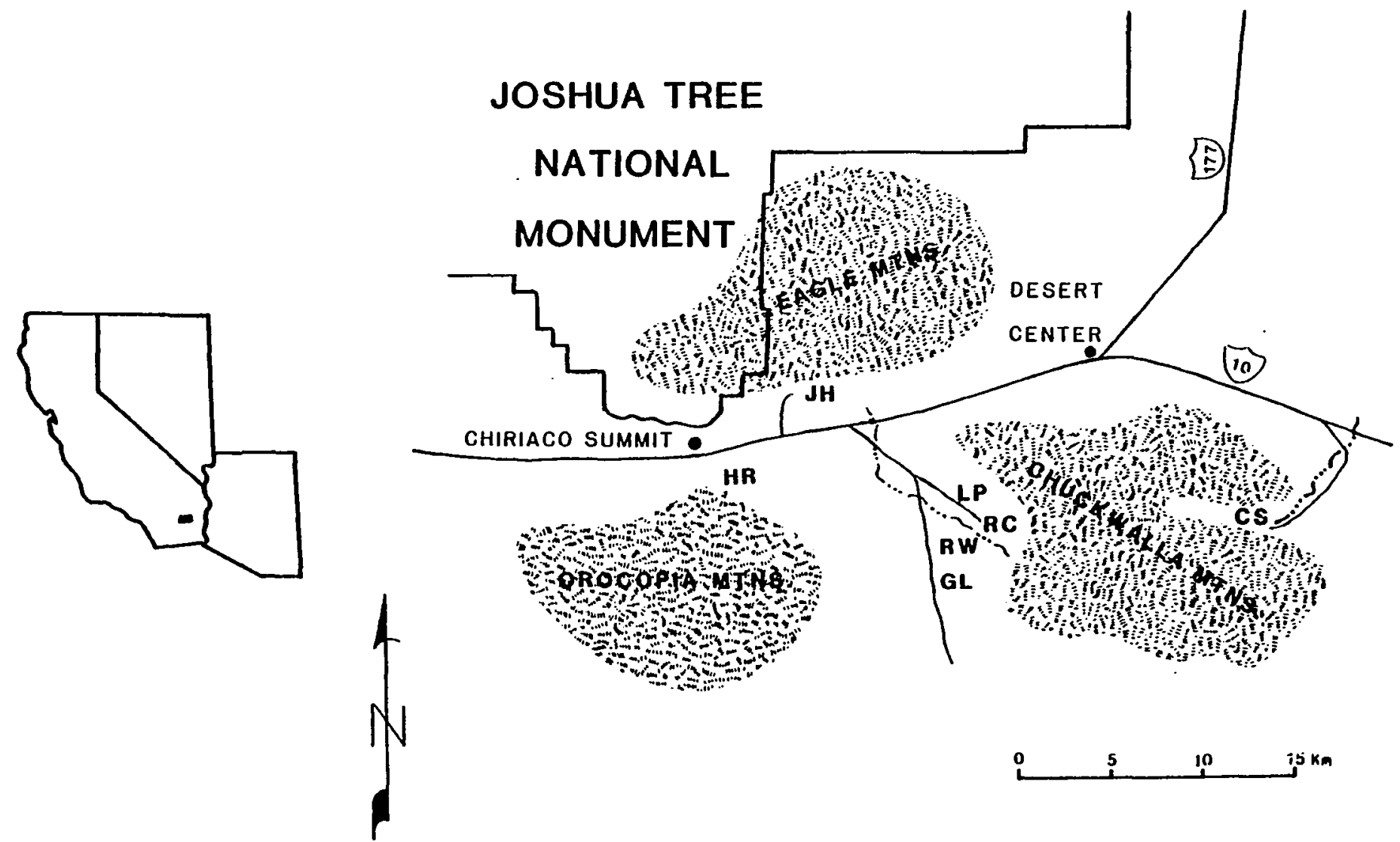
Figure 2. Red Cloud Road study site: a) gravel alluvial flat (foreground), several small rock outcrops (middle across), Chuckwalla mountains (background); b) rocky hillside with several protruding rock outcrops; c) rocky slope (left) gravel flat and Red Cloud Road (right); d) typical rock outcrop with wash in foreground. 

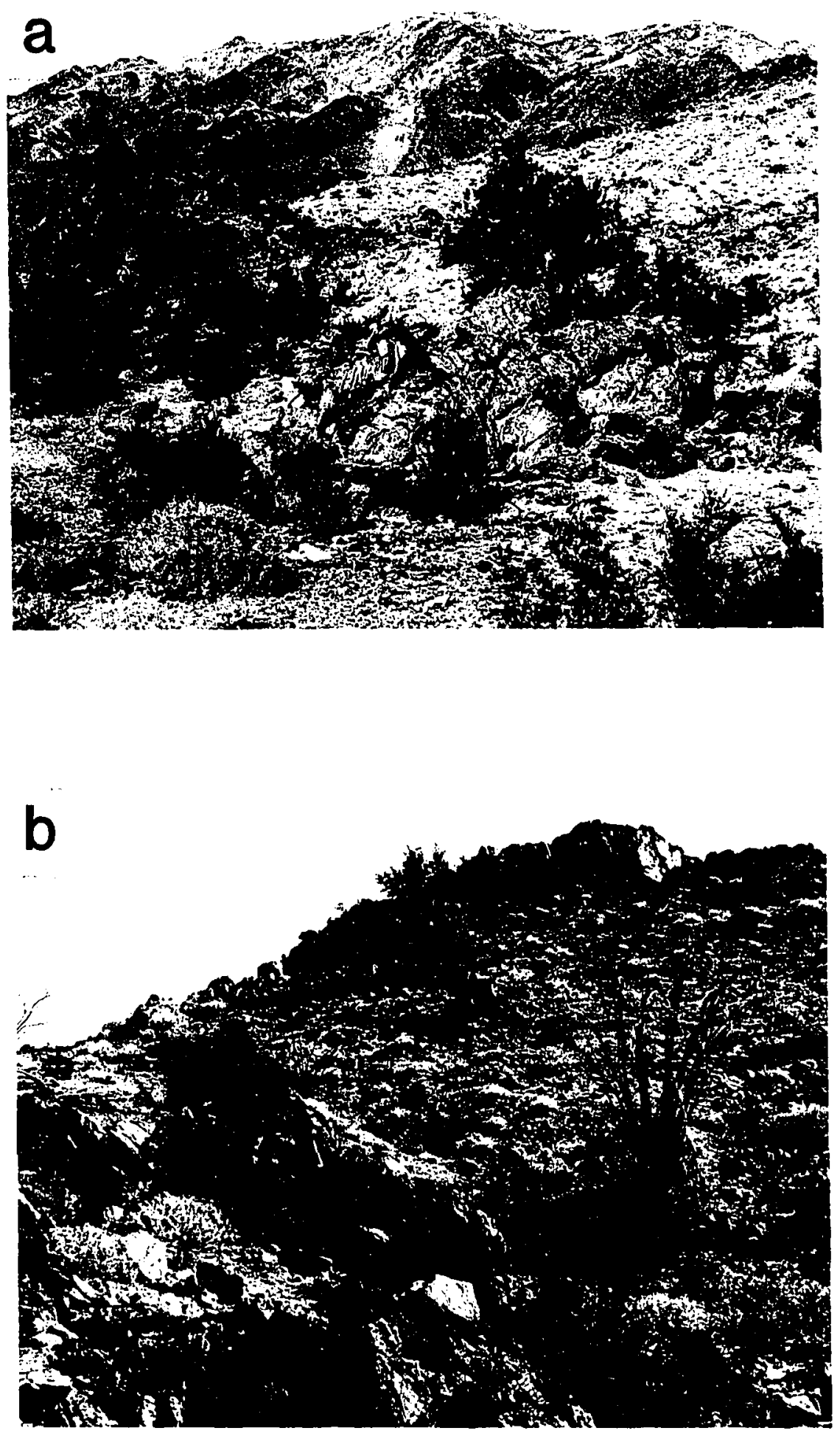

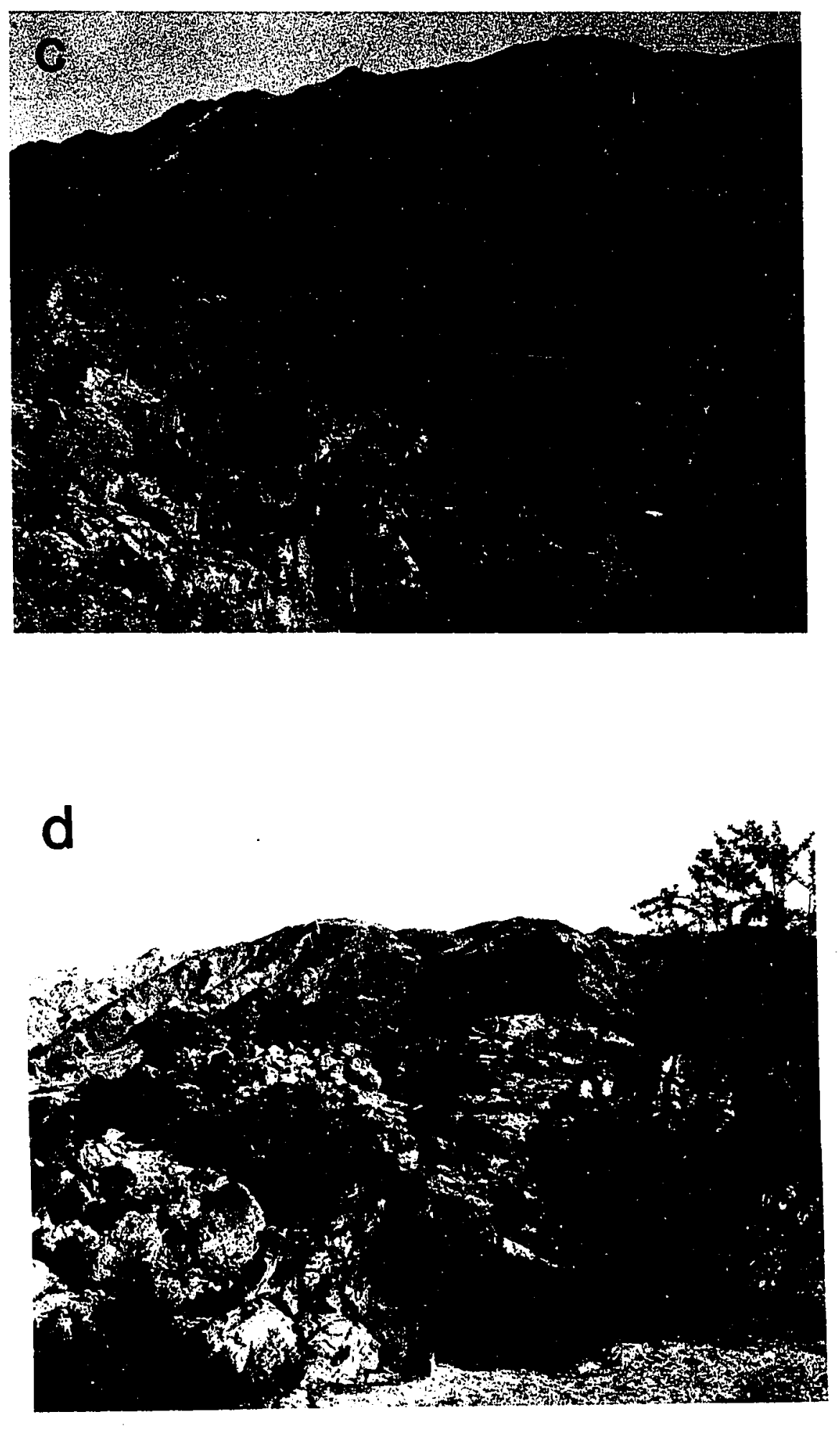
Vegetational data were recorded at the Red Cloud Road study site. Four $225 \mathrm{~m}^{2}$ plots, representative of major substrate types, were monitored monthly 1978 - 1980 and in the spring of 1981 - 1983 (April - June). Growth patterns of annual and perennial plants were recorded for each plot. Annuals which were harvested from an area delineated by a randomly thrown $0.25 \mathrm{~m}^{2}$ hoop, were dried and weighed to estimate standing crop. Tagged perennial plants were measured month1y to determine stem elongation. The influence of climate on the vegatation and how climate and vegetation affected individual growth rates, reproductive success and survivorship of $\underline{\mathrm{S}}$. obesus was examined.

Capture-recapture and observation techniques were employed at the Red Cloud Road study site in 1977 - 1983 and 1978 - 1980, respectively. Prior to 1981, the site was visited between 4 and 12 days per month during the activity season (March through September) and at least one day a month outside the activity season. The study site was visited 1 to 3 times in both April and June during 1981 through 1983. Three hundred and twenty $\operatorname{six} \underline{\mathrm{S}}$. obesus were marked by toe-clipping and by painted lateral numbers (body and tail base) from 1977 through 1983. Approximately two-thirds of these lizards were recaptured 3 - 15 times. Data recorded at every capture included identification number, location, behavior prior to capture, sex, age (if possible), snout-vent length (mm), tail-length $(\mathrm{mm})$, body temperature, various environmental temperatures (substrate and atmosphere), extent of tail break, general condition, and reproductive condition as estimated by palpation of gonads. Mass was measured on a triple-beam balance $( \pm 0.1 \mathrm{~g})$. Body temperatures were recorded to $\pm 0.1^{\circ} \mathrm{C}$ with either a Schultheis thermometer or Yellow Springs 
thermistor probe. Environmental temperatures $\left( \pm 0.1^{\circ} \mathrm{C}\right)$ were measured with the YSI thermistor probe. Each lizard was released where it was captured. Seven hundred and fifty hours were devoted to capture-recapture activity. Observation of $\underline{S}$. obesus was made from behind boulders or temporary blinds. Lizards were watched with $7 \times 50$ binoculars and a $60 \mathrm{X}$ spotting scope. Five hundred hours were devoted to observation.

C apture-recapture data for Red Cloud Road $\underline{S}$. obesus were the primary source for determining most life history attributes. This procedure enable determination of recruitment rate, age at first reproduction, annual reproductive frequency, age-specific fecundity (in part), agespecific survivorship, sex ratio, density and longevity. Population density was estimated by 3 methods, total number of lizards captured and the estimating techniques of Schumacher and Eschmeyer (1943) and Jolly (1965). Both recruitment and survivorship were estimated from the method of Jolly (1965). Regression models of fecundity were constructed using various winter precipitation data. The method of Leslie (1952) allowed the development of predictive models for population age class structure. Observations of $\underline{S}$. obesus provided data on feeding habits, social behavior (territoriality and courtship) and movement and spacing patterms. Movements were plotted on enlarged black and white photographs of the study site. Specific home range areas were calculated from the polygon comprised of points of capture, using an Apple Graphics Tablet for area integration.

Collections of $\underline{S}$. obesus were made at 6 specific locations remote from the study site during the activity season (March through August) during 6 consecutive years (1978 - 1983). The majority of the 
lizards were collected from 1978 - 1980, either bi-monthly or monthly. Lizards were collected after 1980 only in June. About $500 \underline{\mathrm{S}}$. obesus were collected (approximately equal numbers of the sexes). Field data was recorded as for study site individuals. Most of these $\underline{S}$. obesus were collected for autopsy to obtain information on reproduction. Examinations of various structures of the reproductive system included gross morphological and histological measurements. Gross morphological measurements were accomplished with the aid of dial calipers, a dissecting microscope fitted with an ocular micrometer, and an analytical balance $( \pm 0.1 \mathrm{mg})$. Seasonal changes in the gross morphology of testes and ovaries were interpreted according to Mayhew (1963) and Droge et al., (1982), respectively. Oviductal and oviposited eggs were weighed and analysis of egg and soma weights were made after Vitt (1977). Abdominal fat bodies (corpora adiposa) were removed and weighed according to Goldberg (1972a). The left gonad and reproductive tract of male and female $\underline{S}$. obesus were removed and fixed in $10 \%$ buffered formalin. Standard histological procedures included dehydration in an alcohol-xylene series, embedding in paraffin, sectioning at 5 um and staining with Harris' hematoxylin and eosin (Humason, 1979). Measurements were taken according to Mayhew (1966 a \& b, 1971) with the aid of a compound microscope fitted with high dry (40X) and oil-immersion (100X) objectives. These morphological and histological study procedures enabled the determination of a number of reproductive parameters which included lipid cycling, duration of reproductive season, breeding synchrony, egg size, clutch size, relative clutch mass and in part, age-specific fecundity.

Pairwise and multiple comparisons of means were made with a 
t-test (Sokal and Rohlf, 1969) and Scheffe test (Zar, 1984), respectively. The relationships of variables were determined by linear and multiple regression analysis (Sokal and Rohlf, 1969). Tests of regression equations included analysis of variance (Sokal and Rohlf, 1969) and analysis of covariance (Zar, 1984). Tests for goodness of fit (chi-square) were according to Zar (1984). 


\section{CHAPTER I}

\section{CLIMATE AND VEGETATION}

Most of the former studies of $\underline{S}$. obesus were in the northern Mojave Desert (Johnson, 1965; Berry, 1974; Case, 1976). This investigation represents the first study of a Colorado Desert population of this species. The climate of the Colorado Desert is considerably different than that of the northern Mojave Desert (National Weather Service). Ambient temperatures in the Colorado Desert are consistently warmer in the summer (commonly in excess of $45^{\circ} \mathrm{C}$ ) and winter (minima seldom less than $0^{\circ} \mathrm{C}$ ). The majority of the Mojave Desert's annual precipitation occurs in the winter and the summer frequently is subjected to drought. The annual precipitation pattern of the Colorado Desert shows that winter is the wettest time of the year, although the region experiences substantial summer precipitation.

Mean monthly temperatures at Julian-Hinds pumping station (Table I), fifteen kilometers north of the Red Cloud Road study site, show that temperatures from 1977 through 1983 were not significantly different from those of the previous 23 years (Student-t test). Consequent1y, the data for the most recent 30 years was combined. January was the coolest month of the year. However, the other winter months were nearly as cool and freezing night time temperatures occured from late November through mid-March. Freezing nights did not usually exceed 6 per month. The July mean temperature (least variable) was the warmest. At the Red Cloud Road study site, maximum July temperatures exceeded $48^{\circ} \mathrm{C}$ on several occasions. Temperatures in excess of $45^{\circ} \mathrm{C}$ 
TABLE I

MEAN TEMPERATURE $\left({ }^{\circ} \mathrm{C}\right)$ FOR JULIAN HINDS P. S. \pm S. E. OVERALL $=$ SINCE THE FACILITY BEGAN RECORDING WEATHER DATA (1938)

\begin{tabular}{lcccccc}
\hline Time Period & Jan & Feb & Mar & Apr & May & Jun \\
\hline Overal1 & 10.9 & 12.9 & 13.5 & 19.5 & 23.5 & 27.7 \\
Last 30 Years & $\begin{array}{l}11.4 \\
\pm 0.7\end{array}$ & $\begin{array}{l}13.5 \\
\pm 0.7\end{array}$ & $\begin{array}{l}15.4 \\
\pm 0.6\end{array}$ & $\begin{array}{l}19.3 \\
\pm 0.7\end{array}$ & $\begin{array}{l}23.2 \\
\pm 0.5\end{array}$ & $\begin{array}{l}28.4 \\
\pm 0.6\end{array}$ \\
\hline Time Period & Ju1 & Aug & Sep & Oct & Nov & Dec \\
\hline Overal1 & 32.1 & 31.3 & 28.1 & 22.1 & 15.8 & 11.6 \\
Last 30 Years & \pm 0.3 & \pm 0.5 & \pm 0.5 & \pm 0.6 & \pm 0.5 & \pm 0.6 \\
\hline
\end{tabular}


occurred from mid-May into early October.

Winter and summer precipitation greatly affected the life history traits of $\underline{S}$ obesus (Ch. $4 \& 5$ - Life History \& Demography). Survivorship and fecundity schedules were well correlated with food supply which in turn was correlated with precipitation. Since precipitation seems to be a critical factor to this species life history, the pattern of rainfall for the Colorado Desert study area is discussed in greater detail below. Regarding precipitation, vegetation and the impact of the former on the latter, specific questions asked were: 1) How do monthly and seasonal precipitation amounts during the 7 year study compare with the previous 25 year and overall average monthly amounts? 2) What are the dominant plant species of this Colorado Desert area? 3) What are the growth patterns of annual and perennial plant species? 4) What is the relationship between substrate type and the growth of annual and perennial plant species? 5) How do precipitation amounts and timing affect the growth of annual and perennial plant species?

Mean monthly precipitation amounts for Julian-Hinds station (Table II) show the majority of annual precipitation (mean $=7.39 \mathrm{~cm}$ ) occurred during the winter months. However, two summer months, July and August, had mean precipitation similar to the winter months. During the 25 years prior to the study (1951 through 1976), many of the monthly precipitation means (including some critical winter and summer months) were less than the overall means. This difference reflected occasional periods of drought during the 3 decades. During this study, monthly precipitation means were generally similar to or greatly in excess of the overall means. During the study some months were wettest recorded over 30 years (as far back as records are available). Monthly 
TABLE II

MEAN MONTHLY PRECIPITATION $(\mathrm{mm})$ FOR JULIAN HINDS P. S. \pm 1 S. E. OVERALL $=$ SINCE 1938. STARRED VALUES OF 7 YEAR STUDY $=\mathrm{P}<0.05$

\begin{tabular}{|c|c|c|c|c|c|c|}
\hline Time Period & Jan & Feb & Mar & Apr & May & Jun \\
\hline Overall & 11.9 & 5.1 & 6.6 & 2.5 & 0.8 & 0.5 \\
\hline Previous 25 Years & $\begin{array}{r}9.3 \\
\pm 2.5\end{array}$ & $\begin{array}{r}5.6 \\
\pm 2.2\end{array}$ & $\begin{array}{r}5.4 \\
\pm 1.5\end{array}$ & $\begin{array}{r}2.8 \\
\pm 1.2\end{array}$ & $\begin{array}{r}0.7 \\
\pm 0.2\end{array}$ & $\begin{array}{r}0.6 \\
\pm 0.5\end{array}$ \\
\hline 7 Year Study & $\begin{array}{l}27.4 * \\
\pm 8.5\end{array}$ & $\begin{array}{l}24.1 * \\
\pm 11.8\end{array}$ & $\begin{array}{l}32.6 \% \\
\pm 8.9\end{array}$ & $\begin{array}{r}1.6 \\
\pm 1.2\end{array}$ & $\begin{array}{l}8.1 * \\
\pm 5.6\end{array}$ & $\begin{array}{r}0.1 \\
\pm 0.1\end{array}$ \\
\hline Time Period & Jul & Aug & Sep & Oct & Nov & Dec \\
\hline Overall & 6.6 & 10.2 & 4.1 & 7.1 & 7.1 & 11.4 \\
\hline Previous 25 Years & $\begin{array}{r}4.8 \\
\pm 2.7\end{array}$ & $\begin{array}{r}8.8 \\
\pm 2.9\end{array}$ & $\begin{array}{r}8.7 \\
\pm 5.6\end{array}$ & $\begin{array}{r}7.1 \\
\pm 1.9\end{array}$ & $\begin{array}{r}6.7 \\
\pm 2.1\end{array}$ & $\begin{array}{r}9.3 \\
\pm 3.1\end{array}$ \\
\hline 7 Year Study & $\begin{array}{r}8.4 \\
\pm 6.4\end{array}$ & $\begin{aligned} & 27.0 * \\
\pm & 12.7\end{aligned}$ & $\begin{array}{r}4.1 \\
\pm 1.7\end{array}$ & $\begin{array}{r}9.0 \\
\pm 7.2\end{array}$ & $\begin{array}{r}6.2 \\
\pm 3.6\end{array}$ & $\begin{array}{l}10.7 \\
\pm 5.2\end{array}$ \\
\hline
\end{tabular}


precipitation amounts for the 7 year study are shown in Figure 3. Only one short period of drought occurred during this time (from the spring of 1980 to mid-winter of 1981 ).

Five seasonal precipitation categories were used to examine the relationship between vegetation growth and precipitation timing and amounts (Table III). In 4 of the 5 categories, mean precipitation was lower in the 25 years prior to the study than overall, again demonstrating drier conditions before the study period. Except for December, mean precipitation for each category during the study exceeded those for both the previous 25 years and overall. A comparison of values for the 7 year study period with those of the previous 25 years showed the former to be significantly greater for all categories save December (Scheffe test). Table IV shows the 5 precipitation categories for each of the years of the study. To emphasize further the extreme wetness: during the study period the following should be noted: 1) winter precipitation amounts were nearly $3 \mathrm{X}$ the overall mean in 4 of the 7 years; 2) summer precipitation, though variable, was extensive in 4 of the 7 years (including about $6 \mathrm{X}$ the overall mean in 2 of the years); and 3 ) in all 7 years annual precipitation exceeded the overall mean and was nearly $3 X$ it in 3 of the years.

Nonetheless, the amount of precipitation is not necessarily sufficient to ensure optimal vegetation growth. In addition, timing of precipitation is very important. For example, though winter precipitation exceeded the overall mean in 6 of the years (1978 through 1983) only in 3 of these years (1978, 1979 and 1983) were winter annuals abundant. Those years corresponded with the greatest precipitation occurring in the period October through January and for the month of 
Figure 3. Monthly precipitation amounts for the Julian Hinds Pumping Station ( $15 \mathrm{~km}$ north of the study site) during the 7 year study. Shaded areas indicate mean monthly amounts. 
N
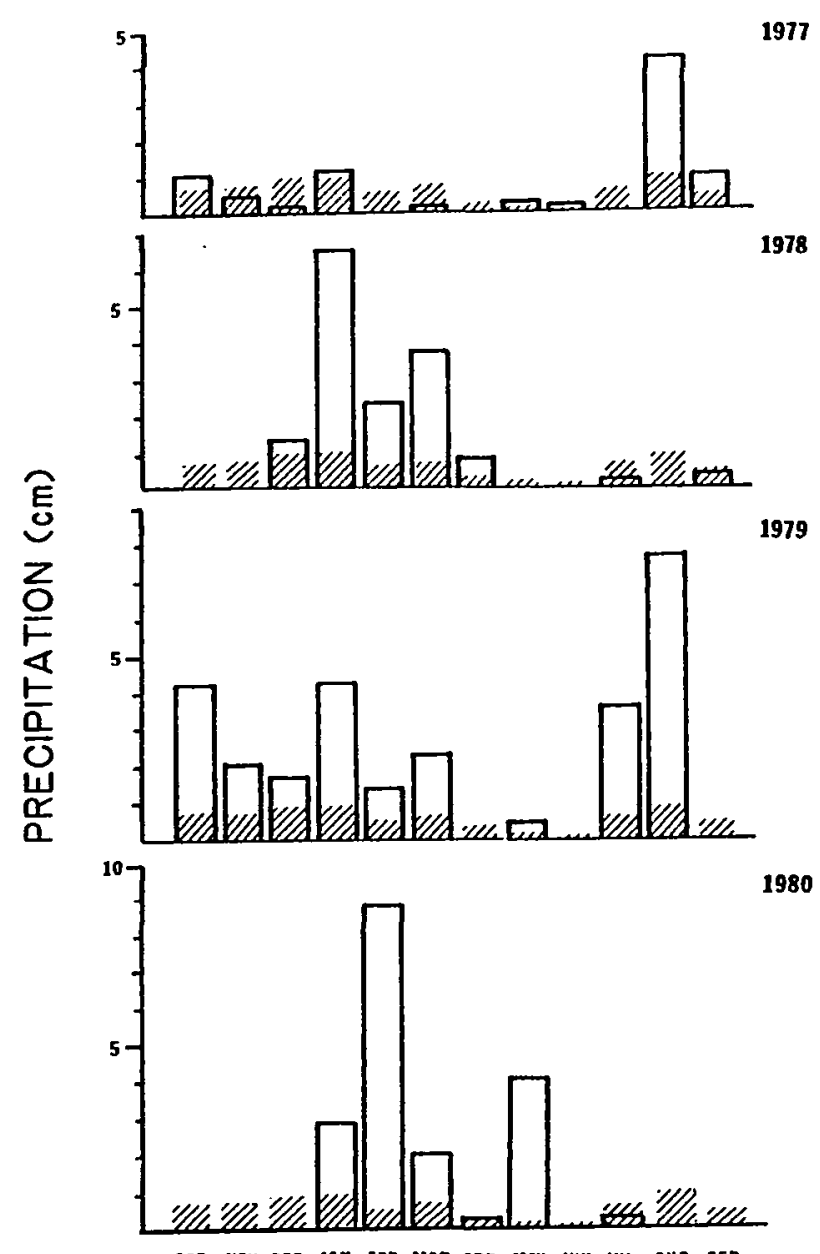

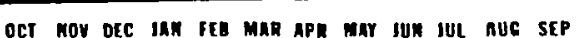
YEARLY PERIOD
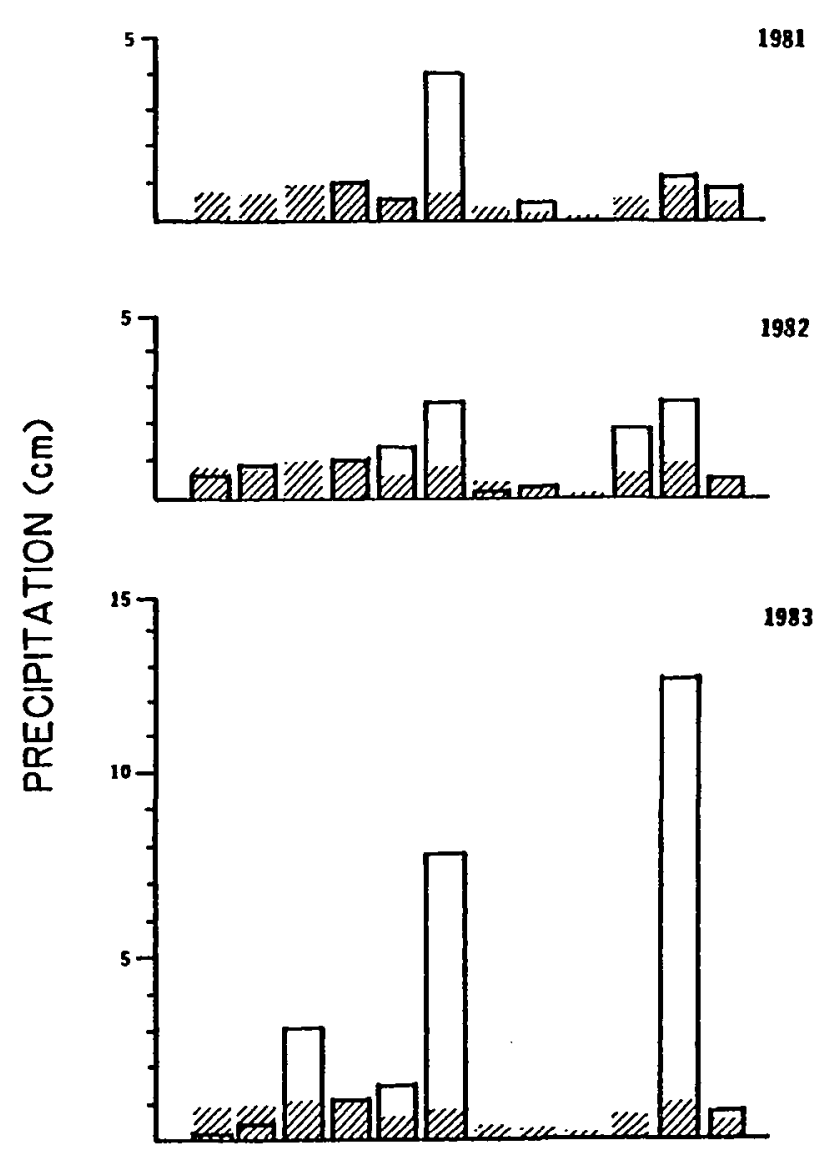

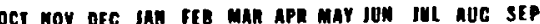
YEARLY PERIOD 
TABLE III

VARIOUS PRECIPITATION CATEGORIES (mm) FOR JULIAN HINDS P. S. \pm 1 S. E. WINTER $=$ OCTOBER THROUGH MARCH; SUMMER $=$ JULY THROUGH SEPTEMBER

\begin{tabular}{lccccc}
\hline \hline \multicolumn{5}{c}{ Category } \\
\hline Time Period & Dec & Oct-Jan & Winter & Summer & Annua1 \\
\hline Overal1 & 11.4 & 37.6 & 49.3 & 20.8 & 73.9 \\
Previous 25 Years & $9.3 \pm 3.1$ & $31.0 \pm 4.8$ & $42.4 \pm 5.5$ & $22.3 \pm 6.9$ & $67.9 \pm 9.0$ \\
7 Year Study & $10.7 \pm 5.2$ & $51.8 \pm 15.6$ & $108.6 \pm 20.2$ & $68.1 \pm 24.5$ & $159.1 \pm 24.0$ \\
\hline \hline
\end{tabular}


December. It appears that sufficient precipitation must occur before early January if winter annuals are to flourish.

Summer precipitation contributed to the growth pattern of vegetation throughout the Colorado Desert. During the past 30 years, summer precipitation has averaged about one-third of the annual amount (Table V). This compares with about one-fifth for many Mojave Desert locations (National Weather Service). Furthermore, this Colorado Desert location is geographically close to desert areas dominated by summer precipitation. According to Hastings and Turner (1968), much of the Sonoran Desert receives more than half of it's annual precipitation during the 6 warmest months (May through October). The study location shows a recent trend of similar nature ( Table $\mathrm{V}$ ). The impact of this trend on the condition of vegetation in the summer has been considerable (see below).

The Colorado Desert study site supports a floral diversity very similar to that of the western Sonoran Desert. However, most common plant species were less abundant at the study site than in the western Sonoran Desert (Abts, personal observation). About 125 plant species were identified at the Red Cloud Road study site. Trees and large shrubs (lneya tesota, Cercidum floridum, Dalea spinosa, Fouquieria splendens, Hyptis emoryi and Simmondsia chinensis) were conspicuous over much of the terrain. Cacti were nearly as conspicuous, and constituted a major segment of the perennial flora. Larger cacti such as barrel cactus (Ferrocactus Acanthodes), silver cholla (0puntia echinocarpa) and jumping cholla (‥ bigelovii) were especially obvious, but up to 10 other species, some common, were recorded for the locality. 


\section{TABLE IV}

7 YEAR PRECIPITATION CATEGORIES (mm) FOR JULIAN HINDS P. S. WINTER AND SUMMER TIME PERIODS SAME AS IN TABLE III

\begin{tabular}{lrrrrr}
\hline \hline Time Period & Dec & Oct-Jan & Winter & Summer & Annual \\
\hline $1976-77$ & 0.7 & 27.9 & 29.2 & 149.6 & 231.4 \\
$1977-78$ & 14.5 & 84.1 & 146.3 & 49.3 & 111.9 \\
$1978-79$ & 18.0 & 130.0 & 168.4 & 2.5 & 227.1 \\
$1979-80$ & 0.7 & 30.7 & 144.3 & 119.6 & 207.8 \\
$1980-81$ & $\mathrm{~T}$ & 11.7 & 57.4 & 0.0 & 187.2 \\
$1981-82$ & 0.0 & 32.5 & 75.9 & 21.1 & 102.6 \\
$1982-83$ & 31.1 & 46.0 & 138.4 & 134.6 & 149.7 \\
\hline \hline
\end{tabular}

TABLE V

WARM SEASON PRECIPITATION FOR JULIAN HINDS P. S.

\begin{tabular}{lcc}
\hline Time Period & $\begin{array}{c}\text { Summer Precipitation } \\
\% \text { of Annual }\end{array}$ & $\begin{array}{c}\text { W Warmest Months } \\
\% \text { of Annual }\end{array}$ \\
\hline Overall & 28 & 40 \\
Previous 25 Years & 33 & 45 \\
7 Year Study & 34 & 48 \\
\hline \hline
\end{tabular}


Dense colorful carpets of annuals were very conspicuous for some years, in early spring (March through April) and late summer (August through September). Winter annual cover was diverse (Plantago insularis, Cryptantha spp., Lupinus arizonicus, Camissonia spp., Eschsholtzia eschsholtzia, Phacelia spp., Perityle emoryi and several others), but summer cover was dominated largely by chinch weed (Pectis papposa).

There was an extensive growing season in the Colorado Desert, influenced by milder winters and frequent yearly precipitation (Fig. 4). Perennial growth (measured by stem elongation) always occurred after substantial precipitation. Annual growth (measured by harvesting $0.25 \mathrm{~m}^{2}$ plots) occurred after winter and summer percipitation. For the purpose of measuring changes in the growth of vegetation, four $225 \mathrm{~m}^{2}$ plots, each of a characteristically different substrate type, have been maintained at the Red Cloud Road study site since 1978. A map of the study site (Fig. 5) reveals the specific location of the 4 plots. These substrates, which contributed to the entire terrain of the site, except for rock outcrops, were gravel alluvial flat (GAF), wash (W), rocky hillside (RHS), and gravel hillside (GHS). RHS areas were most common and together with GHS constituted about $75 \%$ of the substrate between outcrops. While these areas showed gradation, GHS areas were domintated by rocks of a few centimeters diameter, and RHS areas by exposed bedrock with rocks several meters across and talus with rocks $20 \mathrm{~cm}$ diameter. GAF areas, common at the bases of most slopes, constituted most of the remaining $25 \%$ of the terrain. Situated in the vicinity of rock outcrops, all substrate types were frequented by $\underline{\text { S. }}$ obesus. 
Figure 4. Growing season at the Red Cloud Road study site during the 7 year study. Growing season was defined in this study as the period in which vegetation growth could be measured (dry weights of annuals and/or stem elongation of perennials). 


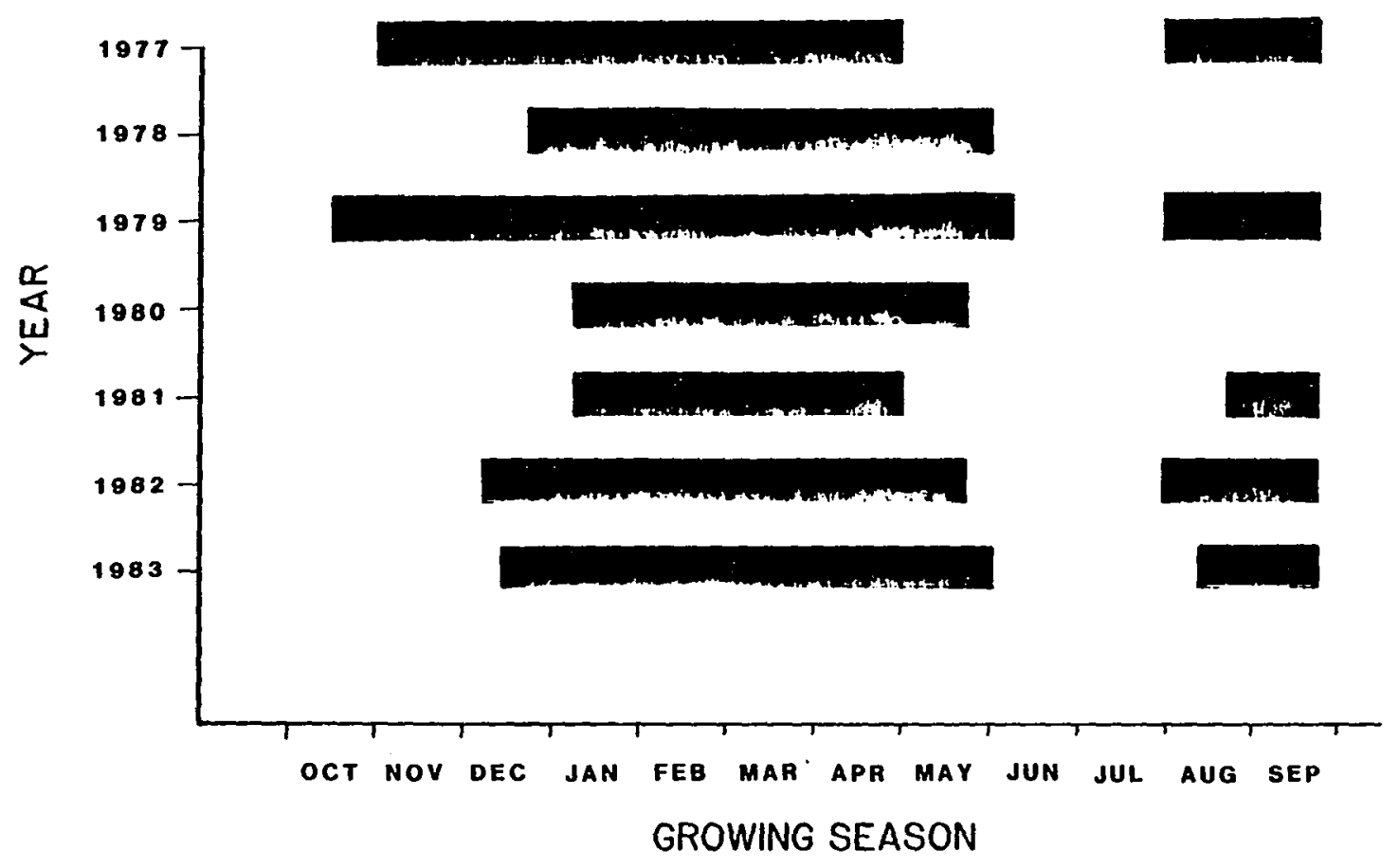


Figure 5. Map of the Red Cloud Road study site. Abbreviations depict location of $225 \mathrm{~m}^{2}$ substrate plots. Circled triangles indicate locations of observation posts. Double lines indicate dirt roads passing in vicinity of site (Red Cloud Road runs left to right in lower portion of figure). half circles $=$ rocky areas; broken lines $=$ washes . 


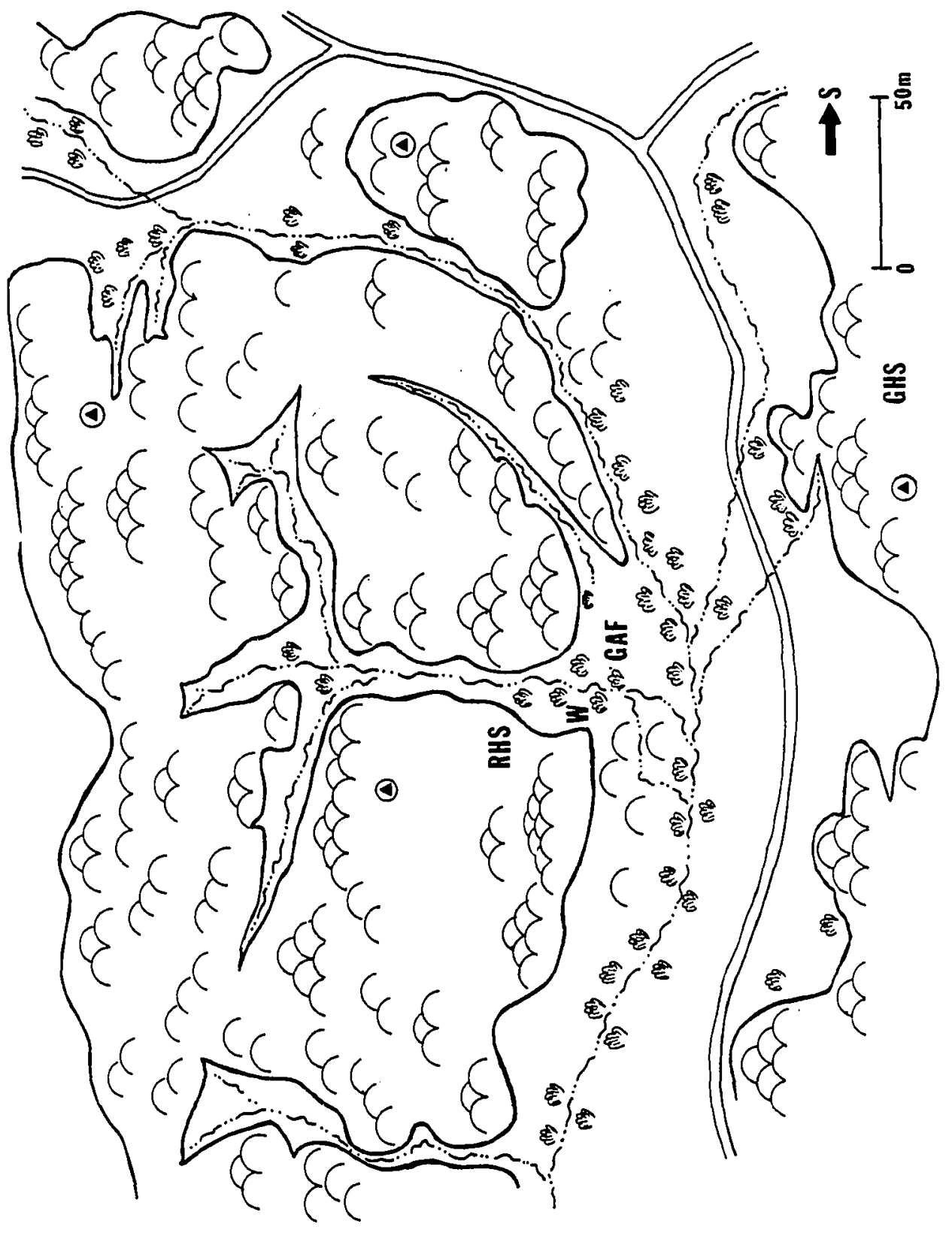


Monthly dry weights of annuals (depicting standing crop) are shown for each of the 4 substrate plots during a 3 year period (Table VI). For winter annuals, within month variability among the 4 plots was usually greatest (5-fold) just after germination and least (less than 3-fold) around the peak standing crop in spring. With one exception, the peak standing crop for the plots over 3 years occurred in mid-April. The exception was in 1980, when the RHS peak standing crop occurred in mid-March. Consequently, regardless of most prevailing climatic conditions, the peak standing crop of winter annuals probably occurs from about late March to mid-April. From 1978 through 1983, mid-April winter annual maximum standing crop occurred in either $\mathrm{W}\left(\overline{\mathrm{x}}=1.98 \pm 1.12 \mathrm{~g}\right.$ per $\left.0.25 \mathrm{M}^{2}\right)$, GHS $\left(\overline{\mathrm{x}}=1.82 \pm 1.18 \mathrm{~g}\right.$ per $\left.0.25 \mathrm{~m}^{2}\right)$, or GAF $\left(\bar{x}=1.62 \pm 0.78 \mathrm{~g}\right.$ per $\left.0.25 \mathrm{~m}^{2}\right)$. In 4 of the 6 years it was least in the RHS plot. The RHS plot, least variable of all 4 for this time, averaged only about 0.5 the standing crop $(\bar{x}=0.85 \pm 0.56 \mathrm{~g}$ per $0.25 \mathrm{~m}^{2}$ ) of the other 3 plots. In all years there was a trend toward reduction in winter annual diversity after March. In some years, plots supported one dominant annual species (e.g., Chaenactis carphoclinia or Pectocaryia platycarpa) by mid-May. The dominant summer annual, Pectis papposa, was encountered only on the $W$ and GAF plots. The peak standing crop of this annual occurred in August.

Table VI and Figure 6 depict monthly means for winter annuals for the 4 plots. This method ignores the difference in area covered by substrates, but it may approximate the year to year variation encountered by the wide ranging $\underline{S}$. obesus. For 1978 through 1980, standing crop of winter annuals increased gradually through February (regardless 
TABLE VI

MEAN MONTHLY STANDING CROP (mg/0.25 $\mathrm{m}^{2}$ ) FOR WINTER ANNUALS AT THE RED CLOUD ROAD STUDY SITE

\begin{tabular}{|c|c|c|c|c|c|}
\hline & & & 1978 & & \\
\hline Month & GAF & WASH & RHS & GHS & $\begin{array}{c}\text { Average of } 4 \text { Plots } \\
\pm 1 \text { S. E. }\end{array}$ \\
\hline $\operatorname{Jan}$ & 48.4 & 11.1 & 44.6 & 18.7 & $30.7 \pm 10.0$ \\
\hline Feb & 200.5 & 46.5 & 81.9 & 217.0 & $136.5 \pm 40.5$ \\
\hline Mar & 904.1 & 539.6 & 226.0 & 807.5 & $619.3 \pm 80.0$ \\
\hline Apr & 1982.4 & 2615.9 & 827.7 & 2767.6 & $2048.9 \pm 440.0$ \\
\hline May & 185.4 & 166.3 & 0.0 & 33.8 & $96.4 \pm 50.0$ \\
\hline & & & 1979 & & \\
\hline Nov & 98.5 & 112.9 & 17.8 & 22.2 & $62.9 \pm 20.0$ \\
\hline Dec & 222.5 & 224.3 & 59.4 & 236.3 & $185.6 \pm 40.0$ \\
\hline Jan & 218.5 & 240.2 & 80.3 & 520.2 & $264.8 \pm 90.0$ \\
\hline Feb & 298.3 & 530.0 & 251.1 & 697.7 & $444.0 \pm 110.0$ \\
\hline Mar & 542.6 & 2093.5 & 880.3 & 2214.6 & $1432.8 \pm 430.0$ \\
\hline Apr & 5259.0 & 7252.1 & 3570.6 & 7337.3 & $5854.8 \pm 900.0$ \\
\hline May & 828.0 & 575.7 & 411.3 & 507.9 & $580.7 \pm 90.0$ \\
\hline & & & $\underline{1980}$ & & \\
\hline Jan & 25.2 & 8.4 & 0.5 & 2.6 & $9.2 \pm$ \\
\hline Feb & 272.9 & 141.6 & 90.7 & 56.3 & $140.4 \pm 50.0$ \\
\hline Mar & 455.2 & 434.0 & 139.8 & 190.3 & $304.8 \pm 80.0$ \\
\hline Apr & 750.6 & 890.7 & 25.9 & 205.6 & $468.2 \pm 210.0$ \\
\hline May & 27.2 & 66.1 & 9.6 & 199.7 & $75.7 \pm 40.0$ \\
\hline
\end{tabular}




\section{TABLE VI (Con't \\ 1979 (Summer)}

\begin{tabular}{|c|c|c|c|c|c|}
\hline Month & GAF & WASH & RHS & GHS & $\begin{array}{c}\text { Average of } 4 \text { Plots } \\
\pm 1 \mathrm{~S} . \mathrm{E} .\end{array}$ \\
\hline Aug & 658.4 & 58.1 & 0.0 & 0.0 & $179.2 \pm 160.0$ \\
\hline \multirow[t]{2}{*}{ Sep } & 276.5 & 348.8 & 0.0 & 0.0 & $156.3 \pm 90.0$ \\
\hline & & & $\underline{1981}$ & & \\
\hline \multirow[t]{2}{*}{ Apr } & 98.6 & 97.1 & 34.4 & 87.7 & $79.5 \pm 15.0$ \\
\hline & & & 1982 & & \\
\hline \multirow[t]{2}{*}{ Apr } & 277.1 & 217.3 & 86.8 & 36.8 & $154.5 \pm 60.0$ \\
\hline & & & 1983 & & \\
\hline Apr & 133.4 & 802.9 & 567.9 & 459.9 & $791.3 \pm 190.0$ \\
\hline
\end{tabular}


Figure 6. Monthly dry weights of Winter annuals at the Red Cloud Road study site (Dry weight mean of four plots). horizontal bars = mean; vertical bars $= \pm$ one standard error. 


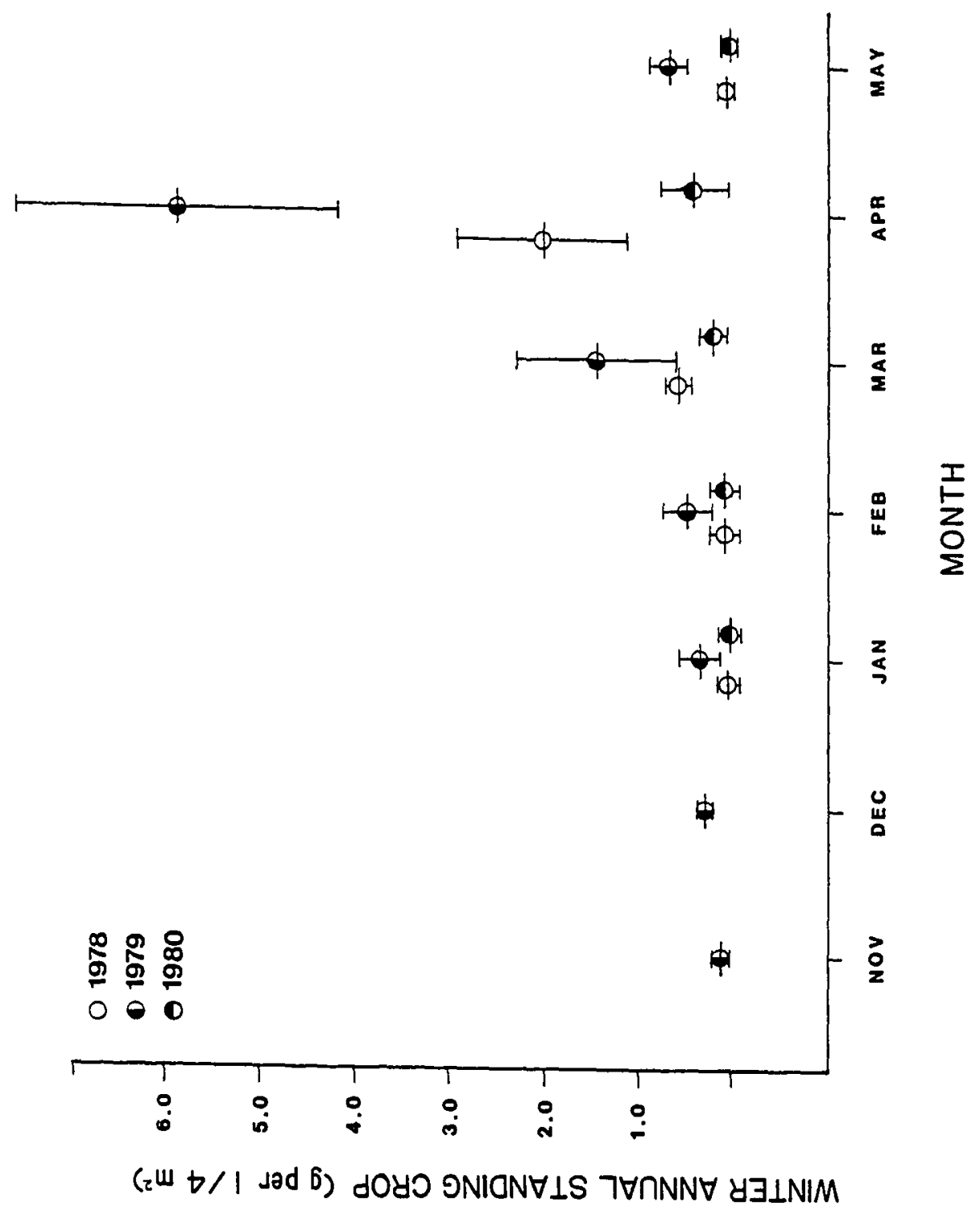


of climatic conditions), but increased rapidly from March through midApril if sufficient winter precipitation occurred. From mid-April through May, winter annual standing crop declined rapidly and was usually nonexitent by early June. The average daily rate of change of winter annual standing crop (Fig. 7) shows that maximum and minimum rates occurred during a 3 month period (mid-March through mid-May). Consequently, even in optimal years, the duration of greatest abundance was very short, usually a few weeks. Winter annuals were probably of little significance to $\underline{\mathrm{S}}$. obesus after mid-May. Mean April winter annual standing crop for 1978 through 1983 (Fig. 8) shows that during this period, the abundance of winter annuals showed a 73-fold variation.

During January of 1978 the stems of several perennial species were tagged to observe their growth patterns. At least 4 individuals of each plant species were tagged in each $225 \mathrm{~m}^{2}$ substrate plot. Growth in perennial stems was measured monthly from 1978 through 1980 and during the spring through June 1981 and 1982. Unfortunately, only the tagged stems of creosote (Larrea tridentata) persisted in sufficient quantity past 1979. Consequently, only this common shrub was considered for the measurement of elongation of perennial stems. In 1978 and 1979, elongation was not significantly different between the substrate plots (student-t test). Therefore, the 4 substrate plots were lumped in each of the 5 years (1978 through 1982). Two primary growth patterns were observed at the study site for perennials (Fig. 9). First, following initial winter precipitation, perennials usually 
Figure 7. Average daily rate of change of Winter annual standing crop for various monthly intervals at the Red Cloud Road study site (values determined from the dry weight mean of the four plots). 


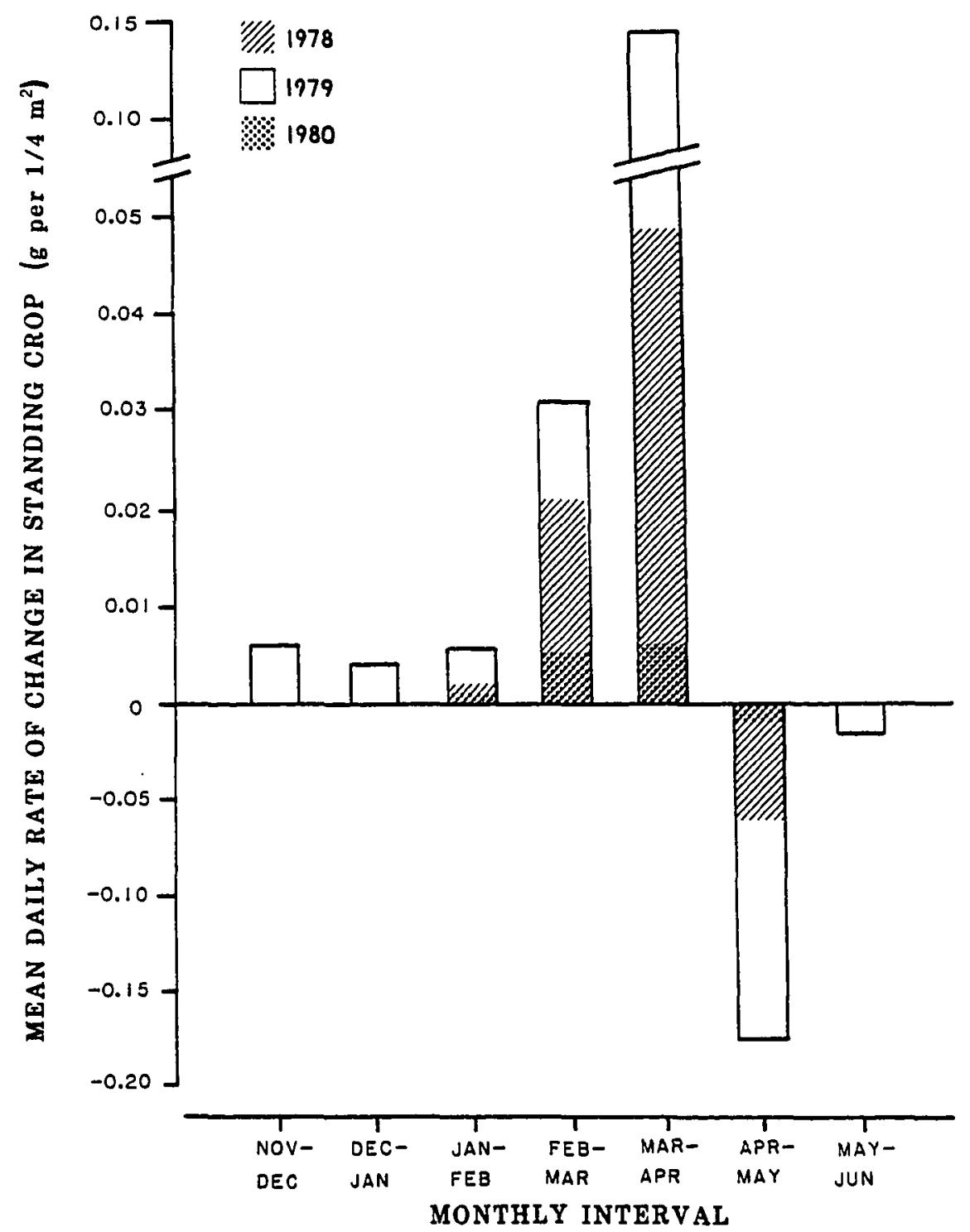


Figure 8. Mean April (peak) winter annual standing crop for the Red Cloud Road study site ( $1 / 4 \mathrm{~m}^{2}$ dry weight mean of the 4 substrate plots). Vertical bars indicate \pm 1 standard error. 


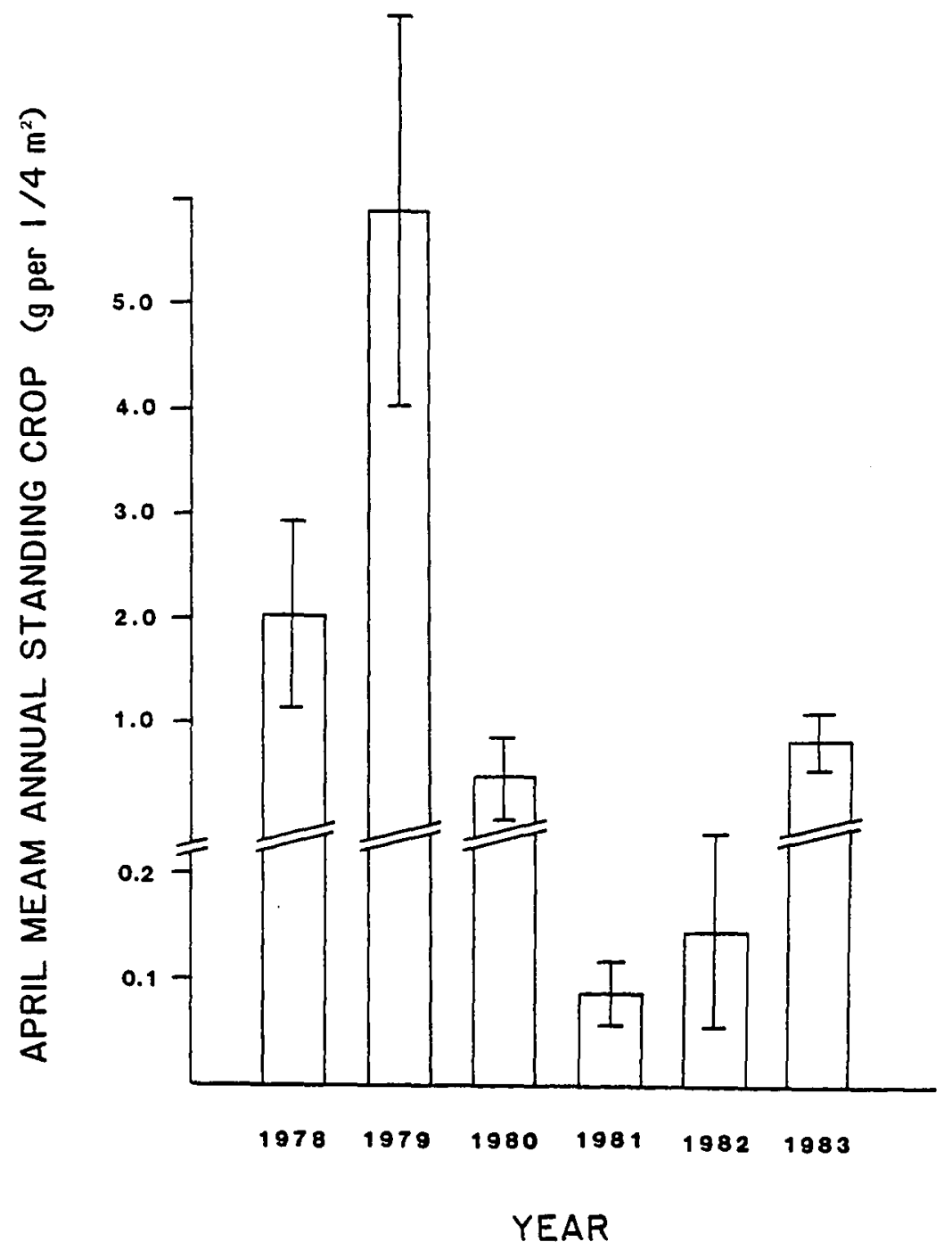


Figure 9. Yearly comparison of perennial stem elongation (Larrea tridentata) at the Red Cloud Road study site. Stem elongation is represented as the amount of winter growth (October through June) and summer growth (July through September). Horizontal lines = mean (of the 4 plots); vertical bars $= \pm$ two standard errors; vertical lines = range. 


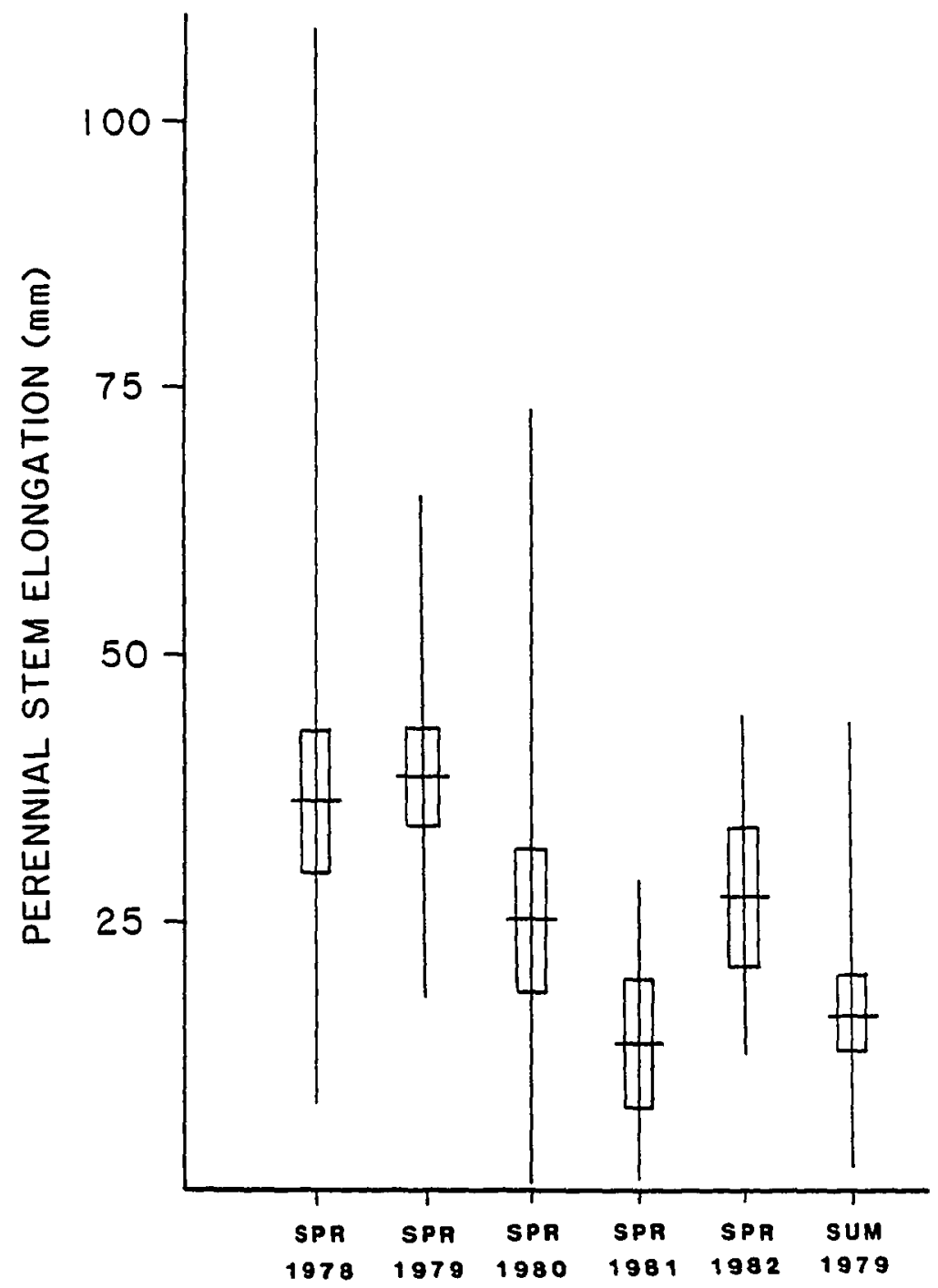


continued to grow into June. Second, if there was sufficient summer precipitation, an additional growth period occurred in August and September. Unfortunately, between 1980 and 1981 the number of tagged perennial stems declined greatly. The cause is unknown, but in the spring of 1981 many stems had become partially to fully broken. Nonetheless, the growth in perennial stems largely paralleled the pattern observed for annuals - i.e., maximum and minimum winter growth occurred in 1979 and 1981, respectively. As indicated above, summer precipitation is a fundamental feature of the climate of the Colorado Desert. Accordingly, in years when substantial summer precipitation followed average winter precipitation, roughly one-third of the yearly perennial stem elongation occurred in the summer.

Vegetational growth was greatly affected by the timing of precipitation. Regression analysis was undertaken on 3 vegetational parameters - perennial stem elongation, winter annual growing season, and April (peak) standing crop. Simple linear regression for each of these parameters with an assortment of climatic parameters (Table VII) clearly illustrates the importance of early winter precipitation. All 3 vegetational parameters were most strongly correlated with October through January precipitation. In the winter months, December precipitation was especially critical. Precipitation later in winter showed little correlation with growing season and peak annual standing crop." This probably contributed to the noticeably lower correlation between the 3 vegetational parameters and total winter precipitation. One other strong correlation was observed for both mean and mean maximum 
TABLE VII

LINEAR REGRESSION ANALYSIS OF VEGETATION GROWTH WITH AN ASSORTMENT OF CLIMATIC PARAMETERS. P VALUE $=$ SIGNIFICANCE LEVEL: NS INDICATES NOT SIGNIFICANT

\begin{tabular}{|c|c|c|c|c|}
\hline \multicolumn{5}{|c|}{ Growing Season } \\
\hline Climatic Parameter & $\mathrm{r}$ & Slope & Intercept & P Value \\
\hline December Precipitation & 0.93 & 50.49 & 110 & $<0.01$ \\
\hline November - January Precipitation & 0.90 & 12.39 & 85 & $<0.01$ \\
\hline October - January Precipitation & 0.99 & 9.78 & 87 & $<0.001$ \\
\hline Winter Precipitation (Oct - Mar) & 0.78 & 7.73 & 52 & $<0.05$ \\
\hline Summer Precipitation (Jul - Sep) & -0.25 & -2.45 & 153 & NS \\
\hline Annual Precipitation & 0.21 & 1.10 & 125 & NS \\
\hline Mean Winter Temperature & -0.81 & -38.48 & 738 & $<0.05$ \\
\hline Mean Winter Maximum Temperature & -0.87 & -31.47 & 860 & $<0.05$ \\
\hline Mean Spring Temperature & -0.05 & -2.08 & 192 & NS \\
\hline Mean Spring Maximum Temperature & -0.01 & -0.49 & 159 & NS \\
\hline Number of Nights $\leq 0{ }^{\circ} \mathrm{C}$ & 0.36 & 2.94 & 119 & NS \\
\hline Previous Years' Standing Crop & 0.06 & 0.32 & 137 & NS \\
\hline Previous Years' Growing Season & 0.19 & 0.19 & 153 & NS \\
\hline
\end{tabular}


TABLE VII $\left(\operatorname{Con}^{\prime} t\right)$

Perennial Stem Elongation

\begin{tabular}{lcccc}
\hline Climatic Parameter & $\mathbf{r}$ & Slope & Intercept & P Value \\
\hline December Precipitation & 0.82 & 8.80 & 23 & $<0.05$ \\
November - January Precipitation & 0.89 & 2.41 & 17 & $<0.01$ \\
October - January Precipitation & 0.89 & 1.75 & 18 & $<0.01$ \\
Winter Precipitation (Oct - Mar) & 0.84 & 1.64 & 9 & $<0.05$ \\
Summer Precipitation (JuI - Sep) & 0.06 & 0.11 & 28 & NS \\
Annual Precipitation & 0.45 & 0.45 & 21 & NS \\
Mean Winter Temperature & -0.70 & -6.59 & 130 & NS \\
Mean Winter Maximum Temperature & -0.87 & -6.19 & 169 & $<0.05$ \\
Mean Spring Temperature & -0.47 & -3.57 & 112 & NS \\
Mean Spring Maximum Temperature & -0.42 & -3.54 & 142 & NS \\
Number of Nights $\leq{ }^{\circ} \mathrm{C}$ & 0.40 & 0.65 & 23 & NS
\end{tabular}


TABLE VII (Con't)

Peak Annual Standing Crop

\begin{tabular}{lcccc}
\hline Climatic Parameter & $\mathrm{r}$ & Slope & Intercept & P value \\
\hline December Precipitation & 0.90 & 9.99 & 0 & $<0.01$ \\
November - January Precipitation & 0.84 & 2.36 & -4 & $<0.05$ \\
October - January Precipitation & 0.96 & 1.94 & -4 & $<.001$ \\
Winter Precipitation (Oct - Mar) & 0.74 & 1.48 & -11 & NS \\
Summer Precipitation (Ju1 - Sep) & -0.32 & -0.64 & 9 & NS \\
Annual Precipitation & 0.15 & 0.16 & 4 & NS \\
Mean Winter Temperature & -0.81 & -7.85 & 128 & 0.05 \\
Mean Winter Maximum Temperature & -0.85 & -6.24 & 149 & 0.05 \\
Number of Nights $\leq{ }^{\circ} \mathrm{C}$ & 0.36 & 0.62 & 2. & NS \\
Previous Years' Standing Crop & 0.04 & 0.05 & 6 & NS \\
Previous Years' Growing Season & 0.18 & 0.04 & 1 & NS \\
\hline
\end{tabular}


winter air temperature. These temperatures were especially important in the growth of winter annuals. Multiple regression analysis undertaken on the same 3 vegetational parameters (Table VIII) shows that the winter annual growing season and peak standing crop remained large1y affected by early winter precipitation. On the other hand, perennial stem elongation showed a stronger correlation when October through January precipitation was paired with mean spring maximum air temperature. Consequently, maximum growth of winter annuals appeared to require early winter precipitation. However, while perennial growth was most enhanced by early winter precipitation, other parameters such as lower maximum spring air temperatures appeared important for maximum growth. Although they rely most heavily on winter annuals, $\underline{S}$. obesus demonstrated opportunistic feeding habits (Ch. 2 - Dietary habits). Therefore, the fact early winter precipitation is critical for growth of both annuals and perennials may make this climatic parameter a reliable predictor of some of the life history of $\underline{S}$ - obesus (Ch. 4 \& 5 - Life History \& Demography). 
TABLE VIII

MULTIPLE REGRESSION ANALYSIS OF VEGETATION WITH AN ASSORTMENT OF CLIMATIC PARAMETERS. * INDICATES P $<0.01$; ** INDICATES $\mathrm{P}<0.001$.

\begin{tabular}{|c|c|c|}
\hline Growing Season & R & $2^{2}$ \\
\hline \multicolumn{3}{|l|}{ October Through January Precipitation With: } \\
\hline Mean Winter Maximum Temperature & 0.98 & $* *$ \\
\hline Mean Spring Maximum Temperature & 0.97 & $* *$ \\
\hline Mean Annual Maximum Temperature & 0.97 & $* *$ \\
\hline Number of Nights $\leq 0^{\circ} \mathrm{C}$ & 0.99 & 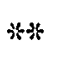 \\
\hline \multicolumn{3}{|l|}{ Peak Annual Standing Crop } \\
\hline \multicolumn{3}{|l|}{ October Through January Precipitation With: } \\
\hline Mean Winter Maximum Temperature & 0.87 & $* *$ \\
\hline Mean Spring Maximum Temperature & 0.88 & $* *$ \\
\hline Mean Annual Maximum Temperature & 0.86 & $* *$ \\
\hline Number of Nights $\leq 0^{\circ} \mathrm{C}$ & 0.88 & $* *$ \\
\hline \multicolumn{3}{|l|}{ Perennial Stem Elongation } \\
\hline \multicolumn{3}{|l|}{ October Through January Precipitation With: } \\
\hline Mean Winter Maximum Temperature & 0.70 & * \\
\hline Mean Spring Maximum Temperature & 0.96 & 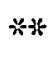 \\
\hline Mean Annual Maximum Temperature & 0.81 & $*$ \\
\hline Number of Nights $\leq 0{ }^{\circ} \mathrm{C}$ & 0.66 & $*$ \\
\hline
\end{tabular}


CHAPTER II

GENERAL ECOLOGY

Annual activity cycle, dietary habits, predators and competitors, movement and spacing patterns and social behavior were investigated in order to provide a comparison with conspecific northern Mojave De-

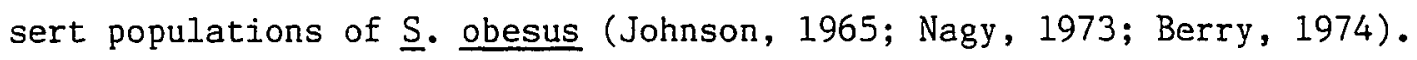
More importantly, such information proved extremely valuable in determining the factors responsible for the life history traits exhibited by Colorado Desert $\underline{S}$. obesus.

\section{ANNUAL ACTIVITY CYCLE OF CHUCKWALLAS}

To date, precise documentation of annual activity for $\underline{S}$. obesus is lacking. Mojave Desert $\underline{S}$. obesus are suspected of being active only in the spring (Nagy, 1973; Berry, 1974). The sighting frequency

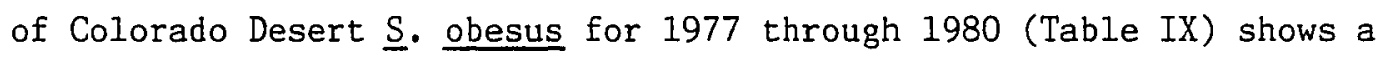
marked increase in surface activity between early February and early March (when daily maximum air temperatures had increased to about $25^{\circ} \mathrm{C}$ ). Activity increased rapidly through the spring and peaked over a 6-week period May through the first half of June (which corresponded to the breeding season). After mid-June, activity declined rapidly with summer dormancy beginning in July. If summer precipitation was less than average, lizards usually remained inactive through winter. However, greater than average summer precipitation in 5 of the 7 years of this study promoted food availability and thus prompted increased activity 
TABLE IX

SIGHTING FREQUENCY (LIZARDS/MAN HOUR) FOR S. obesuS AT THE RED CLOUD ROAD STUDY SITE. \pm 1 S. $\bar{E}$.

\begin{tabular}{|c|c|c|c|c|c|}
\hline \multicolumn{6}{|c|}{ Month } \\
\hline Year & Dec & Jan & Feb & Mar & \\
\hline 1977 & 0.5 & - & 0.6 & 0.5 & \\
\hline 1978 & 0.3 & - & 1.2 & 1.2 & \\
\hline 1979 & - & 0.5 & 0.9 & 1.0 & \\
\hline 1980 & - & 0.7 & 0.6 & 1.5 & \\
\hline $4 \mathrm{Yr} \mathrm{Av}$ & $0.4 \pm 0.1$ & $0.6 \pm 0.1$ & $1.0 \pm 0.2$ & $1.0 \pm 0.2$ & \\
\hline Year & Apr & May & $\left(1^{\text {st }}\right.$ half $)$ & $\begin{array}{c}\text { Jun } \\
\text { (total) }\end{array}$ & Ju1 \\
\hline 1977 & 1.2 & 1.3 & - & 0.4 & 0.5 \\
\hline 1978 & 2.0 & 1.7 & 2.1 & 1.6 & 0.9 \\
\hline 1979 & 1.7 & 2.0 & 2.2 & 1.6 & 1.1 \\
\hline 1980 & 1.6 & 2.3 & 1.5 & 1.7 & 1.4 \\
\hline $4 \mathrm{Yr} \mathrm{Av}$ & $1.7 \pm 0.2$ & $1.8 \pm 0.2$ & $1.9 \pm 0.2$ & $1.3 \pm 0.3$ & $1.0 \pm 0.2$ \\
\hline Year & Aug & Sep & Oct & Nov & \\
\hline 1977 & 1.2 & 0.9 & 0.8 & 0.5 & \\
\hline 1978 & 1.0 & 0.4 & 0.7 & 1.0 & \\
\hline 1979 & 1.5 & 1.4 & 0.7 & 0.8 & \\
\hline 1980 & 0.9 & - & - & - & \\
\hline $4 \mathrm{Yr} \mathrm{Av}$ & $1.1 \pm 0.1$ & $0.9 \pm 0.3$ & $0.7 \pm 0.02$ & $0.8 \pm 0.1$ & \\
\hline
\end{tabular}


in late July or early August. Peak summer activity usually occurred during the middle to later portions of the summer rainfall season (midAugust to early September), but never approached that observed in late spring. Activity greatly declined after mid-September even during very wet summers. The onset of winter dormancy usually occurred by late October when daily maxima repeatedly dropped below about $25^{\circ} \mathrm{C}$. However, hatchlings were often abroad in great numbers until December (Ch. 3 - Incubation and Appearance of Hatchlings). Few $\underline{\text { S }}$ obesus were observed in December and January even in their favorite retreats. However, a few individuals, both adults and subadults, because of being observed in widely separated retreats, were known to undertake considerable movements over winter. These movements seemed to be correlated with feeding efforts (Ch. 2 - Dietary Habits).

\section{FEEDING HABITS}

It appears that $\underline{S}$. obesus is exclusively herbivorous (Shaw, 1945; Nagy, 1973; Hansen, 1974). Specific questions asked for Colorado Desert S. obesus were: 1 ) What is the seasonal and daily feeding pattern? 2) What habitat areas are preferred for feeding? 3) What plant species contribute to the diet? and 4) How does diet change according to the season?

Previous investigators of $\underline{S}$. obesus in the Mojave Desert indicated that feeding was primarily restricted to spring (Nagy, 1973; Berry,

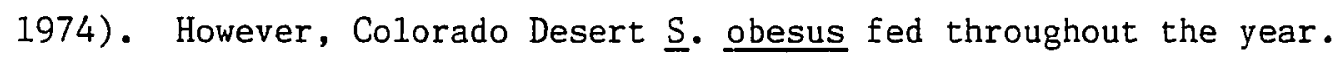
Palpation of individuals captured during the winter routinely revealed engorged stomachs. Feeding was most intense in early spring (March and 
April) when winter annual standing crop was greatest. In years when food was abundant, feeding continued into early summer (through June). However, at the time of peak reproductive activity (May through the first half of June) the frequency was greatly reduced regardless of availability. Feeding resumed at high intensity in late summer (August through September) provided summer precipitation was adequate to stimulate growth of perennials and germination of summer annuals. Palpation of $\underline{S}$. obesus frequently revealed engorged stomachs in October and November (if precipitation was sufficient to stimulate growth of perennials and germination of winter annuals), although frequency of feeding generally declined into the fall as activity diminished.

Periods of feeding were observed throughout most of the day (1000 to $1700 \mathrm{H}$ ) in late winter and early spring. During this time some S. obesus made as many as 3 feeding sallies per day. In late spring, during the breeding season, feeding was primarily restricted to morning and early afternoon (0800 to $1300 \mathrm{H}$ ) and individuals rarely ate more than once per day. The frequency of feeding declined rapidly through June. For 1977 through 1980 no feeding was observed in July and only rarely could food be palpated in the stomachs at this time. If summer precipitation was meager and hence food was limited, feeding did not

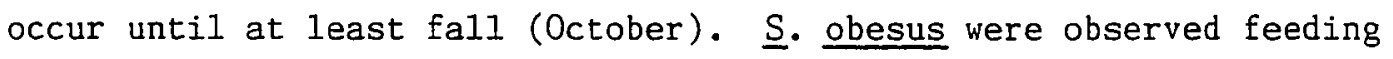
much of morning and late afternoon (0800 to 1100 and 1500 to $1700 \mathrm{H}$ ) when summer precipitation was extensive and food was abundant. Individuals showed varying amounts of activity from February through September. Nonetheless, periods of feeding were consistently brief, from 1 to 5 minutes. This amount of time allowed $\underline{S}$. obesus the opportunity to snip 
off up to 15 bits of vegetation.

Feeding was restricted to locations within $10 \mathrm{~m}$ of favorite rock outcrops. In the early spring, most $\underline{S}$. obesus were observed eating in dense vegetation at the base of favorite basking sites. In late spring, as food resources diminished, some individuals made feeding sallies up to about $30 \mathrm{~m}$ between favorite outcrops. A similar pattern was also observed routinely for late summer.

While diets of Mojave Desert $\underline{S}$. obesus consisted largely of perennial plant species (Nagy, 1973; Hansen, 1974), annual plant species have long been suspected to be critical to high reproductive success (Berry, 1974). Over half (52\%) of the 125 plant species known at the

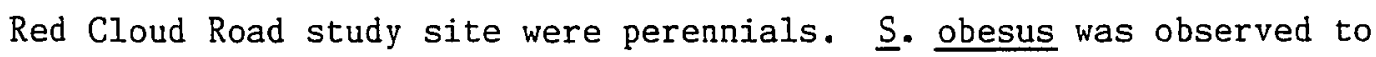
feed on 48 plant species (Table X) in the year of maximal growth (1979). This amounted to about $38 \%$ of the species identified. About $50 \%$ and $28 \%$ of the known annuals and perennials, respectively, were ingested. Consequently, of the 48 plant species known to be eaten, roughly $63 \%$ were annuals.

During 1979 one distinct pattern for feeding was evident. In the early spring (March through April) roughly $70 \%$ of the feedings were on annuals. However, by late spring (May and June), with a profound shift to perennials, annuals amounted only to about $25 \%$ of the feedings. A similar pattern was observed for 1978. Both of these years had early and extensive winter precipitation. A considerably different feeding pattern emerged in 1977 and 1980. Annual standing crop was highly correlated with precipitation (Ch. 1 - Climate and Vegetation), and unusually low later winter precipitation in 1977 resulted in germination of 
TABLE $X$

OBSERVATION DETERMINED DIET FOR RED CLOUD ROAD STUDY SITE $\underline{\mathrm{S}}$. obesus. SYMBOLS ARE AS FOLLOWS: F (FLOWERS), L (LEAVES), AND S (STEMS)

\begin{tabular}{|c|c|c|c|c|c|c|c|c|}
\hline \multirow[b]{2}{*}{ Plant Species } & \multicolumn{8}{|c|}{ Month } \\
\hline & Feb & Mar & Apr & May & Jun & Ju1 & Aug & Sep \\
\hline Ambrosia dumosa & & & $\mathrm{F}, \mathrm{L}$ & $\mathrm{L}$ & & & & \\
\hline Amsinkia tesselata & & & $\mathrm{F}, \mathrm{L}, \mathrm{S}$ & & & & & \\
\hline Bebbia juncea & & & & $\mathrm{F}$ & & & & \\
\hline Calycoseris parryi & & & $\mathrm{F}, \mathrm{L}$ & & & & & \\
\hline c. wrightii & & & $\mathrm{F}, \mathrm{L}$ & & & & & \\
\hline Camissonia boothii & $L, S$ & $F, L, S$ & $F, L, S$ & & & & & \\
\hline c. brevipes & $\mathrm{L}, \mathrm{S}$ & $F, L, S$ & $F, L, S$ & & & & & \\
\hline c. claviformis & $\mathrm{L}, \mathrm{S}$ & & & & & & & \\
\hline Cercidium floridum & & & $\mathrm{F}$ & $\mathrm{F}$ & & & & \\
\hline Chaenactis carphoclina & & $\mathrm{L}, \mathrm{S}$ & $\mathrm{L}, \mathrm{S}$ & $F, S$ & & & & \\
\hline C. stevioides & & & $\mathrm{L}, \mathrm{S}$ & $\mathrm{L}, \mathrm{S}$ & & & & \\
\hline Chorizanthe brevicornu & & & $\mathrm{F}, \mathrm{L}, \mathrm{S}$ & & & & & \\
\hline Cryptantha spp. & $F, L, S$ & $F, L, S$ & $\mathrm{~F}, \mathrm{~L}, \mathrm{~S}$ & & & & & \\
\hline
\end{tabular}


TABLE $X$ (Con't)

\begin{tabular}{|c|c|c|c|c|c|c|c|c|}
\hline \multirow[b]{2}{*}{ Plant Species } & \multicolumn{8}{|c|}{ Month } \\
\hline & Feb & Mar & Apr & May & Jun & Ju1 & Aug & Sep \\
\hline Dyssodia porophyloides & & & & $\mathrm{F}, \mathrm{S}$ & & & & \\
\hline Echinocereus engelmannii & & & $\mathrm{F}$ & & & & & \\
\hline Eriogonum inflatum & $\mathrm{F}, \mathrm{L}$ & $\mathrm{F}, \mathrm{L}$ & $\mathrm{F}, \mathrm{L}$ & $\mathrm{F}, \mathrm{L}$ & $\mathrm{F}, \mathrm{L}$ & & $\mathrm{F}, \mathrm{L}$ & $\mathrm{F}, \mathrm{L}$ \\
\hline Eschscholtzia eschscholtzia & $\mathrm{F}, \mathrm{L}, \mathrm{S}$ & $F, L, S$ & $F, L, S$ & & & & & \\
\hline Euphorbia polycarpa & $\mathrm{L}, \mathrm{S}$ & $\mathrm{L}, \mathrm{S}$ & $\mathrm{L}, \mathrm{S}$ & $L, S$ & & & $\mathrm{~L}, \mathrm{~S}$ & $\mathrm{~L}, \mathrm{~S}$ \\
\hline E. setiloba & & $L, S$ & & & & & & \\
\hline Fagonia chilensis & $\mathrm{L}, \mathrm{S}$ & $\mathrm{L}, \mathrm{S}$ & $\mathrm{L}, \mathrm{S}$ & $F, L$ & $F, L$ & & & \\
\hline Fouquieria splendens & & & $\mathrm{F}, \mathrm{L}$ & $\mathrm{F}, \mathrm{L}$ & $\mathrm{F}$ & & & $\mathrm{L}$ \\
\hline Gilia spp. & & & $\mathrm{F}, \mathrm{L}$ & & & & & \\
\hline Krameria grayi & & & $\mathrm{L}$ & $\mathrm{F}, \mathrm{L}$ & $\mathrm{F}, \mathrm{L}$ & & & \\
\hline Lepidium spp. & $F, L, S$ & $\mathrm{~F}, \mathrm{~L}, \mathrm{~S}$ & $\mathrm{~F}, \mathrm{~L}, \mathrm{~S}$ & & & & & \\
\hline Lotus tomentallus & $\mathrm{L}, \mathrm{S}$ & $\mathrm{F}, \mathrm{L}, \mathrm{S}$ & $\mathrm{F}, \mathrm{L}, \mathrm{S}$ & & & & & \\
\hline L. $\underline{\text { rigidus }}$ & $\mathrm{L}, \mathrm{S}$ & $\mathrm{F}, \mathrm{L}, \mathrm{S}$ & $\mathrm{F}, \mathrm{L}, \mathrm{S}$ & & & & & \\
\hline Lupinus arizonicus & $\mathrm{L}, \mathrm{S}$ & $\mathrm{F}, \mathrm{L}, \mathrm{S}$ & $\mathrm{F}, \mathrm{L}, \mathrm{S}$ & & & & & \\
\hline Machaeranthera tortifolia & & & & $\mathrm{F}$ & & & & \\
\hline
\end{tabular}


TABLE $X\left(\right.$ Con $\left.^{\prime} t\right)$

\begin{tabular}{|c|c|c|c|c|c|c|c|c|}
\hline \multirow[b]{2}{*}{ Plant Species } & \multicolumn{8}{|c|}{ Month } \\
\hline & Feb & Mar & Apr & May & Jun & Ju1 & Aug & Sep \\
\hline Mimulus bigelovii & & & $\mathrm{F}, \mathrm{L}$ & $F, L$ & & & & \\
\hline Mirabilis bigelovii & $\mathrm{L}, \mathrm{S}$ & $\mathrm{F}, \mathrm{L}, \mathrm{S}$ & $\mathrm{F}, \mathrm{L}, \mathrm{S}$ & & & & & \\
\hline Monoptilon belloides & & & $\mathrm{F}$ & & & & & \\
\hline Nicotiana trigonophylla & $F, L$ & $\mathrm{~F}, \mathrm{~L}$ & & & & & & \\
\hline O1neya tesota & & & & $\mathrm{F}, \mathrm{L}$ & $\mathrm{F}, \mathrm{L}$ & & & \\
\hline Pectis papposa & & & & & & & $\mathrm{F}, \mathrm{L}$ & $\mathrm{F}, \mathrm{L}$ \\
\hline Perityle emoryi & $F, L, S$ & $\mathrm{~F}, \mathrm{~L}, \mathrm{~S}$ & & & & & & \\
\hline Phacelia crenulata & & $\mathrm{F}, \mathrm{L}, \mathrm{S}$ & $\mathrm{F}, \mathrm{L}, \mathrm{S}$ & & & & & \\
\hline$\underline{P} \cdot \underline{\text { distans }}$ & & & $\mathrm{F}, \mathrm{L}, \mathrm{S}$ & & & & & \\
\hline Physalis crassifolia & & $\mathrm{F}$ & & & & & & \\
\hline Plantago insularis & $\mathrm{L}, \mathrm{S}$ & $F, L, S$ & $F, L, S$ & & & & & \\
\hline Sphaeralcea ambigua & $\mathrm{L}$ & $\mathrm{F}, \mathrm{L}$ & $\mathrm{F}, \mathrm{L}$ & & & & & \\
\hline Stephanomeria pauciflora & & & & $\mathrm{F}$ & & & & \\
\hline Tricoptilium incisum & & & $\mathrm{L}$ & $\mathrm{F}, \mathrm{L}$ & $\mathrm{F}, \mathrm{L}$ & & & \\
\hline Trixis californica & & & F,L & $\mathrm{F}, \mathrm{L}$ & & & & \\
\hline
\end{tabular}


fewer and shorter-lived annuals. Though observations were not as thorough for other years as for 1979 , enough information was compiled to show that in 1977 and 1980 perennials represented from 50 to 100\% of the feedings throughout the spring.

In 1977 and 1979, summer precipitation was extensive. This resulted in substantial vegetational growth. However, except for chinchweed (Pectis papposa), which appeared in great abundance along washes and over alluvial flats, summer annuals were uncommon at the Red Cloud Road study site. Consequently, perennials constituted about $90 \%$ of the feedings.

Winter annuals usually appeared in dense clumps around the bases of outcrops and shrubs and along wash margins. With a shift to perennials in late spring and late summer, food resources appeared more scattered. Consequently, $\underline{S}$ obesus had to move farther to fulfill their energy requirements. This often resulted in some very acrobatic and vulnerable manuevers in tall vegetation. On several occasions, individuals were observed on limbs 2 to $4 \mathrm{~m}$ above ground, eating flowers and/or leaves of desert ironwood, border palo verde, and ocotillo. With a shift to perennials, the quality of the food was probably declining. Several times $\underline{S}$. obesus were observed eating fallen dried flower petals of certain perennials (especially ocotillo).

Based on observations, $\underline{S}$. obesus demonstrated highly opportunistic feeding habits in 1979. During early spring, a great number of plant species were eaten. No single species exceeded $10 \%$ frequency. Observation showed the following annuals to be most frequently eaten: woolly plantain (Plantago insularis), 10\%; emory rock daisy (Perityle emoryi), 
9\%; and notched-leaved phacelia (Phacelia crenulata), $7 \%$. The most frequently eaten perennials, each amounting to about $7 \%$, were desert trumpet (Erigonum inflatum), wishbone (Mirabilis bigelovii), and desert mallow (Sphaeralcea ambigua). In late spring, though fewer plant species were selected, none exceeded $10 \%$ frequency. Only one annual, pebble pincushion (Chaenactis carphoclina), was routinely eaten (8\%). The most frequently eaten perennials, ( 8 and $10 \%$ frequency), were burrobush (Ambrosia dumosa), fagonia (Fagonia chilensis), and sweetbush (Bebbia juncia). In late summer, the only annual species known to be eaten was chinchweed (Pectis papposa). It amounted to about $10 \%$ frequency. Two perennials contributed equally to about $80 \%$ frequency. They were desert trumpet (E. inflatum), and small-seeded sandmat (Euphorbia polycarpa). Preliminary investigation of stomach contents revealed a similar trend of opportunism in feeding habits. Apparently, for Colorado Desert $\underline{S}$. obesus, overall standing crop was more important than the status of a few plant species. Because the precipitation pattern greatly affected the overall standing crop, such feeding habits help justify an attempt to predict such life history features as fecundity from climatic parameters (Ch. 4 \& 5 - Life History \& Demography).

\section{PREDATORS AND COMPETITORS}

Previous studies (Berry, 1974; Case, 1976, 1982) have considered intensity of predation on $\underline{S}$. obesus but only a few mammalian carnivores have been reported as predators on this species. The role of interspecific competition in the life history strategy of this species remains unknown. Specific questions asked in this study were: 1) What 
are the primary predators of $\underline{S}$ obesus? 2) What are its primary competitors? 3) Which of these factors has the greatest impact on life history?

Five species of snakes, coachwhip (Masticophus flagellum), western patch-nosed (Salvadora hexalepis), desert night snake (Hypsiglena torquata), sidewinder ( $\underline{\text { Crotalus }}$ cerastes) and speckled rattlesnake ( $\underline{\text { C. }}$ mitchelli), were seen during this study. C. mitchelli and $\underline{M}$. flagellum were by far the most frequently seen, each about 150 and 100 times. The other species were seen infrequently, 3- 15 times each. $\underline{\text { C. mit- }}$ chelli was seen in every month except December and January. Individuals were seen basking on rocks, hiding in rock crevices, or hiding beneath boulders. In April and May of 1979, 2 to 6 sightings a day were common. Possible breeding pairs were observed together in May of 1978, 1979

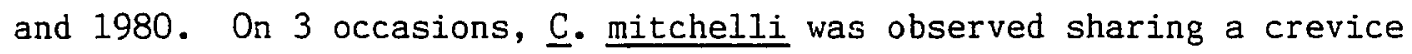
with adult $\underline{\text { S. }}$ obesus. M. flagellum was encountered March through October, but was most common from June through September. Individuals were sighted throughout the day moving swiftly over outcrops, gravel alluvial flats, and washes. During September of 1977 and July of 1978 there were as many as 3 sightings per day. Small lizards were palpated in this species stomach in both spring and late summer months. All 3 of the remaining snake species are known to be lizard predators. However, $\underline{C}$. cerastes was usually not encountered in or near the rock outcrops used by $\underline{S}$. obesus. $\underline{S}$. hexalepis, seen only March through June of $1979,1980,1981$, appeared to be uncommon. Nonetheless, this snake was always sighted in or near rock outcrops and on two occasions lizards were palpated in the stomachs. $\underline{H}$. torquata was encountered most infre- 
quently (March of 1978 and 1979), but because of its crevice-dwelling habits, this species was probably more common than observed. In March 1978, autopsy of an individual accidentally killed revealed a partly digested hatchling $\underline{\text { s. obesus }}(\mathrm{SVL}=55 \mathrm{~mm})$.

Predation by birds and mammals on $\underline{S}$. obesus was evaluated. On several occasions, when red-tailed hawks (Buteo jamaicensis) flew overhead, basking $\underline{S}$. obesus promptly disappeared into crevices. Once, a raven (Corvus corax) was observed attempting to carry away an adult male $\underline{\text { S}}$ obesus $($ SVL $=175 \mathrm{~mm}$ ), and might have been successful had an observer not intervened. Coyotes (Canis latrans) and their scats were common throughout the region. Several coyote dens were located in the larger rock outcrops. Other mammalian carnivores were uncommon in this region. Coyotes appeared to be primarily responsible for tail breaks and the array of other mutilations (such as amputations) observed in

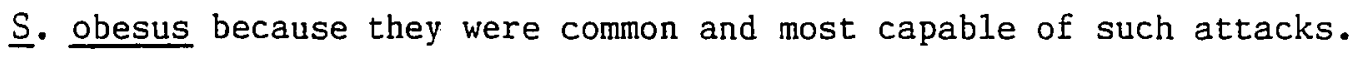
The lizard fauna sympatric with $\underline{S}$. obesus on most study sites was as rich as formerly reported by other studies on $\underline{S}$. obesus. Ten lizard species were encountered at the Red Cloud Road study site (Table XI). Side-blotched lizards (Uta stansburiana) and western whiptail lizards (Cnemidophorus tigris) were very abundant on most microhabitats. Collard lizards (Crotaphytus collaris) and desert iguanas (Dipsosaurus dorsalis) were common on rocky slopes and gravel flats, respectively.

$\times$ Desert spiny. Iizards (Sceloporus magister) were frequently sighted both in rock outcrops and in desert ironwood trees (lneya tesota). Some common lizard species were encountered infrequently because the microhabitats they selected were not routinely investigated (e.g., tree 
TABLE XI

LIZARD SPECIES INHABITING THE RED CLOUD ROAD STUDY SITE. * INDICATES MULTIPLE DAYS. GAF = GRAVEL ALLUVIAL FLAT, GHS = GRAVEL HILLSIDE, RHS $=$ ROCKY HILLSIDE, $W=$ WASH

\begin{tabular}{|c|c|c|c|c|c|}
\hline Lizard Species & Microhabitat & $\begin{array}{l}\text { Activity } \\
\text { Season } \\
\text { (Adult) }\end{array}$ & $\begin{array}{l}\text { Breeding } \\
\text { Season }\end{array}$ & $\begin{array}{l}\text { Maximum \# } \\
\text { Adults/Day }\end{array}$ & $\begin{array}{c}\text { Hatchlings } \\
\text { Sighted }\end{array}$ \\
\hline Dipsosaurus dorsalis & $\begin{array}{l}\text { perennials; } \\
\text { GHS, GAF, W }\end{array}$ & Apr - Aug & May - Jun & 12 & Sep - Oct \\
\hline Crotaphytus collaris & $\begin{array}{l}\text { outcrops and } \\
\text { RHS }\end{array}$ & Mar - Aug & Apr - May & 17 & Sep - Oct \\
\hline Gambelia wislizeni" & $\begin{array}{l}\text { open areas; } \\
\text { GAF, W }\end{array}$ & Apr - Jun & - & 1 & - \\
\hline Callisaurus draconoides & GAF, W & Apr - Aug & - & 3 & May - Oct \\
\hline Uta stansburiana & $\begin{array}{l}\text { outcrops and } \\
\text { RHS, GAF, GHS }\end{array}$ & year round & Jan - Jul & $50 *$ & May - Oct \\
\hline Urosaurus ornatus & $\begin{array}{l}\text { limbs of trees } \\
\text { (desert iron- } \\
\text { wood) }\end{array}$ & Apr - Ju1 & - & 1 & - \\
\hline Sceloporus magister & $\begin{array}{l}\text { tree trunks; } \\
\text { outcrops }\end{array}$ & Mar - Oct & - & 6 & Sep $-0 c t$ \\
\hline Phrynosoma platyrhinos & RHS, GHS, GAF & Mar - Oct & - & 4 & Aug - Oct \\
\hline Cnemidophorus tigris & $\begin{array}{l}\text { around vege- } \\
\text { tation; RHS, } \\
\text { GHS, GAF, W }\end{array}$ & Mar - Jun & Apr - Jun & $30 *$ & Aug - Oct \\
\hline
\end{tabular}


TABLE XI (Con't

\begin{tabular}{llcccc}
\hline Lizard Species & Microhabitat & $\begin{array}{c}\text { Activity } \\
\text { Season } \\
\text { (Adult) }\end{array}$ & $\begin{array}{c}\text { Breeding } \\
\text { Season }\end{array}$ & $\begin{array}{c}\text { Maximum \# } \\
\text { Adults/Day }\end{array}$ & $\begin{array}{c}\text { Hatchlings } \\
\text { Sighted }\end{array}$ \\
\hline Coleonyx variegatus & outcrops & Mar - Jun & - & 2 & - \\
\hline
\end{tabular}


lizards, Urosaurus ornatus - on tree limbs and zebra-tailed lizards, Callisaurus draconoides - on open washes) or because their activity was not common during the hours of study (e.g., banded gecko, Coleonyx variegatus, which is primarily nocturnal). Limited areas of sparsely vegetated flats in the study site probably contributed to leopard lizards (Gambelia wislizeni) being rare. Desert horned lizards, (Phrynosoma platyrhinos), were common on cool spring and fall days, usually on gravel slopes or flats near small shrubs.

D. dorsalis was the only other herbivorous lizard in the study area. Individuals were frequently encountered on rocky slopes where they sometimes basked alongside $\underline{S}$. obesus. $\underline{S}$. magister was most often sighted on rock outcrops and on about 20 occasions shared crevices with S. obesus. Lizards were palpated in the stomachs of $\underline{G}$. wislizeni. Uta and Cnemidophorus tails were observed in the mouths of this carnivorous lizard. However, all $\underline{G}$. wislizeni were encountered in open flats, a microhabitat not routinely frequented by $\underline{S}$. obesus. Consequently, other lizard species appeared not to have a major impact on the life history of $\underline{\text { S. }}$ obesus.

Apparently this region supports one of the densest desert tortoise (Scaptochelys agassizii) populations in southern California (California Desert Plan, 1980). Individuals were encountered February through October. In the early spring and fall, adults were commonly sighted 3 to 5 times a day. They were usually seen in burrows or browsing on low vegetation. Locations included the bases of rocky slopes, on gravel flats, and in or near wahses. In the spring they consumed some annuals, most1y Plantago insularis, Cryptantha spp., and Lepidium spp., but 
throughout the year tortoises differed from $\underline{S}$. obesus in preferring perennials, especially Ambrosia dumosa, Encelia farinosa, and Sphaeralcea ambigua.

A common mammalian resident of outcrops was the desert woodrat (Neotoma lepida). Typically, this rodent constructs elaborate protective barriers of cholla buds (usually Opuntia bigelovii) in front of retreat openings. Several such retreats were frequently visited by $\underline{S}$. obesus. A consequence of such constructions was a 3-fold increase in frequency of lizards bearing embedded cactus spines. Some of these spines had penetrated the abdominal wall. In one case, dissection revealed that a spine had caused an ovarian abcess rendering the organ nonfunctional. Although the incidences of embedded cactus spines was

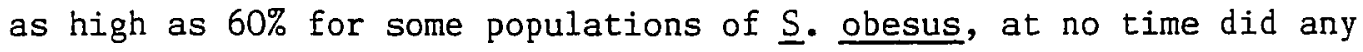
individual appear greatly burdened by such an injury.

These anecdotal observations suggest two trends. First, snakes and coyotes may be important predators of young and adult $\underline{S}$. obesus, respectively. Second, due to the high degree of spatial overlap tolerated by $\underline{S}$. obesus, interspecific competition for food and retreats appeared to be minimal. Consequently, it seems that predation may be a more important factor than interspecific competition in shaping the life history traits of $\underline{S}$ obesus (Ch. 5 - Predation Intensity).

MOVEMENT AND SPACING PATTERNS

Movement and spacing patterns were previously described for $\underline{\mathrm{S}}$. obesus in the:Mojave Desert (Johnson, 1965; Nagy, 1973; Berry, 1974). 
Nonetheless, only Berry considered how these aspects were affected by age and sex. To date, no investigation has considered how movements, territories and home ranges fluctuate according to activities (such as reproduction), or prevailing climate and its effect on availability of food. Specific questions asked in this study were: 1) What is the extent of movement and home range size of immature, subordinate and adult males? 2) What is the extent of movement and home range size of immature and adult females? 3) What factors affect the movements and home range size of adult males and females?

Movement and spacing patterns were determined for $\underline{S}$. obesus at the Red. Cloud Road study site from 1977 through 1980. Both patterns were affected by age, sex, and prevailing climate. In addition, movement and spacing patterns of males were affected by the level of female activity, and movement of females was affected by food availability. Activity sites or home ranges generally encompassed one to several rock outcrops. Territorial behavior and territory size were positively correlated with the level of breeding activity. In optimal breeding years, "tyrant" adult males defended most of their home ranges. Territoriality was observed only infrequently in females and occurred during the peak of the breeding season when courtship was most intense. The territory size of adult female $\underline{S}$. obesus remained consistently small and never encompassed more than a portion of an outcrop.

The 4-year home ranges of the 36 most frequently observed male S. obesus are shown in Figure 10. Table XII shows the mean home range size of various groups according to sex, age, and social status during this study. Each major rock outcrop or rocky slope was patrolled by 
Figure 10. 4 year home ranges $(1977$ - 1980) of the 36 most frequently observed male $\underline{\mathrm{S}}$. obesus at the Red Cloud Road study site. solid lines = tyrants; dot-dash lines = subordinates greater than 4 years old; dash lines $=4$ year old subordinates; numbers $=$ lizard identification. 


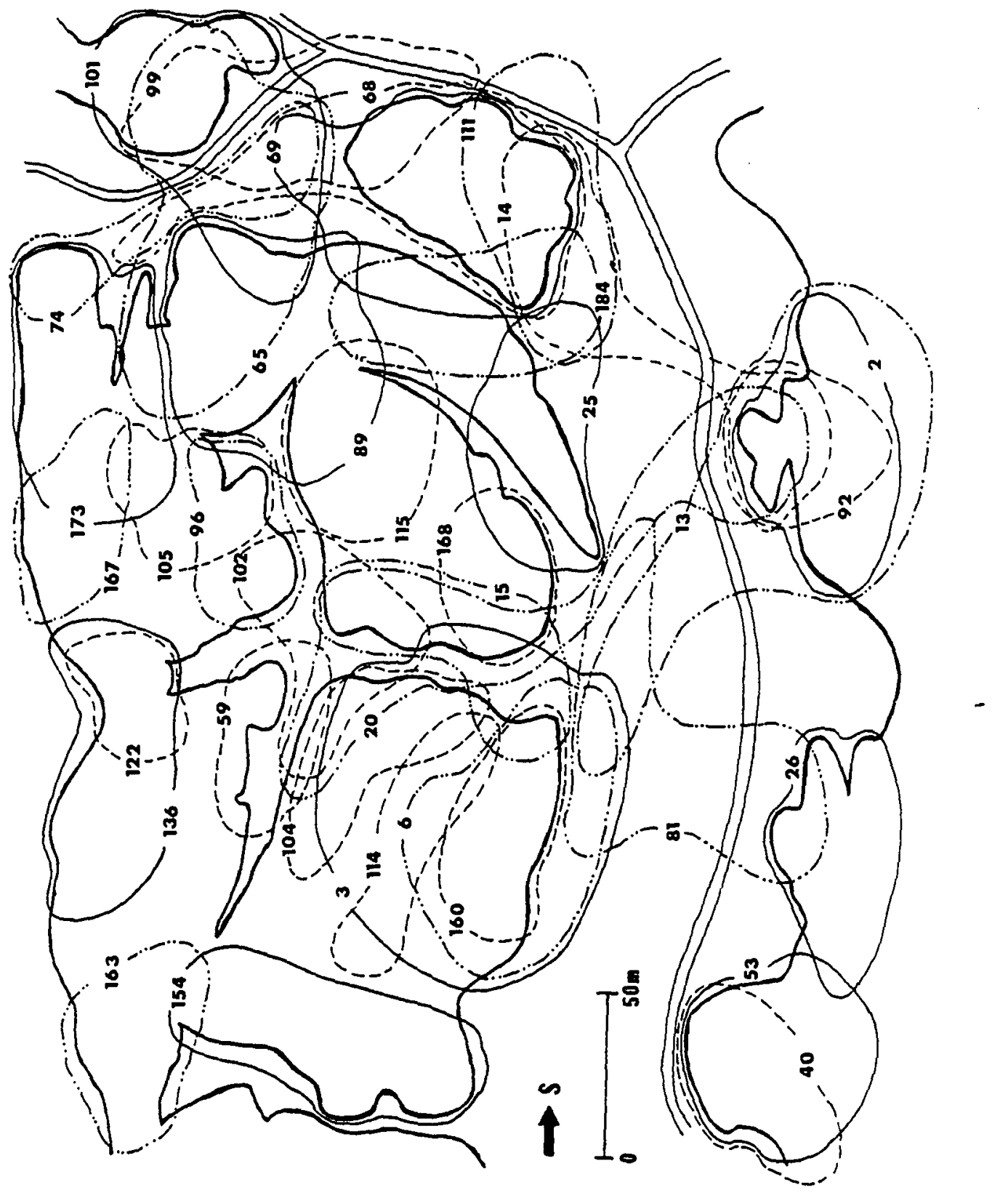


TABLE XII

HOME RANGE SIZE OF VARIOUS $\underline{s}$. obesus GROUPS AT THE RED CLOUD ROAD STUDY SITE

\begin{tabular}{lccc}
\hline Group & $\mathrm{N}$ & Mean $\left(\mathrm{m}^{2}\right) \pm 1$ S. E. & Range \\
\hline $\begin{array}{l}\text { Males } \\
\text { Tyrants }\end{array}$ & 12 & $3726 \pm 843$ & $2242-7707$ \\
$\quad$ Subordinate & & & \\
$\quad$ Narrow Ranging & 17 & $1849 \pm 103$ & $1011-2717$ \\
$\quad$ Wide Ranging & 9 & $4371 \pm 350$ & $3077-6234$ \\
$\quad$ Total & 26 & $2764 \pm 520$ & $1011-6234$ \\
Four Year 0lds & 14 & $2218 \pm 269$ & $1011-4718$ \\
Females & & & $594-2905$ \\
Over Four Years & 31 & $1751 \pm 213$ & $330-1669$ \\
Four Year 0lds & 14 & $1075 \pm 221$ & \\
\hline
\end{tabular}


an adult tyrant male. Males were designated tyrants according to the criteria of Berry (1974); i.e., Table XIII shows the body sizes of study site tyrant $\underline{S}$. obesus. Generally, tyrants were the largest ( $x$ SVL $=189 \pm 3.3 \mathrm{~mm}$ ) and most aggressive males and maintained a ma jority of the largest home ranges (up to $0.8 \mathrm{ha}$ ). Individual tyrants (e.g., numbers 25, 26, 89 and 136) maintained essentially the same home ranges from 1977 through 1982. Each tyrant tolerated considerable overlap with subordinate and immature males, while the home ranges of tyrant males showed limited overlap.

From 1977 through 1980, the home ranges of subordinate males (SVL usually less than $175 \mathrm{~mm}$ ) largely fell into 2 size categories, small and large (Table XII). Home range size of narrow-ranging lizards was usually less than 0.25 ha. Home range size of wide-ranging lizards always exceeded 0.3 ha. The mean home range size of the latter (about $0.44 \mathrm{ha}$ ) was the greatest for all categories. By 1980, wide-ranging lizards (number 13, 14, 20,65, 68, and 81) had attained tyrant size. The wide-ranging behavior probably was indicative of investigative maneuvers to locate suitable home range sites. Lizards 81 and 68 had apparently established home ranges since 1981 that greatly overlap those of tyrant lizards 3 and 69 who were suspected of dying. Perhaps males 81 and 68 were the new tyrants of their respective locations. The youngest males of $\underline{S}$. obesus examined for this period ( 4 years) possessed many of the smallest home ranges. Nonetheless, even individ-. uals of this age class demonstrated the home range size dichotomy discussed above.

Some tyrant male $\underline{S}$. obesus were observed to move as much as $150 \mathrm{~m}$ 
TABLE XIII

THE BODY SIZES (mm SVL) OF TYRANT S. obesus AT THE RED CLOUD ROAD STUDY SITE

\begin{tabular}{rc}
\hline Lizard & SVL (mm) \\
\hline 2 & 182 \\
3 & 193 \\
25 & 172 \\
26 & 184 \\
53 & 185 \\
57 & 188 \\
69 & 185 \\
89 & 191 \\
101 & 202 \\
136 & 196 \\
154 & 213 \\
\hline
\end{tabular}


per day during the breeding season. Subordinate and immature males generally moved considerably less distance per day. For tyrant males, home range size appeared positively correlated with the extent of activity of breeding females (Fig. 11). During the good breeding years (1978 and 1979), tyrant males were encountered over most of their home ranges, but in less than average breeding years (1977 and 1980) they often occupied significantly smaller areas (Table XIV). A similar correlation with females was not observed for subordinate males. Their home ranges remained relatively constant for all 4 years.

Between 2 and 17 adult females were found within the home ranges of tyrant adult male $\underline{S}$. obesus during the study (Table XV). The number of adult females observed per year in each tyrant's home range was positively correlated with the extent of breeding activity - e.g., in 1979 , the best reproductive year of the study, as many as 12 adult females were found per home range. The number of adult females observed within a tyrant's home range was not correlated with the tryant's home range size, activity, or body size. The maximum number of adult females per home range for 1979 occurred in one of the smaller areas maintained by a tyrant; this lizard, number 57 , had apparently disappeared before the breeding season. The nature and extent of vegetation and rocky terrain appear to be of utmost importance to adult female $\underline{S}$. obesus. The home range of tyrant number 57 included a wash, the margins of which often supported lush vegetation in the early spring. Adult females were frequently observed feeding along the wash. The wash offered easy access to vegetation as it passed very close to favorite basking sites and retreats. Similar topographical arrangements for other parts 
Figure 11. Home range sizes for adult male $S$. obesus at the Red Cloud Road study site in a good breeding year (1979) and below average breeding year (1980). 

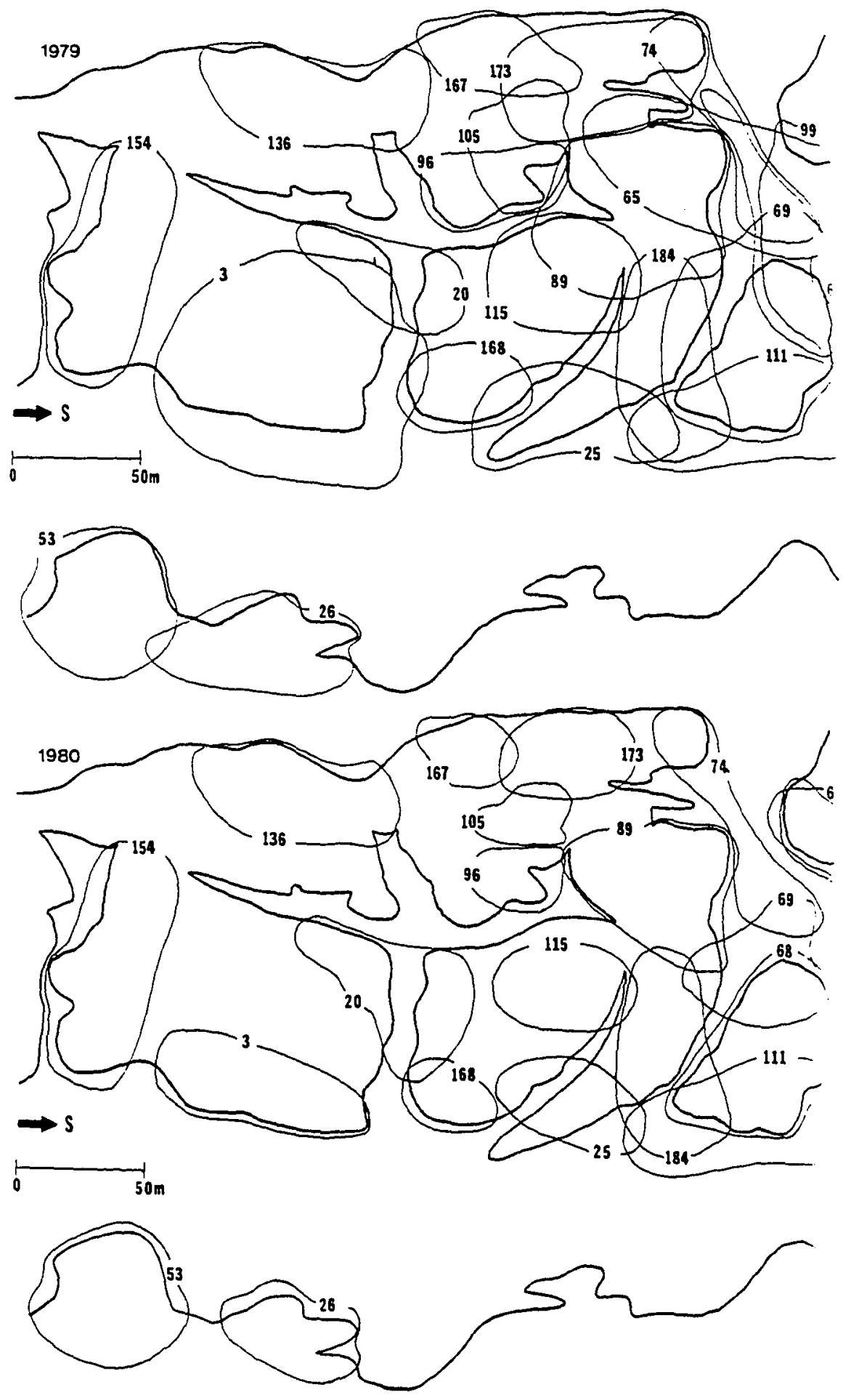
TABLE XIV

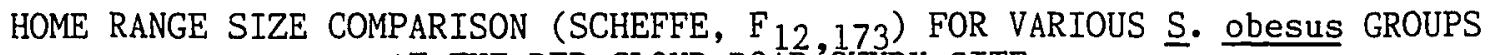
AT THE RED CLOUD ROAD'STUDY SITE

\begin{tabular}{|c|c|c|}
\hline Group & $\mathrm{F}$ & $\mathrm{P}$ \\
\hline \multicolumn{3}{|l|}{ Tyrants With: } \\
\hline \multicolumn{3}{|l|}{ Subordinates } \\
\hline Narrow Ranging Males (NR) & 4.26 & $<0.0005$ \\
\hline Wide Ranging Males (WR) & 0.98 & $>0.50$ \\
\hline Total & 1.86 & $<0.05$ \\
\hline Four Year 0ld Males & 2.59 & $<0.005$ \\
\hline Adult Females & 3.92 & $<0.0005$ \\
\hline Four Year 0ld Females & 4.55 & $<0.0005$ \\
\hline \multicolumn{3}{|l|}{1979 Tyrants With: } \\
\hline 1980 Tyrants & 2.23 & $<0.025$ \\
\hline \multicolumn{3}{|l|}{ NR Subordinates With: } \\
\hline WR Subordinates & 4.13 & $<0.0005$ \\
\hline \multicolumn{3}{|l|}{1979 Subordinates With: } \\
\hline 1980 Subordinates & 1.22 & $>0.50$ \\
\hline \multicolumn{3}{|l|}{ Adult Females With: } \\
\hline Four Year 01d Females & 1.41 & $>0.25$ \\
\hline Four Year 01d Males & 0.98 & $>0.50$ \\
\hline Subordinate Males (NR) & 0.22 & $>0.50$ \\
\hline Subordinate Males (WR) & 4.68 & $<0.0005$ \\
\hline Subordinate Males (Total) & 2.57 & $<0.005$ \\
\hline
\end{tabular}


TABLE XIV (Con' $t$ )

\begin{tabular}{llc}
\hline \multicolumn{1}{c}{ Group } & $F$ & $P$ \\
\hline 1979 Adult Females With: & & $>0.50$ \\
1980 Adult Females & 0.43 & \\
Four Year Females With: & & $<0.02$ \\
Four Year Males & 2.04 & $>0.25$ \\
Subordinate Males (NR) & 1.45 & $<0.0005$ \\
Subordinate Males (WR) & 5.21 & $<0.0005$ \\
Subordinate Males (Total) & 3.44 & $>0.50$ \\
Subordinate Males 0ver 4 & 1.11 & \\
Years With: & & \\
4 Year Males & & \\
\hline
\end{tabular}


TABLE XV

THE NUMBER OF ADULT FEMALES OBSERVED WITHIN THE HOME RANGES OF TYRANT ADULT MALE $\underline{S}$. obesus AT THE RED CLOUD ROAD STUDY SITE

\begin{tabular}{cccccc}
\hline \hline $\begin{array}{c}\text { Tyrant } \\
\text { Number }\end{array}$ & 1977 & 1978 & 1979 & 1980 & 4 Year Total \\
\hline 2 & 3 & 3 & 6 & 4 & 7 \\
3 & 3 & 4 & 11 & 3 & 17 \\
25 & 4 & 4 & 5 & 5 & 5 \\
26 & 3 & 2 & 2 & 2 & 4 \\
53 & 3 & 2 & 2 & 2 & 4 \\
57 & 7 & 7 & 12 & 10 & 12 \\
69 & 4 & 4 & 4 & 4 & 6 \\
89 & 4 & 4 & 5 & 5 & 6 \\
101 & 3 & 3 & 5 & 4 & 5 \\
136 & 2 & 2 & 8 & 7 & 8 \\
154 & 2 & 2 & 2 & 2 & 5 \\
173 & 3 & 3 & 5 & 5 & 5 \\
\hline & & & 5 & 5 & 5 \\
\hline
\end{tabular}


of the site typically attracted an increased number of females.

Figure 12 shows the 4-year home ranges of the 46 most frequently observed females on the study site. Immature females generally maintained the smallest home ranges (some about $0.03 \mathrm{ha}$ ). The youngest females for this period ( 4 years) occupied home ranges significantly smaller than any other groups (Table XIV). The home ranges of adult females were usually considerably smaller than those of tyrant males. In general, they greatly overlapped the size of those for narrow-ranging males, about 0.2 ha. The home ranges of adult females were easily definable, as their boundaries frequently coincided with the margins of rock outcrops. The home ranges of lizards $5,52,60,64,67,88$, 94, 107, 112, 116, 153, and 165 have been stable for 6 consecutive years. The home ranges of adult females demonstrated considerable overlap. At one locality central on the study site as many as 7 adult females possessed very similar home ranges. Except for the time during courtship when a male was present, adult females tolerated the presence of each other and often basked side by side and shared crevices. Both immature and adult females rarely demonstrated a tendency to migrate. In 1980, adult lizards 86 and 100 were encountered in new locations about $100 \mathrm{~m}$ from their favorite outcrops. Since this time, 86 has returned to its favorite outcrop. Until 1980, both these females occupied the home range of tyrant male 69. Apparently 69 died in 1980. Female 100 had enlarged ovarian follicles in June of 1980; 86 did not. Later, this female was observed in the home range of tyrant male 89 , and she shared a crevice with this male. When last sighted, in 1982, 100 was still in the home range of this male. Adult females 
Figure 12. 4 year home ranges $(1977$ - 1980) of the 46 most frequently observed female $\underline{S}$. obesus at the Red Cloud Road study site. solid lines = adults; dash lines = subadults (all 1 to 4 years old); numbers = lizard identification. 


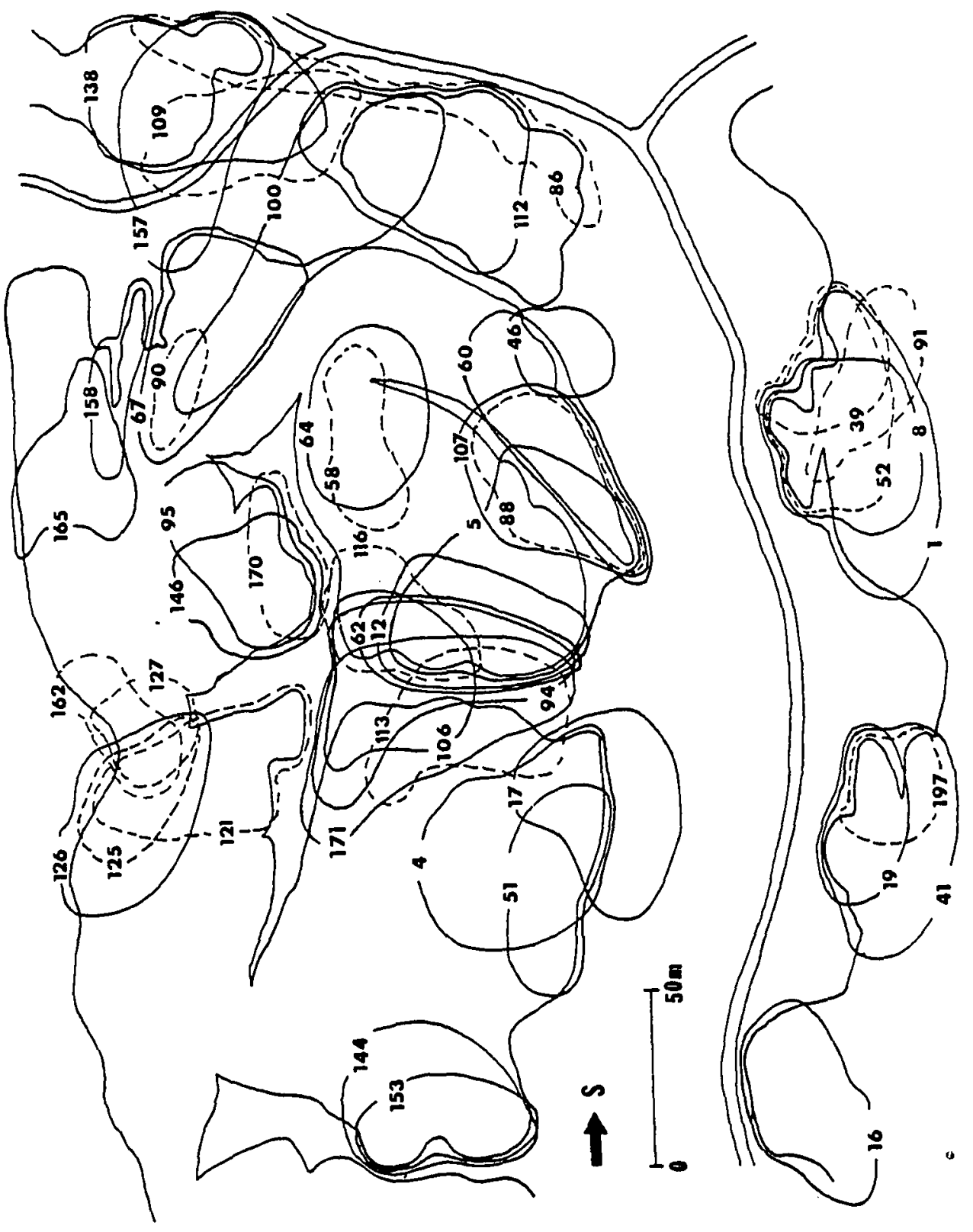


were very selective in choosing mates. Almost always, this meant choosing a tyrant male (Ch. 2 - Social Behavior). Perhaps, when a tyrant disappears, adult females in breeding condition will risk migration to another tyrant's home range just to ensure reproduction. Such a manuever is in accordance with the life history tactics of

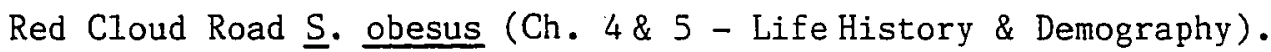
Female $\underline{S}$. obesus moved far less frequently than their male counterparts. Maximum daily movements for adult females occurred during the breeding season. They did not exceed $100 \mathrm{~m}$ per day; most were about $30 \mathrm{~m}$. Immature females, often moving only about $10 \mathrm{~m}$ a day, showed the most severely restricted movements.

Adult female movements appeared not to be correlated with breeding activity (Fig. 13 and Table XIV). Some adult females, such as number $17,64,67,100$, and 122 , occupied a larger portion of their home ranges when preparing to breed. Others, such as number 52, 60, 107, and 153, showed 1ittle variation in area occupied regardless of breeding condition. Perhaps the variation in area visited among breeding adult female $\underline{S}$. obesus reflected different individual nutritive needs and/or differences in microhabitat resource availability.

The home ranges of Red Cloud Road adult male and female $\underline{S}$. obesus were about $25 \%$ of the size of those reported by Berry (1974) for adult male and female conspecifics in the northern Mojave Desert. Home range size for adult males and females in my study was correlated with adult female activity and nutritive requirements, respectively. The fact that the home ranges were considerably larger for Mojave Desert adult

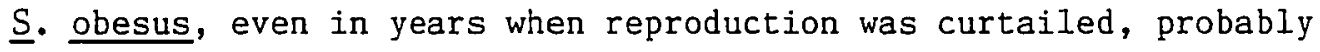


Figure 13. Home range sizes for adult female $\underline{S}$. obesus at the Red Cloud Road study site in a good breeding year (1979) and below average breeding year (1980). 

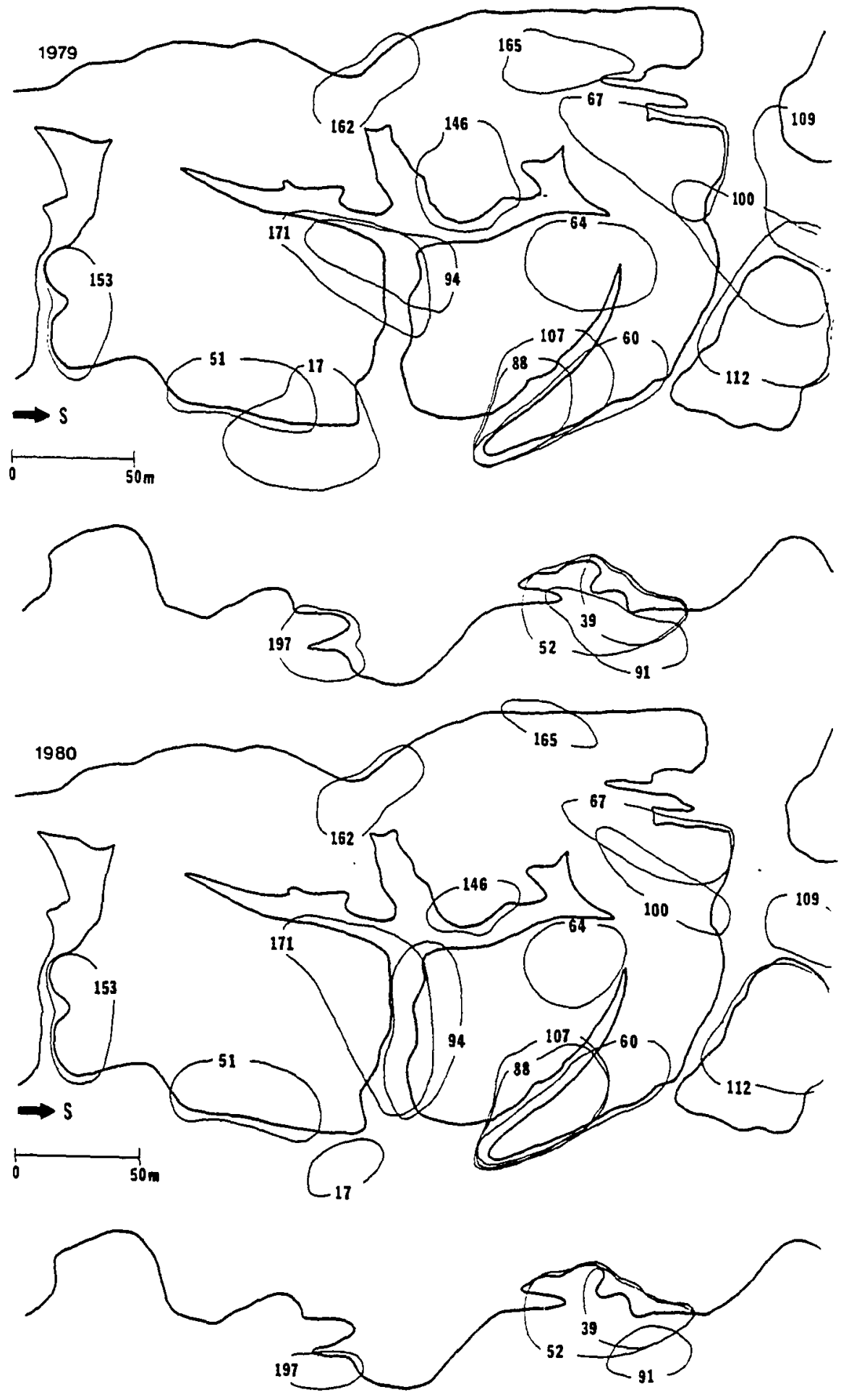
reflected greater difficulty in meeting nutritive needs. Given the harsher climate of the Mojave Desert, this is not surprising (Ch. 1 - Climate and Vegetation). Along with relatively small home range size, a number of other features seem to indicate heightened food availability for Colorado Desert $\underline{\mathrm{S}}$. obesus (Ch. 3 - Male and Female Reproductive Cycles; Ch. 3 - Reproductive Frequency and Ch. 5 - Sex Ratio and Density).

\section{SOCIAL BEHAVIOR}

Any study of the social organization of a lizard population requires the analysis of the mating system, mating strategy and territoriality. A mating system is defined as the manner in which the reproductive members of a population apportion their energy and/or activity for mate acquisition (Emlen and Oring, 1977). Mating systems show a great deal of interspecific and intrapopulational variability which can largely be attributed to life history characteristics such as diet, size, longevity and breeding schedules and to the ecological and social environment of the individual (Dugan and Wiewandt, 1982). According to Dugan and Wiewandt, the mating systems of iguanine lizard species can be broadly classified as "resource defense polygyny". Basically, males acquire multiple mates by defending resources such as food, shelter and nesting sites that are essential to females. Such male behavior exemplifies a mating strategy. Mating systems may consist of one or more mating strategies. While a number of mating strategies have been discerned for male iguanine lizards, little is know about associated female mating strategies (Dugan and Wiewandt, 1982). 
Several mating strategies have been observed for male $\underline{S}$. obesus: 1) dominance hierarchy (Berry, 1974); 2) tyrant-subordinate (Berry, 1974); 3) strict territoriality (Ryan, 1982); and 4) lack of organization (Nagy, 1973). Therefore, exercising particular mating strategies leads to the exhibition of territorial behavior (defense of a specified area from other males in the population by advertisement, threat or attack). Variability in male mating strategy observed between and within populations of $\underline{S}$. obesus can be attributed to asymmetrical costs of territoriality which, according to Ryan (1982), are body-size dependent for male $\underline{S}$ obesus. The degree of territoriality has a tremendous impact on the social organization of most $\underline{S}$. obesus populations, and for a given population is largely influenced by variation in male size, predation pressure, operational sex ratio and spatial distribution of females (Ryan, 1982). All these conditions, strongly affected by environmental factors (e.g., available food), show tremendous annual variation. The influence of these conditions on the social organization and ultimately the life history of $\underline{\underline{S}}$. obesus are considered below (Ch. 5 - Sex Ratio, Predation Intensity and Density). In the meantime, various patterns of social behavior for Red Cloud Road $\underline{S}$. obesus are examined. Specific questions asked were: 1) What are the stereotyped actions of territoriality and courtship? 2) To what extent is there annual variation in social organization? 3) How do immature individuals contribute to the social organization? and 4) What is the mating strategy of adult females?

The social behavior of Red Cloud Road $\underline{S}$. obesus consisted of a variety of sterotyped actions. Following Carpenter and Ferguson (1977), 
these actions were categorized as acts (basic movements produced by a particular set of muscular actions or motor sequences) and act systems (a series of acts performed in a particular sequence simultaneously or in a series). Acts and act systems integral to $\underline{S}$. obesus' territoriality and courtship were recorded for 1977 through 1980. For territoriality and courtship a total of 16 and 20 stereotyped actions, respectively, were recorded. For now, only those acts and act systems which most clearly assisted in determination of this species reproductive tactics are considered.

For $\underline{S}$. obesus at the Red Cloud Road study site, territoriality was defined as the defense of any area within the lizard's home range. From 1977 through 1980 incidences of territorial defense were common for adult males, but infrequent for adult females. Territorial behavior took the form of either low level aggression (assertion display) or high level aggression (threat, challenge and chase). Assertion displays were generally the most common stereotyped act (Table XVI). Assertion displays or pushups usually occurred on a rocky prominence when a lizard paused from movement through it's home range. They were not necessarily directed at a particular adversary and probably served as a general advertisement of the lizard's territorial perimeter. Only male $\underline{S}$. obesus were observed performing assertion displays. A11 males of SVL greater than $130 \mathrm{~mm}$, and who were at least in their second year (Ch. 4 - Size at Reproductive Maturity), performed assertion displays. However, they were much more frequent in adult males of SVL greater than $170 \mathrm{~mm}$ who were at least 4 years old. Adult males were 
TABLE XVI

STEREOTYPED BEHAVIORS ASSOCIATED WITH TERRITORIALITY AND COURTSHIP FOR 1979 OBSERVATIONS OF $\underline{\text { S }}$ obesus AT THE RED CLOUD ROAD STUDY SITE

\begin{tabular}{lr}
\hline \multicolumn{1}{c}{ Category } & Number of Episodes \\
\hline Territoriality & 510 \\
\hline $\begin{array}{l}\text { Low Level Aggression } \\
\text { (assertion display) }\end{array}$ & 12 (total) \\
$\begin{array}{l}\text { High Level Aggression } \\
\text { (threat, challenge or chase) }\end{array}$ & 9 (male-male) \\
& \\
Courtship & 75 \\
Courtship Behavior & 32 \\
Female Enticement of Males & 11 \\
Female Rejection of Males & 51 \\
Crevice Sharing & \\
\hline
\end{tabular}


observed performing assertion displays from mid-February through midOctober, but the frequency was greatest from March through May and, if summer precipitation enhanced food reserves, in August and September. The acts and act systems integral to threat, challenge and chase were numerous (Table XVII), and varied greatly from one confrontation to another. These forms of high level aggression were extremely rare, amounting to about $3 \%$ of the social behavior between conspecifics (Table XVI). Basically, only 2 categories of high level aggression occurred between individual $\underline{S}$. obesus. Most confrontations were between tyrant and subordinate adult males. Such confrontations were observed in May and June of good breeding years (i.e., 1978 and 1979). On only 2 occasions was actual physical contact (tail thrash and biting) observed. Usually, just the appearance of a tyrant male caused a subordinate to retreat. For example:

On 13 June 1979 , at $0835 \mathrm{H}$. subordinate male 167 (SVL = $171 \mathrm{~mm}$ ) was observed courting adult female 165. At 0847 H. tyrant $173(\mathrm{SVL}=212 \mathrm{~mm}$ ) came from the northeast to within a meter of the courting part. As 173 proceeded to display, 167 darted southeast 5 meters out of sight behind a small rock outcrop. For the remainder of the morning 173 attempted to court 165 while 167 apparently went into hiding.

The second type of high level aggression was between adult female S. obesus. Such confrontations were observed in late May and June in the presence of a courting adult male. Occurring in 1978 and 1979, only 3 confrontations of this type were observed. In all 3, the larger female chased the smaller one away. For example:

On 21 May 1978, at $0755 \mathrm{H}$. adult female 5 (SVL $=169 \mathrm{~mm}$ ) 
TABLE XVIT

THE ACTS AND ACT SYSTEMS INTEGRAL IN THREAT, CHALLENGE AND CHASE FOR $\underline{\text { s. obesus }}$ AT THE RED CLOUD ROAD STUDY SITE

\begin{tabular}{ll}
\hline Tail Thrash & A rapid side to side motion of the tail. \\
Retreat & An escape behavior excuted by crawling into crevices. \\
Lateral Compression & A pulling together of lateral portions of the trunk \\
to increase dorso-ventral diameter. & An increase in body size by filling lungs with air. \\
Inflate & $\begin{array}{l}\text { An action where by the mouth is opened to an ex- } \\
\text { aggerated degree. }\end{array}$ \\
Lape & $\begin{array}{l}\text { An orientation of the long axis of the body to an } \\
\text { adversary }\end{array}$ \\
Back Arch & $\begin{array}{l}\text { An elevation of the back dorsally which produces an } \\
\text { arching effect, higher in the center along the lon- } \\
\text { gitudinal axis. }\end{array}$ \\
Pushup & The act of raising and lowering the entire body by ex- \\
tension and flexion of the front limbs. & The active pursuit of an adversary \\
Chase & A ventral projection of the gular region of the throat \\
\hline
\end{tabular}


was observed basking on top of a favorite boulder alongside tyrant male 57. This pair had been courting routinely during the week. At 0805 female 12 (SVL $=155 \mathrm{~mm}$ ) emerged from a retreat site 10 meters to the east. After basking for about 30 minutes, 12 began to move west across several boulders. At $0840 \mathrm{H}$. 12 moved to a basking site 5 meters east of 5 and 57 . Suddenly, 5 faced 12, performed a series of pushups, then darted after 12. 12 responded by turning and running 10 meters back the way she had come. 12 disappeared behind a rock pile. 5, who never got closer to 12 than about 5 meters, returned to her basking site beside 57. Later that morning, 57 and 5 were involved in an elaborate courtship. 12 did not reappear again that day.

For the period 1977 - 1982 low level aggression was usually sufficient for maintenance of territories at the Red Cloud Road study site. Adult males and to a lesser extent adult females defended well defined territories during reproductive years and for males the resulting mating strategy was either strict territoriality or tyrant-subordinate behavior. High level aggression was rarely exhibited probably because relatively wide spread food abundance (Ch. 1 - Climate and Vegetation) and intrinsic population characteristics (Ch. 5 - Sex Ratio, Predation Intensity and Density) made such intense behavior impractical. The near lack of territoriality exhibited by Mojave Desert females (Berry, 1974) may be due to a low number of reproductive females (Ch. 5 - Sex Ratio and Density). In this study, since territoriality was exhibited only at the time of courtship it may imply strong mate choice by adult female $\underline{S}$. obesus. Such behavior in the female mating strategy is highly beneficial to this species' life history strategy (Ch. 4 - Reproductive Frequency and Survivorship and Ch. 5 - Longevity).

Adult male and female $\underline{S}$. obesus usually courted at frequently visited locations, specifically at favorite basking and retreat sites. 
For example, tyrant male 89 was observed courting adult female 67 in three consecutive years (1978 through 1980) at just 2 locations they commonly visited during 6 consecutive years. Courtship locations usually provided one to several crevices within a meter for escape. Therefore, though often easily detected, a courting pair was never far from a well known retreat.

Adult $\underline{\text { S. }}$ obesus courted from late March through most of June. Table XVIII shows seasonal courtship frequency for 1979. In early spring, the courtship frequency was sometimes decreased by prevailing weather, but, by late spring it was clear that the frequency had greatly increased. Courtship frequency peaked in early June.

The number of male $\underline{S}$. obesus observed participating in courtship in 1979 as a fraction of the total male population of that year is depicted in Figure 14. For 1977 through 1980, the smallest male observed courting was $142 \mathrm{~mm}$ SVL. Ninety percent of all courting activities were observed in 1978 and 1979. For these years, mean body sizes of courting adult males were not significantly different (Student-t test). The 2-year mean and standard error of 37 measurements was $173.5 \pm 2.4$ mm SVL. In general, few adult males less than $160 \mathrm{~mm}$ SVL were observed courting. The maximum percentage for this size category occurred in 1979 (27\%). For 1978 and 1979 at least half of the adult males in the 160 to $190 \mathrm{~mm}$ SVL range were observed courting. In both years, all adult males of SVL greater than $200 \mathrm{~mm}$ were observed courting.

Table XIX shows the relationship in 1979 between courtship frequency and body size for adult male $\underline{S}$. obesus. Episodes of courtship were observed less frequently in smaller males. The frequency showed 
TABLE XVIII

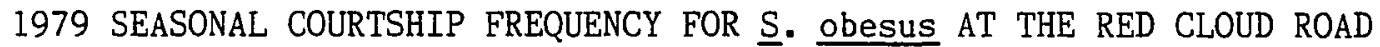
STUDY SITE

\begin{tabular}{|c|c|c|c|c|}
\hline \multicolumn{2}{|c|}{ Date } & \multirow{2}{*}{$\begin{array}{c}\begin{array}{c}\text { Hours of } \\
\text { Observation }\end{array} \\
8.00\end{array}$} & \multirow{2}{*}{$\begin{array}{c}\begin{array}{r}\text { Number of } \\
\text { Courtships }\end{array} \\
1\end{array}$} & \multirow{2}{*}{$\begin{array}{l}\text { Courtships } \\
\text { Per Hour } \\
0.14\end{array}$} \\
\hline Apr & 7 & & & \\
\hline & 13 & 4.00 & 4 & 1.00 \\
\hline & 18 & 4.83 & 1 & 0.21 \\
\hline & 27 & 4.73 & 3 & 0.63 \\
\hline \multirow[t]{7}{*}{ May } & 4 & 6.03 & 3 & 0.50 \\
\hline & 11 & 5.00 & 4 & 0.80 \\
\hline & 12 & 4.73 & 5 & 1.06 \\
\hline & 19 & 8.40 & 4 & 0.48 \\
\hline & 23 & 2.88 & 1 & 0.35 \\
\hline & 26 & 6.77 & 6 & 0.89 \\
\hline & 27 & 5.67 & 7 & 1.24 \\
\hline \multirow[t]{7}{*}{ Jun } & 2 & 4.80 & 6 & 1.25 \\
\hline & 3 & 3.00 & 3 & 1.00 \\
\hline & 9 & 5.83 & 4 & 0.69 \\
\hline & 10 & 5.47 & 7 & 1.28 \\
\hline & 13 & 4.00 & 6 & 1.50 \\
\hline & 18 & 7.33 & 6 & 0.82 \\
\hline & 24 & 3.20 & 4 & 1.25 \\
\hline
\end{tabular}


Figure 14. 1979 frequency distribution for male S. obesus at the Red Cloud Road study site. Shaded area indicates number of individuals in size category observed participating in courtship. 
Figure 15. 1979 frequency distribution for female $\underline{\mathrm{S}}$. obesus at the Red Cloud Road study site. Shaded area indicates number of individuals in size category observed participating in courtship. 

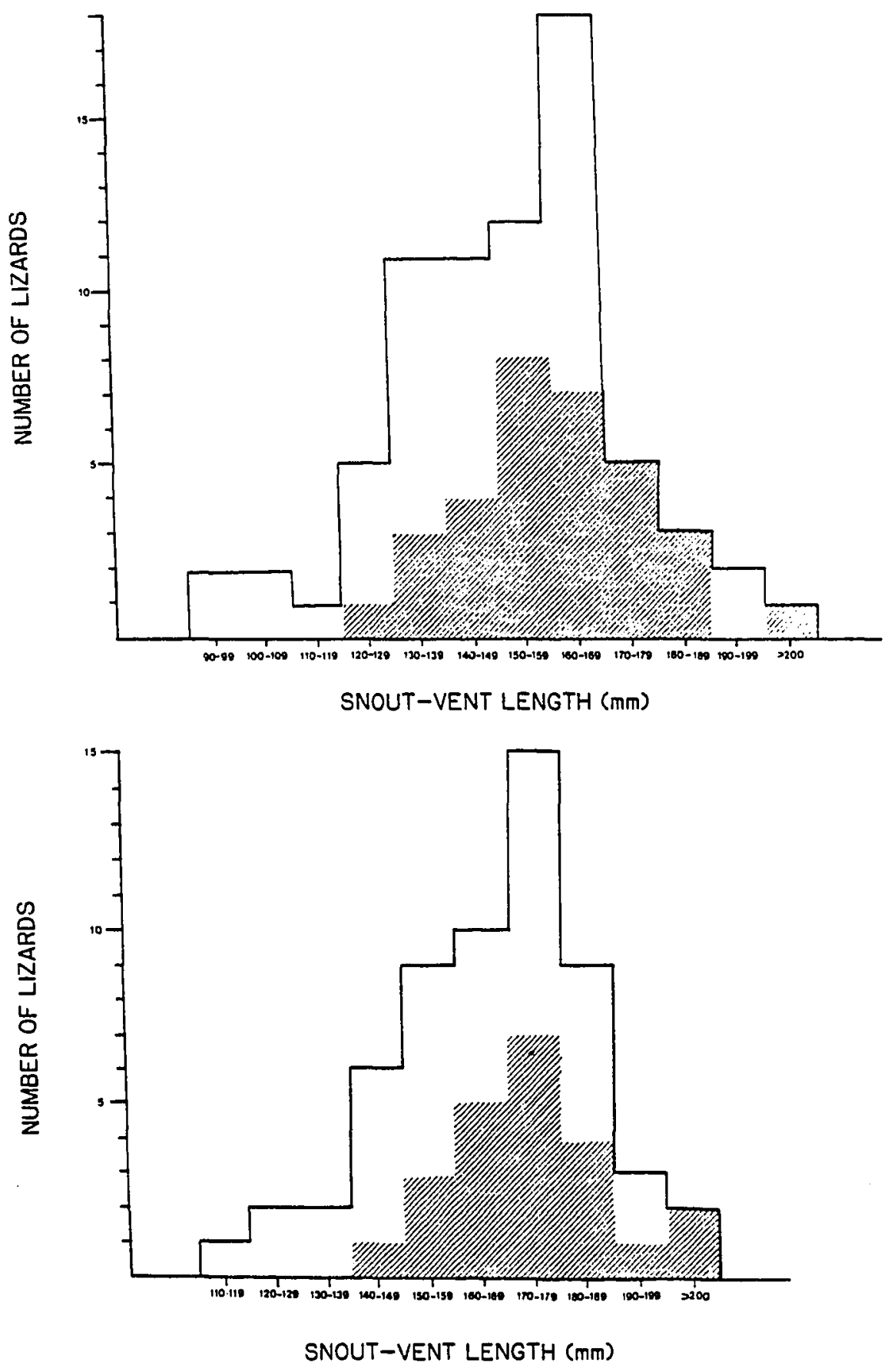

Figure 14 (below) and Figure 15 (above) 
TABLE XIX

1979 RELATTONSHIP BETWEEN COURTSHIP FREQUENCY AND BODY SIZE FOR MALE $\underline{\mathrm{S}}$ - obesus AT THE RED CLOUD ROAD STUDY SITE

\begin{tabular}{cccccc}
\hline $\begin{array}{c}\text { Body Size } \\
(\text { mmSVL })\end{array}$ & $\begin{array}{c}\text { Number of } \\
\text { Lizards }\end{array}$ & $\begin{array}{c}\text { Number of } \\
\text { Courtships }\end{array}$ & $\begin{array}{c}\text { Courtships } \\
\text { Per Lizard }\end{array}$ & $\begin{array}{c}\text { \# Crevice } \\
\text { Sharings }\end{array}$ & $\begin{array}{c}\text { Crevice Sharings } \\
\text { Per Lizard }\end{array}$ \\
\hline $140-149$ & 6 & 1 & 0.17 & 1 & 0.17 \\
$150-159$ & 9 & 6 & 0.67 & 4 & 0.33 \\
$160-169$ & 10 & 10 & 1.00 & 4 & 0.40 \\
$170-179$ & 15 & 22 & 1.47 & 11 & 0.73 \\
$180-189$ & 9 & 19 & 2.11 & 24 & 2.18 \\
$190-199$ & 3 & 9 & 3.00 & 2 & 0.67 \\
$\geq 200$ & 2 & 8 & 4.00 & 5 & 2.50 \\
\hline
\end{tabular}


marked increases in all body size categories greater than $170 \mathrm{~mm}$ SVL. These males were at least 4 years old (Ch. 4 - Age at Reproductive Maturity). Though large males were few, it appeared that they were the most active in courtship. For example, in 1979 male 101 (SVL = $191 \mathrm{~mm}$ ) courted 3 different females for a total of 9 episodes. Most tyrant male $\underline{S}$. obesus were at least about $180 \mathrm{~mm}$ SVL. Consequently, these findings further supported the trend of tyrant males dominating most social activities.

The 1979 number of female $\underline{S}$. obesus observed participating in courtship as a fraction of the total female population is depicted in Figure 15. For 1977 through 1980, two females as small as $121 \mathrm{~mm}$ SVL were courted. The 1978 and 1979 mean body sizes of courting adult females were not significantly different (Student-t test). The 2 year mean and standard error for 53 measurements was $158.4 \pm 2.4 \mathrm{~mm}$ SVL. For 1978 through 1980, courtship was common for adult females of SVL greater than $150 \mathrm{~mm}$. The maximum proportion of females with SVL less than $150 \mathrm{~mm}$ observed courting occurred in 1979 (30\%). For 1978 and 1979, at least half the adult females of SVL greater than $150 \mathrm{~mm}$ were observed courting. In all years, adult females of SVL exceeding 160 mm demonstrated the highest proportion of courting individuals.

Table XX shows the relationship in 1979 between courtship frequen-

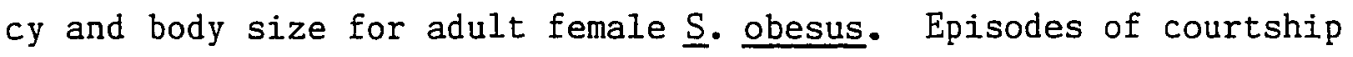
were least frequent in females of SVL less than $150 \mathrm{~mm}$. In 1980 , courtship was not observed for this size group. In 1979 marked increases in courtship frequency were observed for adult females of SVL 170 to $190 \mathrm{~mm}$. These individuals were at least 7 years old (Ch. 4 - Age at Maturity). 
TABLE XX

1979 RELATIONSHIP BETWEEN COURTSHIP FREQUENCY AND BODY SIZE FOR FEMALE S. obesus AT THE RED CLOUD ROAD STUDY SITE

\begin{tabular}{|c|c|c|c|c|c|}
\hline $\begin{array}{l}\text { Body Size } \\
\text { (mmSVL) }\end{array}$ & $\begin{array}{l}\text { Number of } \\
\text { Lizards }\end{array}$ & $\begin{array}{r}\text { Number of } \\
\text { Courtships }\end{array}$ & $\begin{array}{l}\text { Courtships } \\
\text { Per Lizard }\end{array}$ & $\begin{array}{l}\text { \# Crevice } \\
\text { Sharings }\end{array}$ & $\begin{array}{c}\text { Crevice Sharings } \\
\text { Per Lizard }\end{array}$ \\
\hline $120-129$ & 7 & 1 & 0.14 & 0 & - \\
\hline $130-139$ & 14 & 7 & 0.50 & 3 & 0.21 \\
\hline $140-149$ & 9 & 12 & 1.33 & 5 & 0.56 \\
\hline $150-159$ & 13 & 12 & 0.92 & 11 & 0.85 \\
\hline $160-169$ & 13 & 19 & 1.46 & 13 & 1.00 \\
\hline $170-179$ & 8 & 16 & 2.00 & 15 & 1.88 \\
\hline $180-189$ & 3 & 6 & 2.00 & 4 & 1.33 \\
\hline $190-199$ & 2 & 0 & - & 0 & - \\
\hline$\geq 200$ & 1 & 1 & 1.00 & 0 & - \\
\hline
\end{tabular}


Though large individuals represented a small segment of the female population, they were suspected of usually being the most frequently courted. For example, in 1979, during a 3-week period from late May to midJune, female 157 (SVL = $180 \mathrm{~mm}$ ) was seen being courted on 6 different days. The relationship between courtship frequency and body size was greatly affected by availability of food. In general, while the smaller adult females were courted only in years when food supply was abundant (1978 and 1979), the larger sized individuals were courted in all years save the drought of 1981. To further substantiate this tendency, in 1979, when food resources were maximal for the 7 year study (Ch. 1 - Climate and Vegetation) the smallest adult female $\underline{S}$. obesus were still the last to be courted. For example, the SVL mean and standard error for late May and late June courted females was $162.5 \pm 5.0 \mathrm{~mm}(\mathrm{~N}=11)$ and 140.8 $\pm 4.7 \mathrm{~mm}(\mathrm{~N}=6)$. The difference in the 2 means was highly significant. Though the smaller adult females were sometimes chased by the larger ones (Ch. 2 - Territoriality), it appeared that they preferred not to be courted until certain criteria (associated with growth) were established. For the entire Colorado Desert study area, even in years of abundant food (1978 and 1979) a few of the largest adult female $\underline{\text { S. obe- }}$ sus postponed any kind of reproductive activity. Some of these adult females reproduced the previous year. Apparently, there were contrasting differences in physiological demands among $\underline{S}$. obesus females of different body sizes and those of similar body size who might have differed in choice of when to reproduce. Nonetheless, regarding the latter, other adult female $\underline{\mathrm{S}}$. obesus were courted for 3 consecutive years (1978 through 1980). The choice whether or not to be involved in courtship 
was probably influenced by the level of food abundance at the microhabitat level. Spatial difference in food availability was probably a significant factor in all years ( $\mathrm{Ch} .1$ - Climate and Vegetation).

Courtship for $\underline{\mathrm{S}}$. obesus usually spanned several consecutive days. During this time a courting pair spent periods of inactivity occupying the same crevice. Tables XIX and XX show the 1979 relationship between

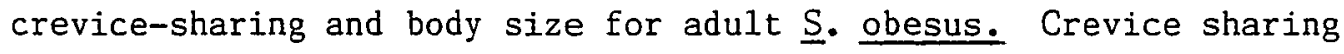
and courtship frequency were positively correlated. However, for 1978 and 1979 episodes of pairs courting and sharing crevices were only 53\% and $42 \%$, respectively. There were several reasons contributing to the limited overlap between the 2 behaviors. First, observations were conducted for only about a third of the total number of days of the courtship season. Second, only about $20 \%$ of the study site could be viewed from any of the 4 observation posts (Fig. 5). Third, many episodes of crevice-sharing were noted at times when the lizards were not being watched with a spotting scope, such as during population censusing efforts. Consequently, a great deal of activity associated with breeding condition (Ch. 3 - Female Reproductive Cycle and Ch. 3 - Reproductive Frequency), no doubt nearly all were involved in courtship. In addition, some crevice sharing appeared to promote pair bond solidification not directly involved with the immediate reproductive concerns. During the breeding season, crevice-sharing frequency included subordinate male-adult female and subordinate male-juvenile female pairings. In addition, during August and September of 1979 a number of crevice-sharing episodes $(N=23)$ were observed between adults of both sexes. Such interactions were probably important in establishing future ties for 
successful reproduction.

A number of episodes of courtship involving young $\underline{S}$. obesus ( 2 to 3 years) appeared not to be concerned with immediate reproductive success. First, a few frequently sighted subordinate males relentlessly attempted to court disinterested adult females. The adult females usually avoided contact with this category of males. For example, in 1979 subordinate male $115($ SVL $=151 \mathrm{~mm})$, a 3 year old, attempted to court adult female $64($ SVL $=172 \mathrm{~mm})$ on 4 different occasions over a 3 week period (mid-May to early June). In every episode, 64 avoided 115. However, during this time she accepted the presence of tyrant 89 $($ SVL $=185 \mathrm{~mm})$. Second, many of the small females ( 2 to 3 years) that were courted did not attain breeding condition. For example, in 1978 second year females 30 and 109 (both of $\mathrm{SVL}=121 \mathrm{~mm}$ ) were actively courted by tyrant males 89 and 69, respectively. Neither female produced enlarged ovarian follicles that year. These routines of establishing pair bonds at young ages were probably of great benefit to

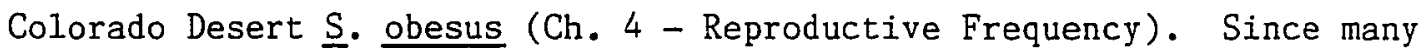
of the young females (including 109) attained breeding condition in 1979, it seemed future reproductive success was enhanced by such interactions.

Courtship activity for $\underline{\mathrm{S}}$. obesus was usually prolonged and entailed a number of complex behaviors (acts and act systems). Nonetheless, as the activity season progressed, several distinct patterns emerged. In nearly all episodes observed from 1978 through $1980(\mathrm{~N}=$ 125) an adult male initiated courtship. In general, the male would advance in the direction of a female, pause within about $25 \mathrm{~cm}$ and 
while facing her, perform a courtship display consisting of one to several pushups. With dorsum arched and gular region lowered, this behavior was more intense than a typical assertion display. During the course of the spring (March through June) the mating strategy of adult female $\underline{\underline{S}}$. obesus in response to an advancing male's courtship display involved 4 distinct behaviors: avoidance, enticement, submission, and rejection. Figures 16 and 17 demonstrate a general scheme of the acts and act ystems associated with female courtship response.

Avoidance occurred from late March through May, but was most common prior to mid-May. Whenever an adult male advanced the female simply moved away. She might have remained basking but always made sure she kept her distance. In most episodes physical contact did not occur. Ultimately, if an ardent male persisted, the female temporarily took refuge in a crevice. Avoidance behavior seemed to serve 2 primary functions. First, throughout the activity season, subordinate male $\underline{S}$. obesus were most frequently avoided. For example:

On 11 May 1979 at $0902 \mathrm{H}$., subordinate male 115 and adult female 64 were sighted $25 \mathrm{~cm}$ apart basking on a small bedrock exposure. At $0906 \mathrm{H}$. lizard 115 began to display. He continued to perform a series of courtship displays ( 2 to 4 per minute) about every 5 minutes. At 0921, 0931, 0938, and $0953 \mathrm{H}$., following the advance of 115 to within $5 \mathrm{~cm}, 64$ tork refuge in a crevice. Each time, she emerged within several minutes and continued basking. After the 0938 display, 115 followed 64 to the crevice opening. As he displayed at the opening, he received 3 tail slaps to the head from 64. However, as long as this male did not engage in courtship behavior his presence was tolerated. In fact, while passive from 0932 to $0938 \mathrm{H}$., sixty four let 115 rest on top of her. A similar sequence of events between these 2 lizards continued until at least $1115 \mathrm{H}$. At this time, 64 moved into a crevice for the rest of the morning.

Thus adult females, by exhibiting this form of behavior, demonstrated a 
Figure 16. Adult female $\mathrm{S}$. obesus response to courting males at the Red Cloud Road study site. $\overline{1}$ and 2 indicate prenuptial behavior. 2 and 3 indicate postnuptial behavior. 


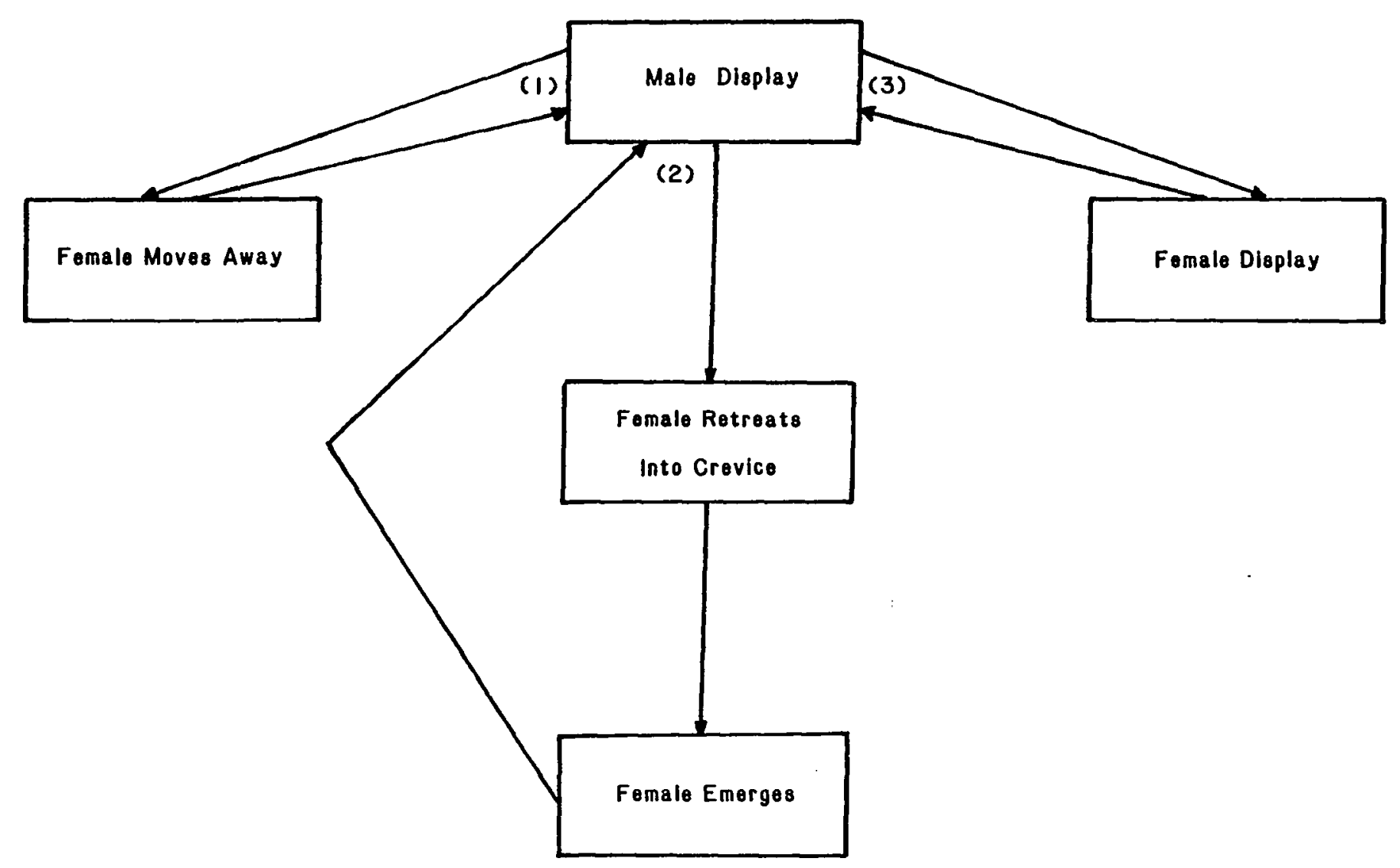


Figure 17. Nuptial behavior of adult female $\underline{S}$. obseus at the Red Cloud Road study site. 1,2 and 3 indicate enticement responses to male display; 4 and 5 indicate responses to male snout rub. 


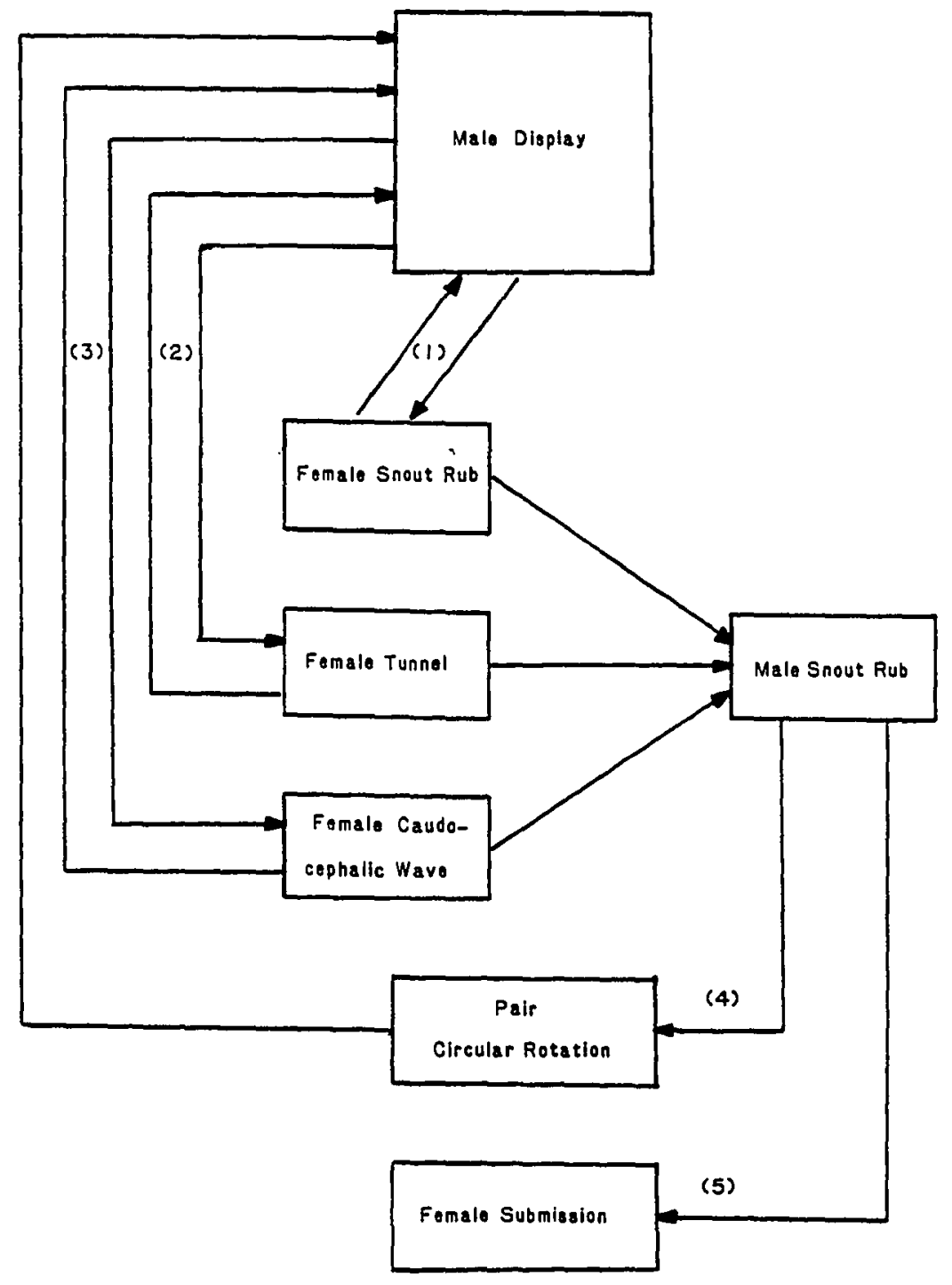


preference for those males most likely to ensure reproductive success i.e., tyrants. Second, in late April and early May even tyrants were avoided. For example:

On 11 May 1979 tyrant male 26 and adult female 41 both emerged at $0801 \mathrm{H}$. At $0815 \mathrm{H}$. twenty six began to display. 6 times during the next 70 minutes 26 advanced toward 41. During the first 5 advances 41 simply moved enough to avoid contact with 26 . At $1017 \mathrm{H}$., when 26 made the sixth advance toward 41, she countered by moving into a nearby crevice. 26 proceeded to move a meter north where he paused to execute pushups. At $1018 \mathrm{H}$., with her suiter temporarily a safe distance away, 41 emerged and returned to her original basking site.

Avoidance of tyrants in April and May probably represented an attempt by female $\underline{S}$. obesus to signal potential mates that they were not physiologically ready to reproduce. For several specific courting pairs (consisting of tyrant male-adult female interaction), avoidance was abandoned in favor of more receptive behaviors once adult females approached breeding condition (Ch. 3 - Female Reproductive Cycle).

Enticement was common from mid-May through mid-June. Enticement incorporated a suite of acts and act systems that were no doubt integral to this species courtship ritual. Usually, female $\underline{S}$. obesus responded to male courtship displays by accepting or even frequently initiating physical contact. For example, on June 2, 1979 tyrant 89 spent about an hour courting adult female 100 (1321 to $1412 \mathrm{H.}$ ). During this time, he performed 25 courtship displays. As depicted in Figure 18, one hundred responded to several of them by repeatedly eliciting 3 forms of physical contact: 1) snout rub - stroking the male's groin, axillary, pectoral, etc. areas with her snout; 2) tunneling - transverse movements beneath the male's pectoral region; and 3) caudocephalic 
Figure 18. 3 forms of enticement behavior elicited by adult female

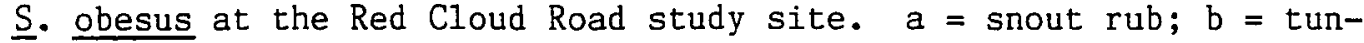
nel; $c=$ caudocephalic wave. 


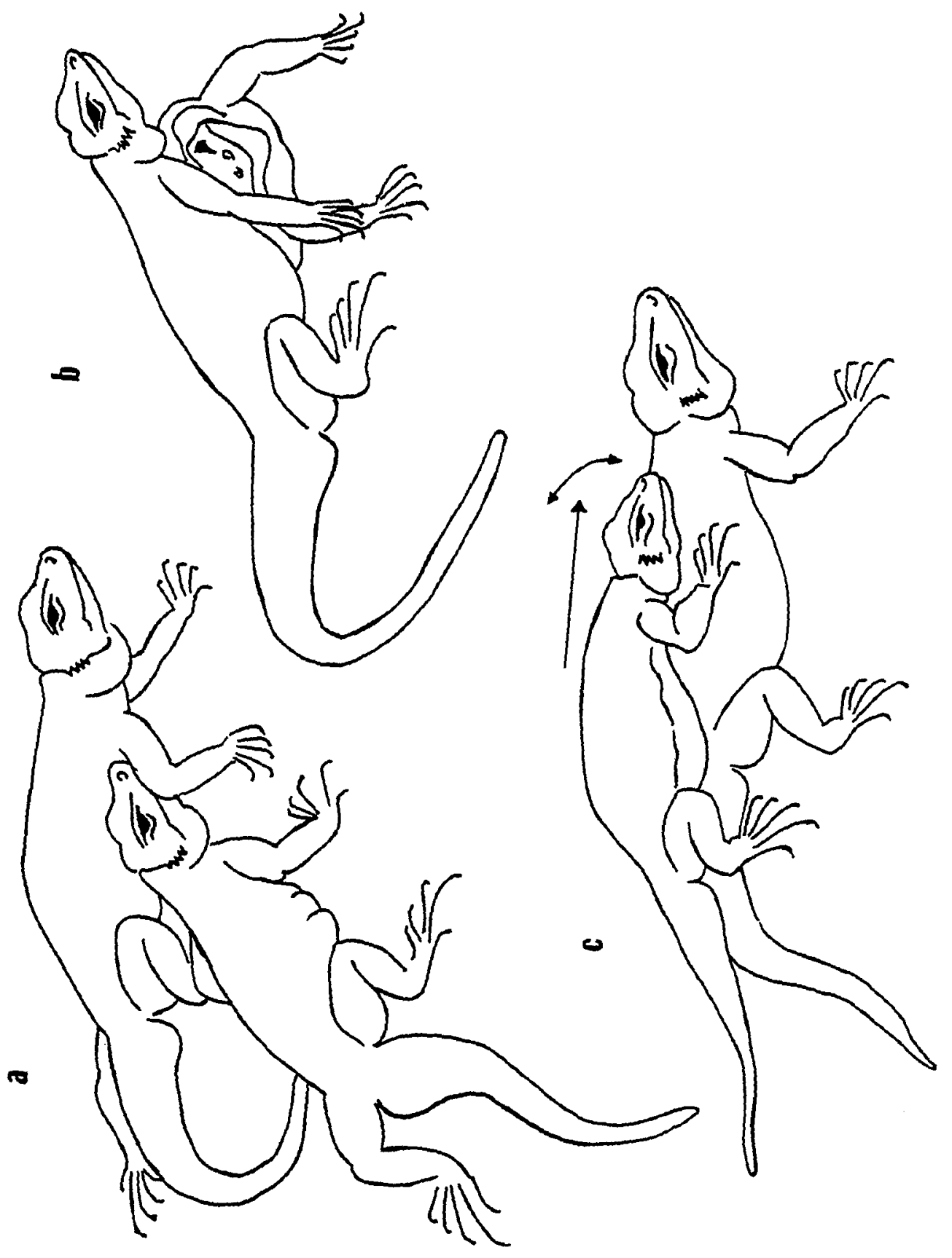


wave - upon straddling the male, an anteriorly directed snout-rub from lower back to head. Along with other act systems, such enticement behaviors seemed to increase the frequency of male courtship display. In addition, they often elicited male acts associated with mating, such as a lunge and neck bite. Therefore, female enticement behavior probab1y served as a signal that a female was entering breeding condition. During observation sessions, females were not receptive to male mating attempts. Consequently, from field data little can be said about submission. Females were most distinctly tolerant of male courtship behaviors from about mid-May through mid-June. It was during this time that males frequently attempted to initiate mating. In captivity, submission and mating sometimes quickly followed enticement (Abts, unpublished data). In the field, no doubt submission, which led to mating, occurred within the time span indicated above.

Rejection of courting males by females was observed frequently during most of June. Adult females responded to male courtship display by performing a counter display of their own. Such displays were often followed by typical avoidance behavior such as tail slap and retreat. For example:

On 18 June 1979, at $1037 \mathrm{H}$. male 65 and female 109 were observed basking side by side on top of a large rock prominence. At 1038 H., 65 performed a courtship display. Immediately, 109 responded with a display sequence, then she moved $0.2 \mathrm{~m}$ west into a crevice. 65 moved south $1.5 \mathrm{~m}$ to another prominence. $1039 \mathrm{H}$., one hundred and nine emerged and returned to the original site. At this time 65 moved to within $10 \mathrm{~cm}$ of 109. $1040 \mathrm{H}$. another exchange of displays occurred and 109 again took refuge in a crevice. She remained in the crevice until $1042 \mathrm{H}$. (when observation shifted elsewhere). 
Mid-June palpation of female 109 revealed she possessed enlarged ovarian follicles. Several other adult females possessing enlarged ovarian follicles or oviductal eggs demonstrated similar male rejection behavior. Adult females that were not in breeding condition never demonstrated this kind of behavior. Consequently, it appeared that this form of behavior was exhibited by already serviced adult female $\underline{S}$. obesus to discourage further male mating attempts.

The social organization of several Mojave Desert populations of S. obesus has been previously reported (Johnson, 1965; Nagy, 1973; Berry, 1974). However, for these studies, the abandonment of mating strategies in nonreproductive years should not be considered a lack of social organization (Ryan, 1982). Berry (1974) offered limited information on the role of immature individuals in the social organization and the mating strategy of adult females. This was due to the existence of relatively poorer reproductive conditions in the Mojave Desert (Ch. 4 - Reproductive Frequency). Therefore, this is the first study to present information on these 2 phenomena for $\underline{S}$. obesus. Both the behavior of immature individuals and the adult female mating strategy have tremendous significance in the life history strategy of Colorado Desert $\underline{S}$. obesus. For example, involvement of immature individuals establishes pair bonds that appear integral to this populations relatively high rate of reproduction (Ch. 4 - Annual' Reproductive Rate and Fecundity) and female mating strategy requires appropriate stereotyped behaviors for securing a suitable mate at the appropriate breeding time (Ch. 3 - Breeding Synchrony). 
CHAPTER III

\section{REPRODUCTION}

Reproductive cycles have been described for numerous lizard species (see Mayhew, 1968; Fitch, 1970; Porter, 1972; Fox, 1977). Nonetheless, few of these studies were undertaken with a concern for how the reproductive cycle related to such phenomena as physiological ecology, demography and life history. In addition, previous studies of lizard reproduction were largely for insectivorous species. To date, the reproductive cycles are known for only a few species of herbivorous iguanine lizards (see Wiewand, 1982). Data on the reproductive cycle of $\underline{S}$. obesus have been limited to a general account of gross gonadal morphology (Johnson, 1965 and Berry, 1974) and male testicular histology (Johnson, 1965). The present is the first thorough study of the reproductive cycle of $\underline{\text { S. }}$ obesus. Among studies of lizard reproductive cycles this one is unusual because: 1) the gonads and reproductive tracts (of both sexes) were studied simultaneously; 2) the data were compared with breeding activities of a marked population; and 3 ) the reproductive cycle was determined simultaneously with the status of corpora adiposa. Such an approach for study of a reproductive cycle was highly instructive in that it provided data which assisted in elucidation of the impact of proximate factors, especially climate, on the demographic and life history attributes of Colorado Desert $\underline{\text { S. obesus. }}$ 
FEMALE REPRODUCTIVE CYCLE

Previous reports on the reproductive cycle of female $\underline{S}$. obesus were limited to examination of the presence of enlarged ovarian follicles (Johnson, 1965; Berry, 1974). In contrast, I measured gross morphological and histological changes in both the ovary and reproductive tract and fluctuation of fat body (corpora adiposa) mass. Specific questions included: 1) What are the major events of the ovarian cycle and when do they occur? 2) How do changes in the reproductive tract correspond to the events of the ovarian cycle? 3) With regard to corpora adiposa, what kind of cycling pattern persists for this form of lipid reserve?

The ovary of $\underline{S}$. obesus consisted of a stroma containing germ tissue elements. The stroma consisted of loose areolar connective tissue (fibroblasts and collagen) and a vascular bed. It was surrounded by a single cell layer of simple cuboidal mesothelium. Germ tissue elements included oogonia and follicles (Figure 19a). The oogonia were found surrounding follicles and were especially numerous in early spring. An homogeneous layered zona pellucida separated follicles from several layers of granulosa cells. In the early stages of development all follicles contained follicular fluid. Maturation of follicles was accompanied by an increasing number of yolk droplets in the fluid. Most of the follicular fluid in advanced follicles was replaced by a dense aggregation of yolk droplets.

Seasonal changes in the number of ovarian follicles for adult female $\underline{\mathrm{S}}$. obesus are shown in Table XXI. Though not shown, 1980 seasonal 
Figure 19a. Ovary of female $\underline{S}$. obesus (430X). The following features are shown: oogonia (a), granulosa cells (b), zona pellucida (c) and previtellogenic follicle (d). 


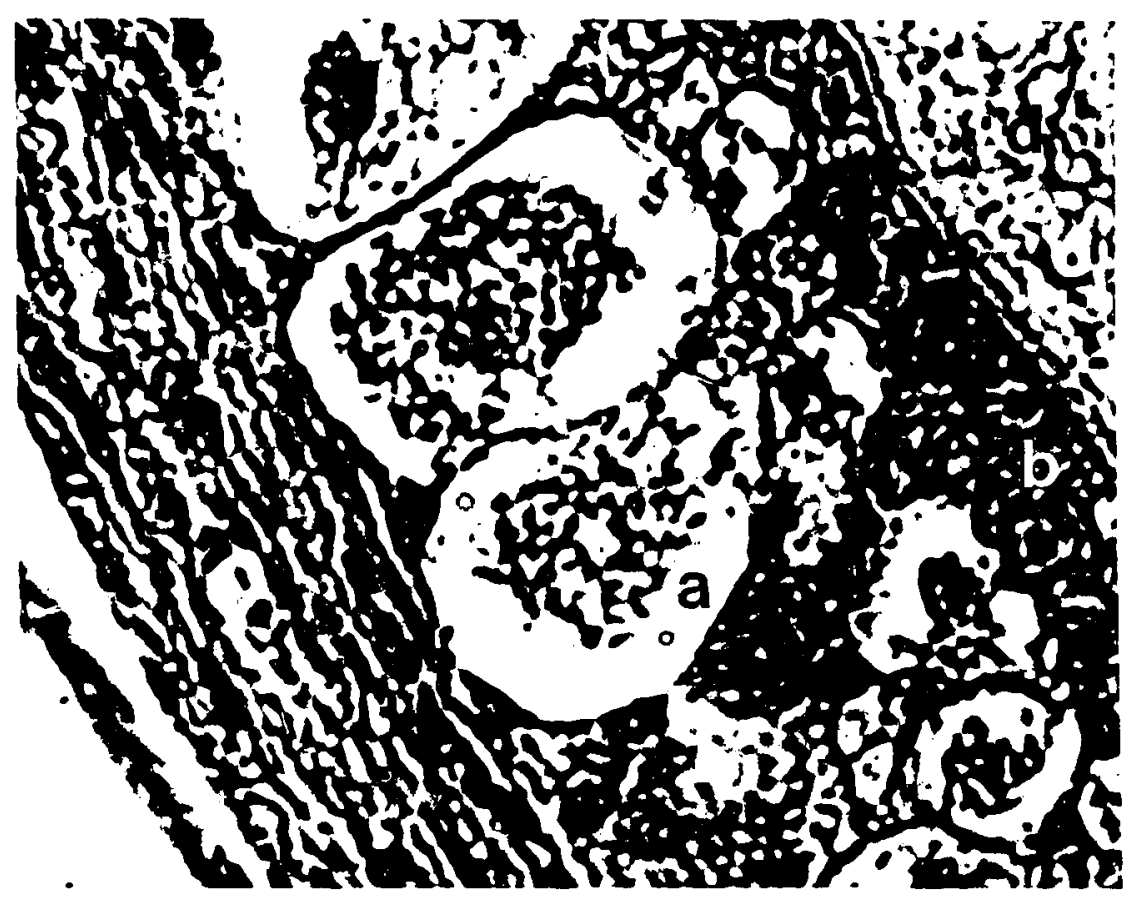


TABLE XXI

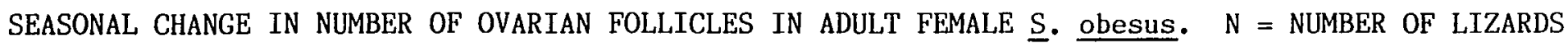
$\mathrm{n}=$ NUMBER OF FOLLICLES

\begin{tabular}{|c|c|c|c|c|c|c|c|c|c|}
\hline \multirow[b]{2}{*}{ Month } & \multicolumn{4}{|c|}{1978} & \multicolumn{5}{|c|}{1979} \\
\hline & $\mathbf{N}$ & $\mathrm{n}$ & $\bar{x}( \pm 2$ s. e. $)$ & Range & $\mathrm{N}$ & $\mathbf{n}$ & $\bar{x}( \pm 2 s$ & - e.) & Range \\
\hline Mid-March & 11 & 447 & $34.4 \pm 5.6$ & $20-49$ & 7 & 272 & $38.4 \pm$ & 6.5 & $32-57$ \\
\hline Late March & 12 & 399 & $33.3 \pm 3.9$ & $23-43$ & 7 & 232 & $33.1 \pm$ & 5.9 & $27-47$ \\
\hline Mid-April & 11 & 469 & $35.0 \pm 6.6$ & $20-56$ & 4 & 158 & $39.5 \pm$ & 6.0 & $33-47$ \\
\hline Late April & 12 & 494 & $41.2 \pm 5.4$ & $27-57$ & 4 & 163 & $40.8 \pm$ & 3.9 & $29-59$ \\
\hline Mid-May & 13 & 481 & $37.0 \pm 6.3$ & $18-59$ & 5 & 223 & $44.6 \pm$ & 10.3 & $27-58$ \\
\hline Late May & 13 & 410 & $31.5 \pm 5.2$ & $22-57$ & 5 & 202 & $40.4 \pm$ & 10.7 & $27-55$ \\
\hline Mid-June & 11 & 376 & $34.2 \pm 6.2$ & $22-53$ & 5 & 172 & $34.4 \pm$ & 5.4 & $29-44$ \\
\hline Late June & 9 & 267 & $29.7 \pm 3.5$ & $22-38$ & 8 & 252 & $31.5 \pm$ & 3.8 & $23-37$ \\
\hline Mid-July & 12 & 414 & $34.5 \pm 4.7$ & $19-45$ & 7 & 209 & $29.9 \pm$ & 6.2 & $15-35$ \\
\hline Late July & 12 & 388 & $32.3 \pm 4.3$ & $16-41$ & 4 & 118 & $29.5 \pm$ & 5.5 & $12-36$ \\
\hline Mid-August & 10 & 321 & $32.1 \pm 7.3$ & $18-53$ & 4 & 122 & $30.5 \pm$ & 9.3 & $17-38$ \\
\hline Late August & 8 & 261 & $32.6 \pm 3.6$ & $21-44$ & 4 & 124 & $31.0 \pm$ & 8.7 & $18-36$ \\
\hline
\end{tabular}


changes in number of ovarian follicles did not deviate greatly from those shown for 1978 and 1979. The mean number of follicles increased until mid to late spring from the onset of activity. By late spring there was a decline of about $15 \%$ in the mean number. The decline leveled off by mid-summer to a mean insignificantly less than that at the onset of activity.

During the lizards'activity season, previtellogenic, vitellognic, atretic and preovulatory ovarian follicles were recognized. Previtellogenic ovarian follicles were present throughout the activity season and probably existed the year round. At all times they were the most abundant type of follicle (Fig. 20a \& b). Lacking yolk (Fig. 19a), they appeared semitransparent. To the unaided eye they were the smallest form of germ tissue present. Most ovarian follicles less than $5 \mathrm{~mm}$ in diameter were previtellogenic. Seasonal changes in their number for adult female $\underline{S}$. obesus are shown in Table XXII. Mean number of previtellogenic ovarian follicles was maximal at the time of onset of the activity season. The minimum number occurred in late spring. The means at these 2 time periods were significantly different. A gradual increase in mean number of previtellogenic follicles occurred through the summer. By late August, the mean number was significantly greater than the spring minimum.

Vitellogenic ovarian follicles were present throughout the activity season (Fig. 20a \& b, Table XXIII). However, they were lacking in some individuals during most capture periods. These follicles contained yolk droplets (Fig. 19b). In early vitellogenic follicles the yolk was centrally located. As follicles developed, the yolk became uniformly 
Figure 19b. Vitellogenic follicle of female $\underline{S}$. obesus (430X). The following features are shown: yolk droplets (a), follicle (b), and zona pellucida (c). 


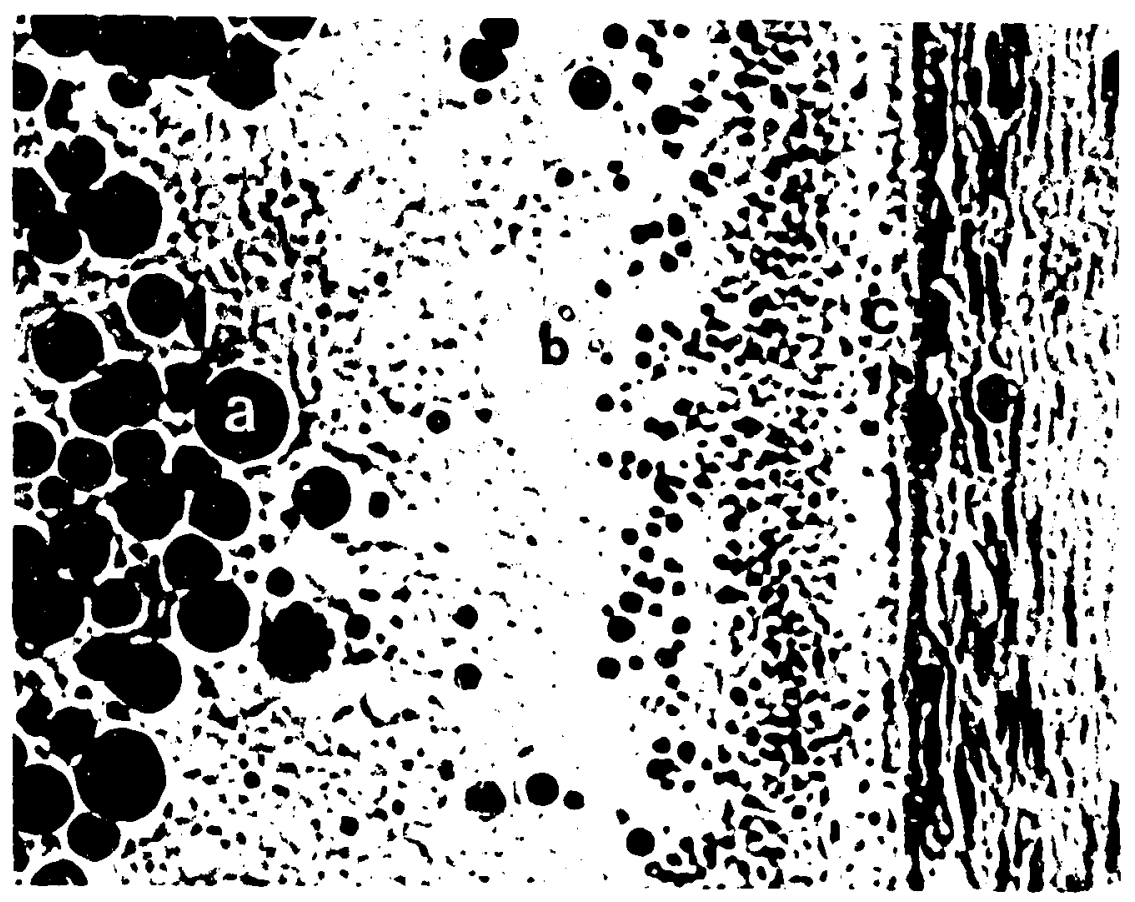


TABLE XXII

SEASONAL CHANGE IN NUMBER OF PREVITELLOGENIC OVARIAN FOLLICLES IN ADULT FEMALE $\underline{S}$ - obesus $\mathrm{N}=$ NUMBER OF LIZARDS; $\mathrm{n}=$ NUMBER OF FOLLICLES

\begin{tabular}{lcccc|cccc}
\hline \multicolumn{7}{c}{} & \multicolumn{7}{c}{1978} & & & 1979 \\
\hline Month & $\mathrm{N}$ & $\mathrm{n}$ & $\overline{\mathrm{x}}( \pm 2 \mathrm{s.e.})$ & Range & $\mathrm{N}$ & $\mathrm{n}$ & $\overline{\mathrm{x}}( \pm 2 \mathrm{~s} . \mathrm{e})$. & Range \\
\hline Mid-March & 11 & 429 & $33.0 \pm 5.3$ & $20-46$ & 7 & 271 & $38.7 \pm 6.6$ & $31-57$ \\
Late March & 12 & 266 & $22.2 \pm 5.8$ & $9-43$ & 7 & 214 & $30.6 \pm 5.3$ & $20-40$ \\
Mid-April & 11 & 286 & $26.0 \pm 5.2$ & $16-44$ & 4 & 122 & $30.5 \pm 6.3$ & $24-38$ \\
Late Apri1 & 12 & 385 & $32.1 \pm 6.2$ & $19-53$ & 4 & 117 & $29.3 \pm 9.8$ & $20-40$ \\
Mid-May & 13 & 323 & $24.9 \pm 6.7$ & $11-45$ & 5 & 160 & $32.0 \pm 6.9$ & $23-43$ \\
Late May & 13 & 244 & $18.8 \pm 2.8$ & $8-30$ & 5 & 110 & $22.0 \pm 7.2$ & $14-35$ \\
Mid-June & 11 & 269 & $24.5 \pm 5.9$ & $13-41$ & 5 & 105 & $21.0 \pm 4.4$ & $15-27$ \\
Late June & 9 & 224 & $24.9 \pm 3.8$ & $18-36$ & 8 & 216 & $27.0 \pm 4.7$ & $13-33$ \\
Mid-July & 12 & 387 & $32.3 \pm 4.5$ & $17-44$ & 7 & 184 & $27.0 \pm 4.9$ & $14-34$ \\
Late July & 12 & 364 & $30.3 \pm 4.5$ & $16-41$ & 4 & 107 & $26.7 \pm 4.4$ & $11-31$ \\
Mid-August & 10 & 290 & $29.0 \pm 7.8$ & $14-52$ & 4 & 117 & $29.3 \pm 8.2$ & $17-34$ \\
Late August & 8 & 241 & $30.6 \pm 4.6$ & $21-40$ & 4 & 117 & $29.3 \pm 9.7$ & $15-36$ \\
\hline \hline
\end{tabular}




\section{TABLE XXIII}

SEASONAL CHANGE IN NUMBER OF VITELLOGENIC OVARIAN FOLLICLES IN ADULT FEMALE S. obesUS. $\mathrm{N}=$ NUMBER OF LIZARDS; $\mathrm{n}=$ NUMBER OF FOLLICLES

\begin{tabular}{|c|c|c|c|c|c|c|c|c|}
\hline & \multicolumn{4}{|c|}{1978} & \multicolumn{4}{|c|}{1979} \\
\hline Month & $\mathrm{N}$ & $\mathbf{n}$ & $\bar{x}( \pm 2$ s. e. $)$ & Range & $\mathrm{N}$ & $\mathbf{n}$ & $\bar{x}( \pm 2$ s. e. $)$ & Range \\
\hline Mid-March & 11 & 18 & $1.6 \pm 2.7$ & $0-15$ & 7 & 1 & $0.1 \pm 0.3$ & $0-1$ \\
\hline Late March & 12 & 123 & $10.3 \pm 4.0$ & $0-23$ & 7 & 18 & $2.6 \pm 2.9$ & $1-9$ \\
\hline Mid-April & 11 & 99 & $9.0 \pm 2.5$ & $0-15$ & 4 & 36 & $9.0 \pm 0.8$ & $8-10$ \\
\hline Late April & 12 & 109 & $9.1 \pm 2.7$ & $4-17$ & 4 & 45 & $11.3 \pm 5.2$ & $2-19$ \\
\hline Mid-May & 13 & 153 & $11.8 \pm 4.1$ & $2-26$ & 5 & 61 & $12.2 \pm 6.2$ & $4-23$ \\
\hline Late May & 13 & 98 & $7.5 \pm 4.4$ & $0-27$ & 5 & 63 & $12.6 \pm 4.4$ & $8-20$ \\
\hline Mid-June & 11 & 19 & $1.7 \pm 1.5$ & $0-5$ & 5 & 10 & $2.0 \pm 1.6$ & $1-5$ \\
\hline Late June & 9 & 20 & $2.2 \pm 1.2$ & $0-5$ & 8 & 17 & $2.1 \pm 1.4$ & $0-5$ \\
\hline Mid-Ju1y & 12 & 17 & $1.4 \pm 0.9$ & $0-4$ & 7 & 21 & $3.0 \pm 2.3$ & $1-9$ \\
\hline Late Ju1y & 12 & 5 & $0.4 \pm 0.3$ & $0-1$ & 4 & 5 & $1.3 \pm 1.5$ & $0-3$ \\
\hline Mid-August & 10 & 11 & $1.1 \pm 0.6$ & $0-2$ & 4 & 1 & $0.3 \pm 0.5$ & $0-1$ \\
\hline Late August & 8 & 6 & $0.8 \pm 0.8$ & $0-3$ & 4 & 1 & $0.3 \pm 0.5$ & $0-1$ \\
\hline
\end{tabular}


distributed throughout the follicle. Increasing quantities rendered the follicles opaque. Vitellogenic ovarian follicles were variable in size ( 3 - $10 \mathrm{~mm}$ diameter). All follicles greater than $5 \mathrm{~mm}$ diameter were vitellogenic. Vitellogenesis continued as follicles grew larger than $10 \mathrm{~mm}$ liameter, but since these larger follicles usually resulted in egg formation they were designated as preovulatory. Vitellogenesis usually commenced within a month of the onset of the activity season. The most rapid accumulation of yolk droplets occurred after late April. The maximum mean number of follicles occurred in May. At this time, they contributed to roughly one-third of the total follicular compliment (Fig. 20a \& b). During June the mean number abruptly declined about $80 \%$. Minimum mean number of vitellogenic follicles occurred at the onset (March) and termination (August) of the activity season (Table XIII). These means were not significantly different. Initiation of vitellogenesis usually occurred earliest in the larger adult females. During the peak of breeding there was also a significant correlation between the number of vitellogenic follicles and body size $(r=0.68$, $y=0.25 x-27.39, N=18, P(0.01)$

Atretic (degenerating) follicles were observed in adult female

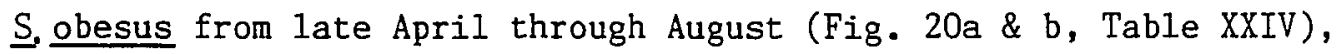
when $20-80 \%$ of the individuals for each capture period possessed corpora atretica. Early stages of atresia revealed vitellogenic follicles that appeared mottled and slightly collapsed. Histological examination showed that corpora atretica consisted primarily of hypertrophied granulosa cells and thecal fibroblasts (Fig. 19c). Yolk droplets were found in the granulosa cell cytoplasm and their overall quan- 
Figure 19c. Atretic follicle of female S. obesus (430X). The following features are shown: yolk droplets (a), granulosa cells (b), and erythrocytes (c). 


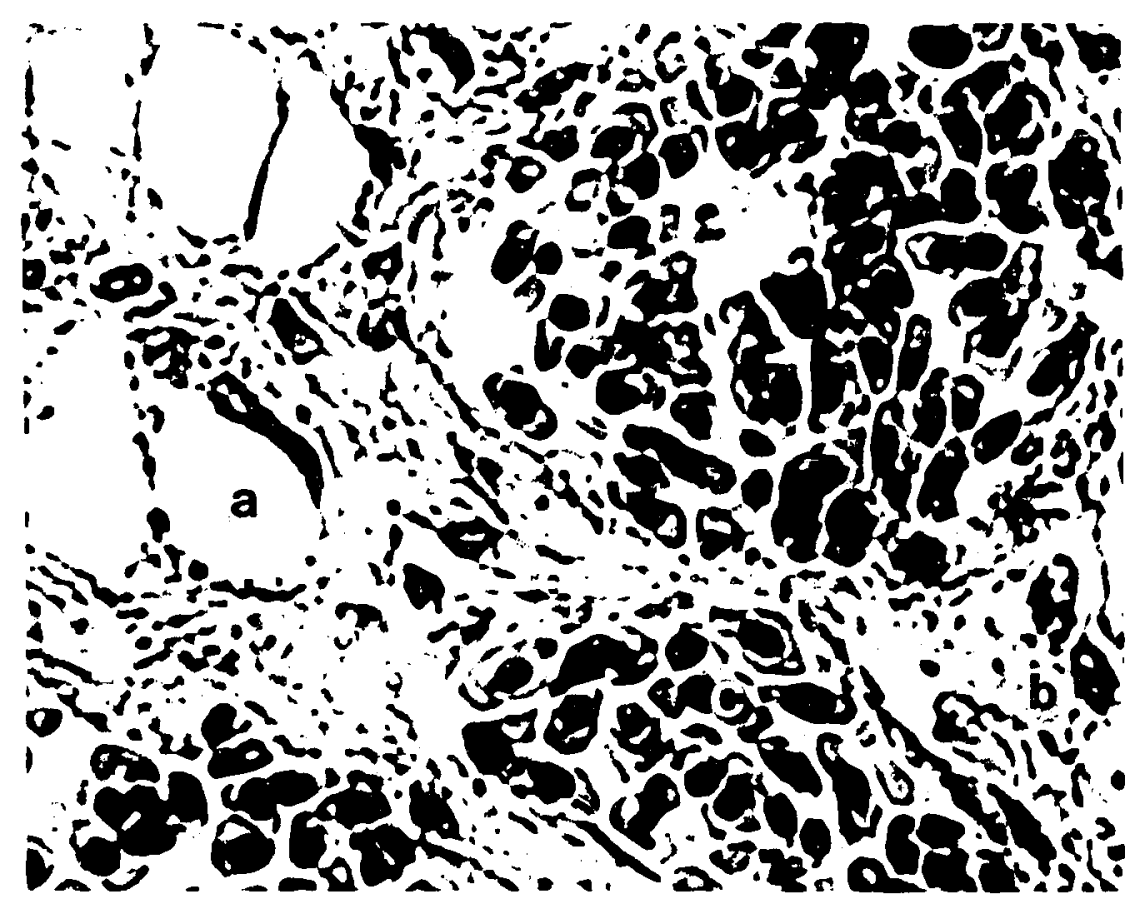


TABLE XXIV

SEASONAL CHANGE IN NUMBER OF ATRETIC OVARIAN FOLLICLES IN ADULT FEMALE $\underline{\mathrm{S}}$. obesus: $\mathrm{N}=$ NUMBER OF LIZARDS; $\mathrm{n}=$ NUMBER OF FOLLICLES

\begin{tabular}{|c|c|c|c|c|c|c|c|c|}
\hline \multirow[b]{2}{*}{ Month } & \multicolumn{4}{|c|}{1978} & \multicolumn{4}{|c|}{1979} \\
\hline & $\mathrm{N}$ & $n$ & $\bar{x}( \pm 2$ s. e. $)$ & Range & $\mathrm{N}$ & $\mathrm{n}$ & $\bar{x}( \pm 2$ s. e. $)$ & Range \\
\hline Mid-March & 11 & 0 & - & - & 7 & 0 & - & - \\
\hline Late March & 12 & 0 & - & - & 7 & 0 & - & - \\
\hline Mid-April & 11 & 0 & - & - & 4 & 0 & - & - \\
\hline Late April & 12 & 1 & $0.1 \pm 0.2$ & $0-1$ & 4 & 1 & $0.3 \pm 0.5$ & $0-1$ \\
\hline Mid-May & 13 & 1 & $0.1 \pm 0.2$ & $0-1$ & 5 & 2 & $0.4 \pm 0.8$ & $0-2$ \\
\hline Late May & 13 & 10 & $0.8 \pm 0.9$ & $0-5$ & 5 & 6 & $1.2 \pm 1.9$ & $0-5$ \\
\hline Mid-June & 11 & 32 & $2.9 \pm 2.7$ & $0-16$ & 5 & 9 & $1.8 \pm 1.2$ & $0-4$ \\
\hline Late June & 9 & 13 & $1.4 \pm 0.7$ & $0-3$ & 8 & 7 & $0.9 \pm 0.8$ & $0-3$ \\
\hline Mid-July & 12 & 10 & $0.8 \pm 0.5$ & $0-2$ & 7 & 4 & $0.6 \pm 0.6$ & $0-3$ \\
\hline Late July & 12 & 19 & $1.6 \pm 1.0$ & $0-6$ & 4 & 6 & $1.5 \pm 1.0$ & $0-2$ \\
\hline Mid-August & 10 & 20 & $2.0 \pm 1.1$ & $0-5$ & 4 & 4 & $1.0 \pm 2.0$ & $0-4$ \\
\hline Late August & 8 & 10 & $1.3 \pm 1.0$ & $0-3$ & 4 & 6 & $1.5 \pm 1.3$ & $0-3$ \\
\hline
\end{tabular}


Figure 20a. Percent frequency of the various types of ovarian follicles for adult female $\underline{S}$. obesus throughout the 1978 activity season. 


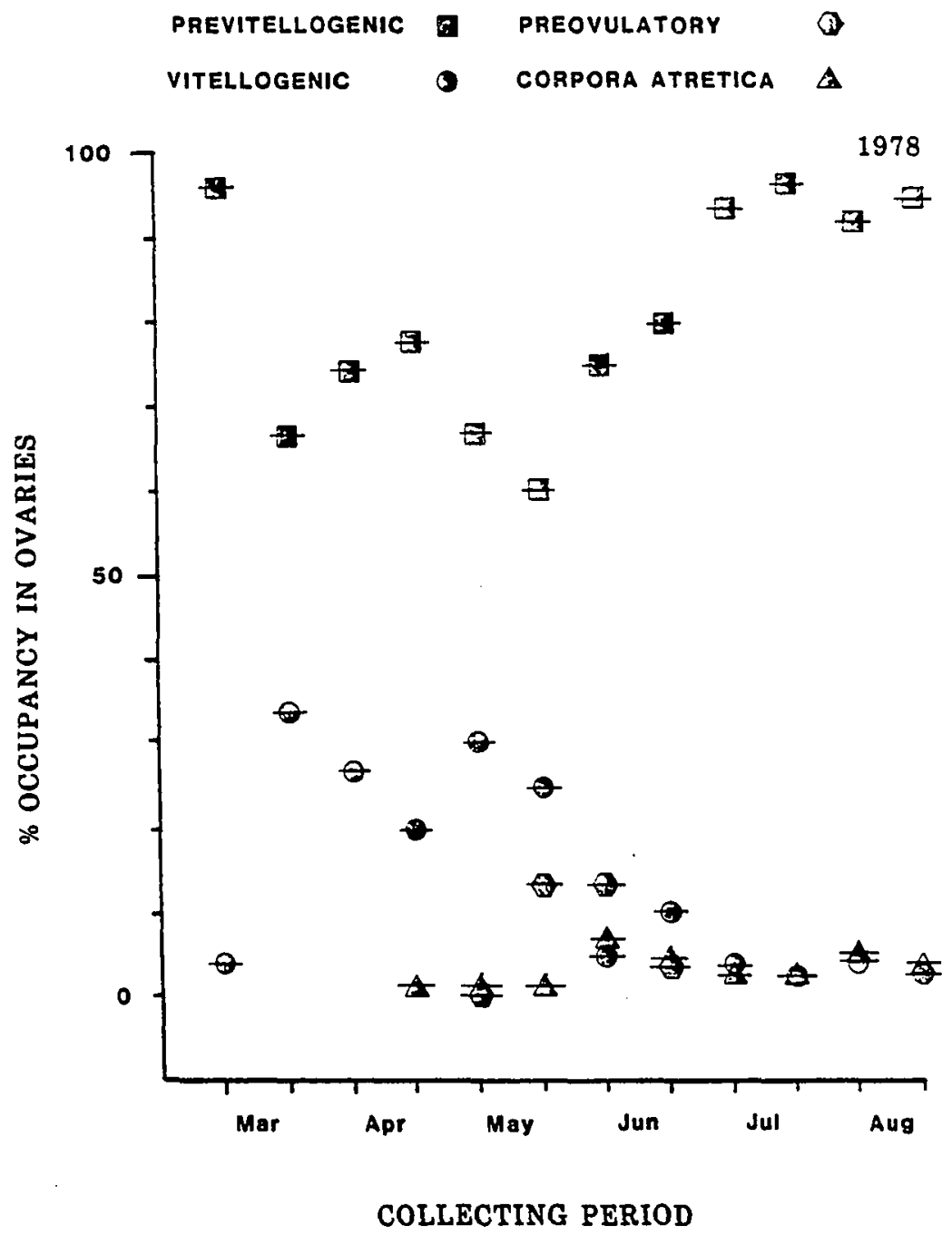


Figure 20b. Percent frequency of the various types of ovarian fol-

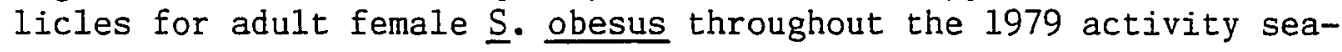
son. 


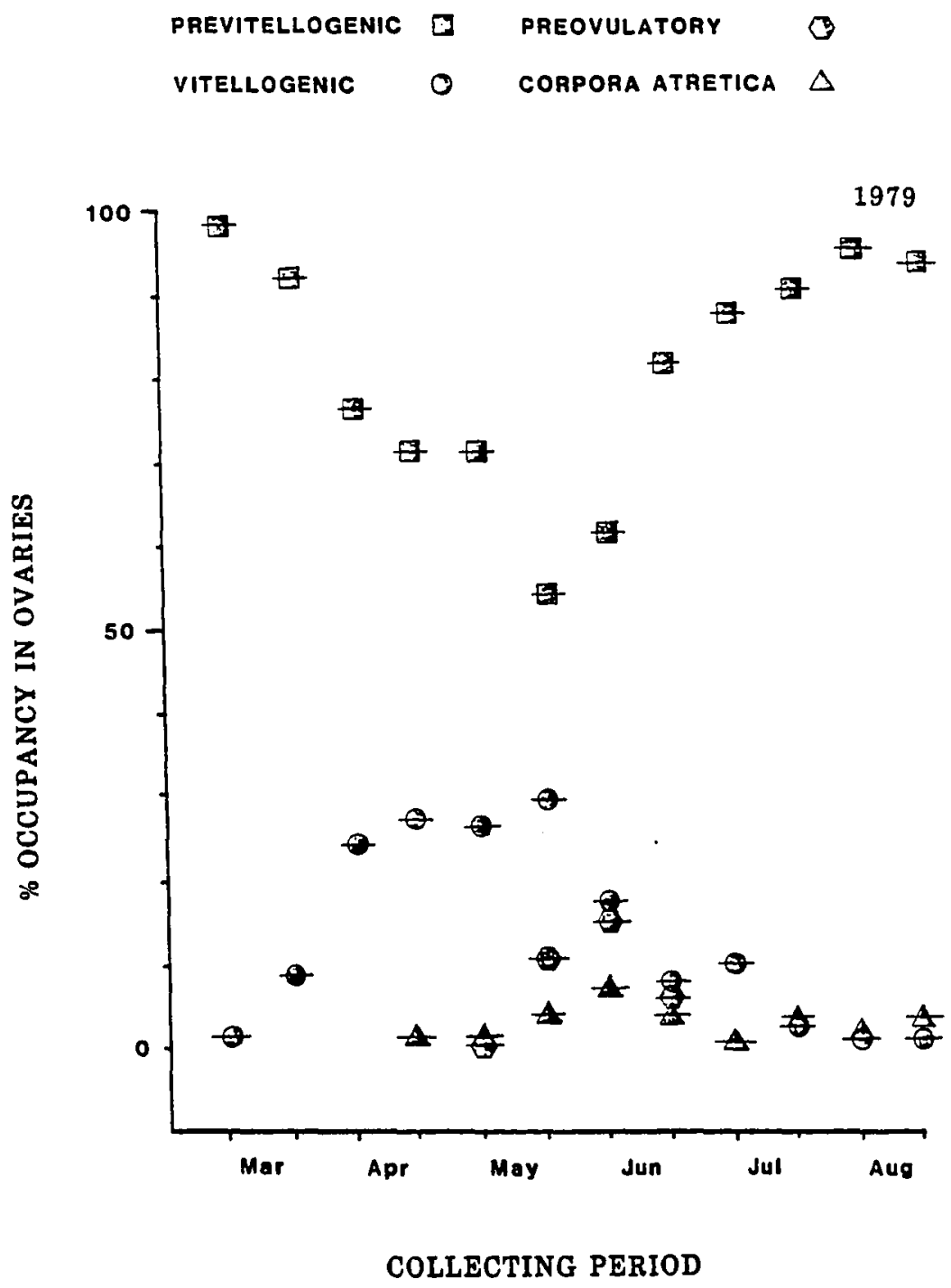


tity was greatly reduced. In most cases extensive infiltration of red blood cells was indicative of hyperplasia. Atresia was most common in follicles 3- $10 \mathrm{~mm}$ diameter. The largest follicle undergoing atresia was $11.6 \mathrm{~mm}$ in diameter. Only $3 \%$ of the ovarian follicles exceeding a diameter of $10 \mathrm{~mm}$ were atretic. Atresia was most common in midJune (about 2 weeks prior to ovulation). There was an average of 5 atretic follicles per lizard in mid-June of 1980 . This was the highest average for 1978 - 1982. The degnerative process of atresia progressed rapidly and within about two weeks following the onset the now-dirty yellow follicles were greatly reduced in size. Except in 1980, no correlation between body size and incidence of atresia existed. In 1980 , incidences of atresia showed a strong negative correlation with body size $(r=-0.77, y=-0.34 x+59.18, N=10, P<0.01)$ and their occurrence was as much as 5 itimes greater in females of SVL less than $150 \mathrm{~mm}$.

All vitellogenic ovarian follicles with diameters greater than $10 \mathrm{~mm}$ were designated pre-ovulatory. Adult female $\underline{S}$. obesus possessed pre-ovulatory follicles from mid-May through late June (Fig. 20a \& b, Table XXV). Histological exmination of these follicles showed they were densely packed with yolk droplets. Changes in the size of preovulatory follicles are shown in Table XXVI. Pre-ovulatory follicles were always most abundant in mid-June. In 1979, all adult females captured in mid-June possessed pre-ovulatory follicles. The mean number, standard error and range for 17 females captured in June were $7.88 \pm 0.57$ and $4-15$, respectively. The number of pre-ovulatory follicles and body size were highly correlated $(r=0.75, y=0.14 x-$ 
TABLE XXV

SEASONAL CHANGE IN NUMBER OF PREOVULATORY OVARIAN FOLLICLES IN ADULT FEMALE $\underline{\mathrm{S}}$. obesus. $\mathrm{N}=$ NUMBER OF LIZARDS; $\mathrm{n}$ = NUMBER OF FOLLICLES

\begin{tabular}{ccccc|cccc}
\hline & \multicolumn{3}{c}{1978} & \multicolumn{3}{c}{1979} \\
\hline Month & $\mathrm{N}$ & $\mathrm{n}$ & $\overline{\mathrm{x}}( \pm 2 \mathrm{s.} . \mathrm{e.})$ & Range & $\mathrm{N}$ & $\mathrm{n}$ & $\overline{\mathrm{x}}( \pm 2 \mathrm{~s}$. e. $)$ & Range \\
\hline Mid-May & 13 & 1 & $0.1 \pm 0.2$ & $0-1$ & 5 & 1 & $0.2 \pm 0.1$ & $0-1$ \\
Late May & 13 & 58 & $4.5 \pm 2.3$ & $0-10$ & 5 & 23 & $4.6 \pm 3.2$ & $4-10$ \\
Mid-June & 11 & 56 & $5.1 \pm 2.2$ & $0-9$ & 5 & 48 & $9.6 \pm 2.9$ & $7-15$ \\
Late June & 9 & 10 & $1.1 \pm 2.2$ & $0-10$ & 8 & 12 & $1.5 \pm 2.1$ & $0-8$ \\
\hline
\end{tabular}


15.37, $\mathrm{N}=17, \mathrm{P}<0.001)$.

Monthly records of seasonal changes in the number of ovarian follicles have been reported for a number of lizard species (Mayhew, 1963, 1965, 1966 a \& b, 1971; Goldberg, 1973, 1975b; Duda and Koul, 1977; Koul and Duda, 1977 and Droge et. al., 1982). For these studies the mean number of follicles present in all months was often $50-70 \%$ less than for $\underline{S}$. obesus. Results of the present study were similar to those of most other studies in that the mean number of follicles increased from onset of the activity season into late spring. Post-oviposition means were variable but generally lower than at the onset of activity. Female $\underline{S}$. obesus demonstrated the greatest difference between these times. Apparently little oocytogenesis occurred in this species late in the activity season.

According to Miller (1948), the timing of vitellogenesis with respect to ovulation falls into 3 categories. First, yolk deposition in maturing follicles occurs shortly before ovulation. Lizard species in this category include Sceloporus orcutti (Mayhew, 1963), $\underline{\text { S. graciosus }}$ (Goldberg, 1975a), S. occidentalis (Goldberg, 1973), Uma inornata (Mayhew (Mayhew, 1965), U. notata (Mayhew, 1966a), ‥ scoparia (Mayhew, 1966b), and Dipsosaurus dorsalis (Mayhew, 1971). Second, yolk deposition occurs gradually throughout the year. Hemidactylus flaviviridis (Sanyal and Prasad, 1967) belongs in this category. Third, yolk deposition occurs shortly after the preceding ovulation with mature ova remaining in the ovaries over winter. Lizard species in this category include Hoplodactylus maculatus (Boyd, 1940).

Since most vitellogenesis takes place prior to ovulation, it ap- 
pears adult female $\underline{S}$. obesus conform to the first category. However, some vitellogenesis was observed throughout the actvity season. The significance of this tendency is not clear. Probably, in years of above average environmental conditions (promoting food availability), development of vitellogenic follicles ensures a head start on reproduction for the following year, and in years when below average environmental conditions prevail, the presence of vitellogenic follicles provide a supplemental energy reserve. For Colorado Desert females, optimal environmental conditions most likely include abundant food during the spring and late summer. In late summer of 1978 many follicles developing yolk had become atretic. Less summer precipitation than normal (National Climatic Center) resulted in the absence of food and necessitated withdrawl of energy from ovarian follicles as a measure to improve chances of survival to the next breeding season. This pattern of vitellogenesis is consistent with observed life history tactics

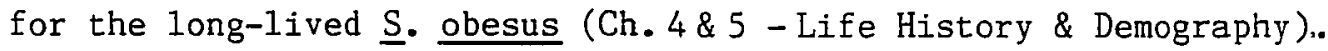

Corpora atretica have been described for a number of lizard species (Boyd, 1940; Miller, 1948; Goldberg, 1970 and 1973). These reports indicate that yolk was reabsorbed by hypertrophied granulosa cells; later these cells became smaller, then disappeared. The vestigial follicle was marked by the presence of thecal fibroblasts. I observed this sequence of events for female $\underline{S}$. obesus.

Seasonal change in the number of corpora atretica in female $\underline{S}$. obesus was similar to that reported for other lizard species (Goldberg, 1970, 1973 and 1965b; and Duda and Koul, 1977). It appears that increases in incidences of atresia around the close of the reproductive 
period is wide spread among lizard species. Year to year variability in number of corpora atretica may show the effect of changes in environmental conditions. The high mean number of corpora atretica in the 1980 June collection was probably the result of diminished available food. The standing crop of winter annuals in 1980 was one-tenth that measured for 1979 (Ch. 1 - Climate and Vegetation). Previous studies have shown corpora atretica to be non-existant in immature individuals. The fact that corpora atretica occurred only in those females of SVL equal to or exceeding minimum adult size, provides evidence for the significance of body size at first reproduction. In 1978 and 1979, when available food was abundant, size at first reproduction was the smallest ever recorded (Ch. 4 - Size At First Reproduction), possibly indicating the minimum body size allowed by life history constraints for female $\underline{S}$. obesus.

In adult female $\underline{S}$. obesus corpora lutea (follicular remnants) were observed from late June through July. This corresponds to the period from ovulation to about two weeks after oviposition. Corpora lutea were most easily recognized in those individuals possessing oviductal eggs. Prior to egg laying, corpora lutea were richly yelloworange in color and elipsoidal in shape. Each possessed a median longitudinal depression. Histological examination of the corpora lutea showed a highly folded thick mass of glandular tissue. The glandular tissue consisted principally of granulosa lutein cells that were peripherally surrounded by a thin layer of theca lutein cells (Fig. 21). Following oviposition corpora lutea turned a dull yellow-brown and rapidly diminished in size. By the end of July they were infiltrated 
Figure 21. Corpus luteum of female $\underline{S}$. obesus (100X). The following features are shown: granulosa lutein cells (a) and theca lutein cells (b). 


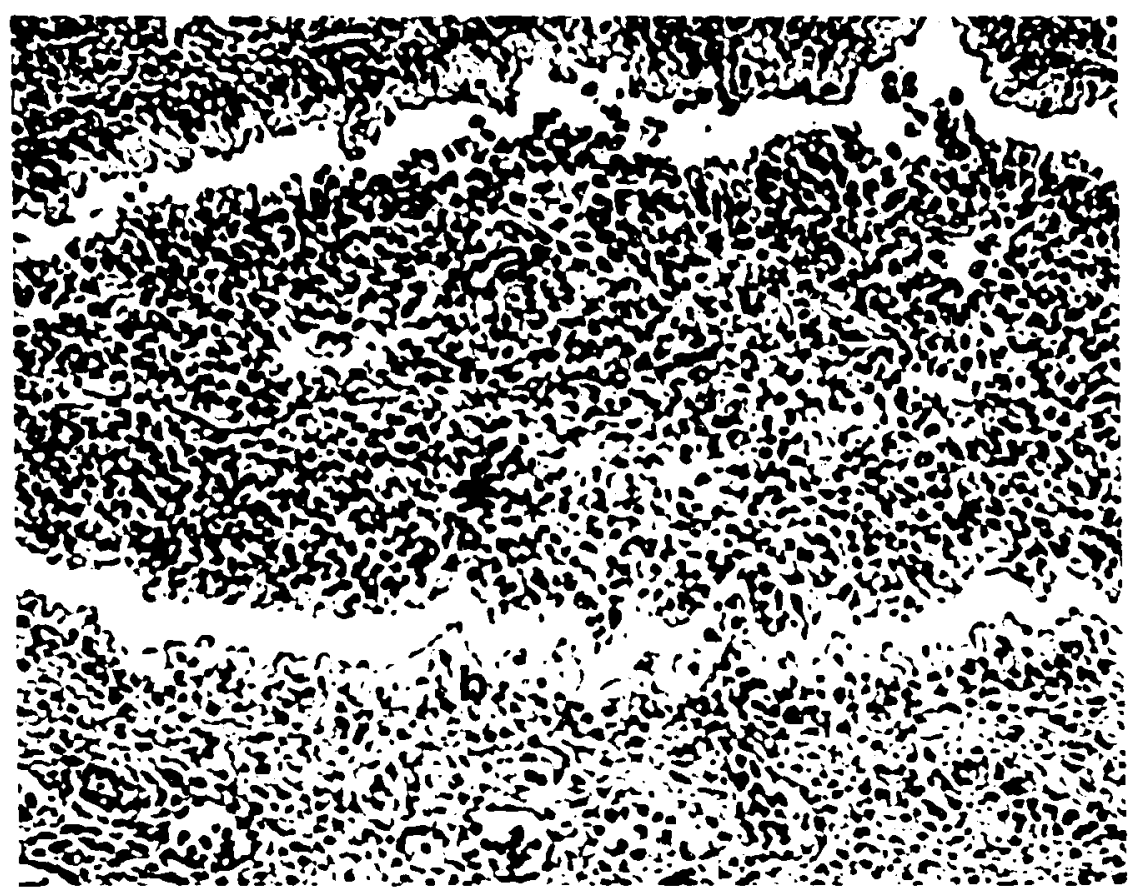


with fibroblasts which resulted in thickened connective tissue areas in the ovarian stroma. The change in size of corpora lutea is shown in Table XXVII. In $1979,86 \%$ of the adult female $\underline{S}$. obesus captured in July possessed corpora lutea. The mean number per adult female was 6.98 ( $\mathrm{S} . \mathrm{E} .=0.37, \mathrm{~N}=42$ ). The number of corpora lutea and body size were highly correlated $(r=0.85, y=0.11 x-11.07, N=42, P<0.001)$.

Corpora lutea have been described in many oviparous and viviparous lizards (Rahn, 1938; Mulaik, 1946; Mayhew, 1963, 1964, 1966 a and b, 1971; Christiensen, 1971 and Goldberg and Bezy, 1974) and probably occur in all mature female lizards (Miller, 1951 and 1959). The structure of the reptilian corpus luteum is generally similar to that of mammals (Forbes, 1961). Corpora lutea develop when the region of the discharged follicle fills with hypertrophied cells of the membrana granulosa (Miller 1948 and 1951 and Goldberg and Bezy, 1974). The structures contributing to corpus luteum formation vary between species

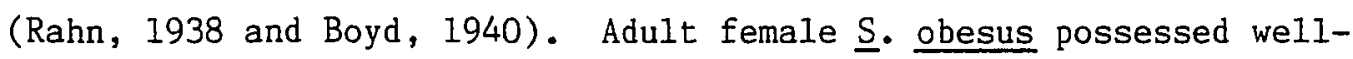
defined theca lutein and granulosa lutein cells and, like at least one other lizard species (Rahn, 1938), possessed a highly vascular theca interna.

The exact function of lizard corpora lutea is not well understood, but they probably prolong egg retention. Their steroidogenic function in production of progesterone is under control of the pituitary gland (Fox, 1977). Progesterone appears to have a variable functional relationship to egg retention and gestation (Callard et. al., 1972; Yaron, 1972). The corpora lutea of adult female $\underline{S}$. obesus were largest and most distinct immediately following ovulation. They decreased in size 
TABLE XXVI

SEASONAL CHANGE IN THE DIAMETER OF PREOVULATORY OVARIAN FOLLICLES OF ADULT FEMALE S. obesus. $\mathrm{N}=$ NUMBER OF LIZARDS;

$\mathrm{n}=$ NUMBER OF FOLLICLES

\begin{tabular}{lrrcc}
\hline Month & $\mathrm{N}$ & $\mathrm{n}$ & $\begin{array}{c}\overline{\mathrm{x}} \text { Diameter } \\
(\mathrm{mm}) \pm 1 \mathrm{~s} . \mathrm{e} .\end{array}$ & Range \\
\hline Late May & 13 & 71 & $12.4 \pm 0.2$ & $10.0-16.4$ \\
Mid-June & 16 & 128 & $16.1 \pm 0.3$ & $10.0-22.1$ \\
Late June & 3 & 18 & $19.5 \pm 0.4$ & $17.3-22.5$ \\
\hline
\end{tabular}

TABLE XXVII

SEASONAL CHANGE IN THE DIAMETER OF CORPORA LUTEA IN ADULT FEMALE $\underline{S}$. obesus. $\mathbf{N}=$ NUMBER OF LIZARDS; $\mathbf{n}=$ NIMBBER OF FOLLICLES

\begin{tabular}{lcccc}
\hline Month & $\mathrm{N}$ & $\mathrm{n}$ & $\overline{\mathrm{x}}$ Diameter \\
\hline Late June & 7 & 55 & $5.8 \pm 0.2$ & Range \\
Late & 14 & 95 & $2.9 \pm 0.8$ & $3.8-7.9$ \\
\hline
\end{tabular}


much more rapidly.

Degeneration of the corpora lutea to a scar tissue remnant takes about 15 - 20 days in adult female $\underline{S}$. obesus and other oviparous lizard species (Johnson, 1960; Tinkle, 1961; Mayhew, 1963, 1966b, 1971; Bostic, 1966; Christiansen, 1971; and Jacob and Ramaswemi, 1976). Vestigial corpora lutea (Corpora albicanatia) are known to persist throughout the life of some lizards (Telford, 1969), but had disappeared by the following spring in adult female $\underline{S}$. obesus.

Average volume of saccular ovaries of adult females (Table XXVIII) increased as much as 100 times between the onset of activity in March and ovulation in June. A similar decrease in volume was observed from the time of ovulation to cessation of activity in late August. Volumes at spring emergence tended to exceed those for late summer though differences were not always significant (e.g., 1979). At the time of emergence, nearly the entire volume (97\%) could be accounted for by the predominance of previtellogenic follicles. Just prior to ovulation, about $93 \%$ of the volume was due to the presence of pre-ovulatory follicles. Immediately following ovulation, about $53 \%$ and $20 \%$ of the ovar:ian volume could be accounted for by corpora lutea and corpora atretica, respectively. In late August previtellogenic follicles contributed to about $71 \%$ of the ovarian volume.

Due to small numbers, immature female $\underline{S}$. obesus were examined on a monthly basis. Except for March, the data represent only captures made in 1978. Seasonal changes in number of ovarian follicles (Table XXIX) show a maximum monthly mean approximately $75 \%$ of the adult average in May. Previtellogenic follicles were predominant throughout the activity 
TABLE XXVIII

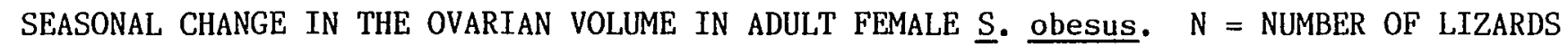

\begin{tabular}{|c|c|c|c|c|c|c|}
\hline & & 1978 & & & 1979 & \\
\hline Period & $\mathrm{N}$ & $\begin{array}{c}\text { Mean } \mathrm{mm}^{3} \\
( \pm 1 \text { s. e. })\end{array}$ & Range & $\mathrm{N}$ & $\begin{array}{c}\text { Mean } \mathrm{mm}^{3} \\
( \pm 1 \text { s. e. })\end{array}$ & Range \\
\hline Spr. Emergence & 12 & $140 \pm 38$ & $77-283$ & 7 & $95 \pm 18$ & $47-17.2$ \\
\hline Pre-0vulatory & 10 & $10348 \pm 2060$ & 2048-19957 & 7 & $11899 \pm 2521$ & $5630-17298$ \\
\hline Post-Ovulatory & 10 & $382 \pm 74$ & $60-725$ & 10 & $273 \pm 88$ & $40-948$ \\
\hline Late Summer & 9 & $49 \pm 5$ & $24-128$ & 4 & $87 \pm 7$ & $73-98$ \\
\hline
\end{tabular}


season. Vitellogenic follicles were present from April through August. In May, $75 \%$ of the individuals possessed vitellogenic follicles but they represented only $12.2 \%$ of the total ovarian follicles present. None of the vitellogenic follicles exceeded a diameter of $5 \mathrm{~mm}$. Corpora atretica were observed in immature females June through July. During July $40 \%$ of the individuals possessed atretic follicles but they represented only $4 \%$ of the total ovarian follicles present. None of the atretic follicles exceeded a diameter of $5 \mathrm{~mm}$. The only individuals showing follicular atresia were those of SVL closest to the minimum adult size $(x=128, S . E .+0.58, N=4)$. Average ovarian size did not increase during the course of the season (Table XXX). The decline in mean size in late summer is partially due to the sample consisting mostly of small individuals (less than a year old). The average monthly ovarian volume of immature $\underline{S}$. obesus was always significantly less than that of adults.

It was difficult to compare the breeding cycle of the female $\underline{S}$. obesus I studied with their conspecifics from the Mojave Desert, largeIy because this is the first thorough study of the breeding cycle for the species. Nonetheless, the following account of the breeding cycle of female $\underline{S}$. obesus attempts to compare the findings of this study with limited previous studies. Seasonal changes in the number of the types of ovarian follicles of female $\underline{S}$. obesus have not previously been reported. Some investigators reported the presence of enlarged ovarian follicles, but only Berry (1974) quantified their sizes. Enlarged ovarian follicles were observed in May (Nagy, 1973); April and May (Johnson, 1965), and April, May, and June (Berry, 1974). Enlarged 
TABLE XXIX

SEASONAL CHANGE IN NUMBER OF OVARIAN FOLLICLES OF IMMATURE $\underline{S}$. obesus. $N=$ NUMBER OF LIZARDS;

$\mathrm{n}=\mathrm{NUMBER}$ OF FOLLICLES

\begin{tabular}{lcccr}
\hline Manth & $\mathrm{N}$ & $\mathrm{n}$ & $\mathrm{x}( \pm 1 \mathrm{~s}, \mathrm{e})$. & Range \\
\hline March & 7 & 167 & $23.9 \pm 5.2$ & $0-43$ \\
April & 6 & 139 & $23.2 \pm 2.3$ & $17-34$ \\
May & 4 & 123 & $30.8 \pm 5.4$ & $19-43$ \\
June & 6 & 166 & $27.7 \pm 3.9$ & $14-41$ \\
July & 5 & 140 & $28.0 \pm 4.2$ & $15-41$ \\
August & 5 & 85 & $17.0 \pm 2.8$ & $7-22$ \\
\hline
\end{tabular}

TABLE XXX

SEASONAL CHANGE IN OVARIAN VOLUME IN IMMATURE FEMALE $\underline{S}$. obesus. $\mathrm{N}=$ NUMBER OF LIZARDS

\begin{tabular}{lccc}
\hline \multicolumn{1}{c}{ Period } & $\mathrm{N}$ & Mean $\mathrm{mm}^{3}( \pm 1$ s. e. $)$ & Range \\
\hline Spr. Emergence & 8 & $38 \pm 7$ & $18-75$ \\
Pre-Ovulatory & 11 & $33 \pm 6$ & $11-77$ \\
Late Summer & 5 & $16 \pm 4$ & $6-26$ \\
\hline
\end{tabular}


ovarian follicles exceeding $10 \mathrm{~mm}$ diameter (corresponding to pre-ovulatory follicles of this study) were observed by Berry in May and June; her observation agreed with those in this study. Johnson (1965) stated that ovulation occurs in early summer. The presence of oviductal eggs was reported by Berry (1974) but she did not mention the timing. Johnson observed a gravid adult female constructing a nest and depositing eggs on 22 June. His estimate for time of ovulation and oviposition were similar to mine. Colorado Desert $\underline{S}$. obesus ovulated mid to late June, and in the 5 reproductive years (1978 - 1980 and 1982 - 1983) oviposition started in early July. Consequently, some of the key events of the female reproductive cycle demonstrated considerable temporal consistency for various widely separated populations of $\underline{S}$. obesus. Perhaps this indicated that the reproductive strategy of $\underline{S}$. obesus evolved under wide spread predictable climatic conditions. The fact that various demographic features showed similar consistency appeared to support this hypothesis (Ch. 4-Clutch Size, Reproductive Effort and Reproductive Output).

The paired oviducts of Colorado Desert adult female $\underline{S}$. obesus were permanently opaque and highly convoluted in gross appearance. Histological examination of the oviducts showed them to be comprised of 3 regions - an anterior fallopian tube, a middle uterus, and a posterior vagina. Roughly $75 \%$ of the oviduct was uterus. The highly glandular uterus was found to possess both unicellular and multicellular branched tubular glands (Fig. 22). Seasonal changes in the uterine epithelium and tubular glands are shown in Figure 23 and Table XXXI, respectively. The epithelial heights of both increased gradually in the early spring but at an accelerated rate in late spring. Peak 
Figure 22a. Hypertrophied uterus of adult female $S$ obesus (100X). The following features are shown: surfact epithelium (a) and branched tubular glands with secretory granules (b). 


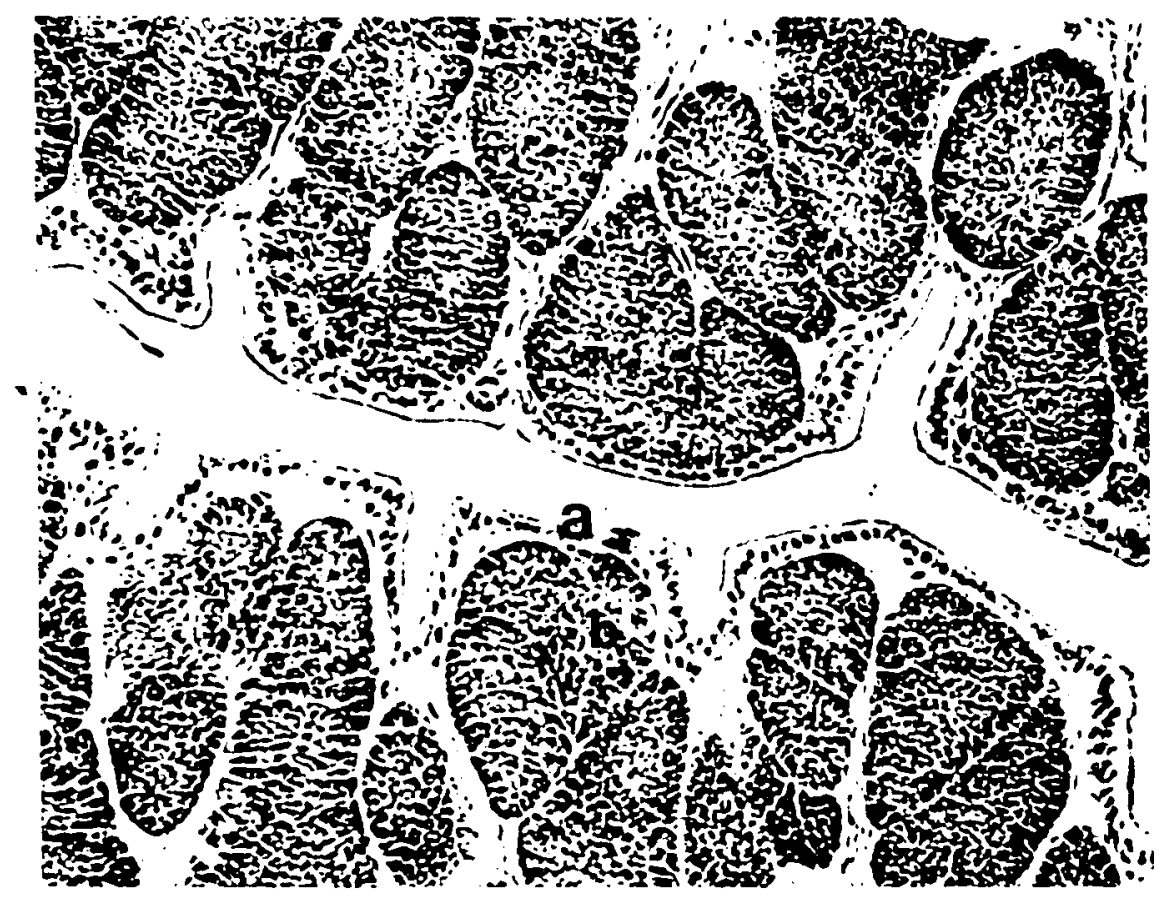


Figure 22b. Regressed uterus of female $\mathrm{S}$. obesus (100X). Note: low cuboidal nature of surface epithelium and absence of branched tubular uterine glands. 


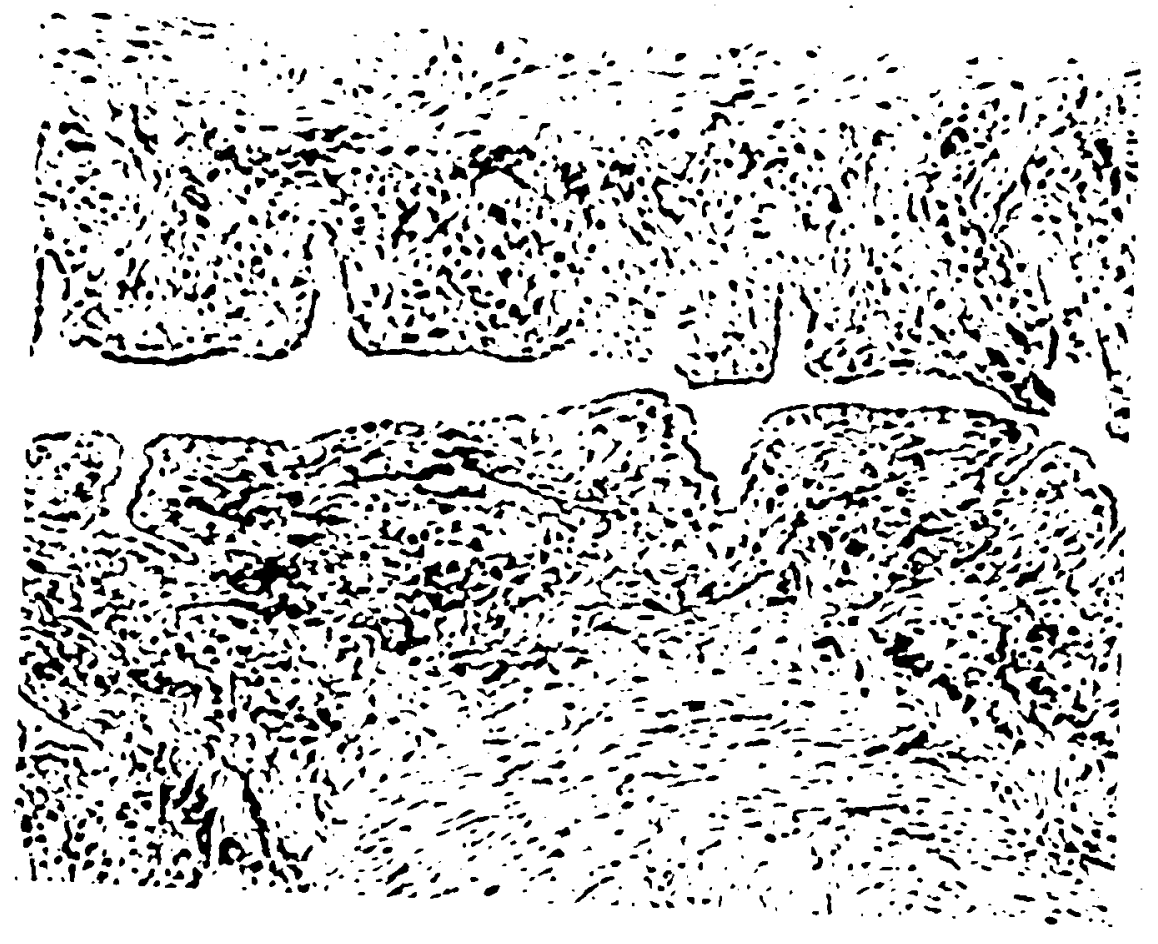


Figure 23. Seasonal changes in mean uterine epithelial thickness of adult female $\underline{S}$. obesus for 1978. Vertical bars indicate \pm 2 standard errors; numbers $=$ sample sizes .

$o$ 


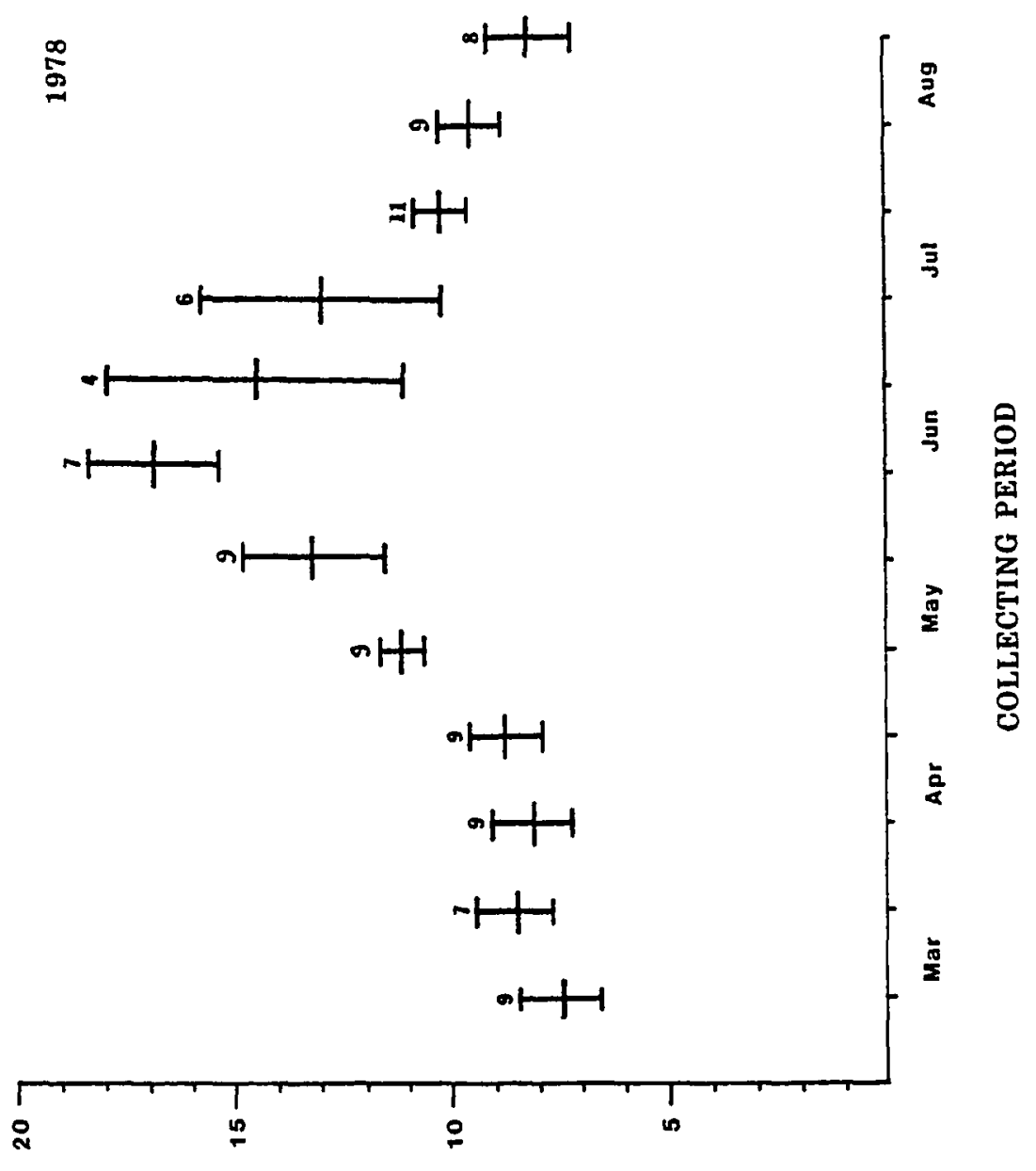

(i) WกITGHLIdG GอพสชกS 
TABLE XXXI

SEASONAL CHANGE IN UTERINE TUBULAR GLAND EPITHELIAL THICKNESS (um) IN ADULT FEMALE S. obesus DURING 1978. $\mathrm{N}=$ NUMBER OF LIZARDS

\begin{tabular}{lcc}
\hline Collection & $\mathrm{N}$ & $\mathrm{x}( \pm 2$ s. e. $)$ \\
\hline Mid-March & 5 & $8.3 \pm 1.0$ \\
Late March & 4 & $10.4 \pm 1.7$ \\
Mid-April & 8 & $10.4 \pm 1.0$ \\
Late April & 8 & $12.7 \pm 1.1$ \\
Mid-May & 9 & $15.6 \pm 1.6$ \\
Late May & 9 & $19.3 \pm 2.6$ \\
Mid-June & 7 & $27.3 \pm 3.2$ \\
Late June & 4 & Collapsed \\
Mid-July & 6 & Collapsed \\
Late July & 11 & Collapsed \\
Mid-August & 9 & $9.5 \pm 0.5$ \\
Late August & 8 & $7.3 \pm 0.6$ \\
\hline
\end{tabular}


thicknesses of the epithelium including unicellular glands, lining the uterine lumen and the epithelium of the tubular glands occurred in midJune. This time period preceded ovulation by about 2 weeks. Decline in epithelial thickness was gradual for the uterine lining but rapid for the tubular glands. Total collapse of the latter by late June was indicative of holocrine secretion. This secretion was highly granular and with the staining technique employed appeared the same throughout the uterus. Regeneration of the tubular gland epithelium was initiated by late summer. For both epithelia, maximum thickness was significantly greater than mean thicknesses in early spring and late summer. Early spring and late summer mean thicknesses proved not to differ significantly •

The paired oviducts of immature female $\underline{S}$. obesus appeared transparent, thin and straight. Histological examination of the glandular uterine portion during peak June secretory activity showed little of the epithelial hypertrophy associated with reproductive maturity.

The oviducts of adult female lizards of some species appear highly convoluted and thick-walled only during the breeding season (Miller, 1948; Mulaik, 1946; Mayhew, 1963). In other species, including S. obesus they remained in this condition throughout life (Mayhew, 1966b \& 1971). Adult female $\underline{S}$. obesus resemble many other lizard species (see Fox, 1977) in having oviducts consisting of anterior fallopian tube, middle uterus and posterior vagina. The uterine mucosa of several lizard species possesses numerous convoluted branched tubular glands. These glands are large during the height of the breeding season but tend to disappear partially or totally afterward. Granular secretions 
from the uterine glands pass into the oviductal lumen by way of short epithelial ducts. These secretions provide albumin and materials for production of shell membranes in oviparous species (Fox, 1977). Showing little exception to this pattern, the uterine glands of adult female S. obesus were of maximum and minimum size prior to ovulation and prior to oviposition, respectively. Such infrequently reported synchrony of ovarian activities with those of the reproductive tract should serve as a model for comparison with other oviparous lizard species (Fig. 24). Seasonal changes during 1978 and 1979 in mean fat body weight and body weight ratio (FBW/BW) for the adult female $\underline{S}$. obesus examined are shown in Figure 25a \& b. From the onset of activity through midApril, mean FBW/BW ratios showed little change or increased only gradually. The maximum increase in mean FBW/BW ratio occurred during the last half of April, but ratios continued to increase at an accelerated rate into late spring. Maximum mean FBW/BW ratios occurred as early as mid-May (1978) and as late as mid-June (1980). Mean FBW/BW ratios declined rapidly through June and at a more gradual rate through summer. Minimum mean FBW/BW ratios occurred in late summer and at the time of spring emergence. Yearly maximum mean FBW/BW ratios did not differ significantly during 1978 - 1980, nor did yearly minimum mean FBW/BW ratios. During 1978 - 1980, yearly maximum mean spring FBW/BW ratios were always significantly greater than spring and summer mean minimums and significantly greater than mean post-ovulatory females. In 1978 and 1979, nonbreeding adult females had significantly greater FBW/BW ratios than females with oviductal eggs. In fact, mean FBW/BW ratios of nonbreeding adult females were not significantly different from 
Figure 24. The relationship of seasonal changes in ovarian and uterine structures for adult female $\mathrm{S}$. obesus. 1 = vitellogenesis; 2 = follicular atresia; 3 = corpus Iuteum; $a=$ zona pellucida; $b=1$ ipid droplets; $c=$ erythrocytes; $d=$ yolk; $e=$ fibroblast; $f$ = hypertrophied granulosa cell; $g$ = granulosa lutein cells; $h=$ theca lutein cells; $i=$ branched tubular glands. 


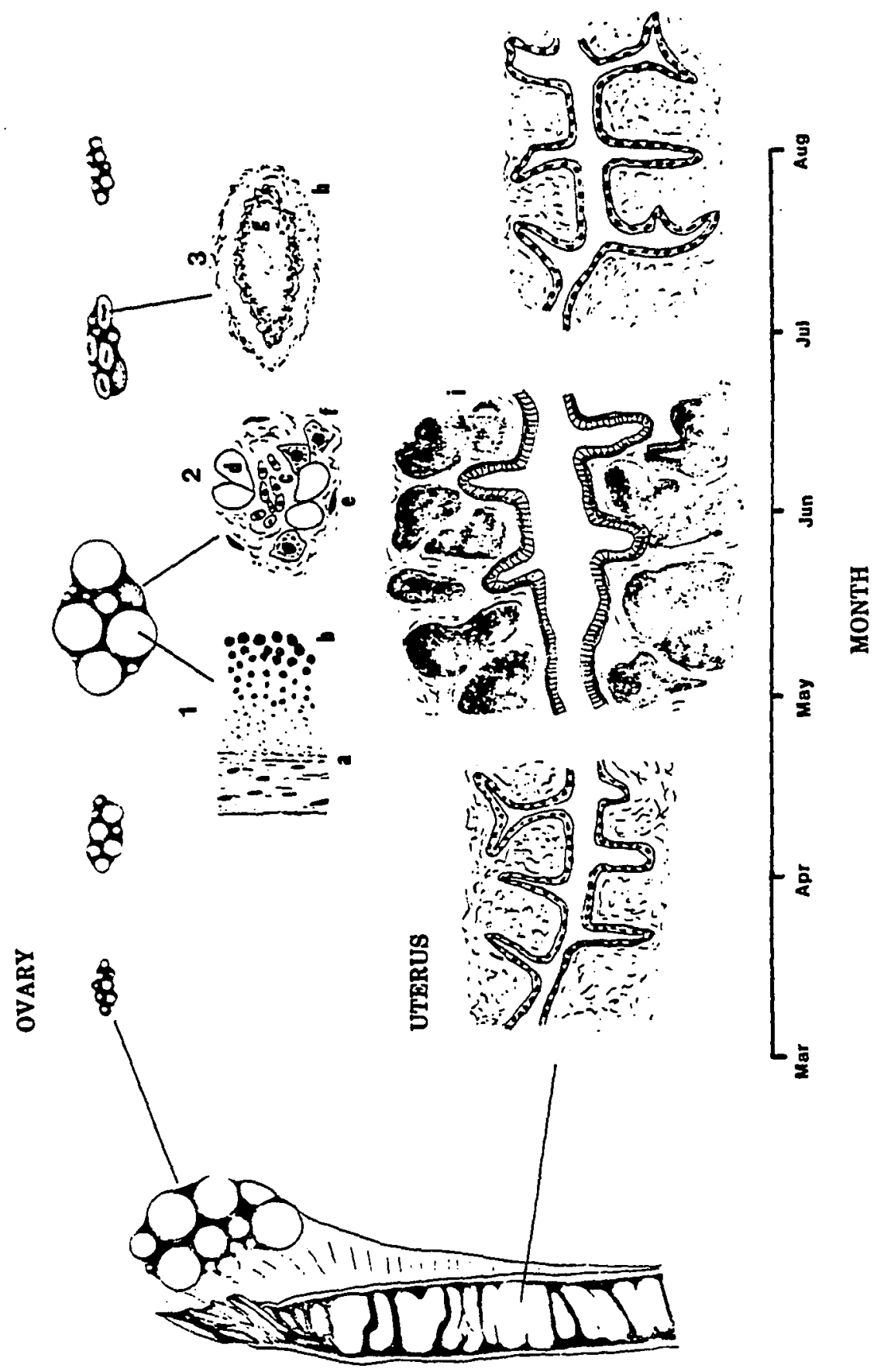


Figure 25a. Seasonal changes in mean fat body weight/body weight ratios of adult female $S$. obesus for 1978. Vertical bars indicate \pm 2 standard errors; numbers indicate sample sizes. 


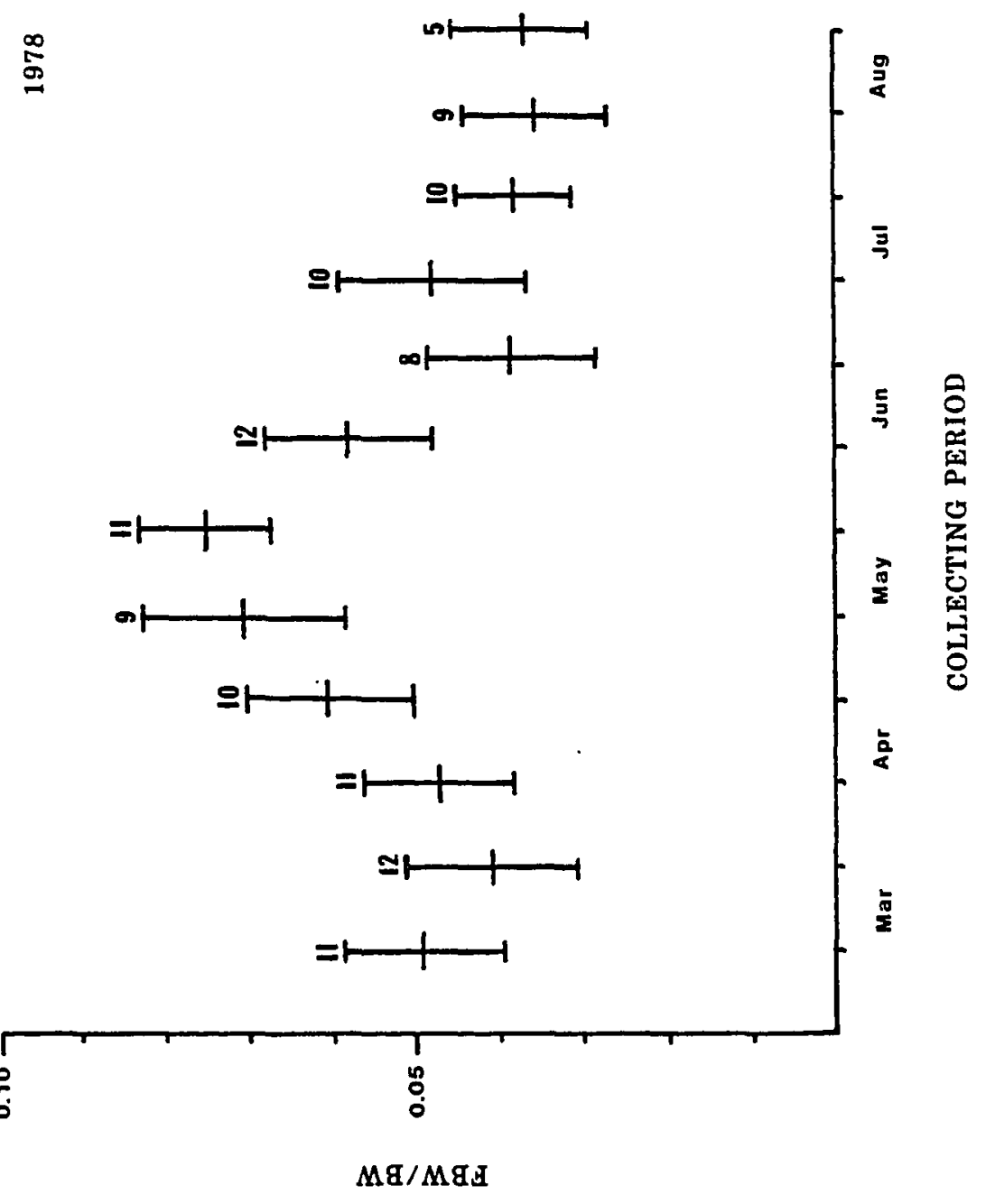


Figure 25b. Seasonal changes in mean fat body weight/body weight ratios of adult female $\underline{S}$. obesus for 1979. Vertical bars indicate \pm 2 standard errors; numbers indicate sample sizes. 


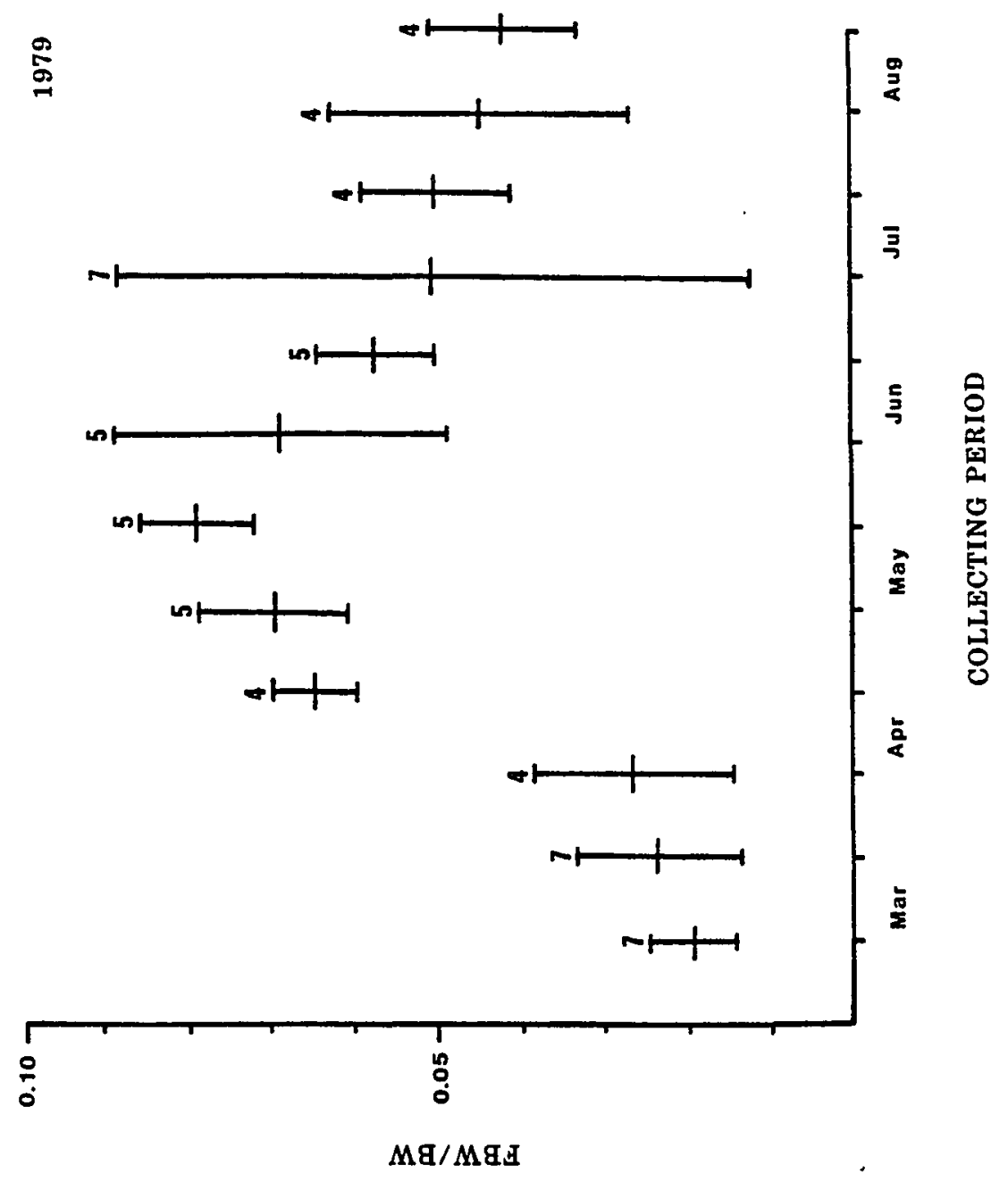


mean spring maxima. Post-ovulatory females had significantly greater mean FBW/BW ratios than did females emerging the following spring. While late summer 1978 and following years (1979) spring emergence FBW/BW ratios did not differ significantly, spring emergence ratios (1978 vs 1979) were significantly different.

Lipids represent an efficient biochemical substrate for energy storage for maintenance, growth and reproduction. Lipids are usually stored subcutaneously or as corpora adiposa. Specific lipid depots for lizards include carcass, tail, corpora adiposa, liver and eggs. However, the bulk of lipids is stored in the carcass and as corpora adiposa, with the latter contributing as much as $50 \%$ of the stored lipid (Derickson, 1976). The liver probably serves as an intermediary organ for both the storage and utilization of lipids (Hahn, 1967). Lipid storage and utilization in lizards demonstrate distinct seasonal cycling patterns which can be explained by seasonal patterns of food availability. Derickson (1976) stated that seasonality in food availability determines the quantity of lipids stored, when lipids are stored, and for what purposes these lipids are utilized. As a result of this phenomenon, lipid cycling patterns are in turn correlated with life histories. Derickson recognized the evolution of 4 patterns of lipid storage and utilization for lizards. First, no lipid cycling occurs in some tropical species that also lack a seasonal cycle of of reproductive activity. This category is limited to 4 species of geckos (Church, 1962; Lannom, 1966) and Anolis trinitatus (Licht and Gorman, 1976). Second, lipid cycling associated only with winter dormancy is known for at least one species, Anolis carolinensis (Dessauer, 
1955). Third, lipid cycling associated only with reproduction occurs in several species that include Uta stansburiana (Hahn and Tinkle, 1965), Cnemidophorus sexlineatus (Hoddenbach, 1966), Ameiva festiva and A. quadrilineata (Smith, 1968), Dipsosaurus dorsalis (Minnich, 1971) and numerous tropical Anolis species (Licht and Gorman, 1970; Gorman and Licht, 1974; Sexton et. al., 1971 and Ruibal et. al., 1972). Fourth, lipid cycling associated with both winter dormancy and reproduction occurs in a number of species which include Takydromus tachydromoides (Telford, 1970), Sceloporus jarrovi (Goldberg, 1972a), S. ma1achiticus (Marion and Sexton, 1971), S. graciosus (Jameson, 1974 and Derickson, 1976a), ․ . occidentalis (Goldberg, 1974 and Jameson and

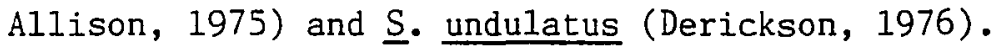

Derickson (1976) stated that while most temperate species apportion some lipids to maintenance needs during winter dormancy, the reproductive demands on stored lipids are apparently much greater. However, reproductive demands on stored lipids frequently differ between the sexes (Gaffney and Fitzpatric, 1973; Jameson, 1974; Goldberg, 1974; Jameson and Allison, 1975 and Droge et al., 1982). Derickson (1976) also stated that the amount of energy available for reproduction in temperate lizard species is determined by the amounts of lipids that can be stored prior to dormancy. Consequently, the amount of available food and the duration and severity of dormancy period must be considered. In previous studies (see Derickson, 1976) lipids remaining after dormancy were devoted to reproduction. Lipid cycling patterns are intimately associated with seasonal changes in food availability. Previous studies have considered females 
of primarily insectivorous lizard species. As herbivores, female $\underline{S}$. obesus are confronted with a pattern of seasonal food availability that is temporally limited (Ch. I - Climate and Vegetation). For Colorado Desert populations, most feeding occurred late winter through spring and in late summer. Frequently, because of inadequate summer precipitation, the latter feeding period did not occur. However, even when food was abundant in the summer the corpora adiposa of most female S. obesus showed little growth. Nonetheless, body weights were known to increase at this time. Consequently, while lipids might be deposited in body tissues whenever food is available, only in the spring are lipids apportioned specifically for growth of corpora adiposa. The fact that corpora adiposa of female $\underline{S}$. obesus did not show a significant decline in size over winter provides further evidence that this lipid depot probably served primarily a reproductive function. The summer deposition of lipids elsewhere possibly serves as a postoviposition and/or dormancy maintenance function. Energy available from plant material is limited (see Pough, 1973), and since standing crop of vegetation in the summer was usually significantly less than in the spring, it is not surprising that the lipid cycling pattern of female $\underline{S}$. obesus - e.g., reduced corpora adiposa in summer - does not conform to those seen in other temperate lizards. Male $\underline{S}$. obesus, which demonstrated a different lipid cycling pattern - e.g., increased size of summer corpora adiposa - also did not conform to the plan typical for other males of temperate species (see below). For Colorado Desert females, there was a correlation between lipid cycling pattern and life history. Life histories should evolve to 
maximize the sum of present reproductive success plus probable future reproductive success (Williams, 1966). The key to maximizirg this sum is the postulated tradeoff between "present" and "future" components. The decision when to reproduce must take into consideration how expenditure on reproduction affects an organisms' chance of survival to next breeding and subsequent growth rate which should enhance later reproduction. Life history theory predicts that the form of this tradeoff between current "profits" and future "losses" is a prime evolutionary determinant of life history parameters (Stearns, 1976). In this study, observation of seasonal changes in weight and body size (survival and growth) on the one hand and seasonal changes of corpora adiposa (reproduction) on the other enabled some assessment of the tradeoff in energy expenditure between present and future components. When food was abundant the following sequence of events occurred. In early spring, energy was largely devoted to maintenance and growth; while there were abrupt gains in body size (SVL) and weight, the growth of corpora adiposa was more gradual. In late spring, after most growth had occurred, corpora adiposa suddenly increased in size rapidly. However, the timing of the breeding cycle was highly snychronized (Ch. 3 - Breeding Snychrony). During years when food availability was severely limited, apportionment of energy to such a parameter as growth was slowed causing a delay in the development of corpora adiposa. Such a situation frequently led to postponement of reproduction. The energy of enlarged corpora adiposa in nonreproductive female $\underline{S}$. obesus was channeled elsewhere, probably for maintenance. A similar observation for Mojave Desert $\underline{S}$. obesus was reported by Case (1976). He stated 
that in years when reproduction failed to occur, very large corpora adiposa were present. Consequently, initial energy utilization was concerned with satisfying maintenance and growth requirements, thereby helping to ensure future reproductive success, and only secondarily concerned with reproduction. Such a sequence of events complied with observed life history attributes of Colorado Desert $\underline{S}$. obesus (Ch. 4\&5Life History and Demography).

Life histories evolve to maximize present and future reproduction (Williams, 1966). Life histories and lipid cycling patterns are strong1y correlated (Derickson, 1976). For female lizards, considering topics such as other sources of lipid storage (liver, carcass, tail, etc.), growth rates, and reproductive effort during different levels of food availability will enhance the understanding of life histories. For female $\underline{S}$. obesus, growth rates and reproductive effort are considered below in Ch. 4 under Reproductive Frequency and Reproductive Effort. Consideration of other lipid stores is an objective of future investigations.

\section{MALE REPRODUCTIVE CYCLE}

Previous reports on the reproductive cycle of male $\underline{S}$. obesus were limited to testicular examination - specifically gross testicular volume (Berry, 1974), or gross testicular weight and histological analysis of seminiferous tubules (Johnson, 1965). Previous reports did not provide a thorough account of establishment of reproductive maturity and attendant seasonal fluctuations in testis size and seminiferous 
activity. Such information is essential to determining the energetic limitations on male reproduction which might have impact on life history tactics. This investigation of the reproductive cycle for Colorado Desert male $\underline{S}$. obesus clearly qualified reproductive maturity and seasonal fluctuation in testis size, seminiferous activity, reproductive tract activity and corpora adiposa size. Specific questions included: 1) In what ways can male reproductive maturity be accurately determined? 2) What are the stages of spermatogenesis and when do they occur? 3) How do changes in the reproductive tract correspond to the events of the testicular cycle? 4) With regard to corpora adiposa, what kind of cycling pattern persists for this form of lipid reserve?

In Colorado Desert males, the volumes of the two testes did not differ significantly from each other. Therefore, only the left testis is considered in this report. The testis volume of males increased markedly during the breeding season (Fig. 26a \& b). Mottling of the testis surface indicated greatly convoluted seminiferous tubules. Outside of the breeding season, the testes appeared deflated, relatively small and without a mottled surface (seminiferous tubules could not be seen).

There was no significant correlation between testis volume and body size early in the breeding season, but as shown in Figure 27a strong correlation existed during the height of the breeding season $(r=0.74, N=14, P<0.001)$. Maximum testis volumes (Fig. 28a \& b) in male $\underline{S}$. obesus were not significantly different for any of the years. However, the timing of maximum volumes did vary from year to year. Maximum volumes occurred during the last half of May. Minimum volumes 
Figure 26a. 1978 seasonal change in reproductive characteristics of adult male $\underline{S}$. obesus. Circles = mean testis volume; triangles = percent stage 6 (mature) seminiferous epithelium; squares $=$ percent with motile sperm at terminal vas deferens; numbers - sample sizes. 


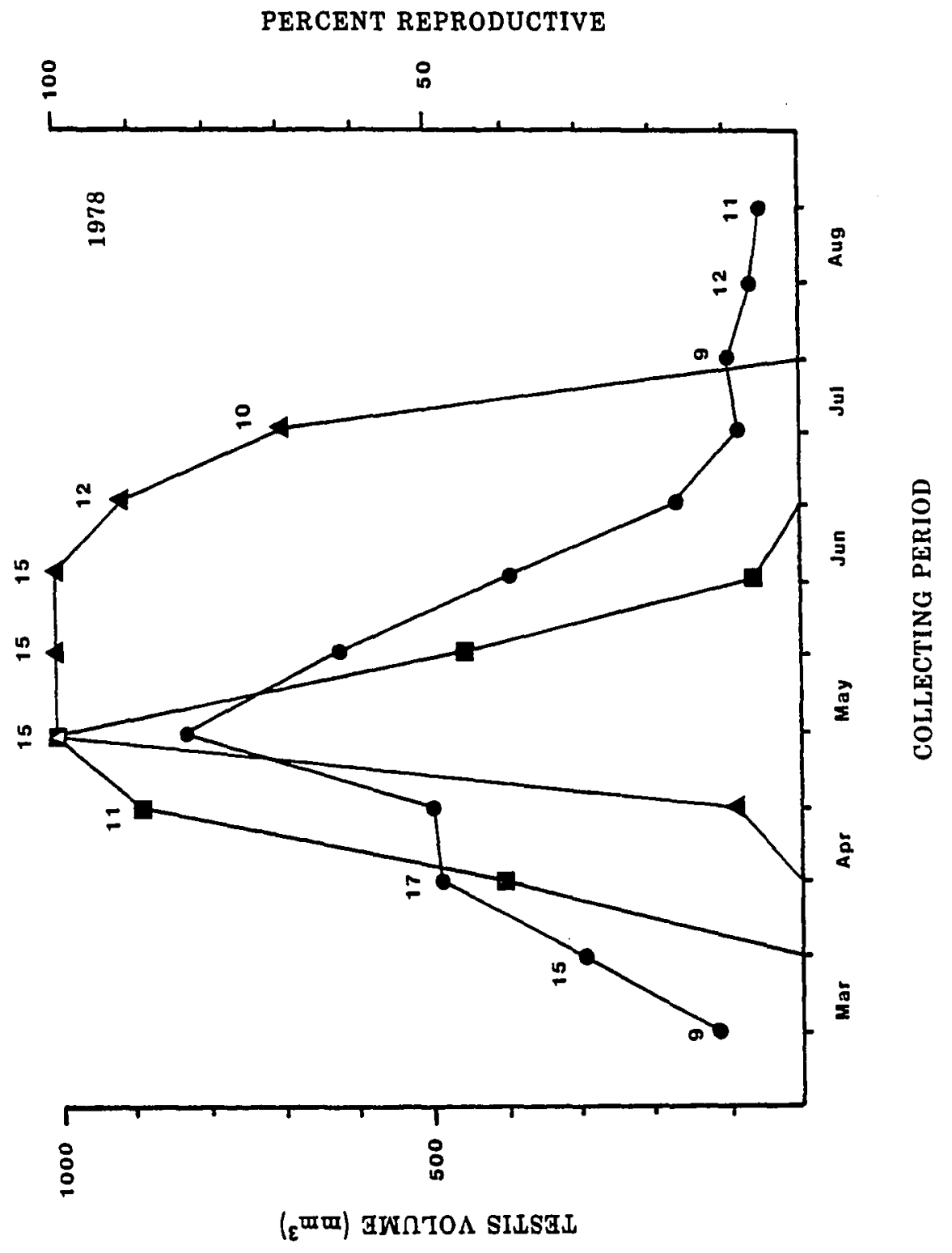


Figure 26b. 1979 seasonal change in reproductive characteristics of adult male $\underline{S}$. obesus. Description same as $26 a$. 
PERCENT REPRODUCTIVE

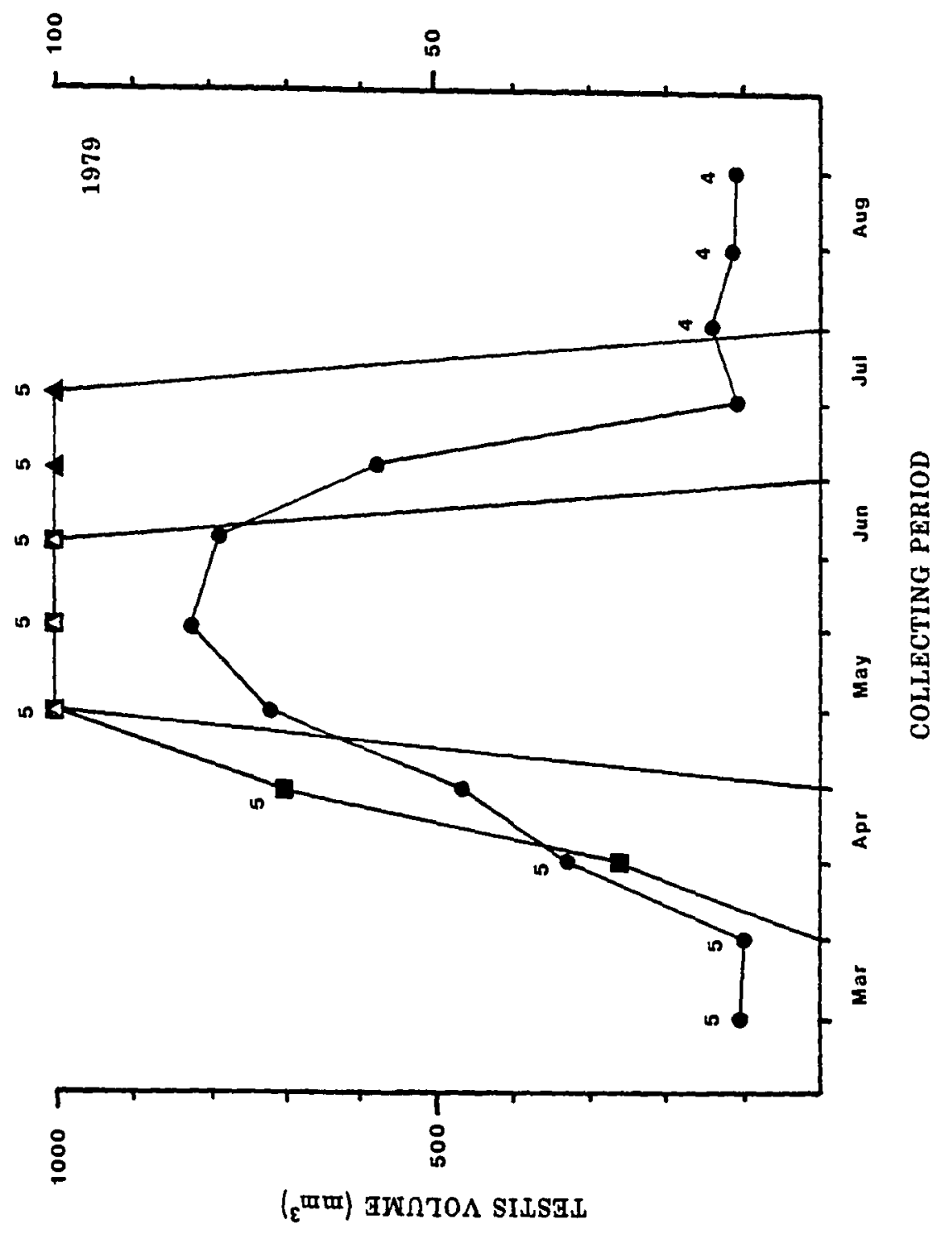


Figure 27. The correlation of testis volume and body size during the 1978 peak breeding season for adult male $\underline{\text { S }}$. obesus. Note: $204 \mathrm{~mm}$ SVL male with testis volume 2340 not shown in figure. 


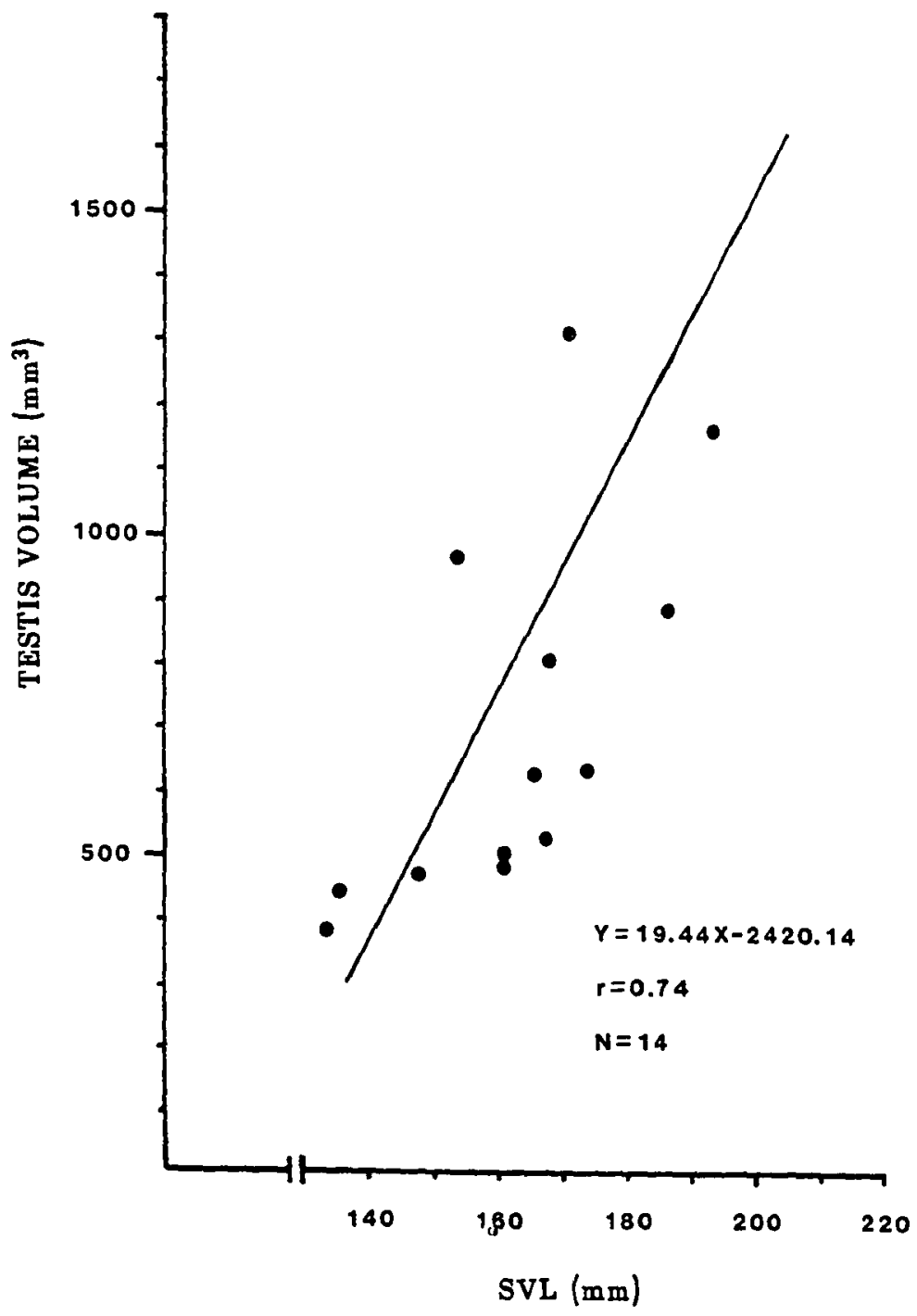


Figure 28a. 1978 seasonal changes in mean testis volume of adult male $\underline{\text { S. }}$ obesus. Vertical lines indicate \pm 2 standard errors; numbers $=$ sample sizes. 


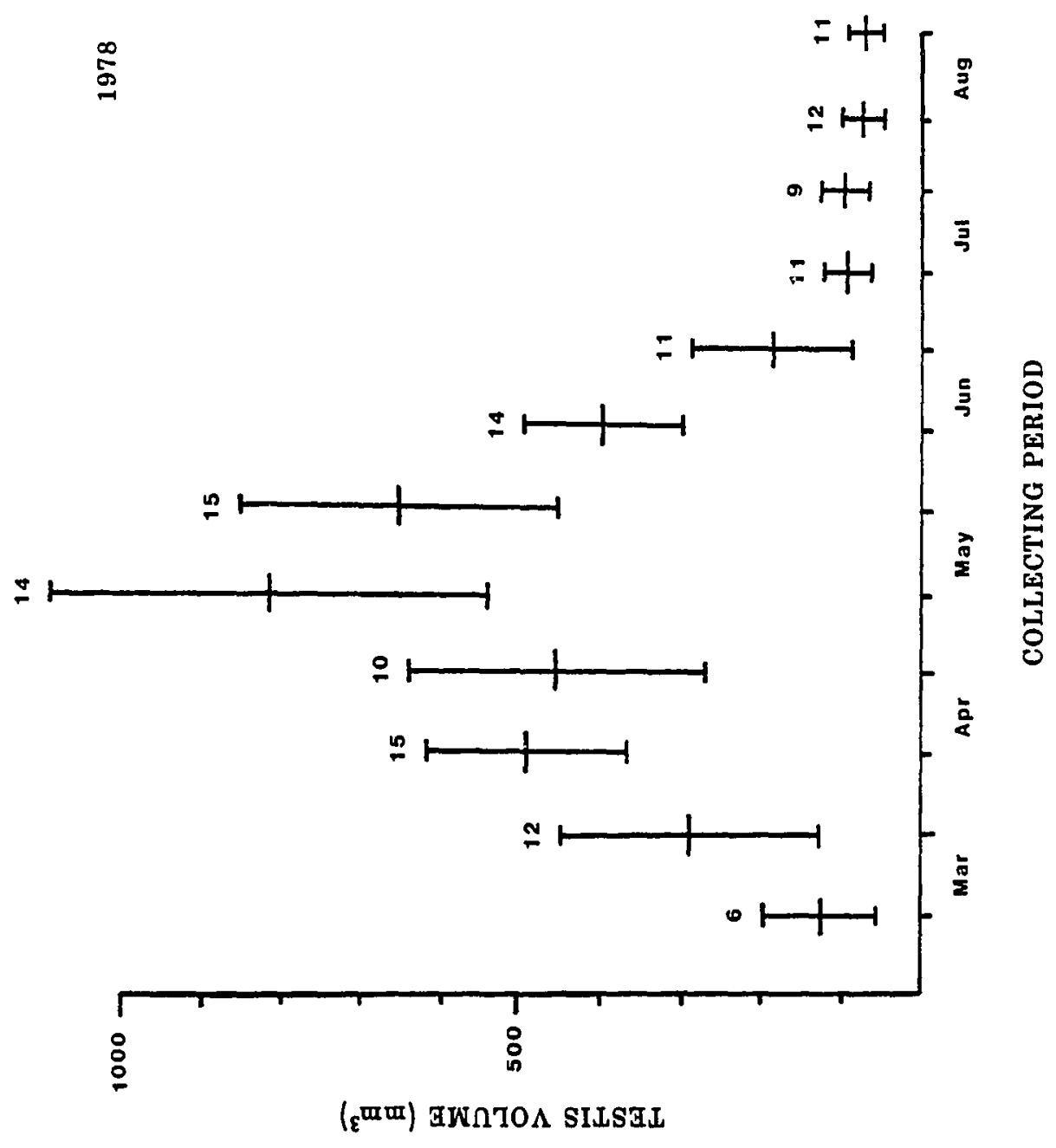


Figure 28b. 1979 seasonal changes in mean testis volume of adult male $\underline{S}$. obesus. Vertical lines indicate \pm 2 standard errors; numbers $=$ sample sizes. 


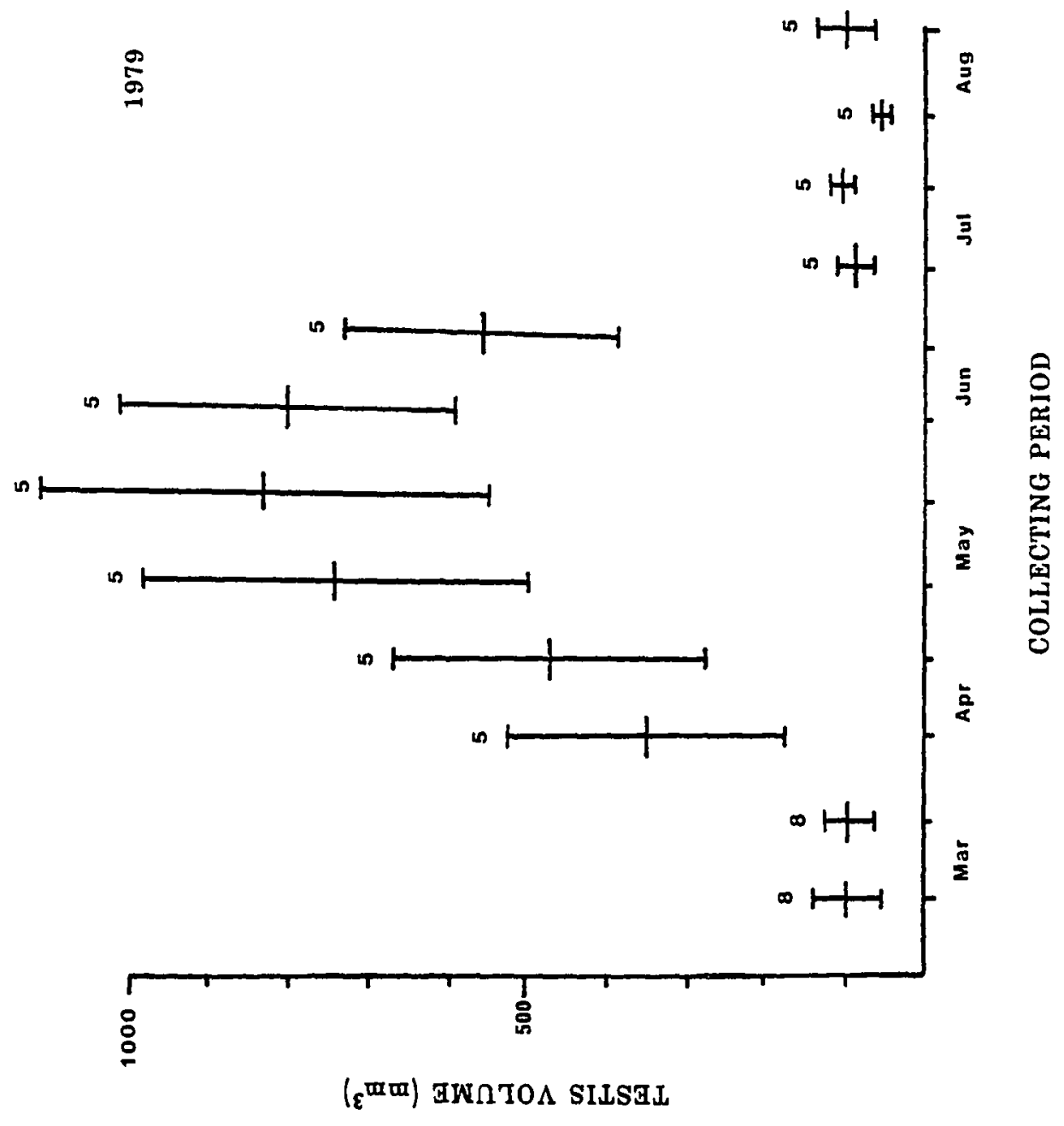


generally occurred in late August, but variation at this time was such that the late August mean volume for 1979 was significantly higher than that for 1978. Mid-March volumes, shortly after emergence from winter dormancy, were not significantly different from those of late August of previous years.

Adult male $\underline{S}$. obesus possessed motile sperm at the terminal end of the vas deferens from late April to mid-July. However, after late June the number of sperm tails in the semen decreased. In early summer most of the sperm tails were no longer motile. In 1978 through 1980 motile sperm were found at the terminal end of the vas deferens in all individuals of SVL greater than $125 \mathrm{~mm}$. Individuals of SVL less than $125 \mathrm{~mm}$ never possessed motile sperm at the terminal end of the vas deferens. Consequently, all individuals larger than $125 \mathrm{~mm}$ SVL were considered potential breeders (Fig. 26a \& b).

The stages of spermatogenesis are shown in Table XXXII. With slight variation, spermatogenic activity in adult male $\underline{S}$. obesus complied with the 8 stages of Mayhew and Wright (1970). A continuous wave of development from spermatogonia to mature sperm was observed. However, certain stages were of longer duration than others.

The histology of spermatogenic activity is shown in Figure 29a through $f$. Stage 1 was best characterized by the abundance of dividing spermatogonia. In most sections, several Sertoli cells were easily distinguished. Lumina of seminiferous tubules usually contained some cellular debris but remained largely unoccluded. In stage 2, primary spermatocytes were dominant at the luminal margin. Variable in appearance, due to different states of activity of the chromatin, this cell 
TABLE XXXII

EIGHT STAGES OF SPERMATOGENESIS FOR MALE $\underline{S}$. obesuS (ACCORDING TO MAYHEW AND WRIGHT, 1970)

\begin{tabular}{ll}
\hline I Dividing Spermatogonia \\
2 Primary Spermatocytes \\
3 Secondary Spermatocytes \\
4 Undifferentiated Spermatids \\
5 Metamorphosing Spermatids \\
6 Mature Sperm \\
7 Early Regression \\
8 Complete Regression \\
\hline
\end{tabular}


Figure 29a. Cross section of seminiferous tubule of male $\underline{S}$. obesus $(430 \mathrm{X})$, indicating stage 1 spermatogenic activity. The following features are shown: spermatogonia (a); sertoli cell (b); and intersitial cells (c). 


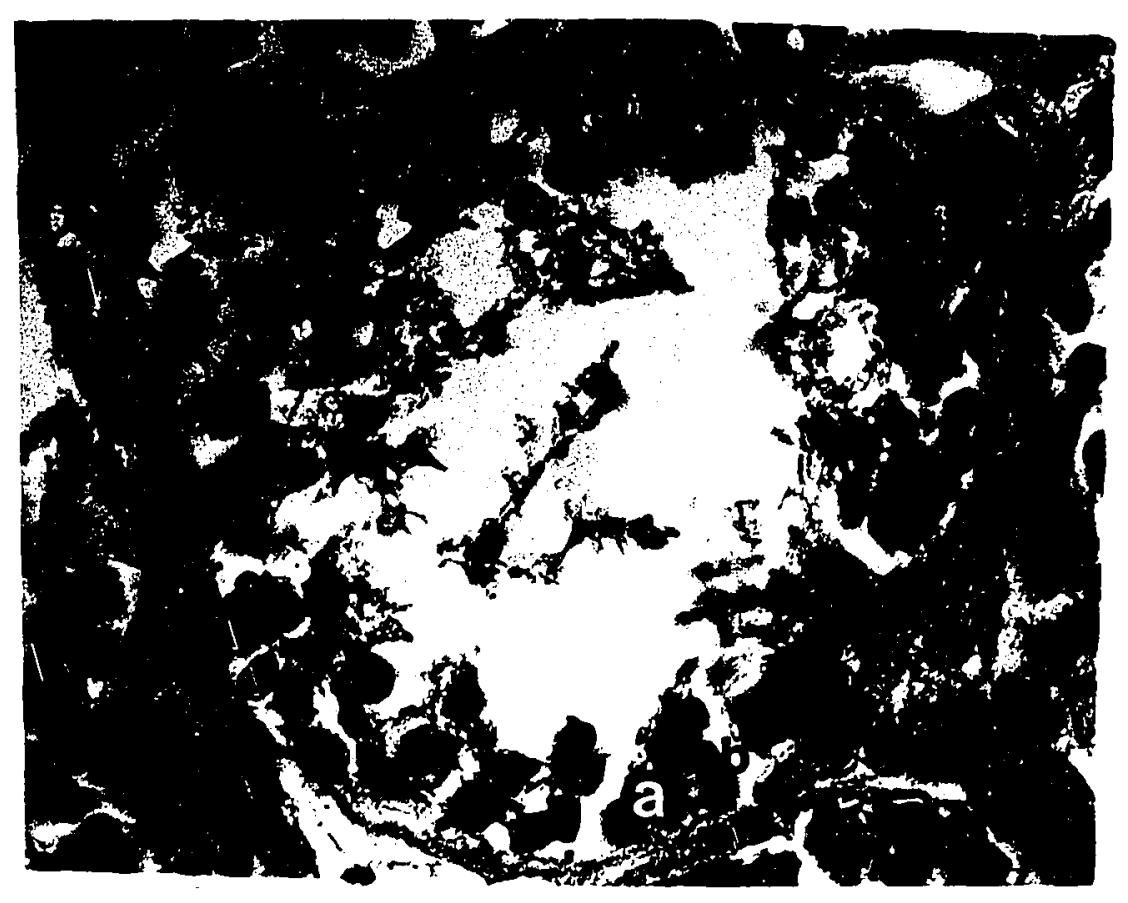


Figure 29b. Cross section of seminiferous tubule of male $\underline{S}$. obesus $(430 \mathrm{X})$, indicating stage 2 spermatogenic activity. The predominant seminiferous cells are primary spermatocytes (a). 


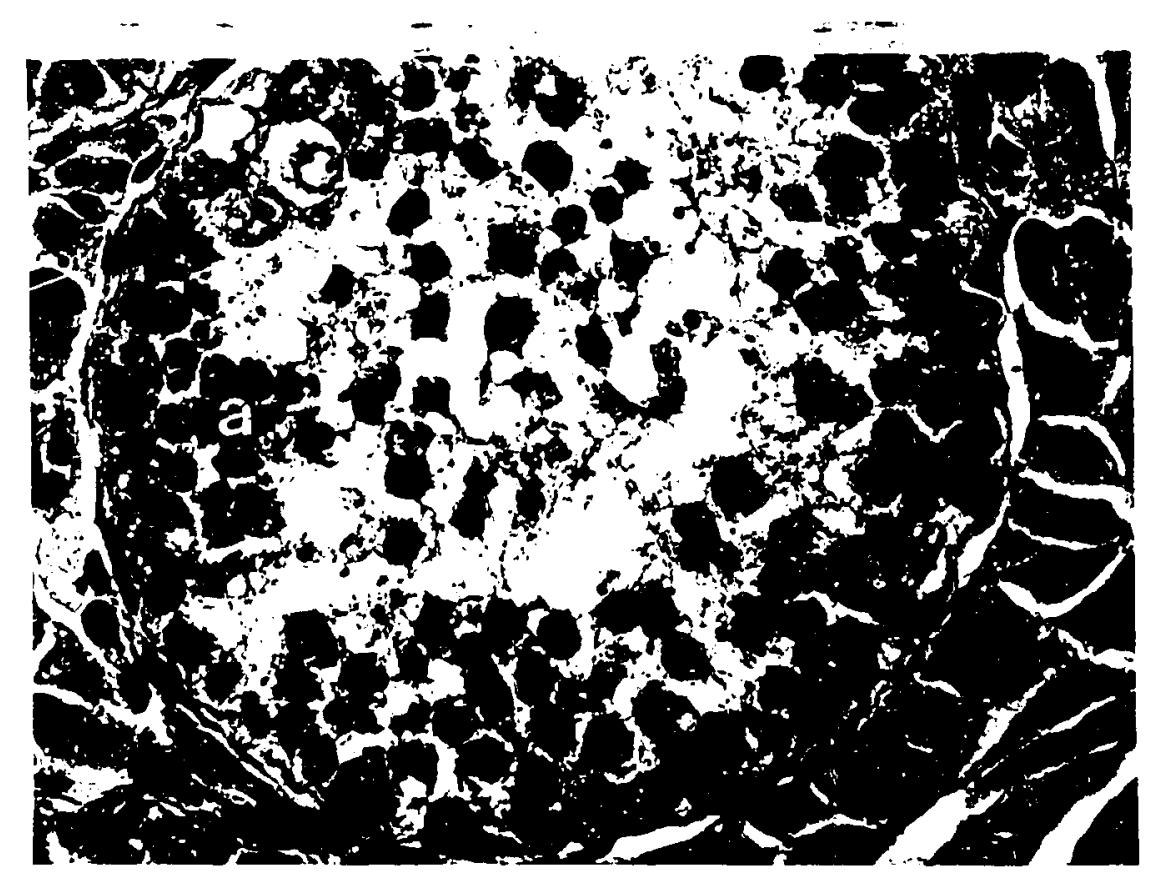


Figure 29c. Cross section of seminiferous tubule of male $\underline{S}$. obesus (430X), indicating stage 4 spermatogenic activity. The following features are shown: primary spermatocytes (a); secondary spermatocytes (b); and undifferentiated spermatids (c). 


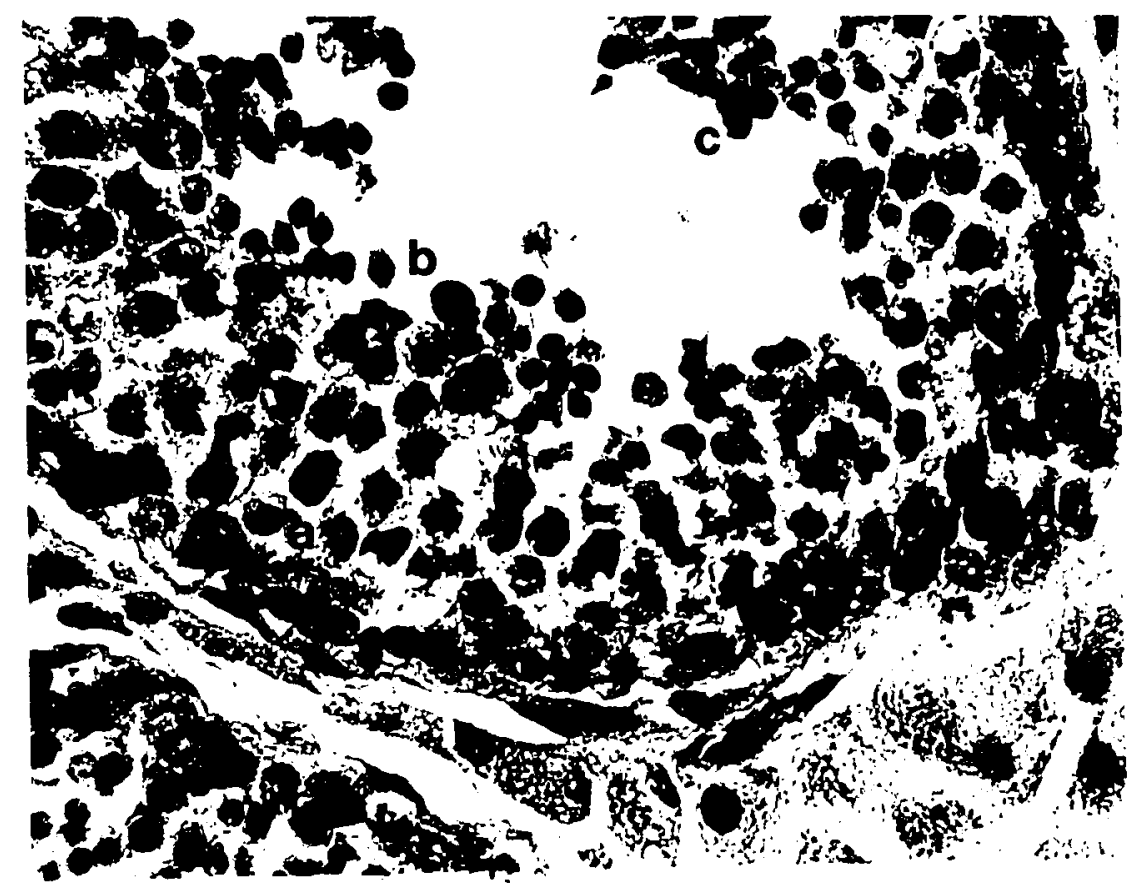


Figure 29d. Cross sections of seminiferous tubules of male $\underline{S}$. obesus $(100 \mathrm{X})$, indicating stage 6 spermatogenic activity. Note: mature sperm at luminal margins (a). 


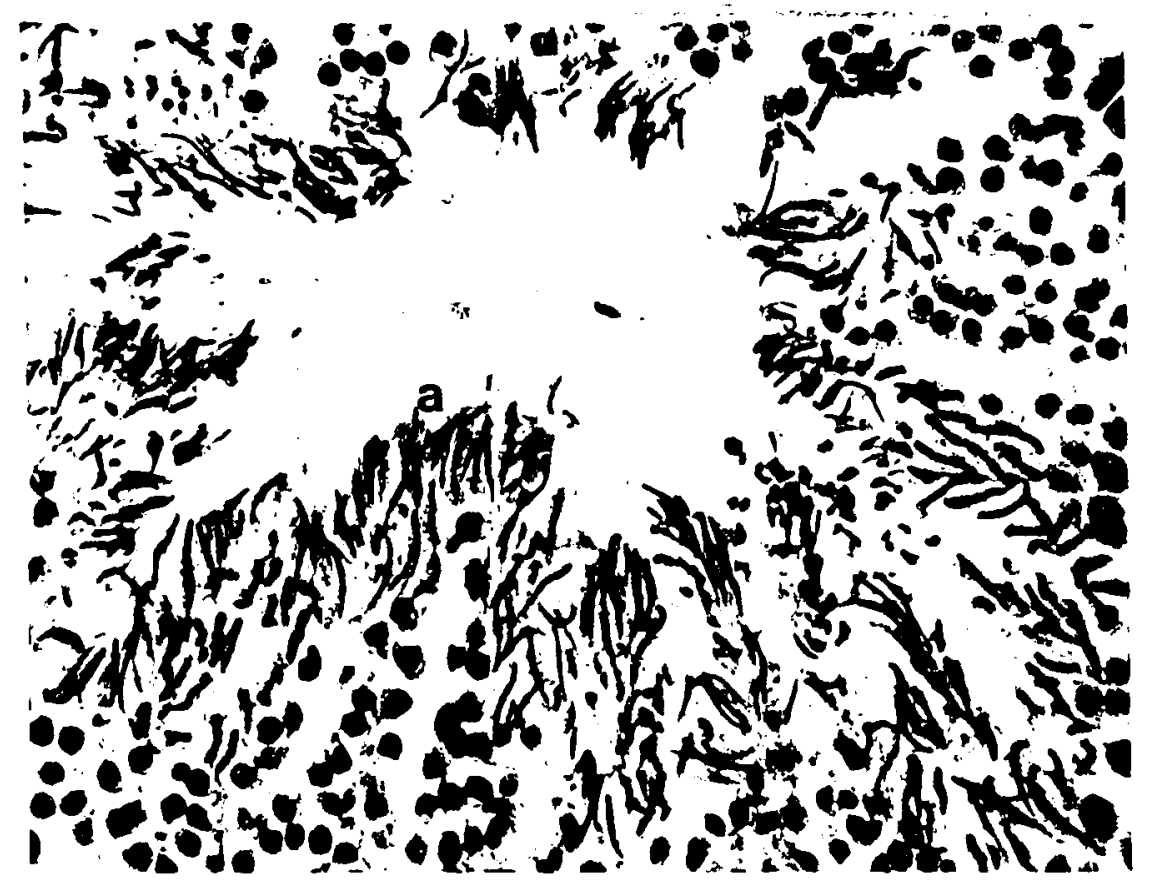


Figure 29e. Cross section of seminiferous tubule of male $\underline{S}$. obesus (430X), indicating stage 7 spermatogenic activity. The following features are shown: mature sperm (a); metamorphosing spermatids (b); undifferentiated spermatids (c). Note: seminiferous cellular debris among sperm. 


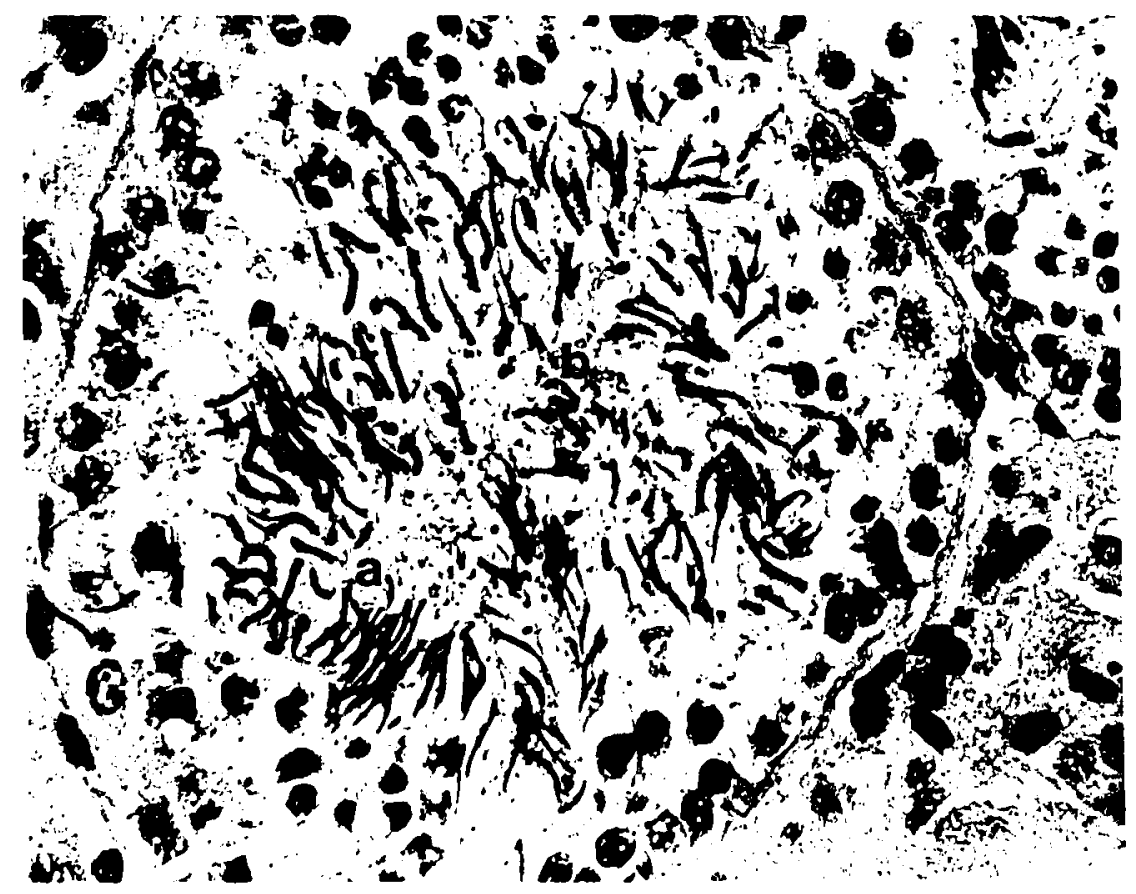


Figure 29f. Cross section of seminiferous tubule of male $\underline{S}$. obesus (430X), indicating stage 8 spermatogenic activity. Note: presence of sertoli cells (a) and convoluted basement membrane (b). 


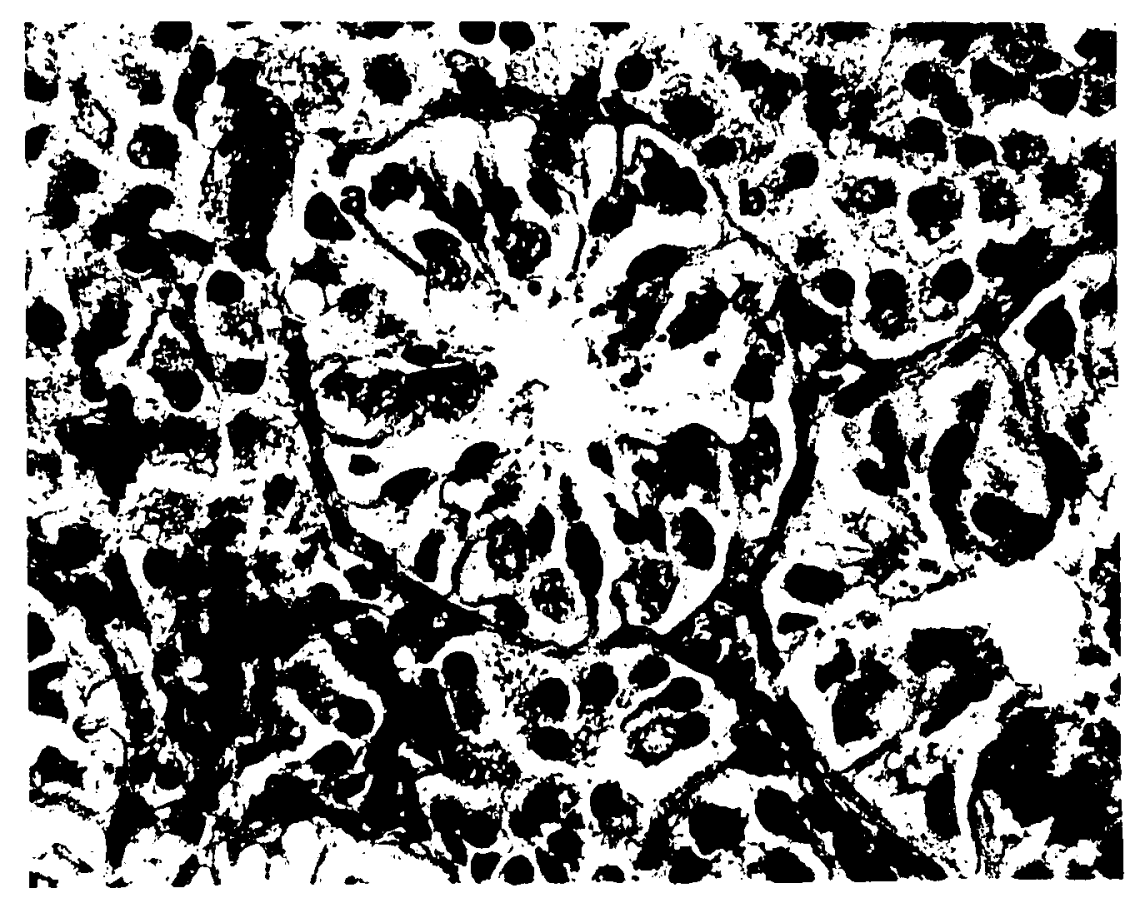


type was often observed to consist of several layers. Stage 3, charac terized by the presence of secondary spermatocytes at the luminal margin, was observed in only a few adult males. Compared to primary spermatocytes, this cell type was smaller and possessed less dense nuclear chromatin. Since lizards were autopsied at shorter intervals in this study than in most other studies, it appeared that individuals pass through this stage rapidly. Stages 4-6 showed the transition from undifferentiated spermatids to mature sperm at the luminal margin. Males in stage 6 were considered to be in full breeding condition (Fig. $26 a \& b)$. This conclusion was reinforced by the presence of motile sperm at the terminal end of the vas deferens in all stage 6 individuals. Stages 7 and 8 were characteristic of early and complete regression, respectively. In early regression, seminiferous tubule lumina contained varying amounts of cellular debris. The dissolving epithelium displayed many of the cell types characteristic of earlier stages. Less advanced stages disappeared first. In most individuals the lumina did not become completely obliterated. Complete regression was characterized by seminiferous tubules displaying a convoluted basement membrane, an epithelium one cell layer in thickness, and distinct Iumina most containing little cellular debris. Sertoli cells were the most abundant cell type present. Nondividing spermatogonia were frequently observed. Seasonal change in spermatogenic activity is shown in Table XXXIII.

During the height of the breeding season, immature males ( $S V L<125 \mathrm{~mm}$ ) remained at stage 1 (Fig. 29a). Generally, they possessed fewer dividing spermatogonia than adults in this stage. 
TABLE XXXIII

BIMONTHLY SPERMATOGENIC ACTIVITY IN ADULT MALE $\underline{S}$. obesus. NUMBERS INDICATE THOSE LIZARDS OF A PARTICULAR STAGE

\begin{tabular}{|c|c|c|c|c|c|c|c|c|c|c|c|c|c|}
\hline Stage & & $\begin{array}{l}\text { Mid } \\
\text { Mar }\end{array}$ & $\begin{array}{l}\text { Late } \\
\text { Mar }\end{array}$ & $\begin{array}{l}\text { Mid } \\
\text { Apr }\end{array}$ & $\begin{array}{l}\text { Late } \\
\text { Apr }\end{array}$ & $\begin{array}{l}\text { Mid } \\
\text { May }\end{array}$ & $\begin{array}{l}\text { Late } \\
\text { May }\end{array}$ & $\begin{array}{l}\text { Mid } \\
\text { Jun }\end{array}$ & $\begin{array}{l}\text { Late } \\
\text { Jun }\end{array}$ & $\begin{array}{l}\text { Mid } \\
\text { Ju1 }\end{array}$ & $\begin{array}{l}\text { Late } \\
\text { Jul }\end{array}$ & $\begin{array}{l}\text { Mid } \\
\text { Aug }\end{array}$ & $\begin{array}{l}\text { Late } \\
\text { Aug }\end{array}$ \\
\hline 1 & & 6 & & & & & & & & & & & \\
\hline 2 & & & 6 & & & & & & & & & & \\
\hline 3 & & & 1 & & & & & & & & & & \\
\hline 4 & & & 5 & 7 & & & & & & & & & \\
\hline 5 & & & & 2 & 1 & & & & & & & & \\
\hline 6 & & & & 5 & 10 & 13 & 7 & 1 & & & & & \\
\hline 7 & & & & & & & 8 & 12 & 3 & & & & \\
\hline 8 & & & & & & & & & 8 & 12 & 9 & 10 & 9 \\
\hline & Number & 6 & 12 & 14 & 11 & 13 & 15 & 13 & 11 & 12 & 9 & 10 & 9 \\
\hline
\end{tabular}


The relationship of stages of the spermatogenic cycle with seminiferous tubule diameter and seminiferous epithelial height is shown in Table XXXIV. It is not surprising that both of these measurements were mostly reduced during complete regression and expanded during the presence of mature sperm. Seasonal changes for 1978 and 1979 in mean seminiferous tubule diameter and epithelial height of male $\underline{S}$. obesus were similar (Fig. 30a through d). Both increased gradually from the beginning of the activity season (mid=March) to late spring and decreased through summer. Epithelial height decreased very rapidly. Maximum diameters and epithelial heights occurred from mid-May (1978) through mid-June (1979). Minimum diameters and epithelial heights occurred in August. However, a slight, though insignificant, increase in both occurred in late August of 1979. From 1978 through 1980, neither maximum diameters and epithelial heights nor minimum diameters and epithelial heights differed significantly. Between late August 1978 and mid-March 1979, a period of inactivity, seminiferous tubule diameter increased significantly. While there was a corresponding increase in epithelial height, the change was not significant. Diameters and epithelial heights in mid-March of 1978 and 1979 were not significantly different.

The correlation of seasonal change in testis size with spermatogenesis has been widely reported (Mayhew, 1963, 1971; Bostic, 1966; Goldberg and Lowe, 1966; Licht, 1970; Mayhew and Wright, 1970; Goldberg, 1971, 1972b, 1975a, 1976; Christiansen, 1971; Vitt, 1973; Goldberg, and Bezy, 1974; Vitt et. al., 1978; Trauth, 1979). These studies and others have shown that 3 major types of testicular cycles can be dis- 
TABLE XXXIV

RELATIONSHIP OF STAGES OF SPERMATOGENIC CYCLE WITH SEMINIFEROUS TUBULE DIAMETER AND SEMINIFEROUS EPITHELIAL HEIGHT IN MALE $\underline{\mathrm{S}}$. obesus. $\mathrm{N}=$ NUMBER OF INDIVIDUALS

\begin{tabular}{crrcrcc}
\hline & & \multicolumn{2}{c}{$\begin{array}{c}\text { Seminiferous Tubule } \\
\text { Diameter }\end{array}$} & & \multicolumn{3}{c}{$\begin{array}{c}\text { Seminiferous Epithelia1 } \\
\text { Height }\end{array}$} \\
\hline Stage & $\mathrm{N}$ & $\overline{\mathrm{x}} \pm 1 \mathrm{~s} . \mathrm{e}$. & Range & $\mathrm{N}$ & $\overline{\mathrm{x}} \pm 1$ s. e. & Range \\
\hline 1 & 29 & $109.8 \pm 3.1$ & $75.2-141.4$ & 28 & $21.6 \pm 0.9$ & $11.4-32.2$ \\
2 & 9 & $149.7 \pm 10.0$ & $109.5-189.5$ & 9 & $38.2 \pm 4.5$ & $22.9-55.1$ \\
3 & 2 & $172.7 \pm 5.9$ & $166.7-178.1$ & 2 & $43.0 \pm 4.8$ & $38.0-47.6$ \\
4 & 19 & $193.4 \pm 10.0$ & $130.5-278.1$ & 18 & $60.5 \pm 3.8$ & $33.5-112.4$ \\
5 & 3 & $187.3 \pm 44.1$ & $124.8-272.4$ & 3 & $54.0 \pm 8.0$ & $42.9-69.5$ \\
6 & 52 & $266.2 \pm 7.7$ & $180.0-385.7$ & 54 & $91.1 \pm 2.5$ & $54.3-130.5$ \\
7 & 26 & $227.7 \pm 9.1$ & $155.2-294.3$ & 26 & $84.5 \pm 3.3$ & $46.0-106.7$ \\
8 & 64 & $92.6 \pm 2.8$ & $38.7-177.1$ & 64 & $23.2 \pm 0.6$ & $9.6-32.0$ \\
Immature & 8 & $85.0 \pm 6.8$ & $55.1-108.6$ & 8 & $17.5 \pm 2.3$ & $10.7-25.0$ \\
\hline \hline
\end{tabular}


Figure 30a. 1978 seasonal changes in mean seminiferous tubule diameter of adult male $\underline{S}$. obesus. Vertical lines indicate \pm 2 standard errors; numbers $=$ sample sizes. 


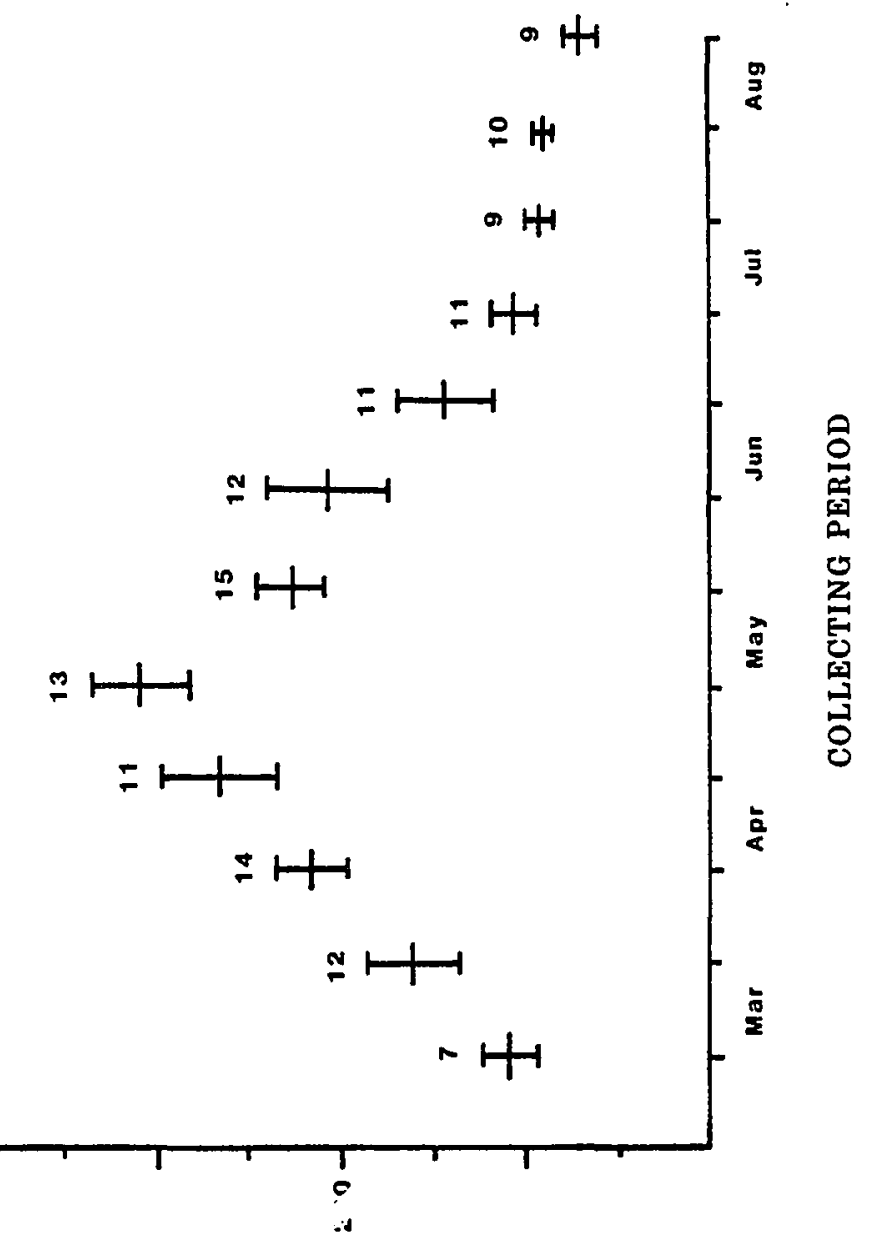

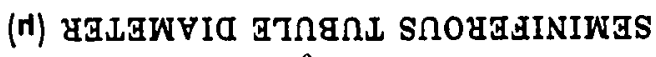


Figure 30b. 1979 seasonal changes in mean seminiferous tubule diameter of adult male $\underline{S}$. obesus. Vertical lines indicate \pm standard errors; numbers $=$ sample sizes. 


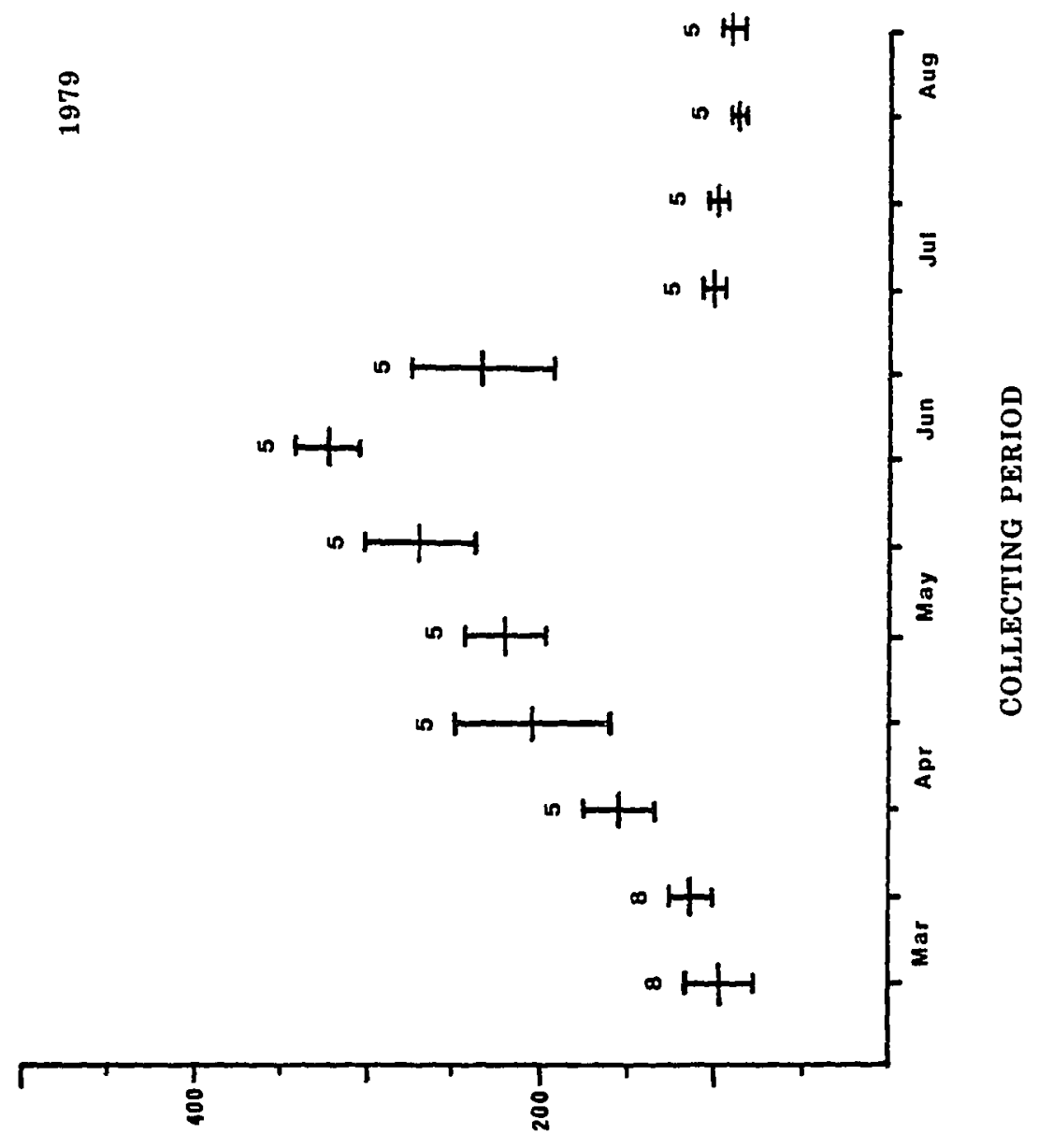

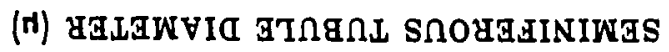


Figure 30c. 1978 seasonal changes in mean seminiferous tubule epithelial height of adult male $\underline{S}$. obesus. Vertical lines indicate \pm 2 standard errors; numbers = sample sizes. 


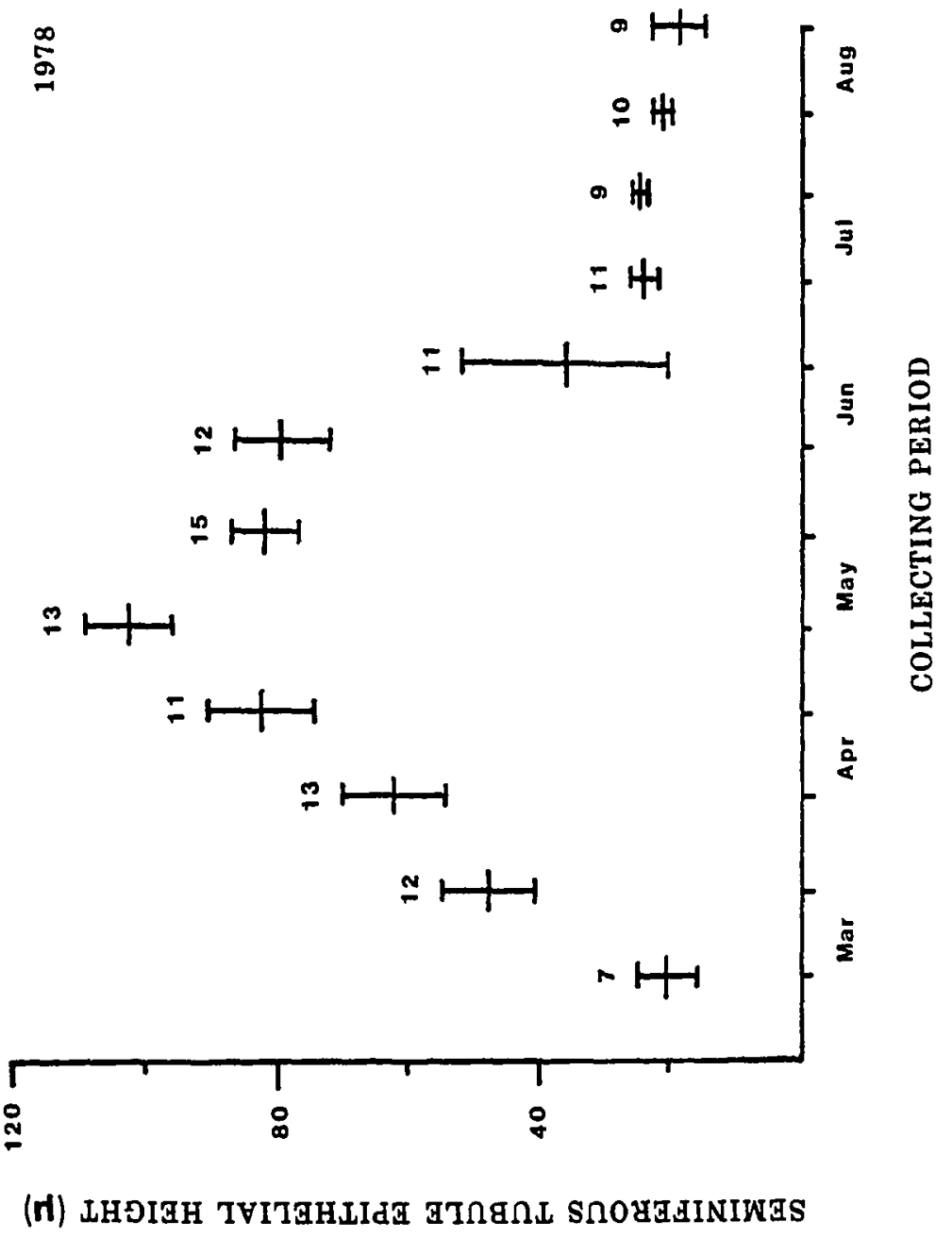


Figure 30d. 1979 seasonal changes in mean seminiferous tubule epithelial height of adult male $\underline{S}$. obesus. Vertical line s indicate \pm 2 standard errors; numbers $=$ sample sizes. 


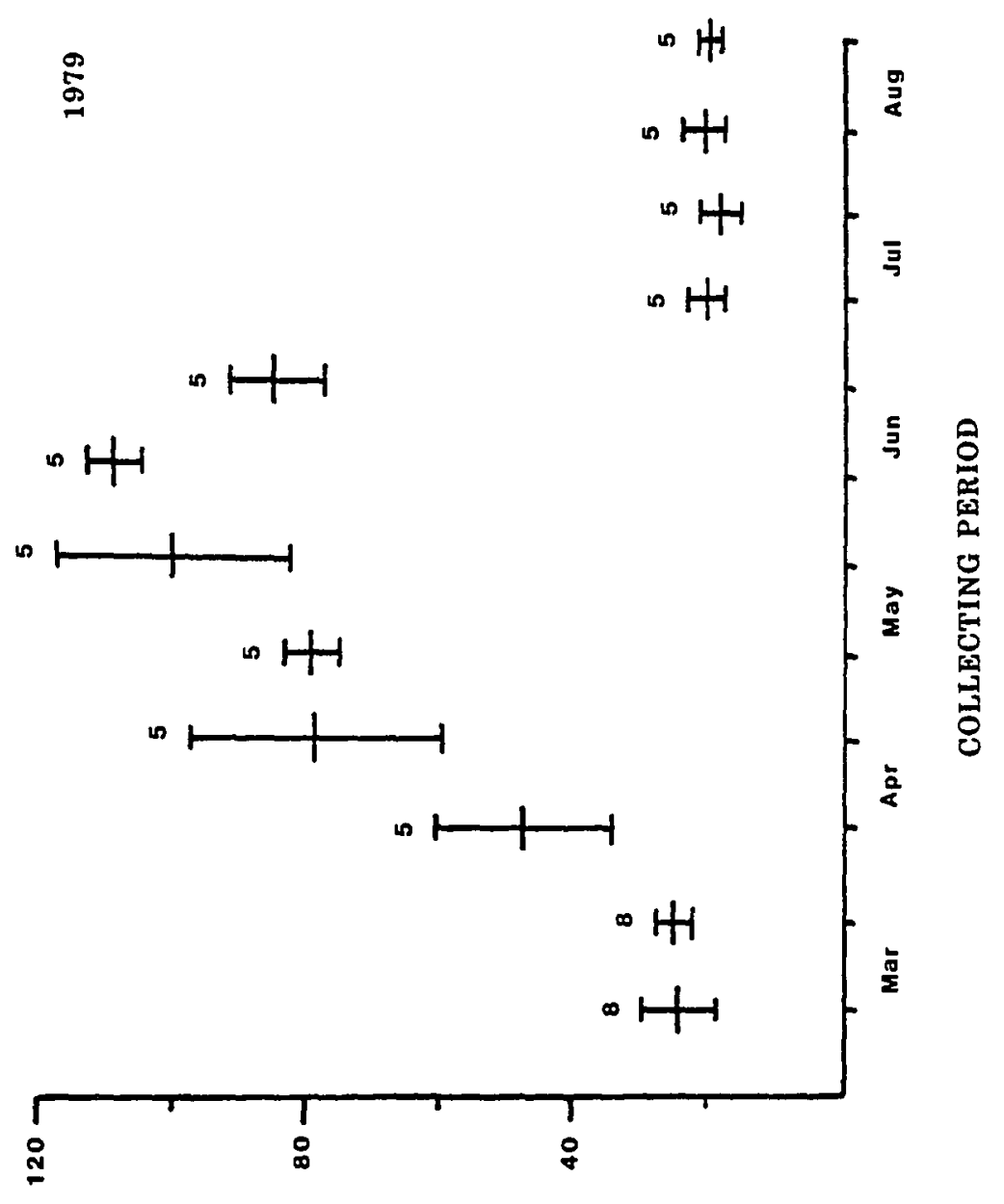

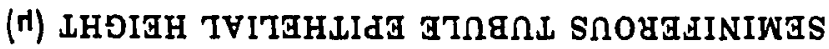


tinguished among lizards: 1) testes of maximum size at the time of emergence from winter dormancy; 2) testes of maximum size in late spring or early summer and 3) testes show no variation in size, and reproduction occurs throughout the year. Some investigators (Ballinger and Shrank, 1973; Newlin, 1976) have considered testicular cycle types to represent different amounts of energetic expenditure in an attempt to assess male reproductive effort. It has been postulated that the extent of energy devoted to spermatogenesis should be greatest in species that show no seasonal variation in size, intermediate in those with testes that are largest at the time of emergence from winter dormancy, and least, in species with testes at maximum size in late spring to early summer. In this study, for 3 consecutive years, adult male $\underline{S}$ - obesus emerged in the spring with testes only slightly larger than minimum size. Maximum size was achieved in late spring. Therefore, this species complies with type 2 testicular cycle and consequently, is categorized as not devoting a large amount of energy to spermatogenesis. Though spermatogenesis represents only a portion of the total amount of energy involved in male reproductive effort (Ballinger and Shrank, 1973 and Newlin, 1976), even if this type of testicular cycle apportioned relatively less energy to reproduction it would correspond to a number of life history attributes demonstrated by Colorado Desert S. obesus (Ch. 4 \& 5 - Life History \& Demography). Comparison of some aspects of the breeding cycle can be made with populations of $\underline{\text { S. obesus }}$ at some Mojave Desert localities. Testis size as an estimate of breeding condition was employed by Johnson (1965) and Berry (1974). Johnson showed maximum size by weight to occur in 
May; Berry showed maximum size by volume to occur from May through the first half of June. Berry arrived at this determination by pooling data for 135 individuals captured throughout the species geographical range over a 62-year period, whereas Johnson obtained his data from 18 individuals taken in one activity season in one locality. Consequent1y Johnson's data is most useful in making geographic comparisons. Nonetheless, both studies showed maximum testis size to occur at a time similar to that found in this study. Johnson (1965) also estimated breeding condition by the change in appearance of the seminiferous tubules. He found the diameters of seminiferous tubule lumina to be greatest in mid-May and counted the greatest number of sperm tails at this time. Both these findings coincided with maximum testis volume. Therefore, throughout much of the geographic range it appears that adult male $\underline{S}$. obesus breed in May through much of June. As for females, perhaps this indicates that the reproductive strategy of $\underline{S}$. obesus evolved under widespread predictable climatic conditions.' Johnson (1965) considered male $\underline{S}$. obesus with testes of maximum size to be potential breeders. In his study, only 9 of the 18 indviduals were in breeding condition. However, the majority of those not in breeding condition were captured after mid-June. In his May sample only small lizards lacked large testes. Others in the sample were probably potential breeders. Berry (1974) stated that only $83 \%$ of the individuals of SVL greater than $150 \mathrm{~mm}$ were potential breeders in May. Unfortunately, her sample was of great temporal and spatial diversity. Thus, Berry's observations were probably influenced by a variety of environmental conditions. In addition, she chose $300 \mathrm{~mm} 3$ 
as the minimum testicular size for mature adults. Her efforts did not include histological analysis of the seminiferous tubule epithelium. In this study, male $\underline{S}$. obesus with testis volumes as small as $125 \mathrm{~mm} 3$ possessed mature sperm at the luminal margin of the seminiferous tubules. Therefore, neither Johnson's nor Berry's studies provided evidence contrary to mine, which shows that under most environmental conditions all adult male $\underline{S}$. obesus are potential breeders. It appears that the reproductive condition of males was rarely restricted by limited food resources which is similar to data for adult males of several insectivorous lizard species (Mayhew, 1963; Mayhew and Wright, 1970).

Interstitial cells can be distinguished in testes of male $\underline{S}$. obesus the year round. Polyhedral in outline and possessing eccentric nuclei, they were most noticeable while producing eosinophilic cytoplasmic granules (Fig. 29a). Such cellular activity occurred from mid-March through June. Seasonal changes in mean interstitial cell diameter during 1978 and 1979 are shown in Figure 31a \& b. The cell diameter increased gradually from mid-March through late spring. In early summer cell diameter declined rapidly then leveled off the remainder of the activity season. Maximum diameter occurred from midMay in 1978 to mid-June in 1979. Minimum diameter occurred late July through August. Maximum interstitial cell diameter in 1978 and 1979 did not differ significantly from each other. Minimum interstitial cell diameters were significantly greater in 1979 than in 1978. In both years the diameters increased slightly but not significantly from July to late August. From late August 1978 to mid-March 1979, inter- 
Figure 3la. 1978 seasonal change in mean interstitial cell diameter of adult male $\underline{S}$. obesus. Vertical lines indicate \pm 2 standard errors; numbers $\equiv$ sample sizes. 


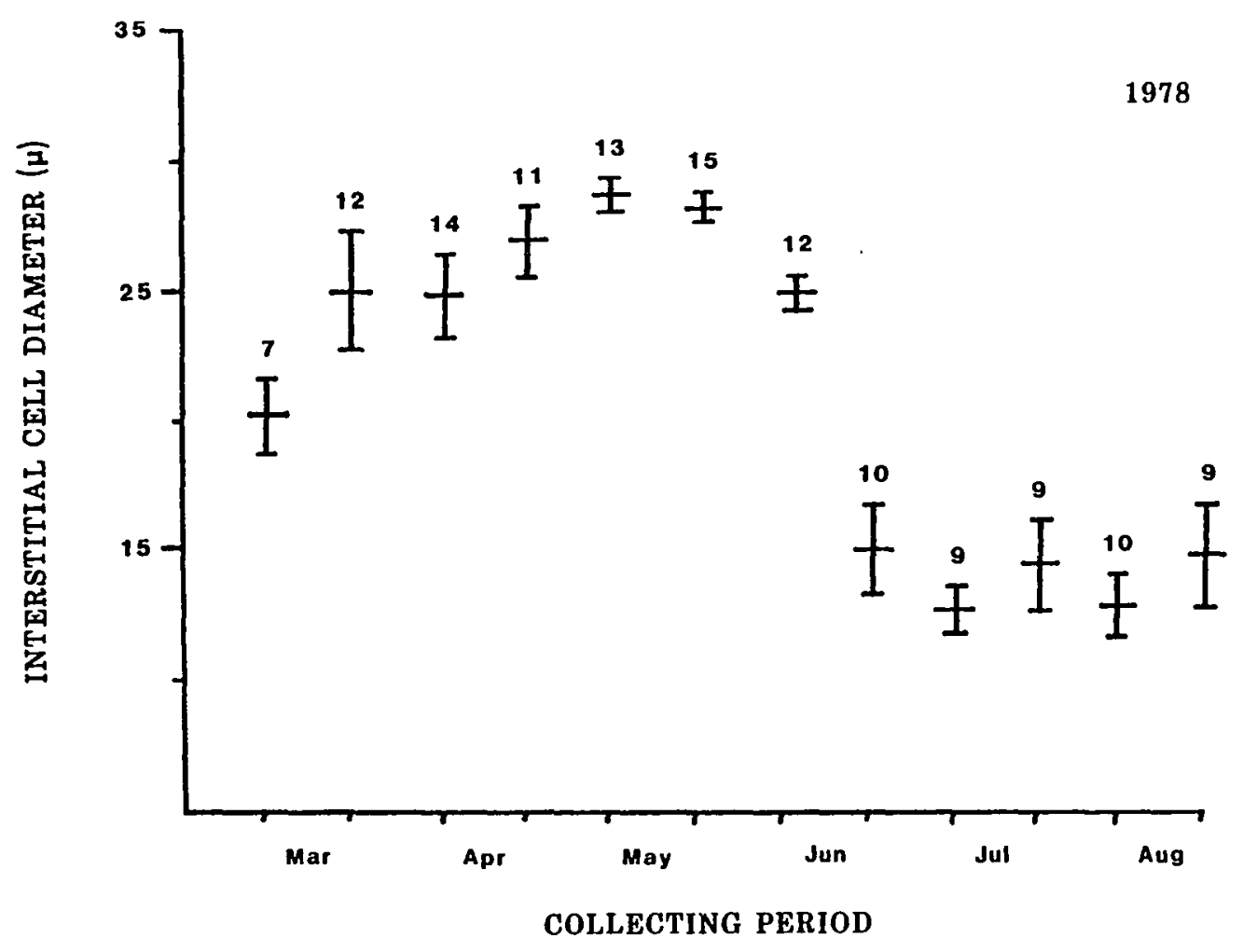


Figure 31b. 1979 seasonal change in mean interstitial cell diameter of adult male $\underline{S}$. obesus. Vertical lines indicate \pm 2 standard errors; numbers $=$ sample sizes. 


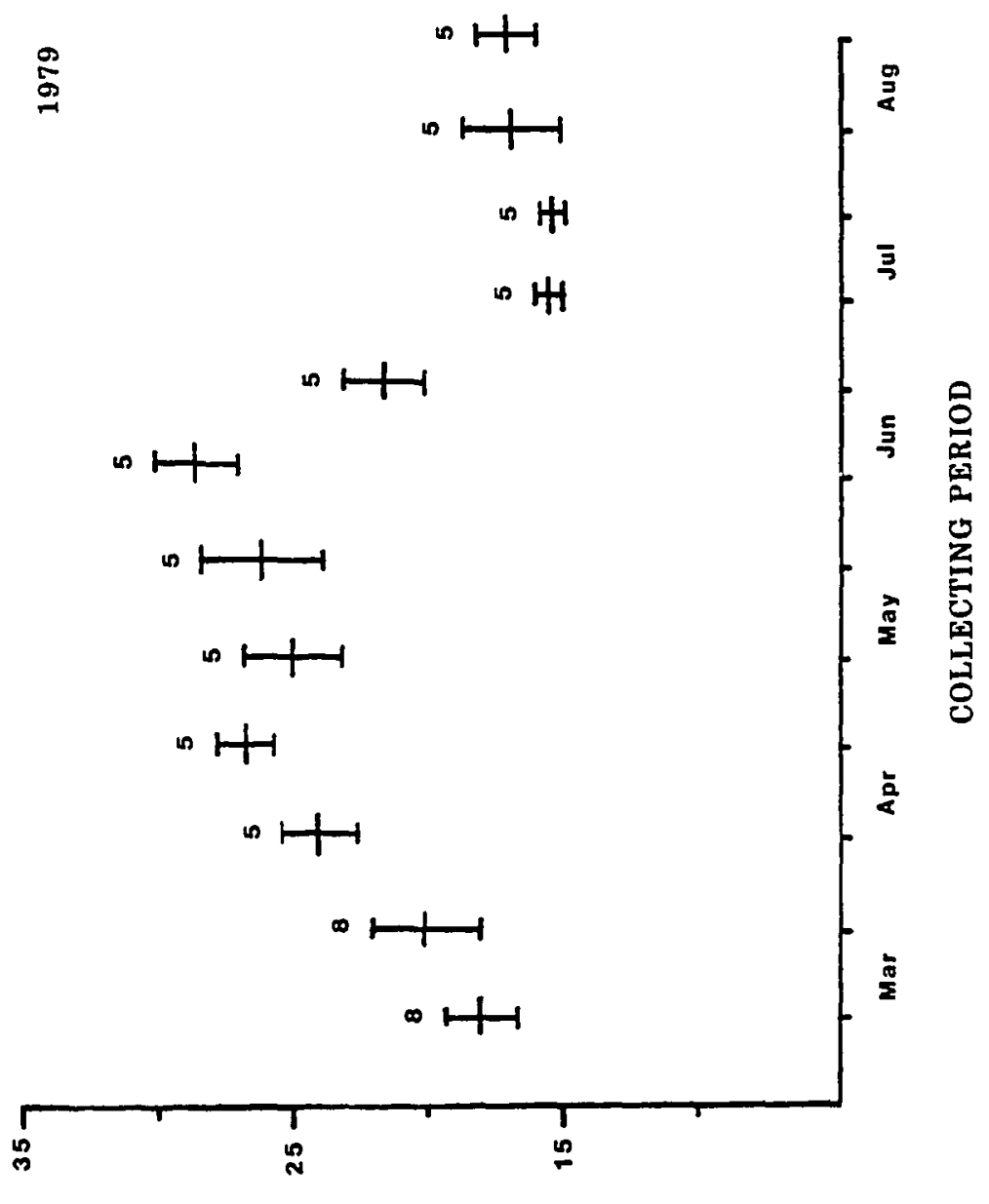

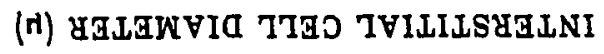


stitial cell diameter increased significantly. March diameters in 1978 and 1979 did not differ significantly from each other. The seasonal change in appearance and diameters of interstitial cells was the same for both immature and adult male $\underline{S}$. obesus. According to Fox (1977), interstitial cells are found between seminiferous tubules, occurring singly or in groups near blood vessels. Their shape is polyhedral, elongated or oval. Occasionally they form a syncytium. They have a large rounded nucleus and vacuolated or alveolar cytoplasm. Interstitial cells are present in most mature reptiles (Forbes, 1961). In lizards, they are few or absent in Sceloporus undulatus (Atland, 1941 and Fox, 1958), s. occidentalis (Wilhoft and Quay, 1961), Xantusia vigilis (Miller, 1948, 1963 and Goldberg and Beze, 1974) and Uma inornata, U. notata and U. Scoparia (Mayhew and Wright, 1970) but common in Ameiva undulata and several species of Cnemidophorus where they even form a circumtesticular tunic (Lowe and Goldberg, 1966). However, their size, number and appearance frequently varies with the season, which may explain why they are sometimes missed (Fox, 1977).

The interstitial cells are probably under control of pituitary hormones (Saint Girons, 1970). Interstitial cells probably secrete androgens, synthesized from cholesterol positive lipids, and their secretory cycle is generally synchronized not with spermatogenesis but with the development of secondary sexual characteristics such as external genitalia, glands, external coloration and courtship behavior (see Fox, 1952; Miller, 1959 and Bellairs, 1970). Their level of secretory activity has been estimated using criteria such as: 1) syncy- 
tial arrangement or change in volume (Blount, 1929; Fox, 1958; Wilhoft and Quay, 1961); 2) nuclear size and appearance (Hahn, 1964; Mayhew, 1971); 3) change in cell number (see Fox, 1977); and 4) changes in vacuolation and/or granulation of the cytoplasm (see Fox, 1977).

In male $\underline{S}$. obesus interstitial cells were always detectable in large numbers. A well-defined circumtesticular tunic was present. The cells appeared polyhedral and mononucleate. Because of increased size and the presence of eosinophilic cytoplasmic granulation, these cells were most obvious during the peak of the breeding season. Such criteria coincided with morphological and behavioral changes associated with the development of sexual characteristics. During the entire season of activity no corresponding changes in nuclear diameter and cell number was observed. Consequently, for male $\underline{S}$. obesus cell size and cytoplasmic appearance best indicated the level of secretory activity.

Seasonal changes in mean epididymal epithelial heights during 1978-79 are shown in Figure 32a \& b. At the start of the activity season the epithelial cells were simple ciliated columnar (Fig. 33a). Lumina usually contained secretory granules and mature sperm. In early sumner the epithelial height declined rapidly. Following the initial decline the epithelial cells were psuedostratified cuboidal (Fig. 33b). After mid-June lumina contained seminiferous cellular debris along with mature sperm. Both persisted in declining amounts through July. After mid-August most lumina were clear. Maximum heights of epididymal epithelium during 1978 and 1979 were significantly different from each other. They occurred from mid-May (1978) to mid-June (1979). Mini- 
Figure 32a. 1978 seasonal changes in mean epididymal epithelial height of adult male $\underline{S}$. obesus. Vertical lines indicate \pm 2 standard errors; numbers = sample sizes. 


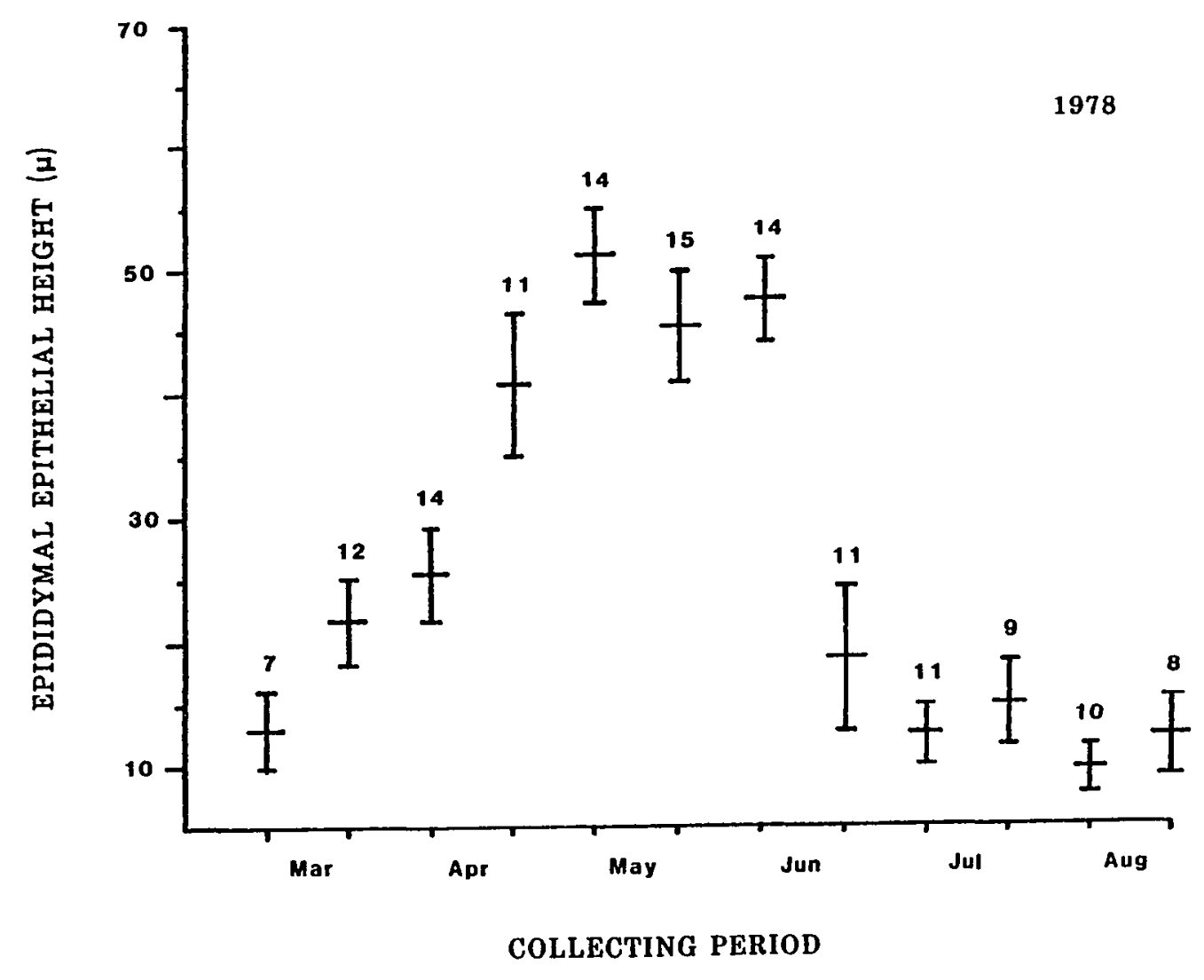


Figure 32b. 1979 seasonal changes in mean epididymal epithelial height of adult male $\underline{S}$. obesus. Vertical lines indicate \pm 2 standard errors; numbers $=$ sample sizes. 
$\underset{\pi}{2}$

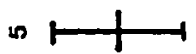

n

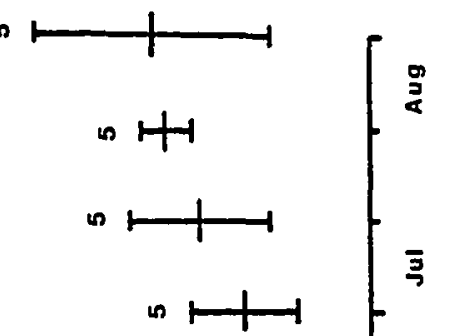

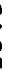

is 1
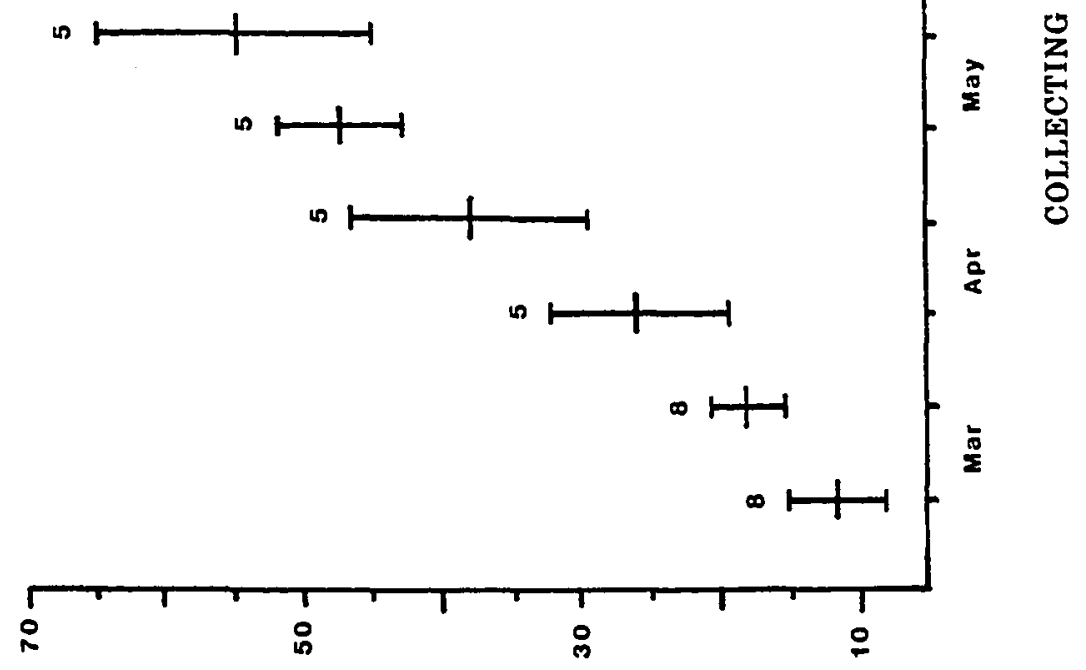

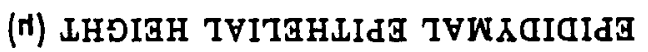


Figure 33a. Cross section of epididymis of male $\underline{S}$. obesus (100X). Note: regressed epithelium and clear lumina. 


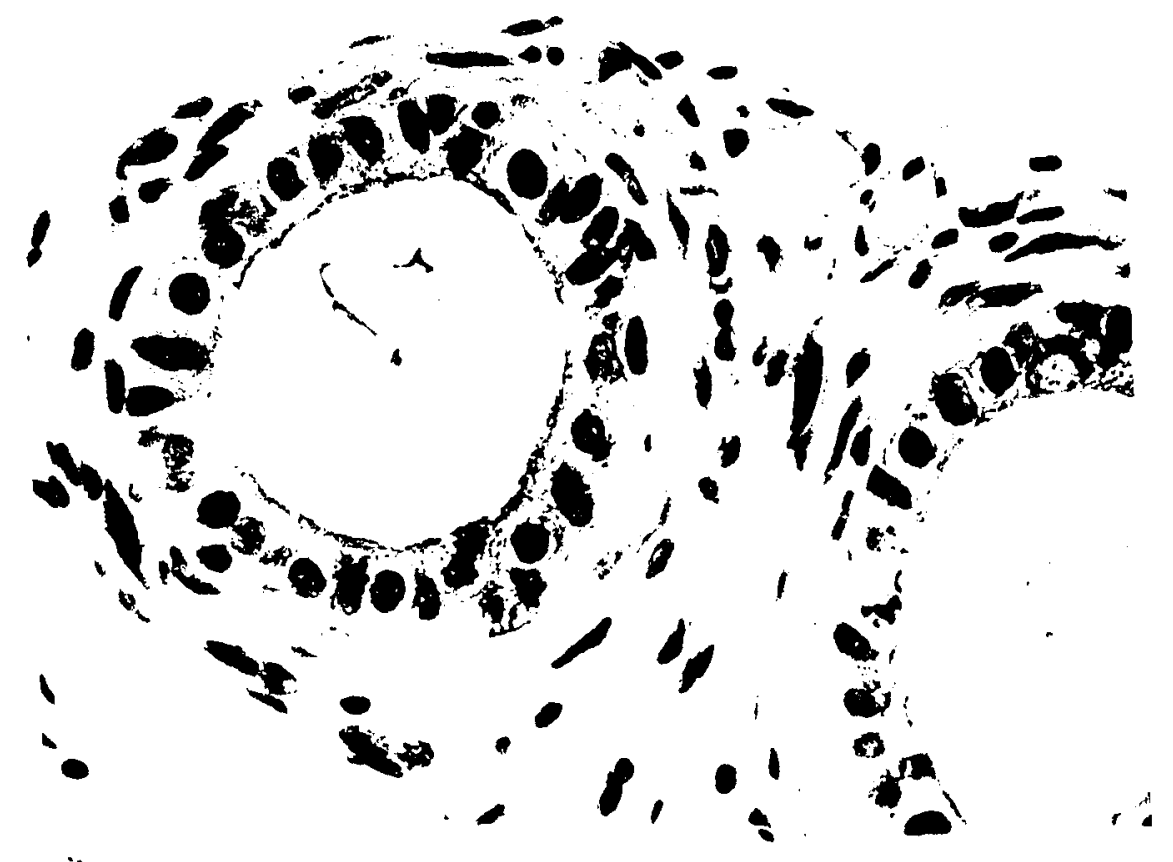


Figure 33b. Cross section of epididymis of male $\underline{S}$. obesus (100X). Note: hypertrophied epithelium and lumina packed with sperm. 


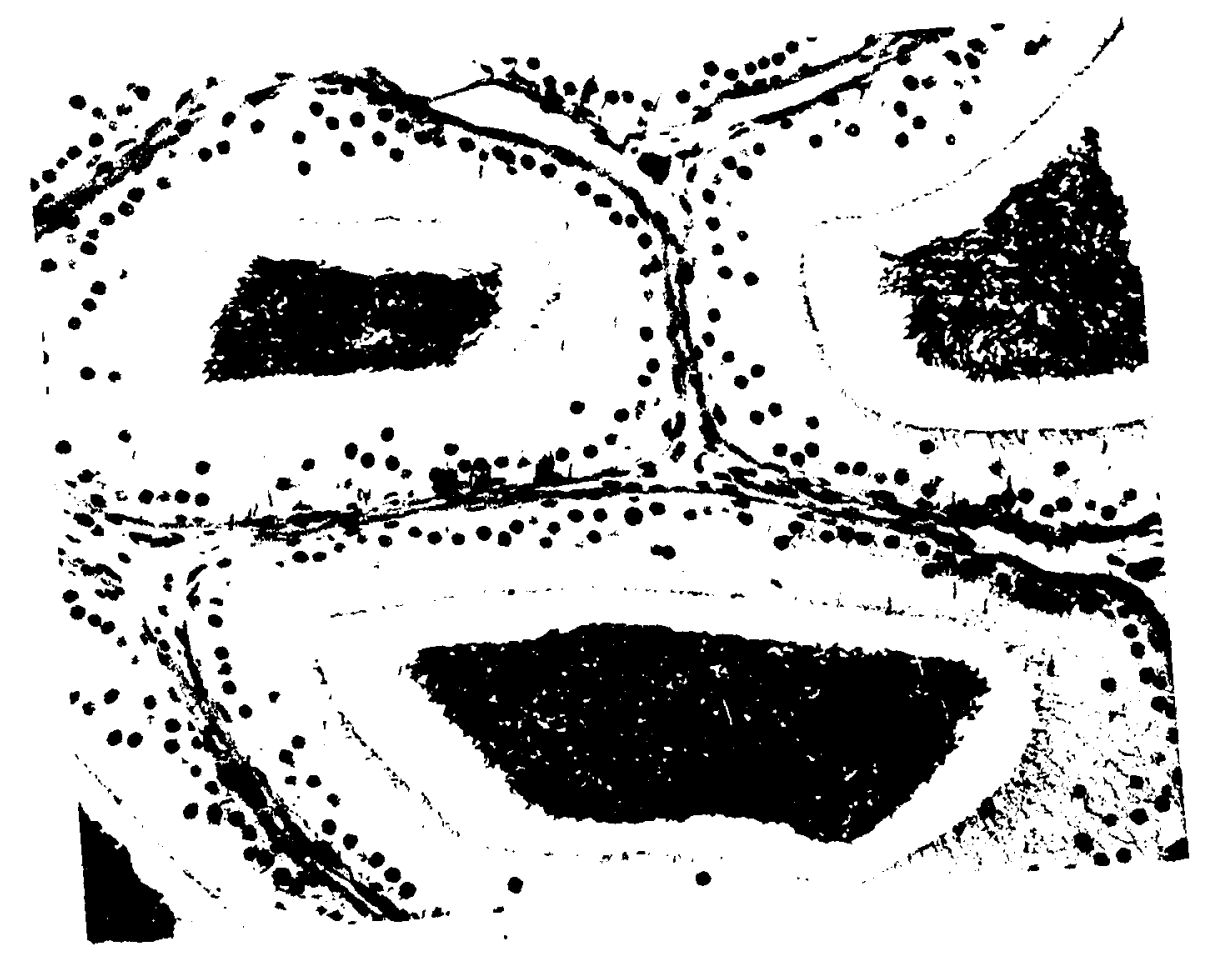


Figure 33c. Cross section of vas deferens of male $\underline{S}$. obesus (100X). Note: ring of dense irregular connective tissue surrounding the epithelium. 


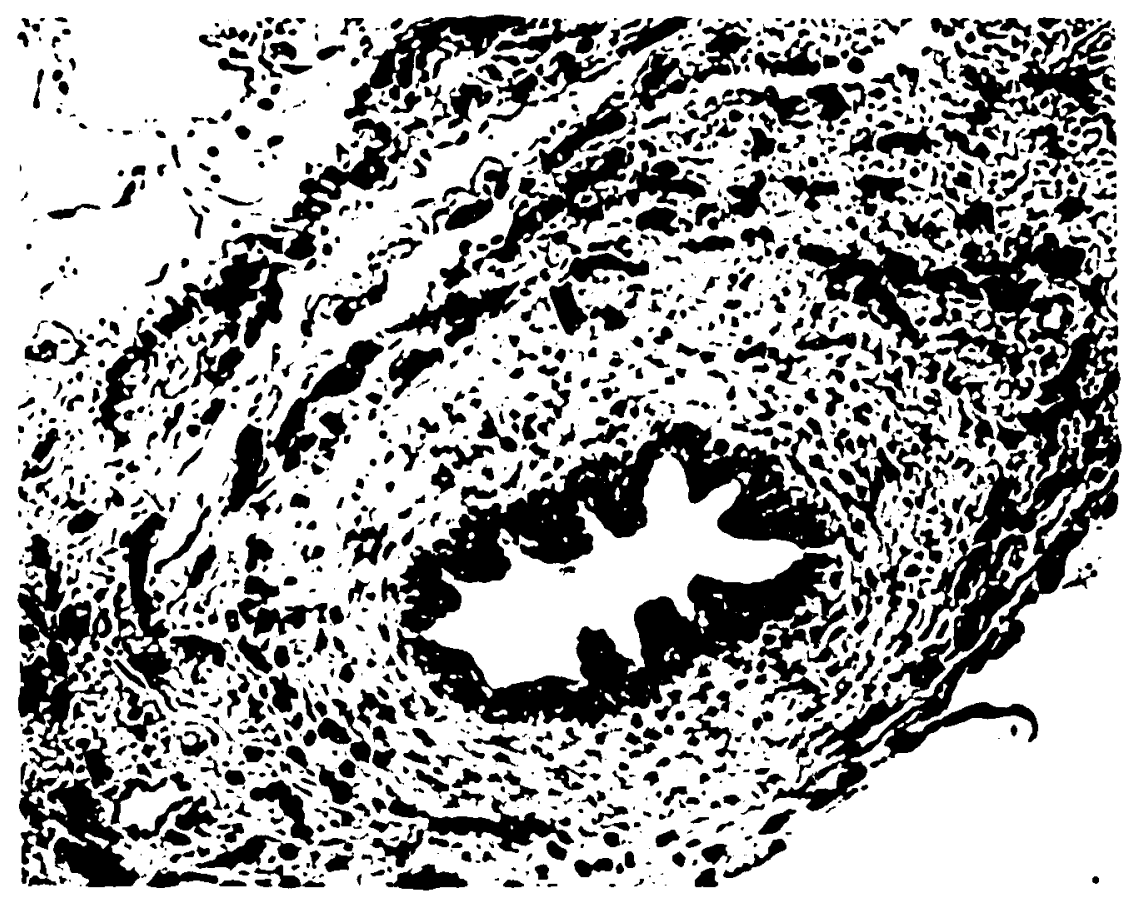


Figure 33d. Cross section of vas deferens of male $\underline{S}$. obesus (100X). Note: lumen packed with sperm. 


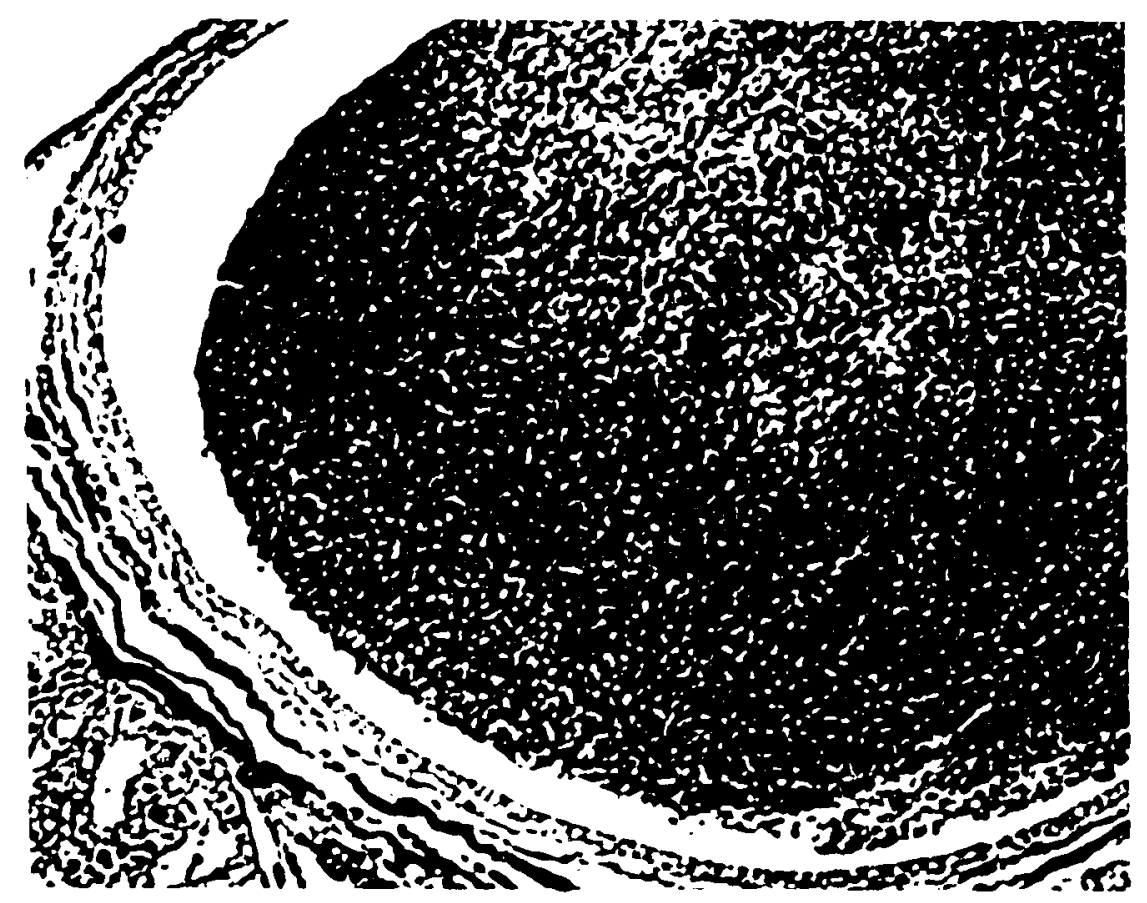


Figure 33e. Cross sections of kidney sexual segment tubules of male S. obesus $(100 \mathrm{X})$. Note: the regressed condition of sexual segment epithelium (a). 


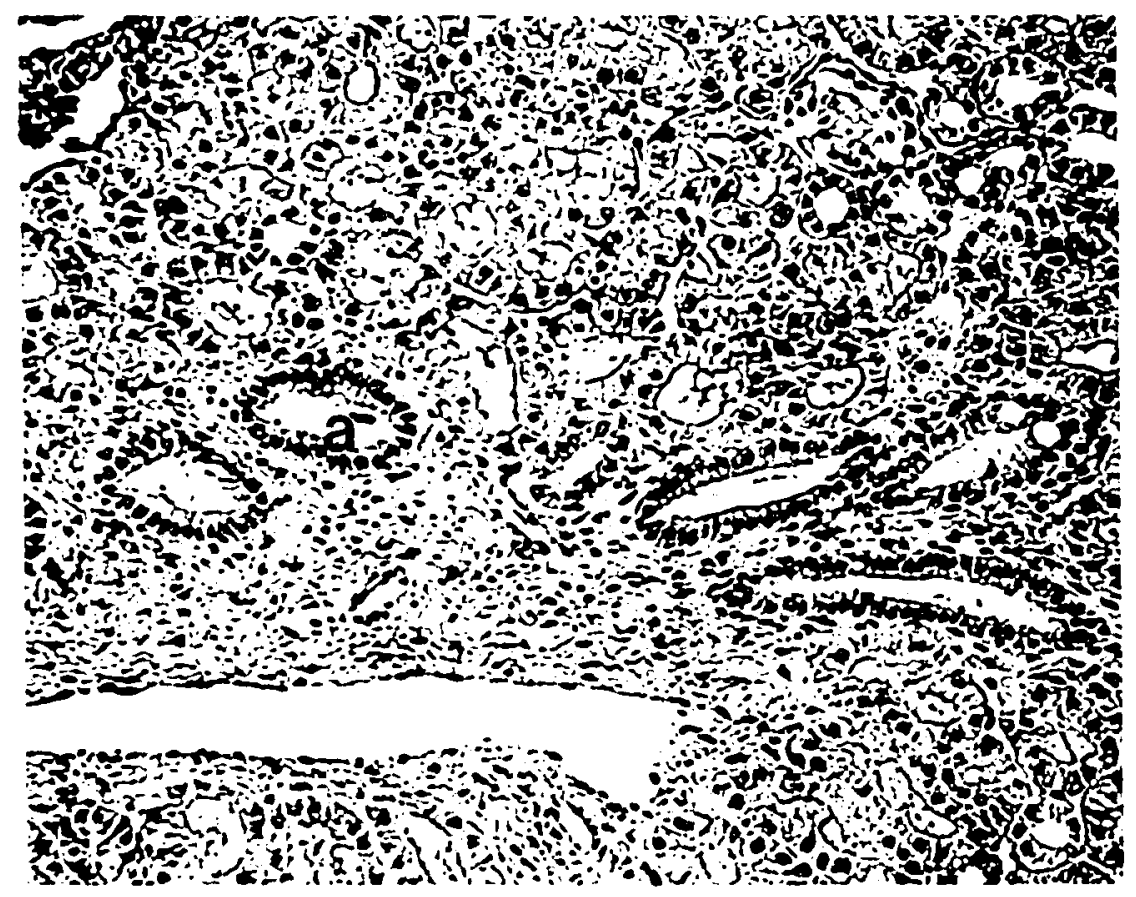


Figure 33f. Cross sections of kidney sexual segment tubules of male S. obesus $(100 \mathrm{X})$. The following features are shown: hypertrophied sexual segment epithelium with secretory granules (a); and portions of nephronic tubules (b). 


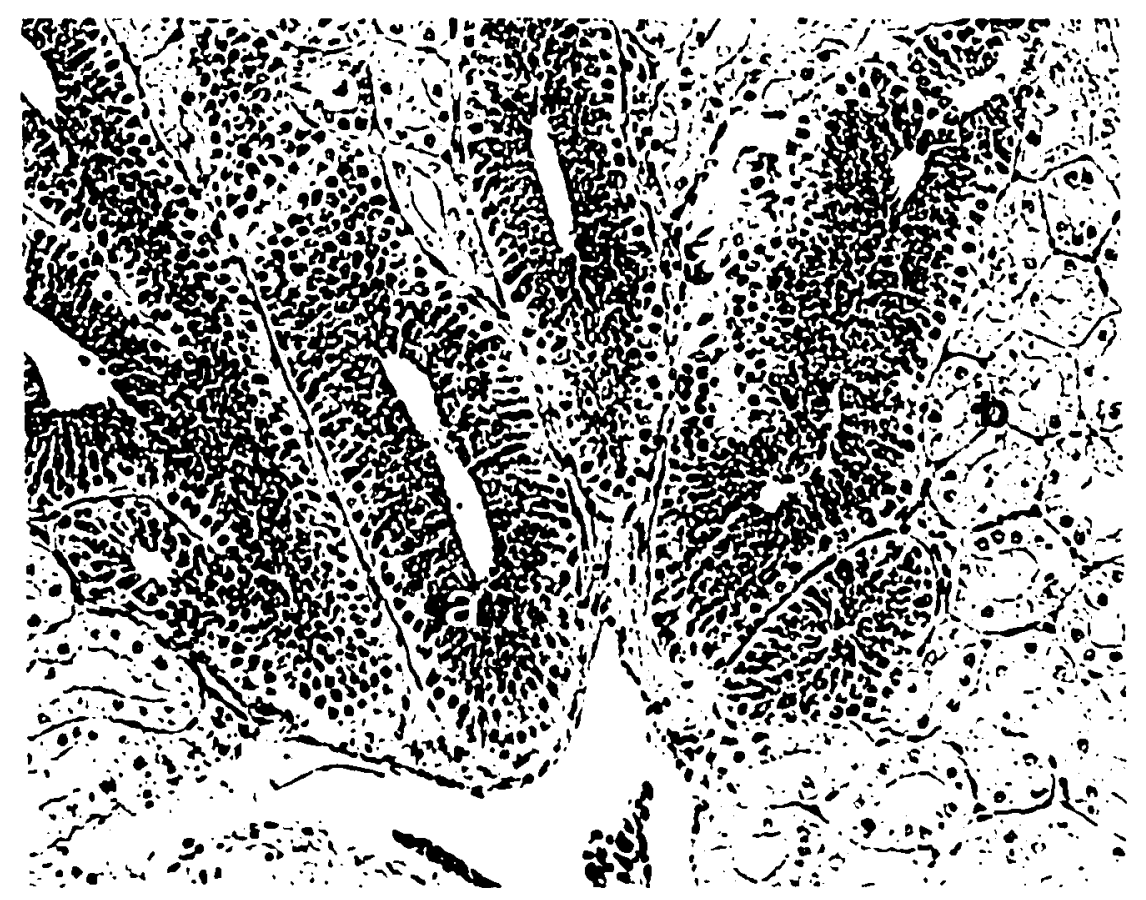


mun heights of epididymal epithelium were not significantly different from each other and occurred in mid-August (1978) and mid-March (1979). In 1979, epithelial height increased between mid-July and late August. As a result, late August epithelial height was significantly greater that year than for late August of the previous year. From late August 1978 to mid-March 1979 heights of epididymal epithelium decreased slightly though not significantly. Epithelial heights in mid-March of 1978 and 1979 did not differ significantly. During the height of the breeding season, the epididymal epithelium of immature male $\underline{S}$. obesus was not unlike the mid-March condition for adults.

Seasonal changes during 1978 and 1979 in height of vas deferens epithelium are shown in Figure $34 \mathrm{a} \&$ b. In mid-March the epithelium was pseudostratified cuboidal and lumina were clear (Fig. 33c). The epithelial height increased through April. In late April, most epithelia were pseudostratified columnar and lumina contained clusters of eosinophilic secretory granules (Fig. 33d). Most lumina also contained small to large sperm clusters. Late spring vas deferens epithelial heights showed considerable variability. Tallest epithelia contained cells with secretory granules at their apices. It appears that the degree of secretory activity accounted for the variability. After May, epithelial height declined rapidly. From June through August the epithelium was mostly pseudostratified cuboidal. Mature sperm persisted in declining amounts into August. Lumina were clear in late August. In both years, maximum height of the vas deferens epithelium occurred in late April. Minimums occurred in mid-August (1978) and late June (1979). Year to year epithelial height maximums 
Figure 34a. 1978 seasonal changes in vas deferens epithelial height of adult male $\underline{S}$. obesus. Vertical lines indicate \pm 2 standard errors; numbers $=$ sample sizes. 


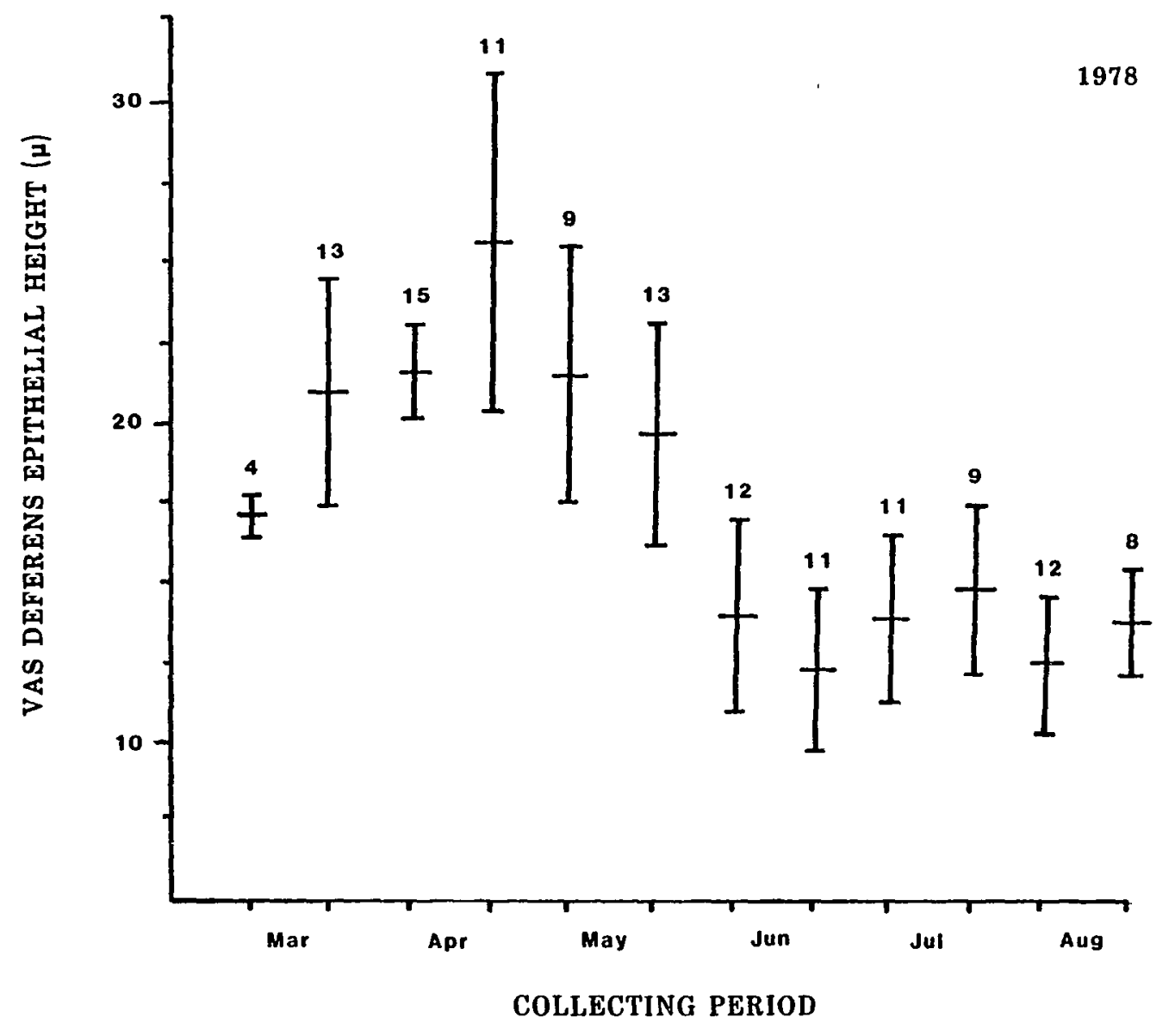


Figure 34b. 1979 seasonal changes in vas deferens epithelial height of adult male $\underline{S}$. obesus. Vertical lines indicate \pm 2 standard errors; numbers $=$ sample sizes. 


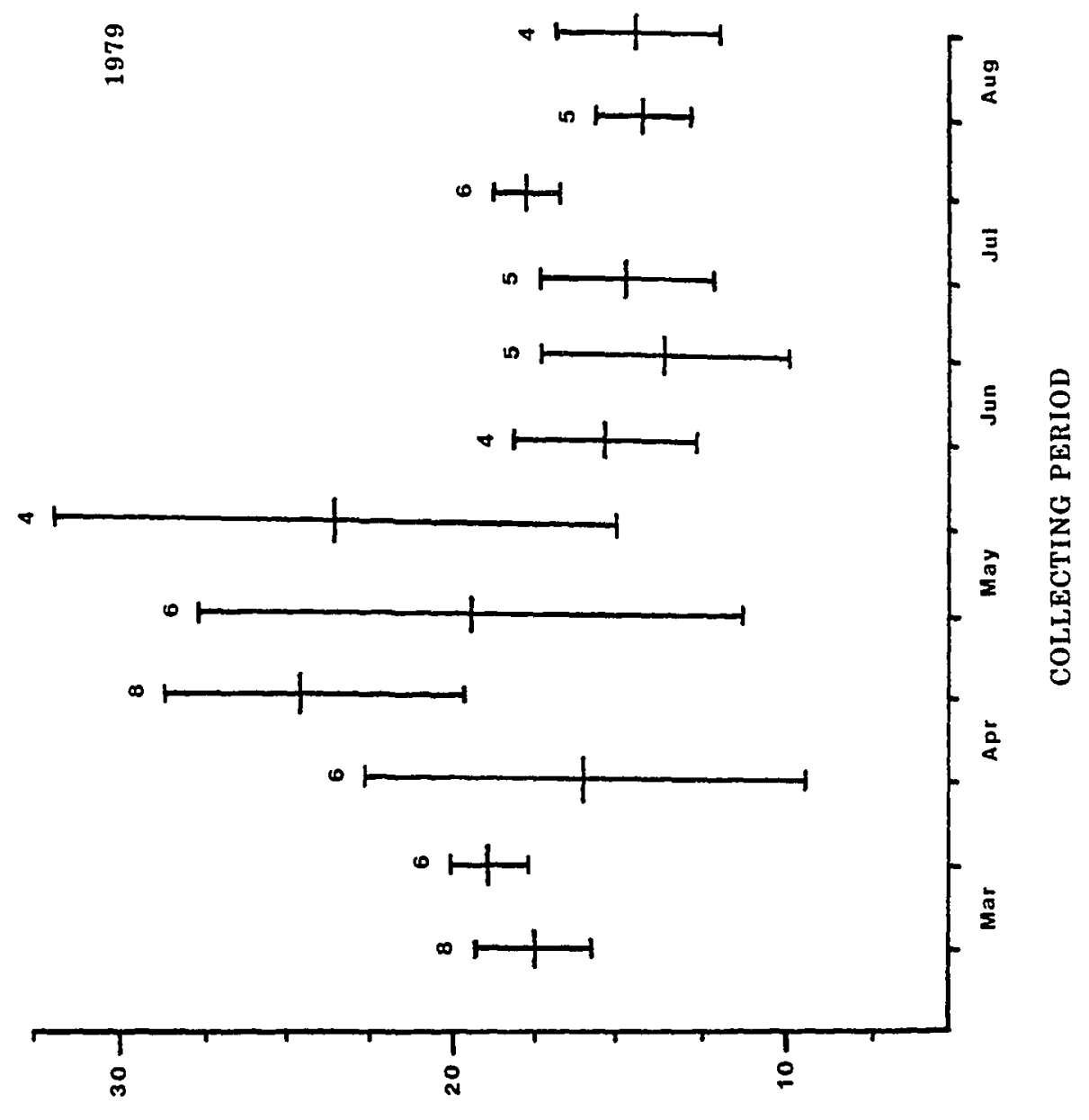

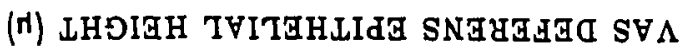


and minimums were not significantly different. Height of the epithelium in mid-March of 1979 was significantly greater than that in late August of 1978. Mid-March epithelial heights were not significantly different. During the height of the breeding season, the vas deferens epithelia of immature male $\underline{S}$. obesus tended to be similar to the condition exhibited by adults in March.

The sexual segment of the kidney in male $\underline{S}$. obesus consisted of terminal segments, collecting tubules and ureter. Seasonal changes in average sexual segment epithelial height during 1978 and 1979 are shown in Figure 35a \& b. At the start of the activity season, epithelia were mostly simple cuboidal with clear lumina (Fig. 33e). By late spring, the epithelial height increased about 4 times. At this time most epithelial cells were simple columnar (Fig. 33f). By late April most of the cell apices contained eosinophilic secretory granules. A holocrine secretion obliterated the lumina of most portions of the sexual segment mid-May well into June. From mid to late June, a new simple cuboidal epithelium was regenerated. By late July most of the lumina were clear. Maximum sexual segment epithelial heights were not significantly different from each other and occurred from mid-May (1978) to mid-June (1979). Minimum epithelial heights were significantly different from each other and occurred in late August both years. From 1ate August 1978 to mid-March 1979, epithelial heights in the sexual segment were not significantly different from each other. During the height of the breeding season, the sexual segment epithelia of immature male $\underline{S}$. obesus tended to be similar to the condition observed in mid-March adults. 
Figure 35a. 1978 seasonal changes in sexual segment epithelial height of adult male $\underline{S}$. obesus. Vertical lines indicate \pm 2 standard errors; numbers $=$ sample sizes. 


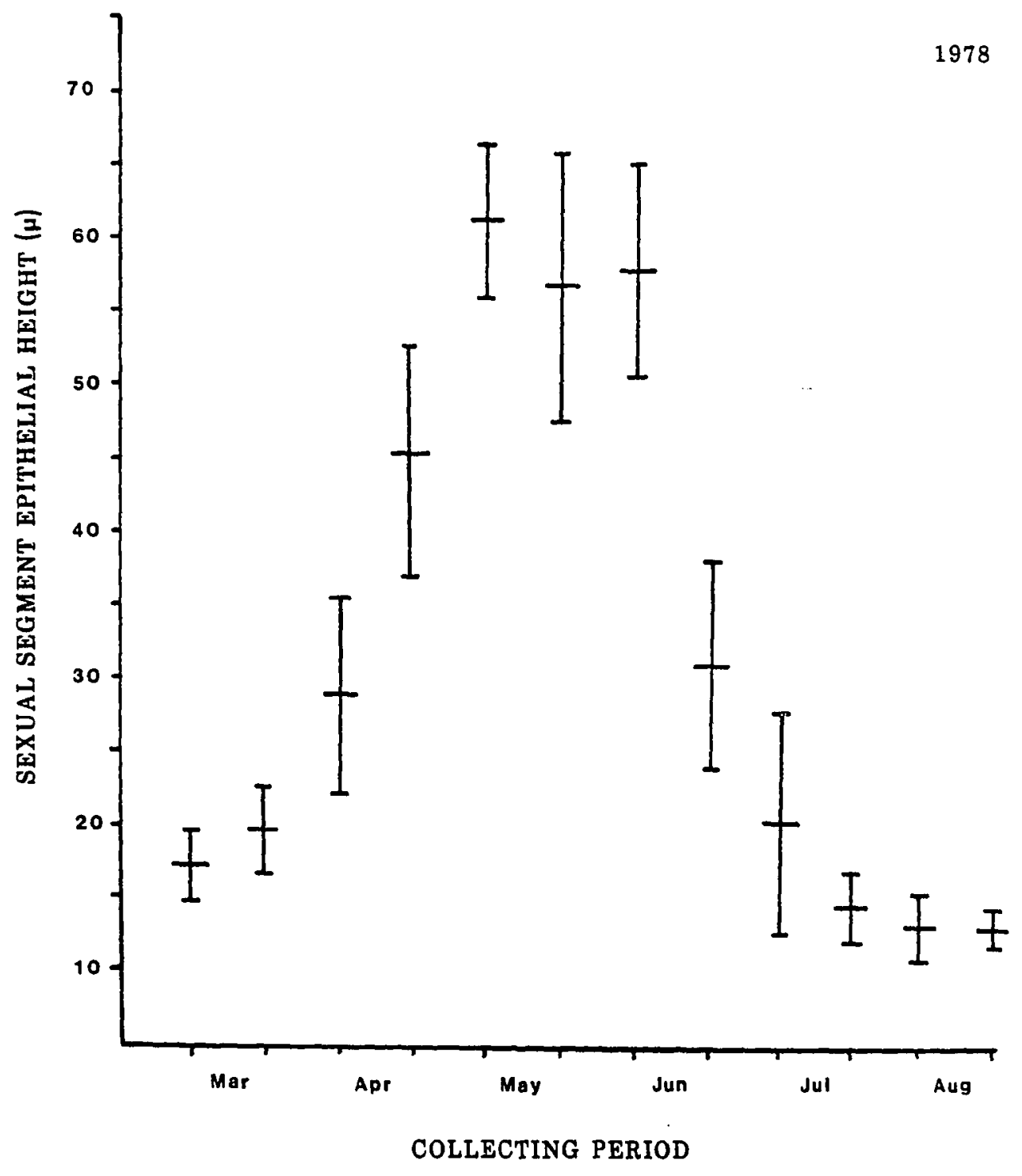


Figure 35b. 1979 seasonal changes in sexual segment epithelial height of adult male $\underline{S}$. obesus. Vertical lines indicate \pm 2 standard errors; numbers $=$ sample sizes. 


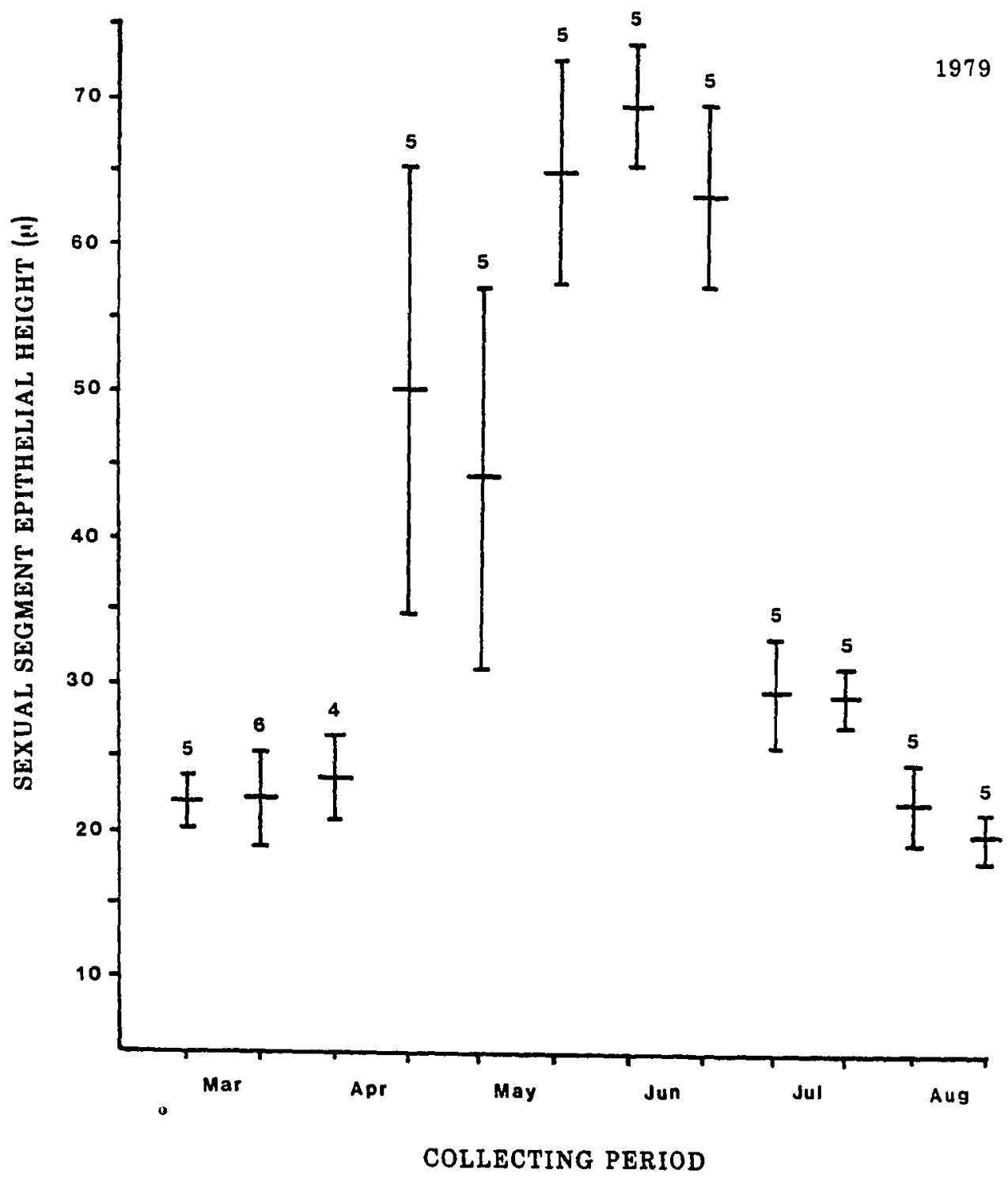


Little has been reported on the accessory ducts of lizard testes. Fox (1977) presented a limited description of the morphology of the epididymis. The epididymis was described as being highly convoluted and epididymal epithelial height varied according to whether the epithelium was secretory or non-secretory. In the non-secretory phase, the epithelium was simple cuboidal, nonciliated and lacked secretory granules. In the secretory phase, the epithelium was simple columnar, ciliated and contained numerous secretory granules.

Epithelia of several studies on mammals have shown that epididymis and vas deferens are secretory and that the secretory contents enhance sperm maturation (B1oom and Fawcett, 1975). In the epidiymis, increased surface area provided by the presence of cilia aids the resorption of seminiferous tubule debris. The vas deferens, surrounded by 2 layers of smooth muscle, is the principle ejaculatory duct.

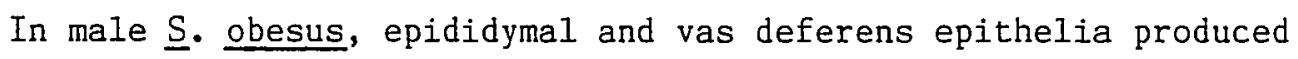
secretions that probably served a function similar to that of mammals. The brush border appearance of much of the reproductive tract may have indicated at least limited resorption capacity. In contrast to the situation in mammals, neither the epididymis or vas deferens possessed a well defined smooth muscle layer, though the latter was surrounded by a highly organized ring of dense connective tissue. Sperm was stored in the vas deferens throughout the breeding season. Consequently, for male $\underline{S}$. obesus the role of the vas deferens as an ejaculatory duct appeared limited.

The following account of the lizard kidney sexual segment is taken from Fox (1977). The sexual segment is absent in females. The loca- 
tion of the sexual segment is variable among species but has been found as part of distal nephronic segments, collecting tubules and ureter. During the course of an activity season epithelial height of the sexual segment fluctuates considerably. During the non-secretory or involuted phased the epithelium is low (20 um), basophilic and mucous-secreting. At this time the sexual segment is barely discernible from uriniferous tubules. During the secretory or hypertrophied phase, the epithelium increases 3-fold in hieght to 60 um and contains numerous apical eosinophilic granules. The eosinophilic granules appear spherical and contain protein and lipid materials. Their formation and secretion are under control of both androgens from the testes and gonadotropins from the pituitary. The function of the sexual segment is still unknown. It has been suggested that kidney sexual segment secretions may be involved in one or a combination of the following: 1) the separation of semen from urine; 2) the retention of semen in the female cloaca or oviduct; 3) the formation of a secent important in mating and 4) the formation of a primitive seminal fluid. For Anolis carolinensis Cuellar et. al., (1972) showed that sperm could be sustained if added to a culture of this species' kidney fluid. Their data seemed to support the hypothesis of Bishop (1959) that the sexual segment provides nutrients and activates sperm.

The sexual segment of adult male $\underline{S}$. obesus consisted primarily of kidney collecting tubules. Changes in moprhology agreed with the above. Peak epithelial height was not attenuated but rather extended and corresponded with the time motile sperm were most abundant at the terminal end of the vas deferens. In view of the histological events, 
it seems possible that sexual segment secretion contributed to semen formation and sperm sustenance and activation.

The synchrony of testicular activities with those of the reproductive tract have rarely been reported for lizards. Summarized in Figure 36 , this report on testis and reproductive tract should serve as a model for comparison with other oviparous lizard species.

Seasonal changes in mean fat body weight/body weight (FBW/BW) ratio

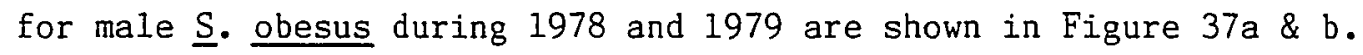
Mean ratios first increased gradually from the beginning of the activity season (mid-March through April) and then at an accelerated rate through late spring. They decreased gradually through the summer except in 1979, when there was a marked increase in late August. Maximum mean ratios occurred from late May (1978) through late June (1980).

Minimum mean ratios occurred in March at the time of emergence from brumation. All seasonal comparisons were evaluated with a Student-t test. Maximum or minimum ratios did not differ significantly from 1978 1980. During the same period, late August mean ratios were not significantly lower than spring maximums. In fact, in 1979 the late August value was actually higher than the preceeding spring maximum. Spring emergence mean ratios were always significantly less than those from late August of the previous year.

Breeding success is greatly affected by available food. When gauging the male energetic expenditures of present and future reproductions, one must consider the effect of available food on such parameters as lipid cycling, growth rates and aggressive behavior. Lipid cycling patterns can be explained by seasonal patterns in food availability 
Figure 36. The relationship of seasonal changes in testicular and reproductive tract structures for adult male $\underline{S}$. obesus. 1 = testis; 2 = epididymis; 3 = vas deferens; 4 = kidney; $a=$ interstitial cells; $\mathrm{b}=$ nephronic tubules. 


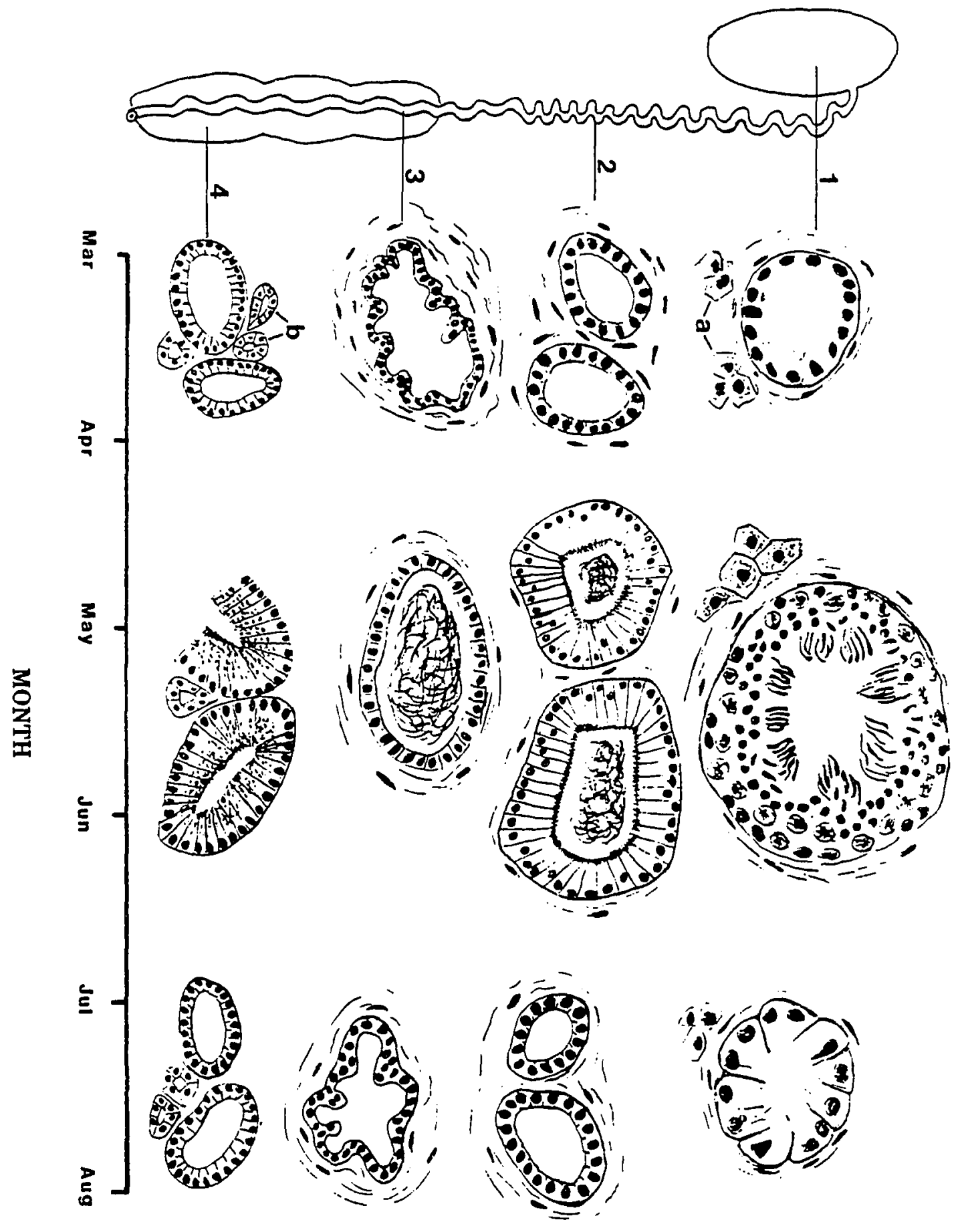


Figure 37a. 1978 seasonal changes in fat body weight/body weight ratios of adult male $\underline{S}$. obesus. Vertical lines indicate \pm 2 standard errors; numbers $=$ sample sizes. 


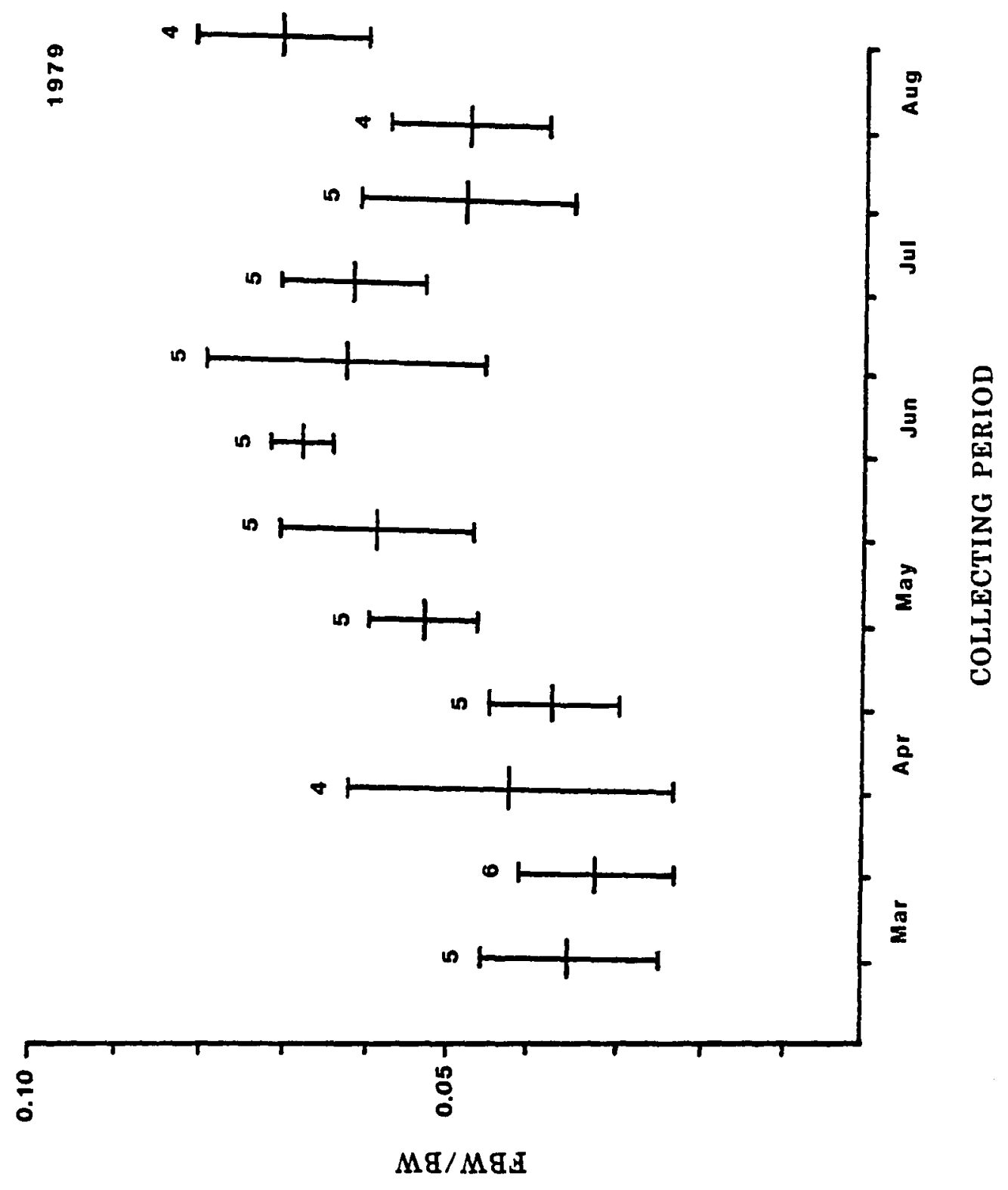


Figure 37b. 1979 seasonal changes in fat body weight/body weight ratios of adult male $\underline{S}$. obesus. Vertical lines indicate \pm 2 standard errors; numbers = sample sizes. 


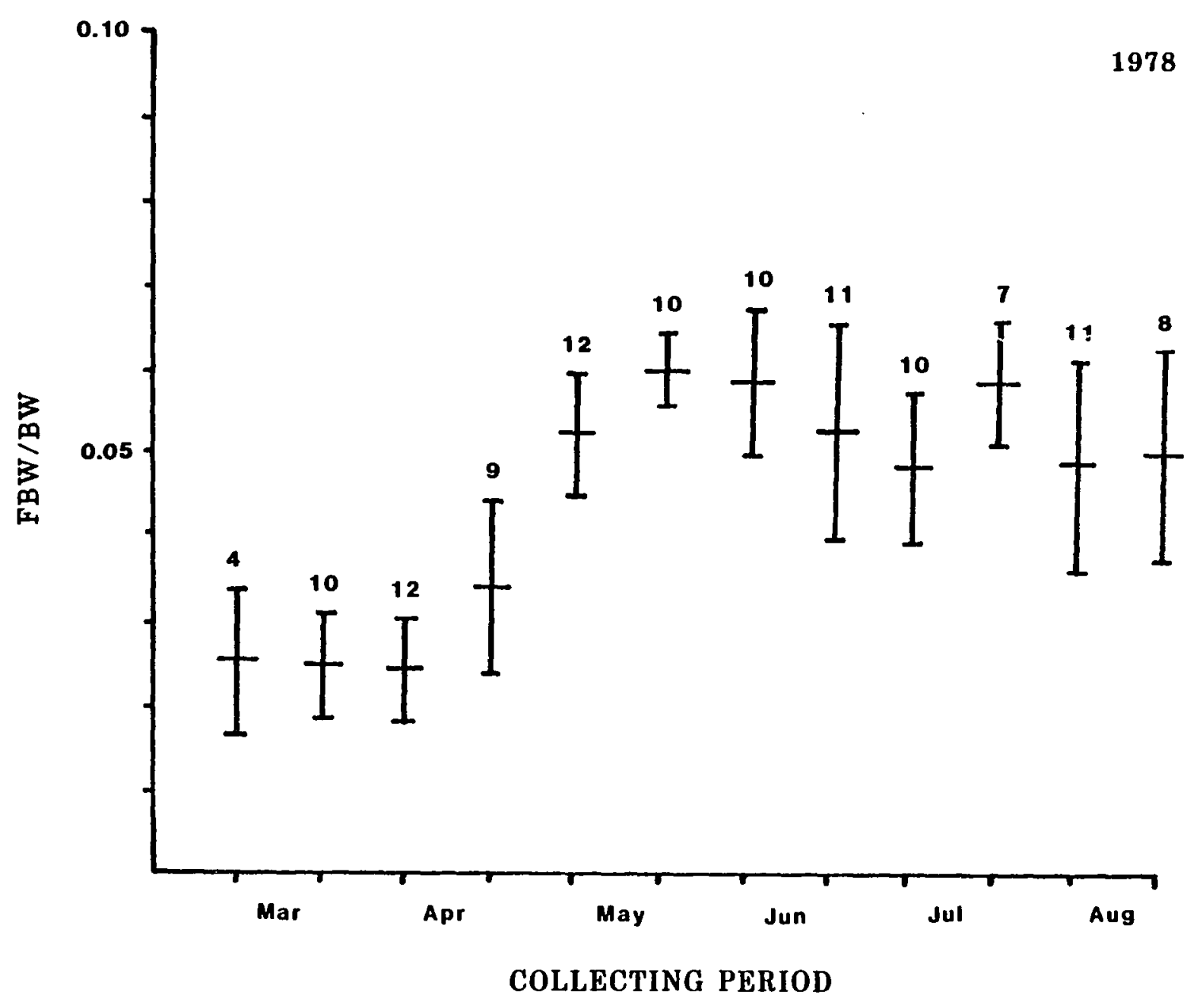


(Derickson, 1976). The cycling of corpora adiposa in Colorado Desert female $\underline{\mathrm{S}}$. obesus has already been considered (Ch. 3 - Female Reproductive Cycle). Regarding males, with corpora adiposa weights decling most drastically over winter, it appeared the energy from this source was devoted to survival (maintenance during dormancy) and/or reproduction. Because winter activity of both sexes was at a similar minimum and because the over-winter decline in the corpora adiposa of females was insignificant in 1978 through 1980, it appeared that in most years the significant over-winter decline of corpora adiposa in males was for spermatogenesis and territorial behavior.

The corpora adiposa of Colorado Desert male $\underline{S}$. obesus were of maximum size during the peak of the breeding season but showed only a slight decline through the summer. They were of minimum size at or shortly after emergence from winter dormancy. This situation differs from the findings for males of other temperate lizard species (Derickson, 1976; Trauth, 1979), in which corpora adiposa were minimal at the peak of the breeding season and storage resumed only after reproduction. Differences in timing of corpora adiposa cycles may reflect how food availability affected life history objectives. Previous studies have considered the males of only insectivorous lizard species (Derickson, 1976; Trauth, 1979). Throughout the activity season, the availability of insects was probably less variable than vegetation. In male $\underline{S}$. obesus, a buildup of corpora adiposa during the breeding season was necessary because of the more critical nature of temporal limitation brought about by herbivory. Also, herbivory places a greater restriction on energy per unit dry weight of food and assimilation efficiency 
(Pough, 1973). In this study, in response to winter and summer precipitation, annuals and perennials were most abundant in mid-spring and late summer. However, the availability of food in the spring was more extensive. From 1978 through 1980, spring food resources were available March to June. Summer food resources, available August into September, were observed only in 1979. Corpora adiposa increased in size for male $\underline{S}$. obesus whenever food was present but such a storage form appeared to be especially geared to spring conditions. It is likely that male $\underline{S}$. obesus apportioned little energy to corpora adiposa after breeding simply because the lower energy yielding plant materials were in limited supply

Available food is a proximal cause for differences in life history among lizard species (Ballinger, 1977, 1983; Dunham, 1978). For insectivorous species, Derickson (1976) stated, lipid is not stored as corpora adiposa during the breeding season so that more will be utilized in the present reproductive effort. In agreement with Williams' hypothesis (1966a \& b), Derickson concluded that a greater reproductive effort in any given season may result in a shorter life span.

Most of the insectivorous lizard species abiding by this approach live only a few years or less. The herbivorous $\underline{S}$ obesus operates differently. In this study, adult males have a life expectancy of about 10 years (Ch. 5 - Longevity). Consequently, it is possible and of great importance to occasionally postpone present reproduction so that future reproduction may be successful. Storing lipids as corpora adiposa during the breeding season may be one means of ensuring available energy for future reproductions. 
Life histories evolve to maximize present and future reproductions. Breeding success and seasonal changes in available food are strongly correlated. For male lizards, considering such topics as other sources of lipid storage, growth rates and frequency of aggressive behavior such as territoriality and courtship during different levels of food availability will enhance the understanding of life histories. Growth rates and frequency of aggressive behavior have been discussed for Colorado Desert male $\underline{S}$. obesus (Ch. 2 - Social Behavior and Ch. 5 - Longevity). Other sources of lipid storage remain to be investigated.

\section{SYNCHRONY OF THE BREEDING SEASON}

Determination of the timing relationship of spermiation and ovulation may indicate the level of breeding success achieved by a population. A number of interrelated environmental factors such as prevailing climate, available food and physiological condition of the lizard affected the breeding cycles of male and female $\underline{S}$. obesus. Such environmental factors were responsible for determining the onset and duration of certain breeding cycle events. An extended period in which food was available (1979) seemed to prolong spermiation in males (Fig. 38) and cool conditions (1979 and 1980) and limited available food in the early spring (1980) delayed the onset of vitellogenesis in females (Fig. 39). The manner in which various environmental factors affected aspects of S. obesus life history are discussed in chapter 4 - Life History and Demography .

Regardless of the particular suite of persisting environmental factors, for 1978 through 1983 key breeding events that culminated in 
Figure 38. The relationship of key reproductive cycle events for adult male $\underline{\mathrm{S}}$. obesus. Diamonds = peak condition. 
1978

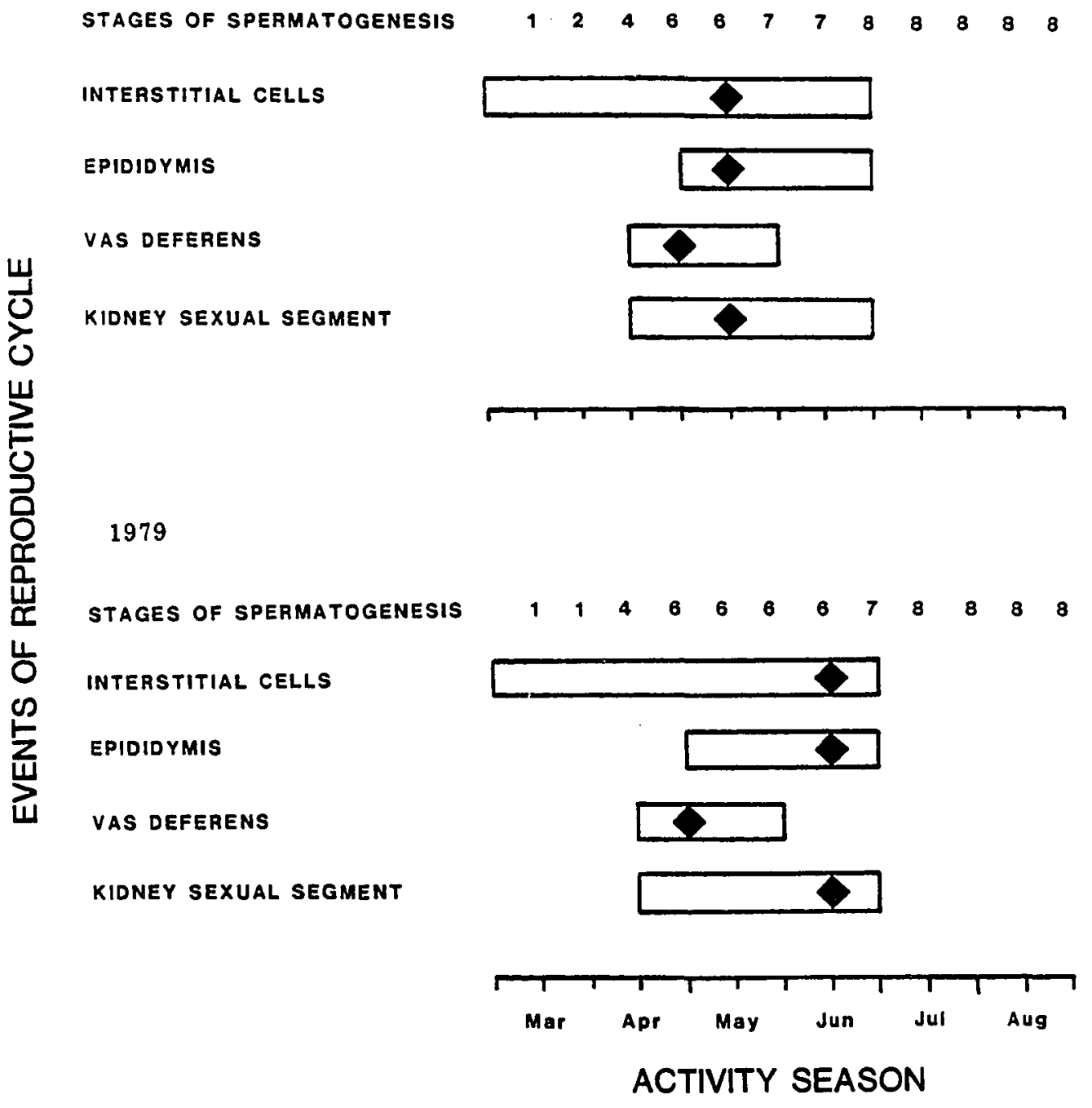


Figure 39. The relationship of key reproductive cycle events for adult female $\underline{S}$. obesus. Figure based on data collected 1978 through 1983. Shaded arrow $=$ onset for 1978; clear arrow $=$ onset for 1980 . 

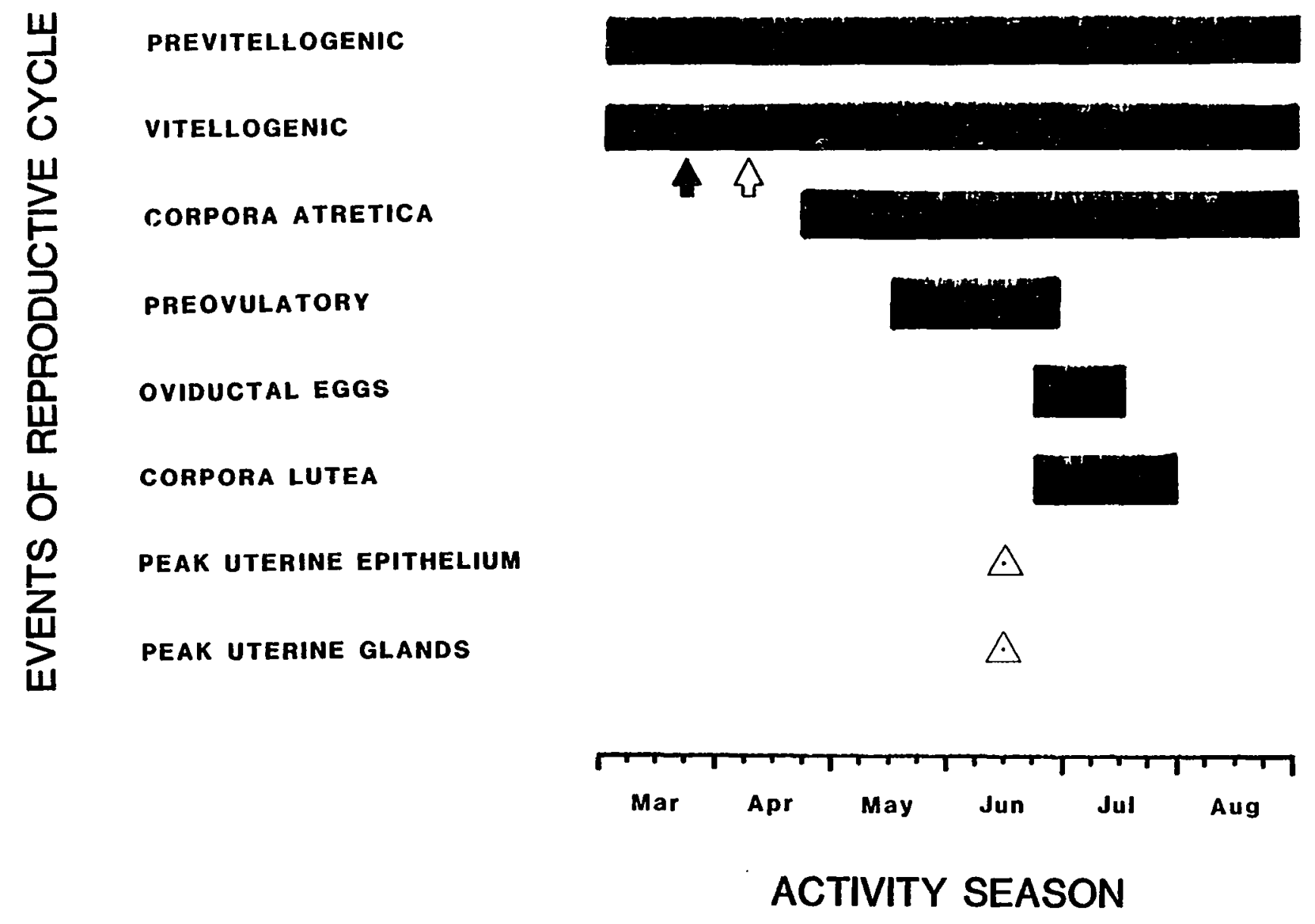
reproduction showed restricted temporal variation (Fig. 40). Events associated with spermiation in male $\underline{S}$. obesus occurred within the same 2-month interval (largely May through June). In all years save 1981, when reproduction did not occur, advanced events of the breeding cycle for female $\underline{S}$. obesus (pre-ovulatory follicles, ovulation, oviductal eggs and oviposition) also occurred during a 2-month interval, roughly mid-May through mid-July. Pre-ovulatory follicles, present in late spring, were prerequisite for adult female interestin mating. Ovulation occurred within 3 weeks of successful mating episodes (1ate June). By the beginning of July, all reproductive female $\underline{S}$. obesus possessed oviductal eggs. Individuals at the Red Cloud Road study site were known to retain eggs in their oviducts for as long as 2 weeks. Oviposition, spanning a 2-week interval, appeared to be completed shortly after the middle of July. Eggs were not palpated from the oviducts of adult female

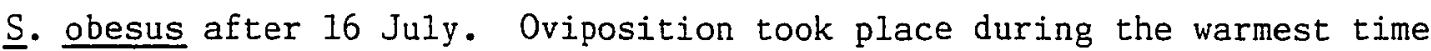
of the year. Although reproduction at this time may have been detrimental to adult females, because the summer precipitation season begins about mid-July it may be highly advantageous from the standpoint of egg and hatchling survival (Ch. 5 - Survivorship).

\section{INCUBATION AND APPEARANCE OF HATCHLINGS}

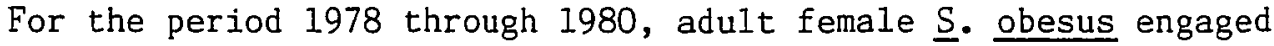
in oviposition from about 5 to $20 \mathrm{July}$. In 1982 and 1983, though field study was not undertaken in July, June investigations revealed progress in female breeding condition on schedule for early to mid-July oviposition. 
Figure 40. The relationship of key male and female reproductive cycle events for Colorado Desert $\underline{S}$. obesus. Triangles = peak frequency of the reproductive event. 
STAGE 6 SEMINIFEROUS T. E.
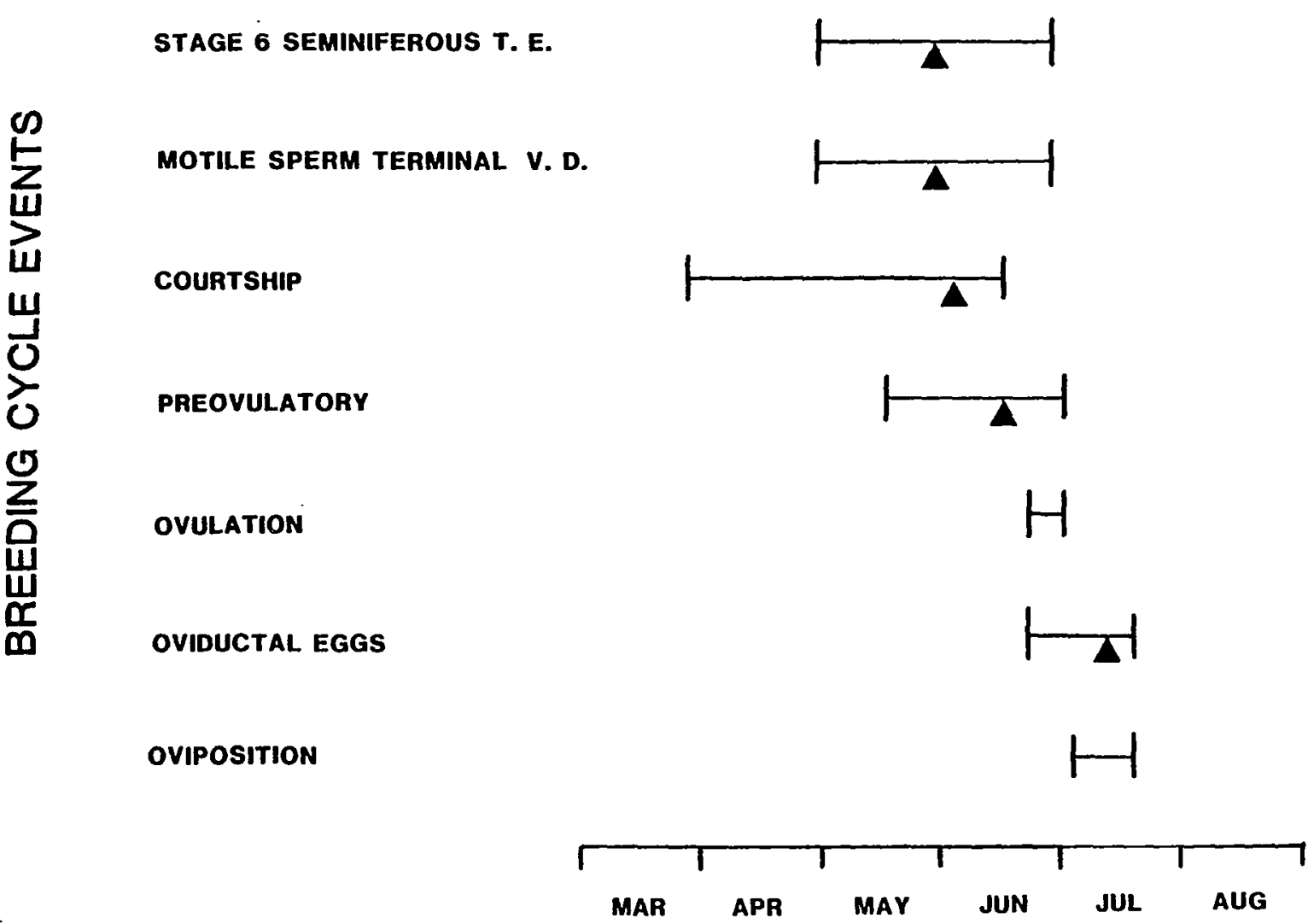

ACTIVITY SEASON 
Table XXXV indicates the frequency of encountering hatchling $\underline{S}$. obesus. The earliest sighting occurred on 23 September 1979. During September and October, hatchlings were encountered infrequently (never more than 1 sighting a day). After early November, frequency of sightings was greatly influenced by prevailing climatic conditions. Hatchlings were encountered least frequently on cool, wet and windy days such as several days during December and January and encountered most often on warm, dry and calm days, primarily in November and February. On some of the milder days activity such as basking, moving in and out of rock crevices and sharing retreats with one or two other hatchlings was obvious. For hatchling $\underline{S}$. obesus, maximum sighting frequency occurred on 5 November 1979 ( 1.25 per man hour).

The presence of incompletely closed yolk scars may indicate recent hatching episodes. Incomplete yolk scars infiltrated with yolk granules or soil were found on hatchling $\underline{S}$. obesus September through January. However, the majority of scars appeared completely healed by December. Apparently, most $\underline{S}$. obesus had hatched prior to this time. Therefore, egg incubation times, showing tremendous variation, ranged from about 2 to 4.5 months. This wide range possibly reflected such variations in microhabitat structure as substrate, depth and slope and such corresponding physical parameters as temperature and humidity between nesting sites. In mid-winter, individuals with incompletely closed and healed yolk scars displayed a similar level of general health. Therefore, the ecological ramifications of this phenomenon remains unclear.

From 1978 through 1980, the sighting frequency of hatchling $\underline{S}$. obesus appeared to be correlated with breeding success and prevailing 
TABLE XXXV

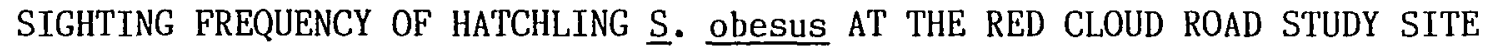

\begin{tabular}{llcccc}
\hline Year & Month & $\begin{array}{c}\text { Number of } \\
\text { Field Days }\end{array}$ & $\begin{array}{c}\text { Number of } \\
\text { Man Hours }\end{array}$ & $\begin{array}{c}\text { Number of } \\
\text { Hatchlings }\end{array}$ & $\begin{array}{c}\text { Hatchling Sightings } \\
\text { Per/Man Hour }\end{array}$ \\
\hline $1977-78$ & Sept & 2 & 20 & 0 & - \\
& Oct & 4 & 40 & 2 & 0.05 \\
& Nov & 2 & 20 & 3 & 0.15 \\
& Dec & 3 & 24 & 8 & 0.33 \\
& Jan & 1 & 5 & 3 & 0.60 \\
& Feb & 1 & 4 & 2 & 0.50 \\
& Sept & 1 & 8 & 0 & - \\
& Oct & 2 & 9 & 1 & 0.11 \\
& Nov & 2 & 18 & 6 & - \\
Dec & 3 & 15 & 2 & 0.13 \\
& Jan & 1 & 4 & 0 & -
\end{tabular}




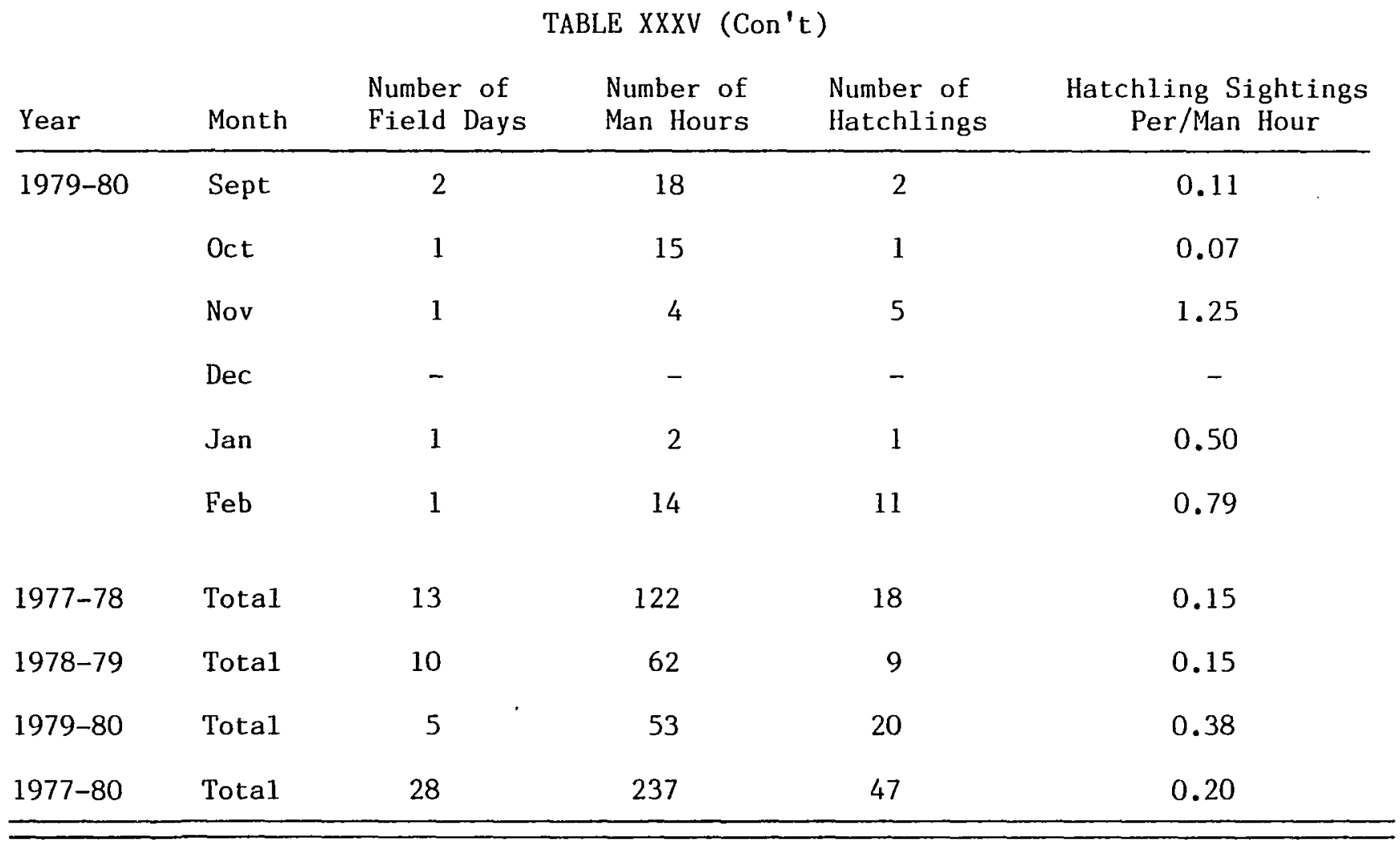


summer climate, especially precipitation. For example, a highly successful breeding season followed by an abundance of summer precipitation in 1979 resulted in an increase in sighting frequency at least 2.5 times that of other years. The reproductive output in 1978 was much closer to that of 1979 than 1977 (Ch. 4 - Annual Reproductive Output and Fecundity). However, hatchling sighting frequency was very similar to that for 1977. Examination of summer precipitation revealed that while 1977 was exceptionally wet, 1978 was plagued by drought. Perhaps summer precipitation played a role in egg survival. Though there were fewer eggs in 1977, summer precipitation may have been responsible for a higher percentage of them surviving to hatching. While several factors are considered for hatchling survival (Ch. 5 - Survivorship), the fact that no hatchlings were sighted after December 1978 until March 1979 and then as yearlings only infrequently throughout the spring, may indicate that summer precipitation, affecting food availability in the fall, contributed to lowered hatchling survival too. 
CHAPTER IV

LIFE HISTORY: REPRODUCTION

SIZE AND AGE AT REPRODUCTIVE MATURITY

Size at reproductive maturity is an important parameter in life history studies of lizards. Size is often used to estimate age, and size is usually a more convenient indicator of reproductive maturity than is age.

Size at reproductive maturity in $\underline{S}$. obesus was reported for Mojave Desert populations by Johnson (1965) and Berry (1974), who assessed reproductive maturity largely from the appearance and size of the gonads. Size at reproductive activity, however, is usually much greater (Berry 1974 and Ch. 2 - Social Behavior). I posed the following questions about size at reproductive maturity for Colorado

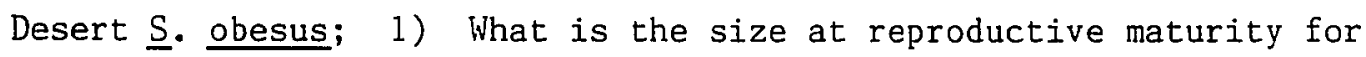
males? 2) What is the size at reproductive maturity for females? 3) How does the size at reproductive maturity vary from year to year in the two sexes?

Berry (1974) proposed a minimum volume of $300 \mathrm{~mm}^{3}$ per testis as the criterion for reproductive maturity in male $\underline{S}$. obesus: This volume corresponded to SVL $\geq 150 \mathrm{~mm}$. However, since testis volume is strongly correlated with male body size (Ch. 3 - Male Reproductive (ycle), this value may be too high to show reproductive maturity for populations dominated by small adult males. For example, in this 
study, the smallest males to produce sperm had testis volumes of only $150 \mathrm{~mm}^{3}$. Using criteria such as testicular and reproductive tract histology, size at reproductive maturity for Colorado Desert male S. obesus was $125 \mathrm{~mm}$ SVL in 4 to 5 years. For 1978 through 1980, all males greater than or equal to this size were reproductively mature. In 1981, a drought year, all but one male larger than $125 \mathrm{~mm}$ SVL were reproductively mature. Consequently, reproductive maturity at $125 \mathrm{~mm}$ SVL appears typical for Colorado Desert $\underline{\mathrm{S}}$. obesus and is considerably smaller than previoulsy reported.

While most male $\underline{S}$. obesus achieved reproductive maturity at a relatively small size, they did not make a significant reproductive contribution until they became considerably larger. Only adult male S. obesus about $165 \mathrm{~mm}$ SVL and larger were able to mate successfully. Berry (1974) also reported that only the largest adult males - tyrants - were able to mate successfully. However, in her study these lizards were always larger than $185 \mathrm{~mm}$ SVL. Consequently, from an ecologcal as well as morphological perspective, Colorado Desert male $\underline{S}$. obesus attained reproductive maturity at a much smaller size.

Berry (1974) proposed enlarged ovarian follicles $\geq 10 \mathrm{~mm}$ as the criterion for reproductive maturity in female $\underline{S}$. obesus. This value corresponded to SVL $\geq 150 \mathrm{~mm}$. Enlarged ovarian follicles are a reliable measurement of reproductive maturity, but in this study, the presence of oviductal eggs and corpora lutea made more precise recognition of this life history parameter possible. Thus, female $\underline{\text { S. obesus }}$ in the Colorado Desert were reproductively mature at body sizes as small as $127 \mathrm{~mm}$ SVL. However, the size at reproductive matur- 
ity in females was strongly correlated with food availability (Table XXXVI). In 1979, when food was most abundant, nearly all females 125 - $140 \mathrm{~mm}$ SVL attained reproductive condition. In 1980 and 1982, when food availability was considerably less, very few individuals smaller than $150 \mathrm{~mm}$ SVL attained reproductive condition. It appeared that the latter situation more closely approximated typical environmental conditions (Ch. 5 - Life Tables). Therefore, size at reproductive maturity of Colorado Desert female $\underline{S}$. obesus may of ten be about $150 \mathrm{~mm}$ SVL. This body size is the same as that reported by Berry (1974), but it appears many more $150 \mathrm{~mm}$ females attained reproductive maturity in this study than Berry's. Consequently, size at reproductive maturity for Colorado Desert female $\underline{S}$. obesus was frequently smaller than previously reported. Age at reproductive maturity is a fundamental parameter of life history studies (Cole,1954; Williams,1966a \& b; Stearns, 1976), but it is difficult to discern for several lizard species. Berry (1974) measured age at reproductive maturity of Mojave Desert $\underline{S}$. obesus from growth rates of marked lizards. Ideally, age at reproductive maturity can be discerned by mark and recapture of cohorts initially captured in their first year, a procedure I used at the Red Cloud Road study site. Questions I asked for Colorado Desert $\underline{\text { S. obesus }}$ were: 1) What is the age at reproductive maturity for males? 2) What is the age at reproductive maturity for females? 3) How does the age at reproductive maturity vary from year to year in both sexes?.

Berry (1974) reported that nearly all male $\underline{S}$. obesus attained reproductive maturity ( $150 \mathrm{~mm}$ SVL) at 3 years of age in the Mojave 
TABLE XXXVI

BREEDING FREQUENCY OF COLORADO DESERT FEMALE $\underline{S}$. obesus DURING 5 CONSECUTIVE YEARS. NUMBERS IN BRACKETS INDICATE SAMPLE SIZES

\begin{tabular}{|c|c|c|c|c|c|}
\hline \multirow[b]{2}{*}{ SVL } & \multicolumn{5}{|c|}{ Breeding Frequency } \\
\hline & 1978 & 1979 & 1980 & 1981 & 1982 \\
\hline $125-129$ & $0.05(21)$ & $1.00(1)$ & - & $0.00(1)$ & $0.00(1)$ \\
\hline $130-139$ & 0.29 (17) & $0.92(13)$ & $0.00(1)$ & $0.00(2)$ & $0.00(4)$ \\
\hline $140-149$ & 0.74 (19) & $1.00(11)$ & $0.12(17)$ & $0.00(6)$ & $0.00(4)$ \\
\hline $150-159$ & $0.91 \quad(32)$ & $0.95(21)$ & 0.38 (13) & $0.00(6)$ & $0.38(6)$ \\
\hline
\end{tabular}


Desert, but since only tyrants court adult females successfully, ecological maturity (> $185 \mathrm{~mm}$ SVL) required over 6 years for most individuals. My observation of cohorts at the Red Cloud Road study site (Fig. 41 and Table XXXVII), revealed that male $\underline{\mathrm{S}}$ obesus usually produced sperm in their second year ( $\geq 125 \mathrm{~mm} \mathrm{SVL}$ ) and successfully courted adult females in their fourth year ( $\geq 165 \mathrm{~mm}$ SVL). In addition, most male $\underline{\mathrm{S}}$. obesus attained tyrant status within 6 years at the Red Cloud Road study site. Consequently, Colorado Desert male S. obesus attained physical and ecological maturity at a younger age and smaller size than did their male counterparts in the Mojave Desert. According to Berry (1974), it required 5 years for some northern Mojave Desert female $\underline{S}$. obesus to attain reproductive maturity $(150 \mathrm{~mm}$ SVL). Furthermore, her data suggest that most individuals required several more years to become reproductively mature (Ch.5 - Life Tables). My study of marked cohorts at Red Cloud Road (Fig. 41 and Table XXXVII), revealed that female $\underline{S}$. obesus there usually attained reproductive maturity at between 2 and 5 years of age. As stated above, reproductive maturity and food availability were strongly correlated in this study. In 1978 and 1979 when food was abundant, females frequently became mature at 2-3 years (130 mm SVL), but in 1980 and 1982 much less food was available and females became mature at 4 - 5 years ( $150 \mathrm{~mm}$ SVL). It appears that the latter age is more typical because of prevailing environmental conditions (see Ch. 5 Life Tables). In either case, female $\underline{\mathbf{s}}$ - obesus in the Colorado Desert attained reproductive maturity at a younger age - sometimes in half the time - than did their Mojave Desert female counterparts. 
Figure 41. Growth rates of a cohort of Red Cloud Road study site S. obesus marked as yearlings in 1977. Shaded bars = females and clear bars $=$ males; horizontal lines = means; vertical lines = ranges; bars $= \pm 2$ standard errors; numbers = sample sizes. 


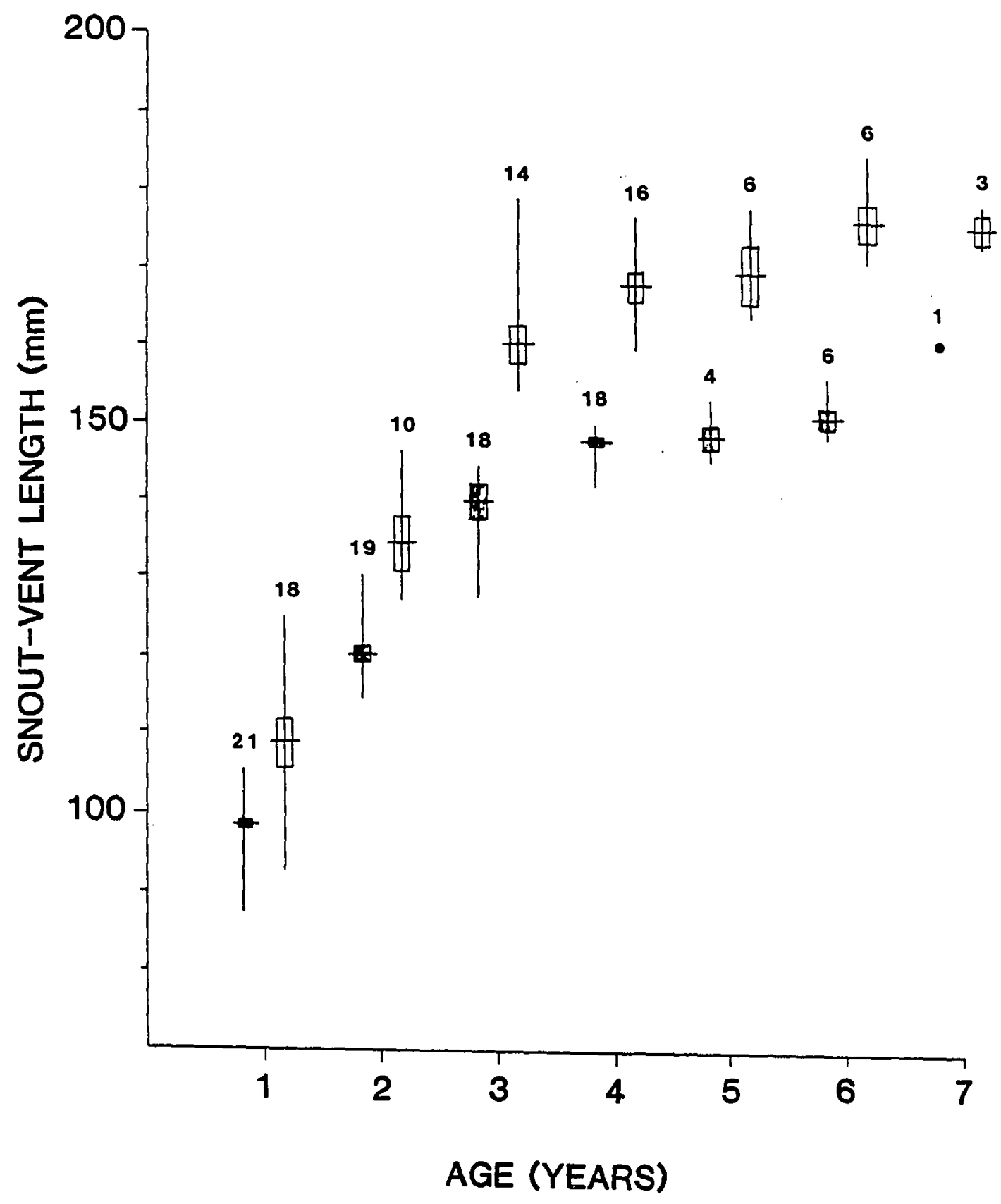


TABLE XXXVII

RANGE IN BODY SIZE FOR 7 AGE CLASSES OF COLORADO DESERT $\underline{\text { S. obesus }}$ DATA WERE COMPILED FROM 5 DIFFERENT COHORTS $\mathrm{N}=$ SAMPLE SIZE

\begin{tabular}{ccccc}
\hline & \multicolumn{2}{c}{ Males } & \multicolumn{2}{c}{ Females } \\
\hline Year & SVL Range & $\mathrm{N}$ & SVL Range & $\mathrm{N}$ \\
\hline 1 & $93-131$ & 27 & $86-115$ & 34 \\
2 & $113-150$ & 22 & $107-142$ & 27 \\
3 & $143-177$ & 20 & $127-152$ & 21 \\
4 & $153-178$ & 22 & $139-155$ & 22 \\
5 & $153-178$ & 11 & $146-150$ & 4 \\
6 & $171-186$ & 6 & $145-157$ & 6 \\
7 & $172-177$ & 7 & 161 & 1 \\
\hline
\end{tabular}


Relatively early maturity for Colorado Desert $\underline{S}$. obesus coincided with other life history attributes I observed. It will be shown that this population frequently experiences high reproductive success, high juvenile survivorship and low adult survivorship. High reproductive success due to increased food availability, and high juvenile survivorship due to increased summer precipitation, result in greater numbers of individuals which probably make this population more susceptible to predation and hence lower its adult survivorship. Since the environmental conditions that promote reproduction also lower adult survivorship, it is important for reproductive maturity to occur at an early age. Preliminary investigation indicates that under more severe environmental conditions such as limited food availability and summer precipitation, delayed maturity for Mojave Desert $\underline{S}$. obesus complies with such life history attributes as low reproductive success, low juvenile survivorship and high adult survivorship. Consequently, these observations for various populations of $\underline{S}$. obesus are in accordance with contemporary theories of life history evolution (see Ch. 5 Life Tables).

\section{CLUTCH SIZE}

Clutch sizes were determined for adult female $\underline{S}$. obesus captured within a $15 \mathrm{~km}$ radius of the Red Cloud Road study site. Three different criteria were used to determine clutch size: 1) enlarged ovarian follicles (diameters $\geq 10 \mathrm{~mm}$ ); 2) oviductal eggs; and 3) corpora lutea. Enlarged ovarian follicles and corpora lutea estimate clutch size as reliably as the presence of oviductal eggs, since the former rarely 
became atretic and the latter were clearly discernable for at least a month after oviposition (Ch. 5 - Female Reproductive Cycle). Consequently, the 3 criteria have been pooled in the calculation of mean clutch size and all ensuing relationships. The following questions regarding the clutch size of Colorado Desert female $\underline{S}$. obesus were asked: 1) What is the mean clutch size? 2) To what extent is clutch size correlated with body size ( $\mathrm{mm}$ SVL)? 3) What environmental factors influence the correlation between body size and clutch size?

Limited information was available on clutch size for adult female S. obesus (Berry, 1974; Case, 1982). Berry (1974) reported a mean clutch size of 7.8 eggs for 22 museum specimens collected between 1908 and 1970 throughout the range of $\underline{S}$. obesus based mainly on enlarged ovarian follicles (diameter $\geq 10 \mathrm{~mm}$ ). However, from extrapolations of her regression figure, I calculated a mean clutch size of 8.5 (S. E. \pm 0.47$)$ eggs. The mean annual and mean 6-year (1978 - 1983) clutch sizes for female $\underline{S}$. obesus I studied were less than either of these means except in 1982 (Table XXXVIII). For example, a mean clutch size of 6.9 (S. E. \pm 0.22 ) eggs was calculated for the 6-year period. However, from the comparison of clutch size and body size (see below) it appears that the differences in mean clutch size between the 2 studies can be accounted for to a large extent by differences in mean body sizes.

Linear regression analysis for Berry's (1974) data indicate that clutch size and body size (SVL) were highly correlated $(r=0.70$, clutch size $=0.12 \mathrm{~mm}-11.36, \mathrm{~N}=22, \mathrm{P}<0.001)$. An analysis of covariance (ANCOVA) was performed 1978 through 1980 to see if there 
TABLE XXXVIII

MEAN CLUTCH SIZE AND MEAN BODY SIZE (mm SVL) FOR ADULT FEMALE $\underline{\text { s. obesuS }}$

\begin{tabular}{|c|c|c|c|c|c|}
\hline Study & N & $\begin{array}{l}\text { Mean Clutch } \\
\text { Size } \pm 1 \text { s. e. }\end{array}$ & $\begin{array}{l}\text { Clutch Size } \\
\text { Range }\end{array}$ & $\begin{array}{l}\text { Mean SVL } \\
\pm 1 \text { s. e. }\end{array}$ & SVL Range \\
\hline Berry (1974) & 22 & $8.5 \pm 0.5$ & $6-13$ & $164.0 \pm 2.7$ & $145-189$ \\
\hline \multicolumn{6}{|l|}{ Present } \\
\hline 1978 & 47 & $6.7 \pm 0.3$ & $2-14$ & $155.9 \pm 2.4$ & $127-208$ \\
\hline 1979 & 47 & $6.9 \pm 0.4$ & $3-15$ & $157.3 \pm 2.4$ & $131-205$ \\
\hline 1980 & 16 & $7.1 \pm 0.5$ & $3-11$ & $160.6 \pm 2.5$ & $146-177$ \\
\hline 1982 & 3 & $8.7 \pm 0.6$ & $8-10$ & $168.3 \pm 3.8$ & $161-174$ \\
\hline Total & 115 & $6.9 \pm 0.2$ & $2-15$ & $157.6 \pm 1.4$ & $127-208$ \\
\hline
\end{tabular}


was an annual variation in clutch size for Colorado Desert female S. obesus of a given SVL, in addition to clutch size variation reflecting differences in body size. Results of this analysis indicated that there were no significant differences among years for both slope (ANCOVA: $F_{2}, 104=1.94, P>0.50$ ) and elevation (ANCOVA: $F_{2}, 104=$ $0.19, P>0.50$ ) of clutch size versus body size. Consequently, pooling individuals from the period 1978 through 1983 (Fig. 42) showed a highly significant correlation between clutch size (CS) and snoutvent length $(\mathrm{mm}) ; C S=0.12 \mathrm{~mm}-11.4(\mathrm{r}=0.77 ; \mathrm{N}=115 ; \mathrm{P}<0.001)$ similar to the results of Berry. For the present study, clutch size increased by 1 egg for every $8.62 \mathrm{~mm}$ increase in SVL. The variation in clutch size explained by body size was somewhat less in Berry's study than in the present one $\left(r^{2}=0.49\right.$ and 0.59 , respectively). Regarding the former, the large temporal and spatial data base is probably accompanied by tremendous variation in environmental factors. Certain environmental factors explain much of the variation in clutch size for Colorado Desert female $\underline{S}$. obesus. Nonetheless, the nearly identical slopes of the 2 samples suggests that the effects of body size on clutch size were similar. From this, it would appear that throughout the species' geographic range, a particular change in SVL will yield a similar change in clutch size.

Studies that have considered the influence of climatic factors on reproduction are essentially lacking for iguanine lizards (Wiewandt, 1982), and no studies have determined the effect of various climatic factors on the clutch size of $\underline{S}$. obesus. Regression analyses were performed to discern the relationship of clutch size to a number of 
Figure 42. Clutch size body size relationship for 115 adult female $\underline{\text { S}}$. obesus captured during 6 consecutive years $(1978$ - 1983). Numbers indicate multiple values. 


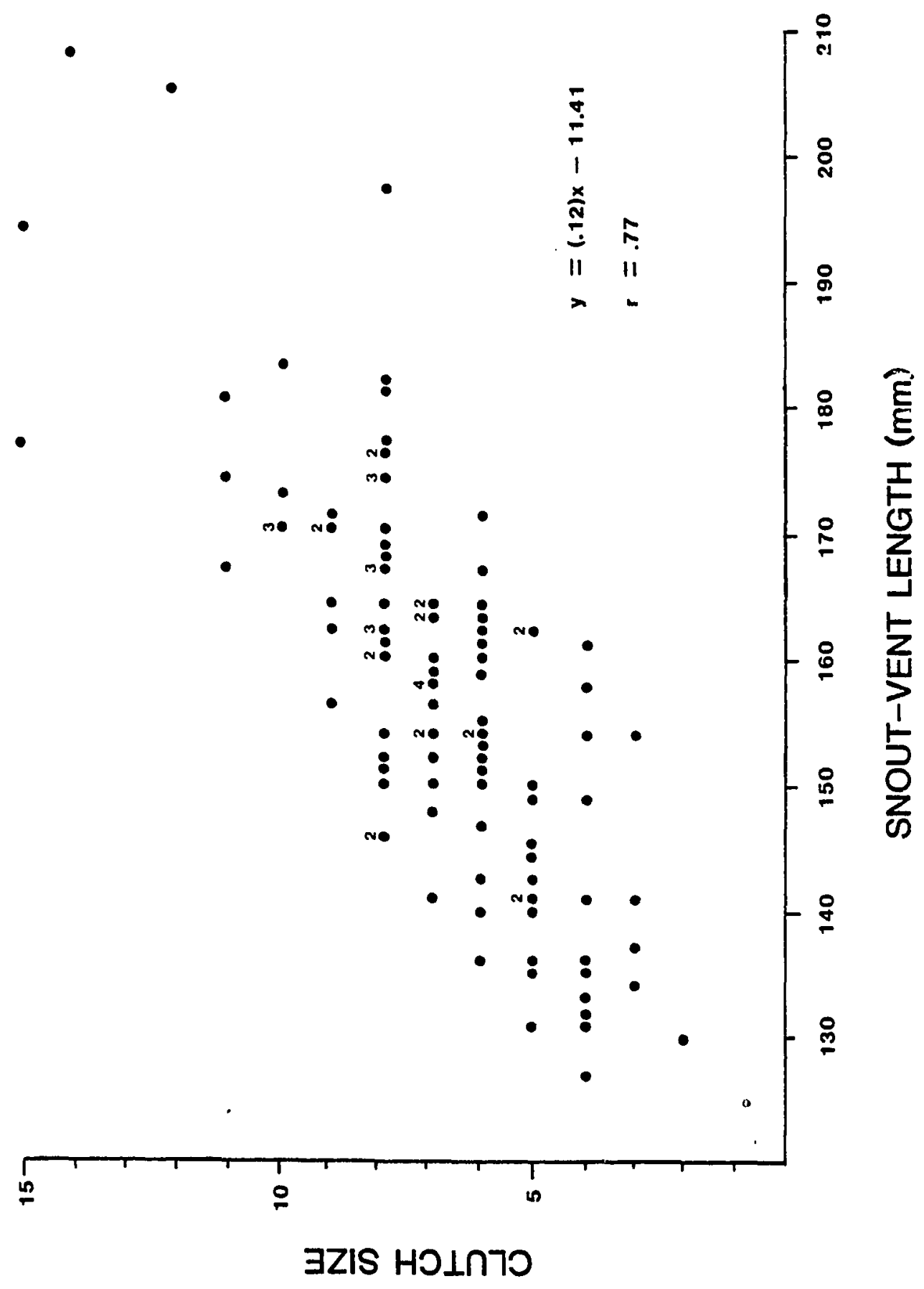


climatic factors for Colorado Desert female $\underline{S}$. obesus (Table XXXIX). Simple linear regression of clutch size on 11 climatic factors, showed that the growth of perennial stems and precipitation October through January were most highly correlated with clutch size $(P<0.001)$.

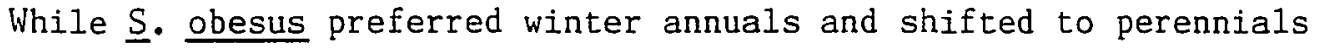
only when the former declined, the correlation with perennial stem elongation may reflect the fact that this parameter served as a good predictor of overall vegetation growth. The same may be said for October through January precipitation. A 2-variable multiple regression which matched certain climatic factors with body size showed perennial stem elongation and spring growing season to have the highest correlation with clutch size. Spring growing season was simply the time period within the activity season of Colorado Desert $\underline{S}$. obesus in which winter annuals were available. Consequently, it served as an indication of the length of time that optimal dietary sources were present. A combination of body size and these 2 climatic factors in a 3-variable multiple regression accounted for about $80 \%$ of the variance in clutch size for this species. The remaining $20 \%$ of the variance may include other climatic factors that were not considered and such complexities as the effect of reproduction in consecutive years on clutch size.

Several tendencies for clutch size of Colorado Desert female s. obesus were apparent. In order for mean clutch size to have relevance in life history studies, size-specific (or age-specific) relationships of breeding females must be available. Investigations on the influence of environmental factors for a given size category, 
TABLE XXXIX

REGRESSION ANALYSIS OF THE RELATIONSHIP OF CLIMATIC FACTORS AND CLUTCH SIZE. UNITS AS IN CHAPTER 1. *** DENOTES $\mathrm{P}<0.001$;

** DENOTES $\mathrm{P}<0.01 ; *$ DENOTES $\mathrm{P}<0.05 ; \mathrm{N}=25$

\begin{tabular}{|c|c|c|c|c|}
\hline Climatic Parameter & Slope & Intercept & \multicolumn{2}{|l|}{$\mathrm{r}^{2}$} \\
\hline \multicolumn{5}{|l|}{ Linear Regression } \\
\hline Winter Precipitation (Oct-Jan) & 0.69 & 9 & $0.45:$ & 和米 \\
\hline Perennial Stem Elongation & 0.28 & 3 & $0.44 *$ & 前: \\
\hline Mean Winter Temperature (max) & -01.62 & 42 & $0.28 *$ & $\because \%$ \\
\hline Winter Precipitation (Oct-Mar) & 0.43 & 2 & $0.26 *$ & $* *$ \\
\hline Spring Growing Season & 2.86 & 69 & $0.25 *$ & \\
\hline December Precipitation & 0.10 & 0 & $0.22 ;$ & * \\
\hline Peak (Apr) Standing Crop & 0.17 & 4 & $0.16:$ & \\
\hline Mean Winter Temperature & 0.70 & 47 & 0.10 & \\
\hline March Precipitation & 0.01 & 1 & 0.09 & \\
\hline Summer Precipitation (Jul-Sep) & 0.34 & 2 & 0.08 & \\
\hline February Precipitation & 0.09 & 8 & 0.07 & \\
\hline \multicolumn{5}{|l|}{ Multiple Regression } \\
\hline $\begin{array}{l}\text { Perennial Stem Elongation } \\
\text { with Spring Growing Season }\end{array}$ & - & - & $0.43=$ & *K \\
\hline $\begin{array}{l}\text { Body Size with Perennial } \\
\text { Stem Elongation }\end{array}$ & - & - & $0.76=$ & 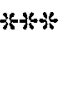 \\
\hline $\begin{array}{l}\text { Body Size with Spring } \\
\text { Growing Season }\end{array}$ & - & - & 0.67 & F** \\
\hline $\begin{array}{l}\text { Body Size with Perennial } \\
\text { Stem Elongation and Spring } \\
\text { Growing Season }\end{array}$ & - & - & 0.77 & * \\
\hline
\end{tabular}


presently lacking, may illustrate the uniformity of clutch size in different body size categories. Individuals of a given SVL, had a uniform clutch size between years (Fig. 42). However, variability in clutch size tended to increase with increases in body size. This flexibility probably reflected certain physiological advantages - e.g., resistance to poor environmental conditions - acquired for being larger (Wiewandt, 1982). Nonetheless, in this study large female $\underline{S}$. obesus were rare (Ch. 5 - Longevity). It is interesting to note that for a given body size the clutch size of individuals in Berry's (1974) study were very similar to the present study. Even the subspecies $\underline{s}$ 으 tumidus, which is similar in size to $\underline{S}$. ㅇ. obesus appeared to show this same relationship (Prieto, 1977). Case (1982) believed giant Sauromalus on islands demonstrated a unique reproductive tactic of reproducing maximally or not at all. This so called "boom or bust" iteroparity seems just as applicable to some mainland $\underline{S}$ - obesus populations. Many individual $\underline{S}$. obesus often put off reproduction, and thus showed yearly fluctuation in the range of body sizes successfully achieving reproduction, in the face of changing climatic conditions, instead of altering their clutch size (Ch.4-Reproductive Frequency). When food resouces were optimal, all females of SVL $\geq 125 \mathrm{~mm}$ were potential breeders. When food resources were average, the minimum SVL of breeding females was about $150 \mathrm{~mm}$. This situation appeared different than that determined for a number of insectivorous lizards (Turner et al., 1970; Tinkle and Ballinger, 1972; Dunham, 1982). Consequently, clutch size of Colorado Desert $\underline{S}$. obesus does not fully reflect the resource availability component of life history theory (Stearns, 1976 \& 1977). 
Instead, for reproductive individuals, stability in clutch size may be the result of the impact of the demographic environment (Ch. 5 Survivorship). For the Colorado Desert study area, stability in clutch size may be further enhanced by increased predictability over the Mojave Desert of climate, especially with regard to longer growing season and summer precipitation (Ch. 5 - Life Tables).

\section{FREQUENCY OF REPRODUCTION}

Previous estimates of reproductive frequency (percent of the population breeding in a given year) for female $\underline{S}$. obesus have limited application for understanding a population's nesting phenology. This is because they were established from population studies that did not determine minimum size of reproduction (Johnson, 1965; Nagy, 1973; Berry, 1974) or from examination of museum specimens collected within a wide temporal and spatial framework (Berry, 1974; Case, 1982). While some of these studies hypothesized the environmental causes of reproductive frequency for females, none attempted to quantify specific parameters. Nesting phenology only has relevance when interpreted in light of its role in life history strategy, which in turn is broadly influenced by the environment, especially climatic factors. The following questions were addressed regarding reproductive frequency in Colorado Desert female $\underline{S}$. obesus; 1) What is the frequency of reproduction? 2) Why is there variability in frequency of reproduction? 3) What climatic factors affect reproductive frequency?

Earlier investigations have suggested that frequency of reproduction for female $\underline{S}$. obesus is low. Annual population estimates have 
ranged from 0\% (Nagy, 1973; Berry, 1974) to about 32\% (Johnson, 1965). I suspect the value of $32 \%$ should be higher because some of the females in Johnson's sample $(N=19)$ were well below minimum size for reproduction. Berry (1974) and Case (1982) made 2 overlapping examinations of museum specimens collected throughout most of the century over much of the species range. Their efforts revealed a frequency of reproduction of $42 \%(N=47)$ and $38 \%(N=32)$, respectively. Such observations have led to the suggestion that female $\underline{S}$. obesus largely reproduce in alternate years.

Frequency of reproduction for Colorado Desert adult female $\underline{S}$. obesus in this study from 1978 - 1982 (Fig. 43) revealed significant variation from year to year (ANOVA: $F_{4,17}=14.25 ; P<0.01$ ). The frequency of reproduction ranged from 0\% (1981) to about 95\% (1979) and was correlated with variation in climate (see below). The 5-year mean frequency of reproduction was 52 (S. E. \pm 16 ) percent. This value was considerably greater than any previously reported. However, in 1981, a full year of drought occurred, and at this time reproduction was curtailed. During the 25 years prior to this investigation dry years such as 1981 were common (Ch. 1 - Climate and Vegetation). Consequently, reproductive frequency for female $\underline{S}$. obesus in the study region probably is lower for other time periods. While my data showed that nearly $100 \%$ of the adult females can reproduce in one year, it appears that such high frequencies of reproduction are uncommon based on climatic data for the region. Both 1980 and 1982 appeared to be intermediate climatic years (see below). For these years, frequency of reproduction was $39 \%$ and $45 \%$, respectively. These values are simi- 
Figure 43. Annual reproductive frequency for Colorado Desert adult S. obesus. shading = reproductive adult females; year, sample size and reproductive frequency provided above. 


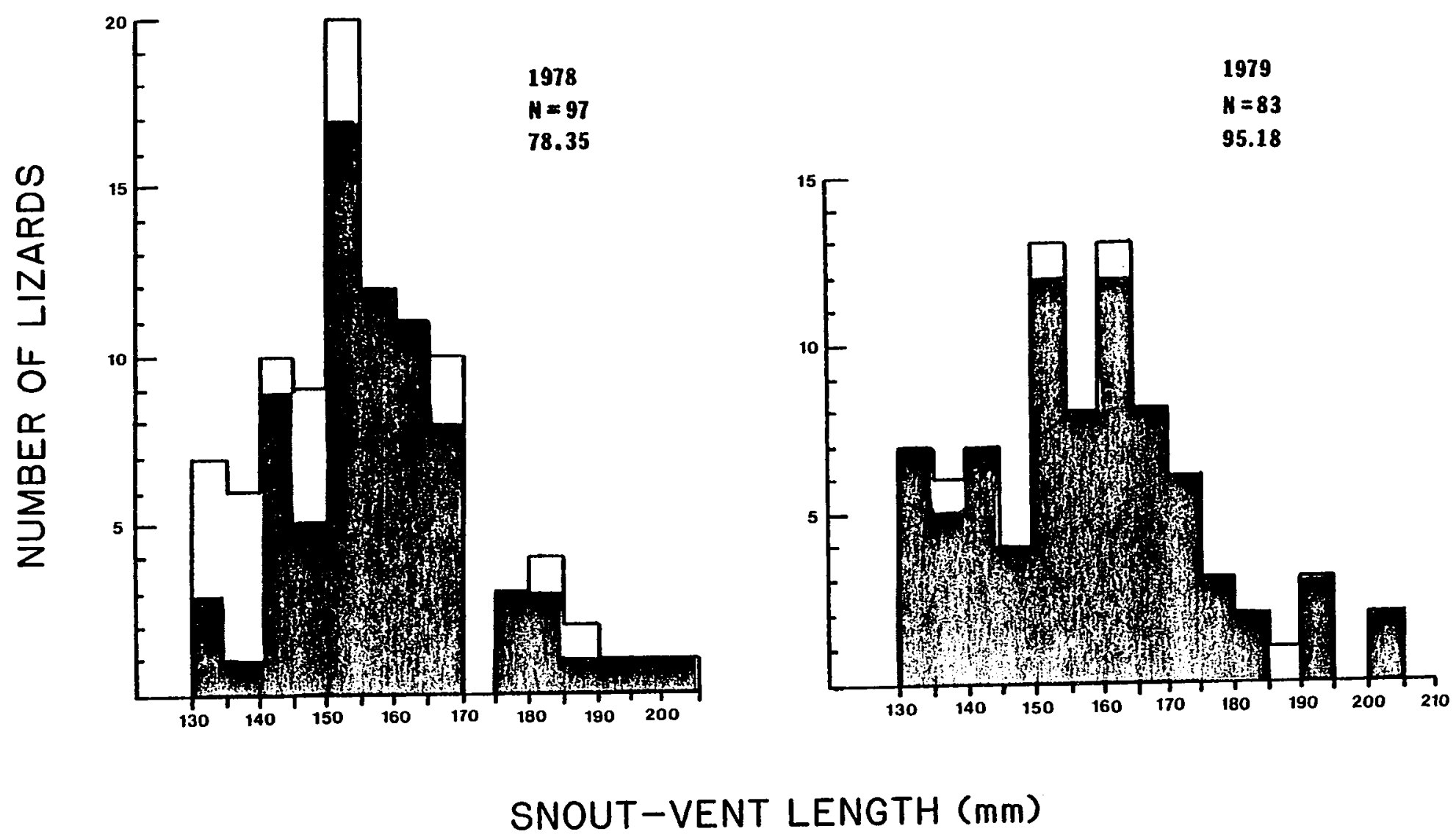



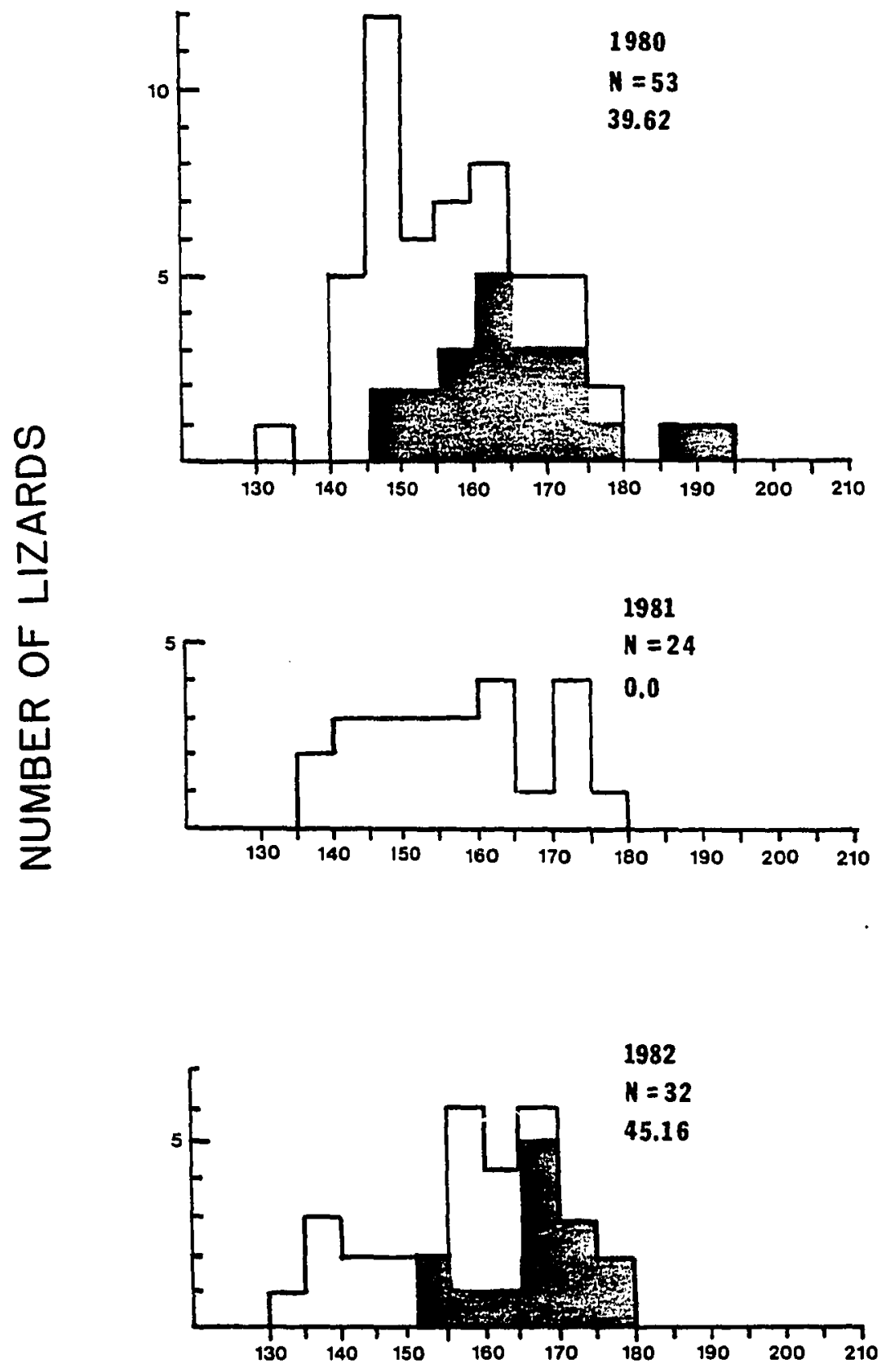

SNOUT-VENT LENGTH $(\mathrm{mm})$ 
lar to those reported for other studies (Berry, 1974; Case, 1982). Because my determinations are based on individuals collected over a 5-year period, perhaps the mean for this time reflects a normal response to the overall prevailing climate and thus suggests an average reproductive frequency for female $\underline{S}$. obesus.

Reproductive frequency between different size groups (increments of $10 \mathrm{~mm}$ SVL) significantly varied during the 5-year study (ANOVA: $\mathrm{F}_{20,190}=2.42 ; \mathrm{P}<0.01$ ). In general, the smallest individuals (SVL about $130 \mathrm{~mm}$ ) reproduced in only the most favorable years such as 1978 and 1979 , but individuals of SVL $\geq 150 \mathrm{~mm}$ reproduced in all years equal to or exceeding average conditions (1978 - 1980, 1982 - 1983). Recapture data for the marked population at Red Cloud Road from 1978 1981 allowed determination of the effect of body size on frequency of reproduction. Twenty-two marked female $\underline{S}$. obesus, encompassing the entire range of adult body sizes for the population, were recaptured during the breeding season in each of the 4 years (Table XXXX). A 4-year mean SVL and frequency of reproduction was determined for each individual. Linear regression analysis of the relationship of mean SVL and frequency of reproduction showed a significantly positive correlation $(r=0.78, y=(0.01) x-1.29, N=22, P<0.001)$. Larger female S. obesus have a much higher frequency of reproduction than do smaller females. To document this tendency further, for the period 1978 1983, 2 adult female $\underline{\text { S. }}$ obesus, 67 (SVL last capture $=174 \mathrm{~mm}$ ) and 107 (SVL last capture $=172 \mathrm{~mm}$ ) have reproduced in 5 of 6 consecutive years. From the above, it would appear that breeding in consecutive years is possible much of the time. A similar trend was observed for 
TABLE XXXX

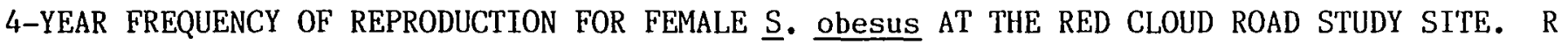
DENOTES REPRODUCTIVE AND N DENOTES NONREPRODUCTIVE

\begin{tabular}{|c|c|c|c|c|c|c|}
\hline \multirow[b]{2}{*}{ Lizard } & \multicolumn{4}{|c|}{ SVL/Year } & \multirow[b]{2}{*}{$\begin{array}{l}\text { 4-year } \\
\bar{x} \text { SVL }\end{array}$} & \multirow[b]{2}{*}{$\begin{array}{l}\text { Frequency of } \\
\text { Reproduction }\end{array}$} \\
\hline & 1978 & 1979 & 1980 & 1981 & & \\
\hline 5 & $169 \mathrm{R}$ & $171 \mathrm{R}$ & $178 \mathrm{~N}$ & $178 \mathrm{~N}$ & 174 & 0.50 \\
\hline 17 & $192 \mathrm{R}$ & $194 \mathrm{R}$ & $195 \mathrm{R}$ & $195 \mathrm{~N}$ & 194 & 0.75 \\
\hline 51 & $147 \mathrm{R}$ & $153 \mathrm{R}$ & $162 \mathrm{~N}$ & $162 \mathrm{~N}$ & 156 & 0.50 \\
\hline 52 & $117 \mathrm{~N}$ & $140 \mathrm{R}$ & $149 \mathrm{~N}$ & $150 \mathrm{~N}$ & 139 & 0.25 \\
\hline 58 & $120 \mathrm{~N}$ & $144 \mathrm{R}$ & $150 \mathrm{~N}$ & $150 \mathrm{~N}$ & 141 & 0.25 \\
\hline 60 & $142 \mathrm{R}$ & $161 \mathrm{R}$ & $164 \mathrm{R}$ & $164 N$ & 158 & 0.75 \\
\hline 62 & $139 \mathrm{~N}$ & $155 \mathrm{R}$ & $157 \mathrm{~N}$ & $157 \mathrm{~N}$ & 152 & 0.25 \\
\hline 64 & $165 \mathrm{R}$ & $174 \mathrm{R}$ & $175 \mathrm{R}$ & $175 \mathrm{~N}$ & 172 & 0.75 \\
\hline 67 & $152 \mathrm{R}$ & $160 \mathrm{R}$ & $167 \mathrm{R}$ & $168 \mathrm{~N}$ & 162 & 0.75 \\
\hline 86 & $121 \mathrm{~N}$ & $140 \mathrm{R}$ & $146 \mathrm{~N}$ & $147 \mathrm{~N}$ & 139 & 0.25 \\
\hline 88 & $122 \mathrm{~N}$ & $140 \mathrm{R}$ & $147 \mathrm{~N}$ & $147 \mathrm{~N}$ & 139 & 0.25 \\
\hline 94 & $160 \mathrm{R}$ & $169 \mathrm{R}$ & $172 \mathrm{R}$ & $172 \mathrm{~N}$ & 168 & 0.75 \\
\hline 100 & $153 \mathrm{R}$ & $165 \mathrm{R}$ & $171 \mathrm{~N}$ & $174 \mathrm{~N}$ & 166 & 0.50 \\
\hline
\end{tabular}


TABLE XXXX (Con't)

\section{SVL/Year}

\begin{tabular}{lllllll} 
Lizard & 1978 & 1979 & 1980 & 1981 & $\begin{array}{l}\text { 4-Year } \\
\bar{x} \text { SVL }\end{array}$ & $\begin{array}{l}\text { Frequency of } \\
\text { Reproduction }\end{array}$ \\
\hline 107 & $158 \mathrm{R}$ & $163 \mathrm{R}$ & $165 \mathrm{R}$ & $166 \mathrm{~N}$ & 163 & 0.75 \\
109 & $121 \mathrm{~N}$ & $140 \mathrm{R}$ & $150 \mathrm{R}$ & $150 \mathrm{~N}$ & 140 & 0.50 \\
112 & $167 \mathrm{R}$ & $172 \mathrm{R}$ & $174 \mathrm{R}$ & $174 \mathrm{~N}$ & 172 & 0.75 \\
116 & $115 \mathrm{~N}$ & $137 \mathrm{R}$ & $144 \mathrm{~N}$ & $146 \mathrm{~N}$ & 136 & 0.25 \\
125 & $127 \mathrm{~N}$ & $140 \mathrm{R}$ & $147 \mathrm{~N}$ & $148 \mathrm{~N}$ & 141 & 0.25 \\
146 & $146 \mathrm{~N}$ & $152 \mathrm{R}$ & $157 \mathrm{~N}$ & $157 \mathrm{~N}$ & 153 & 0.25 \\
153 & $143 \mathrm{~N}$ & $154 \mathrm{R}$ & $160 \mathrm{R}$ & $160 \mathrm{~N}$ & 154 & 0.50 \\
170 & $123 \mathrm{~N}$ & $137 \mathrm{R}$ & $149 \mathrm{~N}$ & $150 \mathrm{~N}$ & 140 & 0.25 \\
171 & $152 \mathrm{R}$ & $158 \mathrm{R}$ & $162 \mathrm{R}$ & $162 \mathrm{~N}$ & 159 & 0.75 \\
\hline
\end{tabular}


S. ㅇ․ tumidus in Arizona (Prieto, 1977).

Although the SVL of females 67 and 107 were large for the Red Cloud Road population, they are near the low end of the range (170 $205 \mathrm{~mm}$ SVL) of the adult contingent reported by Berry (1974) to contribute most to reproduction. Apparently, though large body size imparts some reproductive advantages, achieving near maximum size is not prerequisite to successful reproduction. According to life history theory, selection should favor individuals making the earliest possible investment in reproduction without sacrificing long-term reproductive success (Pianka, 1976). A female accomplishes this by channelling energy either into ova (present reproduction) or into growth (for future reproduction). Climatic conditions impose limits on the time and duration of a female's growing and reproductive season (Wiewandt, 1982). Such climatic limits are extremely variable for inhabitants of North American Deserts. The decision to reproduce carries with it risks such as dehydration, starvation and susceptability to predation. Based on the data of previous studies (Johnson, 1965; Nagy, 1973; Berry, 1974), female $\underline{S}$. obesus did not produce clutches every year because annual reproduction curtailed growth (mm SVL) and decreased the chance of survival. In other words, low frequency of reproduction minimized the cost of devoting a great deal of energy in an uncertain environment. According to Wiewandt (1982) in order for reproduction to be possible for iguanines, 2 criteria have to be met: foraging conditions have to be greatly increased prior to the nesting season, and energy reserves must be elevated in the previous year. These criteria have been considered for female $\underline{S}$. obesus at the Red 
Cloud Road study site (Ch. 5 - Life Tables).

A rough estimate of the cost or reproduction as it pertains to starvation and dehydration was achieved by recording maximum spring and mid-summer body mass of recaptured individuals. Table XXXXI shows the mean percentage of maximum spring body mass of individuals captured in mid-summer from 1977 - 1980. Reproduction occurred in all 4 years, and all 1978 and 1979 recaptures represent female $\underline{S}$. obesus that reproduced. One shortcoming of this procedure is that mass includes some individuals with engorged digestive tracts. However, the masses of gut contents were not great enough to obscure the pattern presented. The mean mass percentages of 1977 and 1979 were considerably greater than for 1978 and 1980. The mean mass percentage of reproductive females for 1979 was significantly greater than that for 1978 and 1980 combined $(t=5.48, d f=27, P<0.001)$. In 1977 and 1979 , there was a marked increase in summer activity in response to summer precipitation (Ch. 2 - Annual Activity Cycle of Chuckwallas). Episodes of feeding were common at this time. Consequently, female S. obesus regained some of the mass lost over the summer. Loss of mass can be attributed to the laying of eggs and to the draining of somatic energy reserves. The latter can occur during 3 intervals around reproduction: 1) preoviposition - no room for food in the abdomen; 2) oviposition - the searching for and construction of a nest and 3) postoviposition - food resources were nonexistant when no summer precipitation occurred. Clutch mass accounted for about one-third of the total spring maximum body mass (Ch.4 - Reproductive Effort). Additional observed losses in body mass were due to meta- 
TABLE XXXXI

BODY MASS FLUCTUATION FOR RED CLOUD ROAD STUDY SITE FEMALE $\underline{S}$. obesus. EXPRESSED AS MEAN SUMMER BODY MASS PERCENT OF PEAK SPRING BODY MASS. ALL FEMALES IN

1978 AND 1979 SAMPLES WERE REPRODUCTIVE. $\mathrm{N}$ = SAMPLE SIZE. * INDICATES YEAR IN WHICH THERE WAS SUBSTANTIAL SUMMER PRECIPITATION

\begin{tabular}{lccc}
\hline Year & $\mathrm{N}$ & Mean $\pm 1 \mathrm{~s} . \mathrm{e}$ & Range \\
\hline $1977 *$ & 12 & $0.85 \pm 0.02$ & $0.71-0.98$ \\
1978 & 5 & $0.53 \pm 0.03$ & $0.45-0.63$ \\
$1979 *$ & 19 & $0.79 \pm 0.02$ & $0.57-0.90$ \\
1980 & & & \\
Total & 15 & $0.73 \pm 0.03$ & $0.57-0.89$ \\
$\quad$ Reproductive & 6 & $0.62 \pm 0.02$ & $0.57-0.69$ \\
$\quad$ Nonreproductive & 9 & $0.80 \pm 0.03$ & $0.62-0.89$ \\
\hline
\end{tabular}


bolic costs $(\bar{x}=10 \%$, S. E. $\pm 0.05, N=10)$. By reproducing, some individuals lost over half their spring maximum body mass, whereas most individuals that did not reproduce lost only about one-fifth of their spring maximum body mass. For 1980, the difference was highly significant $(t=7.87, \mathrm{~d} f=12, \mathrm{P}<0.001)$. Since the difference indicated lowered stores of water and energy, reproductive female $\underline{S}$. obesus might be considerably more vulnerable to starvation and/or dehydration. However, for the Colorado Desert study area, a significant portion of the annual precipitation falls in the summer (Ch. 1 - Climate and Vegetation). This is not true for the Mojave Desert localities in which other studies were undertaken (Johnson, 1965; Nagy, 1973; Berry, 1974). Consequently, female $\underline{S}$. obesus in the Colorado Desert have increased chances of replenishing depleted energy reserves over the summer. This situation has tremendous influence on over-winter survival.

Though climatic conditions in the Colorado Desert might have been favorable for reproduction, the fact that smaller female $\underline{S}$. obesus (SVL range 130-150 mm) reproduced only in optimal years seemed to indicate that larger size imparted some advantages. According to Wiewandt (1982) the advantages of large size for female iguanines includes: 1) increased fecundity; 2) production of clutches with greater consistency or at shorter intervals; 3 ) a significant decrease in predation; 4) increased success in nest defense, and 5) increased resistance to dehydration and starvation. It has been shown that for female $\underline{S}$. obesus inhabiting the Colorado Desert,body size is highly correlated with clutch size and frequency of reproduction. Two other 
points, predation and nest defense, were only marginally investigated. The role of predation will be considered below (Ch. 5 - Predation Intensity). From extensive field observations it appears that nest defense against conspecifics is of minimal importance. The one remaining point, increased resistance, will be considered presently.

Female $\underline{S}$. obesus at Red Cloud Road exhibited a pattern of satisfying growth requirements first and reproduction second. For reproducing individuals, increments of spring growth (mm SVL) were generally completed by early May. After this time females began to accelerate the yoking of ovarian follicles. Table XXXXII shows the frequency of reproduction and mean spring growth for female $\underline{S}$. obesus at Red Cloud Road from 1978 - 1982. Because they consistently represented the majority of adult females, data in the table are derived soley from individuals in the $150-170 \mathrm{~mm}$ SVL range. Linear regression analysis revealed a strong positive correlation between spring growth rates and frequency of reproduction $(r=0.98, y=(0.09) x+0.02$, $N=5, P(0.01)$. If smaller female $\underline{S}$. obesus are more susceptible to dehydration and starvation, selection would favor putting energy into growth because that would improve chances of survival to the next reproduction. Just how much a lizard grows before channeling energy into reproduction probably reflects adaptation to prevailing environmental conditions. $\underline{5}$. obesus may reproduce more in the Colorado Desert study area than elsewhere because of the annual precipitation pattern. Summer precipitation is a significant part of the region's annual climatic pattern and it enhances winter survival by making food available in late summer. When summer precipitation is predic- 
TABLE XXXXII

SPRING GROWTH AND FREQUENCY OF REPRODUCTION FOR RED CLOUD ROAD STUDY SITE FEMALE S. obesus OF SVL RANGE 150 - $170 \mathrm{~mm}$. NUMBERS IN PARENTHESES INDICATE SAMPLE SIZE

\begin{tabular}{lcc}
\hline Year & $\begin{array}{c}\text { Frequency of } \\
\text { Reproduction }\end{array}$ & $\begin{array}{c}\text { Mean Spring } \\
\text { Growth (mm SVL) }\end{array}$ \\
\hline 1978 & 0.91 & (16) $10.8 \pm 1.1$ \\
1979 & 0.95 & (19) $9.5 \pm 0.9$ \\
1980 & 0.50 & (15) $4.5 \pm 0.9$ \\
1981 & 0.00 & (7) $0.6 \pm 0.3$ \\
1982 & 0.47 & (10) $4.5 \pm 1.0$ \\
\hline
\end{tabular}


table, growth may more easily be achieved and more frequent reproduction is possible. Since summer precipitation is usually not a significant part of the annual pattern for much of the Mojave Desert (National Weather Bureau), adult female $\underline{S}$. obesus inhabiting this region may greatly benefit by concentrating on growth. That Mojave Desert female $\underline{S}$. obesus breed in alternate years may reflect the fact that they required more time to restore the energy debt of reproduction. Certainly, larger individuals would be less vulnerable to climatic conditions and require less time to accomplish this task. If this is true, it may explain why Berry's adult female population consisted of individuals of much greater size.

Though summer precipitation appeared to enhance the survival

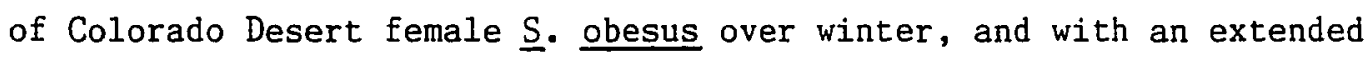
spring growing season shortened the time required to replenish energy stores, winter precipitaion was necessary for reproduction. Vegetation growth - available food - was affected by the timing as well as the amount of precipitation (Ch. 1 - Climate and Vegetation). At Red Cloud Road, $\underline{S}$. obesus preferred to eat winter annuals rather than perennials (Ch. 2 - Dietaty Habits). Substantial early winter precipitation promoted optimal growth in winter annuals. The effect of climate on the frequency of reproduction for Colorado Desert adult female

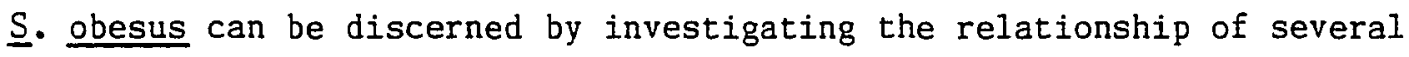
environmental parameters with annual reproduction. Linear regression analysis matching annual breeding success for 5 specific size groups (SVL 135 - $175 \mathrm{~mm}$ ) with 18 environmental parameters from 1978-1982 (Table XXXXIII) showed a strong positive correlation with 11 of the 
TABLE XXXXIII

REGRESSION ANALYSIS OF THE RELATIONSHIP OF CLIMATIC FACTORS AND REPRODUCTIVE FREQUENCY. * DENOTES $\mathrm{P}<0.001 ; \mathrm{N}=25$;

UNITS AS IN CHAPTER 1

\begin{tabular}{|c|c|c|c|}
\hline \multicolumn{4}{|c|}{ Linear Regression } \\
\hline Climatic Parameter & Slope & Intercept & $r^{2}$ \\
\hline Perennial Stem Elongation & 3.82 & -60 & $0.65 *$ \\
\hline Spring Growing Season & 0.40 & 63 & $0.65 *$ \\
\hline $\begin{array}{l}\text { Winter Precipitation } \\
\text { (Oct - Jan) }\end{array}$ & 7.30 & 7 & $0.62 *$ \\
\hline $\begin{array}{l}\text { Winter Precipitation } \\
\text { (Nov - Jan) }\end{array}$ & 9.99 & 2 & $0.60 *$ \\
\hline December Precipitation & 37.93 & 24 & $0.56 *$ \\
\hline $\begin{array}{c}\text { Winter Precipitation } \\
\text { (Nov - Dec) }\end{array}$ & 19.97 & 22 & $0.52 *$ \\
\hline Peak (Apr) Standing Crop & 3.26 & 26 & $0.50 *$ \\
\hline Mean Winter Temperature (max) & -23.70 & 588 & $0.49 *$ \\
\hline $\begin{array}{c}\text { Winter Precipitation } \\
\text { (Oct - Mar) }\end{array}$ & 6.39 & -27 & $0.48 *$ \\
\hline January Precipitation & 12.02 & 8 & 0.41 \\
\hline Mean Winter Temperature & -14.73 & 930 & 0.36 \\
\hline October Precipitation & 0.01 & 0 & 0.34 \\
\hline November Precipitation & 0.05 & 0 & 0.27 \\
\hline Annual Precipitation & 1.43 & 25 & 0.09 \\
\hline March Precipitation & 0.002 & 1 & 0.08 \\
\hline Mean Spring Temperature & -5.05 & 424 & 0.06 \\
\hline February Precipitation & 0.76 & 51 & 0.004 \\
\hline Summer Precipitation & -0.44 & 51 & 0.002 \\
\hline
\end{tabular}


TABLE XXXXIII (Con $\left.{ }^{\prime} t\right)$

Multiple Regression

\begin{tabular}{lc}
\hline Variable & $\mathrm{r}^{2}$ \\
\hline $\begin{array}{l}\text { Perennial Stem Elongation with: } \\
\text { Winter Precipitation } \\
\quad \text { (Oct - Jan) }\end{array}$ & $0.75 *$ \\
$\quad$ Peak (Apr) Standing Crop & \\
Spring Growing Season & $0.65 *$ \\
Mean Winter Temperature (max) & $0.63 *$ \\
Spring Growing Season with: & $0.63 *$ \\
Mean Winter Temperature (max) & \\
Winter Precipitation & $0.63 *$ \\
$\quad$ (Oct - Jan) & $0.63 *$ \\
Peak (Apr) Standing Crop & $0.63 *$
\end{tabular}

3 Variables

Body Size with:

Spring Growing Season and

$0.78 *$

Perennial Stem Elongation

\section{Variables}

Body Size with:

Spring Growing Season, Perennial Stem Elongation and Winter Precipitation (Oct - Jan) 
TABLE XXXXIII (Con't

Multiple Regression

\begin{tabular}{lc}
\hline 2 Variable & $r^{2}$ \\
\hline Perennial Stem Elongation with: & \\
$\quad$ Winter Precipitation & $0.75 *$ \\
$\quad$ (Oct - Jan) & \\
$\quad$ Peak (Apr) Standing Crop & $0.65 *$ \\
$\quad$ Spring Growing Season & $0.63 *$ \\
$\quad$ Mean Winter Temperature (max) & $0.63 *$ \\
$\quad$ Spring Growing Season with: & \\
$\quad$ Mean Winter Temperature (max) & $0.63 *$ \\
$\quad$ Winter Precipitation & $0.63 *$ \\
$\quad$ (Oct - Jan) & \\
$\quad$ Peak (Apr) Standing Crop & $0.63 *$ \\
& \\
&
\end{tabular}


PLEASE NOTE:

Duplicate page numbers. Text

follows. Filmed as received.

University Microfilms International 
environmental parameters $(P<0.001)$. As was the case for clutch size, perennial stem elongation appeared to show the highest correlation with reproduction frequency. However, the correlation of spring growing season with reproductive frequency was almost as high as for perennial stem elongation. These 2 climatic parameters probably best served as predictors of overall standing crop. The next 4 highest correlations with breeding success were for different winter precipitation periods. It should be noted that the third highest correlation value was that of breeding success with October through January precipitation. This further supports consideration of the timing of early winter precipitation. Precipitation for late winter (after January) and other seasons was not significantly correlated with annual breeding success.

Multiple regression analysis was undertaken for 5 of the most highly correlated environmental parameters. Two-variable multiple regression analysis in which one of the independent variables was either perennial stem elongation or spring growing season revealed that the combined effects of perennial stem elongation and October through January precipitation were most highly correlated with annual breeding success (Table XXXXIII). Together, they accounted for almost $75 \%$ of the variance in annual breeding success. Three and 4-variable multiple regression analysis, when one of the independent variables was body size increased explanation of the variance in annual breeding frequency only slightly. Maximum correlation occurred when the independent variables were perennial stem elongation, October through January precipitation, spring growing season and body size. These parameters accounted for about $80 \%$ of the variance in annual breeding 
frequency. The $20 \%$ of the variance that remains unaccounted for may reflect other parameters of demography, life history and socio-ecology (Dunham, 1982; Vitt and Price, 1982; Dugan and Wiewandt, 1982). Some of these will be considered below (Ch. 4 - Reproductive Effort and. Survivorship and Ch. 5 - Sex Ratio, Predation Intensity and Density).

\section{REPRODUCTIVE EFFORT}

\section{Egg Size}

Egg mass is an important life history parameter because it reflects the amount of energy devoted to producing individual offspring. Among conspecifics, geographic differences in mean egg mass might be the result of different selection pressures (Dunham, 1982). Within a population, differences in egg mass probably are due to fluctuating resources (Ballinger, 1977). Therefore, within a species, variable egg size can be attributed to either ultimate (evolutionary) for proximate (ecological) causes. Estimates of mean egg mass are available for solitary populations of most iguanine species (Wiewandt, 1982). Mean egg masses for $\underline{S}$. obesus are especially limited in that they have been derived from only 2 clutches (Iverson, 1979; Case, 1982) and interpretation of the significance of these values is difficult because simultaneous measurements of other life history parameters were apparently not undertaken. In this study, egg masses were determined for a population of Colorado Desert $\underline{S}$. obesus and the following questions were addressed: 1) What is the mean egg wet mass (EWM)? 2) How does EWM compare with egg dry mass (EDM)? 3) How is egg mass correlated with body size? 4) How is egg mass correlated with clutch size? 5) 
How does climate influence egg mass?

Previous estimates of mean EWM for $\underline{S}$. obesus were $8 \mathrm{~g}$ (Case, 1982) and $\log$ (Iverson, 1979). Means for EWM were determined in this study for 38 clutches from collections made largely from 1978 through 1980. However, the mean masses for 23 clutches obtained by dissection were usually much lower than those for 15 clutches laid in the laboratory. The mean EWM's for dissection and laboratory laid clutches $(5.8 \mathrm{~g}, \mathrm{~S} . \mathrm{E} . \pm 0.3, \mathrm{~N}=161$, and $8.4 \mathrm{~g}, \mathrm{~S} . \mathrm{E} . \pm 0.3, \mathrm{~N}=110$, respectively) were significantly different from each other $(t=3.57$, $\mathrm{df}=270, P(0.001)$. Only the values for eggs laid are considered below. The overall EWM for $\underline{S}$. obesus from my study area (Table XXXXIV) was between the values indicated above for solitary clutches (Iverson, 1979; Case, 1982). However, the values for the 2 solitary clutches fall within the range found in this study, indicating geographic consistency for this parameter.

While mean EDM has been reported for a number of iguanid lizard species (see references in Vitt, 1977; Vitt and Price, 1982), it has yet to be reported for any species in the subfamily Iguaninae. Mean EDM in this study was roughly $40 \%$ of the mean EWM values (Table XXXXIV). EDM is a better indicator than EWM of the energy alloted to individual eggs. Energy allotment to the clutch - i.e., reproductive effort - is considered below.

The relationships of mean EWM to body size and clutch size have not been reported for other iguanine species. Linear regression analyses for EWM with wet body mass SVL and for EWM and clutch size (Table XXXXV) show that EWM was not correlated either with body size or with 
TABLE XXXXIV

EGG AND CLUTCH DATA FOR FEMALE $\underline{S}$. obesus. FROM GRAVID FEMALES BROUGHT INTO THE LABORATORY

\begin{tabular}{|c|c|c|c|}
\hline Category & $\bar{N}$ & Mean \pm 1 s. e. & Range \\
\hline \multicolumn{4}{|l|}{ Mean Wet Mass of Eggs } \\
\hline 1978 & 2 & $8.0 \pm 0.7$ & $7.4-8.7$ \\
\hline 1979 & 7 & $8.2 \pm 0.5$ & $6.6-10.1$ \\
\hline 1980 & 4 & $8.4 \pm 0.3$ & $8.0-9.6$ \\
\hline Total (1978-1982) & 15 & $8.4 \pm 0.3$ & $6.6-10.1$ \\
\hline Mean Dry Mas of Eggs & 4 & $3.5 \pm 0.2$ & $3.1-4.0$ \\
\hline \multicolumn{4}{|l|}{ Relative Clutch Mass } \\
\hline 1978 & 2 & $32.3 \pm 0.3$ & $34.1-34.6$ \\
\hline 1979 & 7 & $35.1 \pm 1.4$ & $30.3-40.8$ \\
\hline 1980 & 4 & $34.8 \pm 1.4$ & $30.9-37.4$ \\
\hline Total (1978-1982) & 15 & $34.4 \pm 0.8$ & $29.5-40.8$ \\
\hline \multicolumn{4}{|c|}{ Expenditure Per Progeny } \\
\hline 1978 & 2 & $4.1 \pm 1.7$ & $2.4-5.8$ \\
\hline 1979 & 7 & $5.7 \pm 0.7$ & $3.7-8.2$ \\
\hline 1980 & 4 & $4.7 \pm 0.3$ & $4.2-5.2$ \\
\hline Total (1978-1982) & 15 & $5.3 \pm 0.4$ & $2.4-8.3$ \\
\hline
\end{tabular}


TABLE XXXXV

REGRESSTON ANALYSIS OF EGG AND CLUTCH DATA FOR FEMALE $\underline{\mathrm{S}}$. obesus *** INDICATES $\mathrm{P}<0.001 ; *$ INDICATES $\mathrm{P}<0.01 ; \mathrm{N}=15$

\begin{tabular}{|c|c|c|c|}
\hline Category & Slope & Intercept & $r^{2}$ \\
\hline \multicolumn{4}{|c|}{ Mean Wet Mass of Eggs } \\
\hline Clutch Size & -0.38 & 10.34 & 0.02 \\
\hline SVL & 1.88 & 145.56 & 0.01 \\
\hline Wet Body Mass & -1.95 & 110.59 & 0.002 \\
\hline \multicolumn{4}{|c|}{ Relative Clutch Mass } \\
\hline Clutch Size & 0.29 & -2.72 & 0.12 \\
\hline SVL & 0.53 & 143.15 & 0.008 \\
\hline Wet Body Mass & -1.08 & 131.67 & 0.01 \\
\hline \multicolumn{4}{|c|}{ Expenditure Per Progeny } \\
\hline Clutch Size & -1.34 & 14.27 & $0.74 \%$ \\
\hline SVL & -8.69 & 207.82 & $0.61 * *$ \\
\hline Wet Body Mass & -15.47 & 177.30 & $0.55 *$ \\
\hline
\end{tabular}


clutch size in the lizards I examined.

There is little year-to-year variation in egg mass (Table XXXXIV). There were no significant differences in mean EWM from 1978 through 1980 (Scheffe test, $P>0.50$ ). The extremes for 1978 and 1980 were well within the range for that of the greatest sample size (1979). This 3-year span encompassed diverse climatic conditions. Climate strongly influences reproduction by female $\underline{S}$. obesus in the Colorado Desert, but it appears not to influence egg mass. Perhaps egg mass is fixed, which might indicate a common selection pressure operating to optimize egg and/or hatchling survival (Ch.4 - Expenditure Per Progeny (EPP) and Ch. 5 - Survivorship).

\section{Relative Clutch Mass}

One useful measurement of reproductive effort is relative clutch mass (RCM), which is defined as the ratio of clutch mass to total body mass. The following ratios are frequently employed: 1) wet clutch mass/wet total mass; 2) dry clutch mass/dry total mass; and 3) clutch calories/total calories. Recently, investigators have questioned relying solely on these measurements to characterize reproductive effort because they consider only the clutch (Tinkle and Hadley, 1975 and Hirschfield and Tinkle, 1975). Nonetheless, RCM continues to be widely employed (see references in Vitt and Price, 1982) because it remains one of the easiest methods of quantifying energy allocation to reproduction. According to Vitt (1978), RCM is under different selection pressures than egg size. While the latter is influenced by advantages associated with offspring size, the former is influenced 
by differential mortality and the energetic costs of locomotion for gravid females. It is thought that adaptations concerned with coevolved phenomena that enhance survival - e.g., escape from predators, foraging mode and habitat specificity - play the biggest role in determining RCM (Vitt and Price, 1982). From such adaptations Vitt and Price constructed a model for RCM in insectivorous lizards that was based on a species foraging mode. Those species that were "sit-andwait" foragers tended to have a higher RCM than those species that were "wide-ranging" foragers. Among sit-and-wait foragers, RCM tended to be higher in those species displaying cryptic morphology. Vitt and Price admitted their model was not designed to include herbivorous lizard species such as the iguanines. Furthermore, while RCM has been reported for most of the iguanine species, few investigators have simultaneously determined other life history characteristics, such as survivorship, which may determine this reproductive parameter. Nor has the influence of the environment - e.g., climatic factors on RCM been reported for any iguanine species. Consequently, while the mean RCM for iguanines of 29.6 , S. E. \pm 2.4 (largely from Iverson, pers. comm.) is higher than the mean of 25.6 (S. E. \pm 0.9 ) for other iguanid species (Vitt and Price, 1982), little can be said of how RCM functions in the overall life history response to selection pressures. The effect of reproduction on the survival of Colorado Desert female $\underline{S}$. obesus will be considered in Ch. 5 - Survivorship. In determining the RCM of this species, the following questions were addressed: 1) What is the mean RCM? 2) What is the relationship between RCM and body size? 3) What is the relationship between RCM and 
clutch size? 4) How do climatic factors affect RCM? and 5) With regard to habitat specificity, how does flattened morpholology affect RCM?

Previous estimates of RCM for female $\underline{S}$. obesus, based on wet mass ratios for a few solitary clutches, ranged from 35 to 45 (Iverson, 1979 and pers. comm.; Case, 1982). From wet weight ratios, I determined a mean RCM of 34.3 (S. E. $\pm 0.3, N=15$ ) for females captured 1978 through 1980. This value was slightly below the minima reported by the above two investigators. However, the range of RCM in this study greatly overlapped that of the earlier studies and therefore, seemed to indicate some geographic consistency for this parameter.

The ratio of dry clutch mass to dry total mass has yet to be reported for female $\underline{S}$. obesus. The mean ratio from 4 individuals in this study was 50.0 (S. E. \pm 1.4 ). Caloric estimates for eggs and body also have yet to be reported for female $\underline{S}$. obesus. The formulae of Vitt (1977) were employed to convert dry weight measures for this species into calories. From the clutch and body dry weights above, a caloric ratio of 0.54 (S. E. \pm 0.01 ) was derived. These ratios were much greater than those reported for most other iguanids (Vitt, 1977). Hopefully this difference will encourage a detailed evaluation of the selective factors that influence the life histories of herbivorous lizards. In addition, the determination of clutch and body dry mass/or caloric ratios for other iguanines would be of great assistance in the evaluation of energy devoted to reproduction. Analysis of covariance (ANCOVA) indicated that the regression of RCM as a function of SVL did not differ significantly between 1979 and 1980 in either slope $\left(F_{1,7}=0.03 ; P>0.50\right)$ or elevation $\left(F_{1,7}=\right.$ 
$0.03 ; P>0.50)$. Linear regression analysis was performed for RCM with body size and clutch size (Table XXXXV). This indicates that RCM for Colorado Desert $\underline{\text { S. }}$ obesus was not correlated with either body size or clutch size. Thus, larger individuals (having larger clutches) do not necessarily have larger RCM's.

A Student-t Test analysis of data gathered in 1979 and 1980 was used to determine if climatic factors, hence available food, had an effect on mean RCM for Colorado Desert $\underline{S}$. obesus. Judging by preciptation, 1979 was considerably more suitable for reproduction than 1980. Nevertheless, RCM did not differ significantly between the two years $(t=0.2$, df $=9, P>0.50)$. RCM, like egg mass, appears to be a stable reproductive parameter for female $\underline{S}$. obesus.

Flattened body form, a habitat specialization that enables lizards to escape predation by slipping into narrow rock crevices, places constraints on RCM (Vitt, 1981). Platynotus semitaeniatus, a saxicolous iguanid of flattened form, routinely enters narrow crevices for escape. The RCM of this species was 19.5, a value considerably less than the mean of 25.6 for the noniguanine species of the family. Apparently, maintenance of a flattened shape is critical to survival of Platynotus. Selection has favored reduced RCM because the gains in escape from predation were high. $\underline{S}$. obesus demonstrates a similar specialization. If relative morphological measurements for $\underline{P}$. semi$\underline{\text { taeniatus }}$ and $\underline{S}$. obesus are compared (Table XXXXVI), the results showed only slight differences for 4 of the 5 measurements considered. Both species seem morphologically well-suited for dwelling in rock crevices, but female $\underline{S}$. obesus have a relatively greater body width, and the RCM 
TABLE XXXXVI

COMPARISON OF RELATIVE MORPHOLOGICAL MEASUREMENTS BETWEEN Platynotus semitaeniatus AND Sauromalus obesus. DATA ON P. semitaeniatus FROM VITT (1981)

\begin{tabular}{lccccc}
\hline \multicolumn{1}{c}{ Species } & Head Width & $\frac{\text { Head Length }}{\text { SVL }}$ & $\frac{\text { Head Height }}{\text { SVL }}$ & $\frac{\text { Body Width }}{\text { SVL }}$ & $\frac{\text { Body height }}{\text { SVL }}$ \\
\hline$\underline{P} \cdot \frac{\text { Semitaeniatus }}{(\mathrm{N}=60)}$ & 0.19 & 0.22 & 0.08 & 0.32 & 0.11 \\
$\frac{\mathrm{S}}{\left(\mathrm{N} \frac{\text { obesus }}{=500)}\right.}$ & 0.18 & 0.18 & 0.09 & 0.43 & 0.11 \\
\hline
\end{tabular}


of $\underline{\mathrm{S}}$ obesus is much higher than the mean for both family and subfamily. This suggests that flattened morphology may put less constraint on the RCM of iguanines than for other members of the family, but the difference is consistent with the overall selection pressures affecting RCM. Probably the larger body size and foraging and nesting habits of female $\underline{S}$. obesus lower their susceptability to mortality and cost of locomotion (see below - Comparison of Iguanine Species). A time budget analysis would help to evaluate differences in RCM for the 2 species. In addition, the relative body width of female $\underline{S}$. obesus is probably the greatest reported for lizard species. This suite of characteristics probably favors increased RCM.

\section{Expenditure Per Progeny}

A measurement often erroneaously associated with reproductive effort is the absolute egg mass to total body mass. Termed expenditure per Progeny (EPP) by Pianka (1976), this measurement represents a compromise in that the cost of larger eggs and hatchlings is a smaller clutch size and that of a larger clutch is smaller eggs and hatchlings. Therefore, this parameter is associated with advantages of offspring size, indicating the proportion of energy of reproduction devoted to an

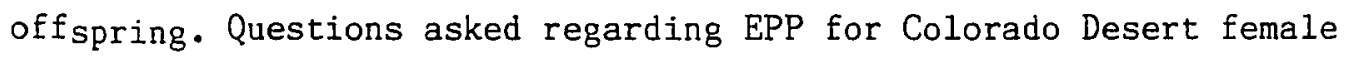
S. obesus were: 1) What is the mean EPP? 2) What is the relationship between EPP and body size? 3) What is the relationship between EPP and clutch size? and 4) How do climatic factors affect EPP?

Previous estimates of EPP for $\underline{S}$. obesus, based on wet mass ratios

for a few clutches, ranged from 4.5 to 5.5 (Iverson, 1979 and pers. 
comm.; Case, 1982). Collection, sample size and protocol for determination of mean EPP were the same as for determination of RCM. The total mean EPP and various annual mean EPP (Table XXXXIV) for Colorado Desert female $\underline{S}$. obesus were similar to the values shown above. Therefore, it appears that EPP is yet another reproductive parameter for S. obesus that showed geographical consistency. Analysis of covariance (ANCOVA) indicated that the regression models for EPP as a function of SVL did not differ significantly among years, 1979 and 1980, in either slope $\left(F_{1,7}=0.66 ; P>0.50\right)$ or elevation $\left(F_{1,7}=0.17 ; P>0.50\right)$. To determine the relationship of EPP and body size, linear regression analysis was performed matching wet egg and total body mass ratios with wet body mass and SVL (Table XXXXV). The analysis showed a strong negative correlation of EPP with SVL $(P<0.001)$ and wet body mass $(P<0.01)$ for $\underline{S}$. obesus. Since absolute egg size is independent of body size in $\underline{S}$. obesus, it follows that as individual females grow larger EPP gets smaller. Linear regression analysis matching wet egg and total body mass ratios with clutch size (Table XXXXV) showed a strong negative correlation of EPP with clutch size $(P<0.001)$ for $\underline{S}$. obesus. Again, if egg size remains stable, an increase in clutch size reduces the contribution of one egg to the total mass.

If absolute egg size, clutch size and RCM were stable reproductive parameters for female $\underline{S}$. obesus among years it seems likely that the same can be said for EPP. Student-t Test analysis on the data from 1979 and 1980 confirmed this hypothesis $(t=0.03$, df $=9, P>0.50)$. 


\section{Comparison of Iguanine Reproduction}

Enough data on egg size, RCM and EPP have been compiled for most New World iguanines (Iverson, 1979; Wiewandt, 1982; Case, 1982; Werner, 1983) to illustrate trends in reproductive strategy (Table XXXXVII). The mean RCM for 12 species was 29.6 (S. E. \pm 2.4 ). However, the data seemed to indicate that the 12 species could be placed into 2 groups based on energy devoted to reproduction, one of low RCM $(\bar{x}=23.6$, S. E. $\pm 0.8, N=7)$ and the other of high RCM $(\bar{x}=39.1$, S. E. $\pm 2.9, N=5$ ). The difference between these 2 means was highly significant $(t=7.88, \mathrm{~d} f=11, \mathrm{P}<0.001)$. This dichotomy was associated with different habitats. All iguanine species, both temperate and tropical, that exhibited a low RCM were island inhabitants. Iguanine species that exhibited a high RCM were, with one exception, inhabitants of temperate and tropical continental locations. According to Vitt and Price (1982), the energetic costs of locomotion influence RCM. This relationship is clear for 2 island species, Amblyrhynchus cristatus and Conolophus subscristatus. The former species makes frequent dives into the ocean to obtain food (Carpenter, 1966; Bartholomew et al., 1976); the latter species must make migrations of 10 $\mathrm{km}$ to locate suitable nesting sites (Werner, 1983). While the reason for low RCM in the other species is less obvious, it may be related with complex foraging and nesting strategies. For example, the arboreal habits of Sauromalus hispidus may indicate extremely limited food resources (Case, 1982). The extended migrations and nest defense of most Cyclura species may indicate the predominance of poor soil conditions for nesting (Wiewandt, 1982). If cost of locomotion is a 
TABLE XXXXVII

COMPARISON OF REPRODUCTIVE PARAMETERS FOR 12 SPECIES OF IGUANINES

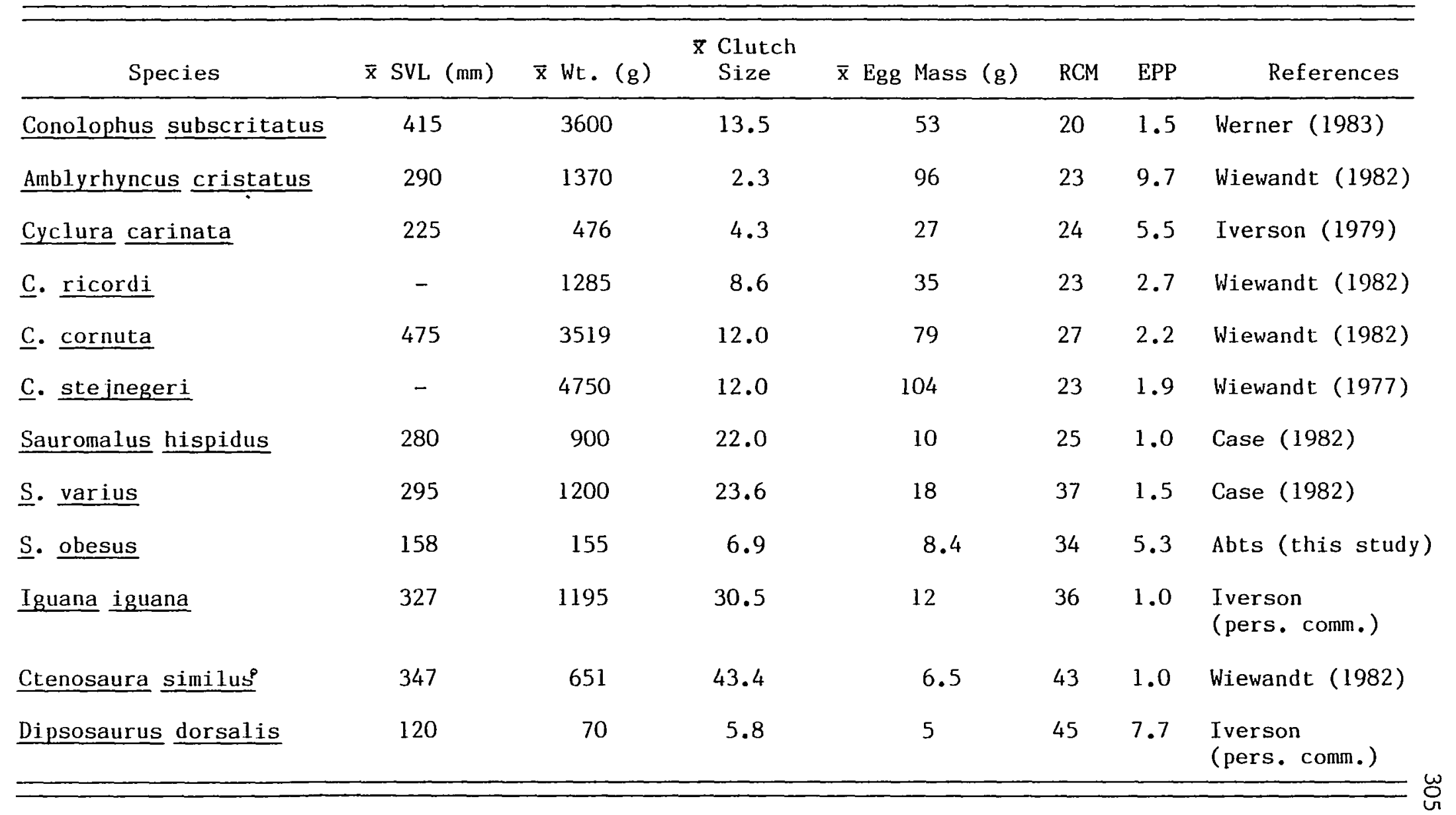


major factor in the determination of RCM, it appears that continental species are less mobile. According to Case (1982), female $\underline{S}$. varius, the one island species exhibiting a high RCM, are extremely sedentary. Female $\underline{S}$. obesus I studied made very few extensive movements (Ch. 2 Movement and Spacing Patterns) and possessed a relatively high RCM. In order to better clarify this situation for RCM in iguanine species, future investigations should thoroughly monitor movement and nesting and feeding habits.

EPP indicates the proportion of energy alloted to individuals. Females demonstrating a high EPP put proportionately more energy into each egg and thus produce smaller clutches; females demonstrating a low EPP put proportionately less energy into each egg and thus produce larger clutches. The mean EPP for 12 iguanine species was 3.42 (S. E. \pm 0.85 ). For these species a dichotomy existed that was even greater than for RCM (Table XXXXVII). Mean high and low EPP were 7.05 (S. E. \pm 1.04 ) and 1.6 (S. E. \pm 0.22 ). A Student-t Test analysis showed the 2 means to be highly significantly different $(t=$ 5.8; $\mathrm{df}=11 ; \mathrm{P}<0.001)$. The decision to produce proportionally larger but fewer eggs has a number of advantages largely associated with protection against desiccation and starvation (Wiewandt, 1982). Iguanines exhibiting a high EPP inhabit either subtropical islands or temperate continental desert environments where precipitation is uncertain. It has been shown that egg and hatchling survival for $\underline{\text { S. }}$ obesus was greatly enhanced when summer precipitation occurred Ch. 5 - Survivorship). Some island species as well as continental subtropical and tropical species produce proportionally smaller but 
more numerous eggs. Advantages here may lie in the increased numbers of offspring that encounter heavy predation pressures. (Wiewandt, 1977; Iverson, 1979; Case, 1982) or extended periods of drought during which a11 age classes experience heavy mortality (Case, 1982). The uniformity of egg size and high EPP in female $\underline{S}$. obesus may indicate that throughout the species' geographic range, mortality due to climatic uncertainty is more important than is predation in shaping reproductive strategy. Monitoring the impact of predation on a population, however, is difficult. At present, methods employed to measure predation in lizard populations are inadequate (Ch. 5 - Predation Intensity). Estimation of predator pressure is essential to understanding life history and for $\underline{S}$. obesus should be a parameter of future consideration.

ANNUAL REPRODUCTIVE OUTPUT AND FECUNDITY

Natural selection operates through differential reproductive success. An organism can improve its reproductive success either by producing many offspring of low individual fitness or by producing fewer offspring of high individual fitness. There is generally an inverse relationship between reproductive rate and average offspring firness, since the amount of energy for reproduction is limited. The best reproductive strategy must be a compromise between these 2 conflicting demands (Pianka, 1978). The exact nature of the compromise reflects a number of variables, may of which are considered in this study (Ch. 4 - Clutch Size, Reproductive Frequency and Survivorship). An organism has a number of alternatives for increasing reproductive output, all of which require either a larger total energy 
budget or a reapportionment of the energy budget (Pianka, 1978). These alternatives include: 1) breeding more often within one year; 2) increasing clutch cize; 3) breeding over a longer period of time; and 4) in expanding populations, where there is less competition for resources, breeding at an earlier age. Cole (1954) first developed a theory of evolution of reproductive patterns. His theoretical explorations produced a number of important principles which included: 1) repeated reproduction is more advantageous for long-lived organisms and/or those with delayed reproduction than it is for rapidly maturing and/or short-lived species; 2 ) increased clutch size is more advantageous for short-lived and/or rapidly maturing organisms than for long-lived organisms with delayed reproduction; and 3) when adult survivorship is low, a large first clutch can offset the advantage of repeated reproductions.

Reproductive patterns have been described for a number of iguanid lizard species (Fitch, 1956; Blair, 1960; Tinkle, 1967, 1972, 1973; Turner et a1., 1970; Tinkle and Ballinger, 1972; Van Devender, 1982a). However, age specific changes in reproduction are presently available for only on iguanine, Cyclura carinata (Iverson, 1979). I investigated the following questions concerning reproductive rates for female $\underline{S}$. obesus: 1) What is the annual reproductive output? 2) What is the age specific fecundity? 3) What causes annual variation in age specific fecundity? And 4) How do reproductive output and fecundity in female $\underline{S}$. obesus compare with that for other iguanids?

Some investigators have reported annual reproductive output as the mean number of eggs produced in an activity season (Dunham, 
1982). This value would be equal to mean clutch size in species that produce one clutch per year. However, the determination of the annual reproductive output in this manner does not represent breeding success of the entire population. Reproductive output for an average adult female in the population can be obtained as the product of mean clutch size and the fraction of the adult female population that is reproductively active. Annual reproductive output was determined for Colorado Desert $\underline{S}$. obesus from mean clutch size and an adjustment for frequency of reproduction (Table XXXXVIII). Annual variation in reproductive output for years when reproduction occurred was attributable to variation in body size: between years (Ch. 4 - Clutch Size) and variation in frequency of reproduction was attributable to climatic factors (Ch. 4 - Reproductive Frequency).

Values for mean total clutch size and the product of mean total clutch size and reproductive frequency for $\underline{S}$. obesus were generally less than half of those for species known to produce multiple clutches per season (Blair, 1960; Tinkle, 1967; Turner et al., 1970; Dunham, 1982) and about half of those for other iguanids with single clutches per season (Fitch, 1956; Tinkle, 1972, 1973). S. obesus produces annual clutches that are much smaller than those of several iguanine species (Table XXXXVII). It would appear from estimates of clutch frequency and clutch size that annual reproductive output in female s. obesus is small. However, Colorado Desert females adjust for this condition by having high lifetime reproductive output. In other words, they exhibit early maturity (Ch. 4 - Age at Maturity) and breed over an extended period of time (Ch. 5 - Longevity). While data are limited, 
TABLE XXXXVIII

5-YEAR ANNUAL REPRODUCTIVE OUTPUT FOR FEMALE $\underline{\mathrm{S}}$. obesus. SAMPLE SIZES INDICATED IN PARENTHESES

\begin{tabular}{cccc}
\hline Year & $\begin{array}{c}\text { Mean Clutch } \\
\text { Size } \pm 1 \text { s. e. }\end{array}$ & $\begin{array}{c}\text { \% Frequency of } \\
\text { Reproduction }\end{array}$ & $\begin{array}{c}\text { Reproductive } \\
\text { Output/Lizard }\end{array}$ \\
\hline 1978 & $6.6 \pm 0.3(47)$ & $78.3(97)$ & 5.3 \\
1979 & $6.9 \pm 0.4(47)$ & $95.2(83)$ & 6.5 \\
1980 & $7.1 \pm 0.5(16)$ & $39.6(53)$ & 2.8 \\
1981 & 0.0 & $0.0(24)$ & 0.0 \\
1982 & $8.7 \pm 0.6(3)$ & $45.2(31)$ & 4.0 \\
\hline
\end{tabular}


it appears that a number of iguanines reduce reproductive rate to improve the fitness of individual eggs (Ch. 4 - Comparison of Iguanine Reproduction).

Age specific fecundity is the number of female offspring produced by an average female during a particular age period (usually designated $\mathrm{m}_{\mathrm{x}}$ ). Age-specific fecundity is of considerable interest to population ecologists because it clearly reveals the reproductive strategy of the species. Age-specific fecundity has been reported for a number of iguanids (Blair, 1960; Fitch, 1967; Tinkle, 1967, 1972 and 1973; Turner et. al., 1970; Tinkle and Ballinger, 1972; Van Devender, 1982a), but the only age-specific fecundity data available for iguanines is for Cyclura carinata (Iverson, 1979).

Annual age-specific fecundity was determined for Colorado Desert adult female $\underline{S}$. obesus from 1978 through 1982 as the product of mean clutch size and frequency of reproduction for each one-year age class. In addition, a mean age-specific fecundity was calculated for the 5-year period. The annual values and the 5-year mean are shown in Table XXXXIX. Age classes are shown for only the first 10 years because older female $\underline{S}$. obesus were too few to be captured in every year of the study. Older age classes are considered below in the section concerning iguanid comparisons.

Fecundity is highly correlated with age for Colorado Desert adult female $\underline{S}$. obesus (Table L). This is not surprising because older (i.e., larger) individuals produced larger clutches. This is common for species that display indeterminant growth patterns (Ricklefs, 1979). However, a high frequency of reproduction also contri- 
TABLE XXXXIX

AGE SPECIFIC FECUNDITY FOR ADULT FEMALE $\underline{\mathrm{S}}$. obesus

\begin{tabular}{ccccccc}
\hline Age (Years) & 1978 & 1979 & 1980 & 1981 & 1982 & $\begin{array}{c}\text { Year } \\
\pm \text { Year Mean s. e. }\end{array}$ \\
\hline 3 & 0.0 & 0.0 & 0.0 & 0.0 & 0.0 & 0.0 \\
3 & 1.4 & 2.2 & 0.0 & 0.0 & 0.0 & $0.7 \pm 0.5$ \\
4 & 2.4 & 3.0 & 0.5 & 0.0 & 1.0 & $1.4 \pm 0.6$ \\
5 & 2.4 & 3.0 & 0.7 & 0.0 & 0.9 & $1.4 \pm 0.6$ \\
6 & 3.5 & 3.3 & 2.2 & 0.0 & 1.0 & $2.0 \pm 0.7$ \\
7 & 3.6 & 3.6 & 2.3 & 0.0 & 2.0 & $2.3 \pm 0.7$ \\
8 & 3.6 & 3.8 & 2.4 & 0.0 & 2.8 & $2.5 \pm 0.7$ \\
9 & 3.9 & 4.1 & 2.5 & 0.0 & 3.1 & $2.7 \pm 0.7$ \\
10 & 4.2 & 4.2 & 2.6 & 0.0 & 3.2 & $2.8 \pm 0.8$ \\
\hline 10 & - & - & - & - & - & $4.4 \pm 0.5$ \\
\hline
\end{tabular}


TABLE L

LINEAR REGRESSION ANALYSIS SHOWING THE CORRELATION OF FECUNDITY (CLUTCH SIZE X REPRODUCTIVE

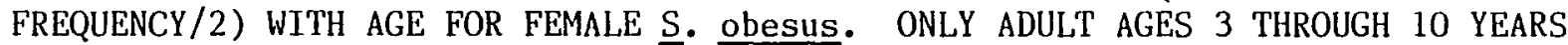
WERE CONSIDERED. NO REPRODUCTION OCCURRED IN 1981

\begin{tabular}{lcccc}
\hline Year & Slope & Intercept & $\mathrm{r}^{2}$ & $\mathrm{P}$ \\
\hline 1978 & 0.37 & 0.72 & 0.88 & $<0.001$ \\
1979 & 0.26 & 1.70 & 0.96 & $<0.001$ \\
1980 & 0.40 & -0.96 & 0.86 & $<0.001$ \\
1981 & - & - & - & - \\
1982 & 0.38 & -0.62 & 0.81 & 0.01 \\
5 -Year & 0.30 & 0.04 & 0.96 & 0.001 \\
Average & & & \\
\hline
\end{tabular}


buted to the high fecundity of older age classes. This is attributable to having large body size (SVL), that probably enables them to better absorb the costs of reproduction (Wiewandt,1982).

Annual variability in fecundity was largely related to climate. During my 7-year study, the entire climatic continuum from drought to mesic conditions prevailed (Ch. 1 - Climate and Vegetation). Available food was scarce during the driest period (1981) and reproduction was curtailed for all age classes (Table XXXXIX). Reproduction was optimal for all age classes in years when wet climatic conditions promoted an abundant food supply (1978 and 1979). The correlation of fecundity with age was lowest in years of intermediate climatic conditions (1980 and 1982), reflecting a smaller rise in fecundity among the younger age classes. This was largely due to decreased frequency of reproduction. Consequently, the older females were better able to undertake the burden of reproduction in poor years.

A number of climatic and vegetational parameters are positively correlated with age-specific fecundity. The 3 parameters showing the strongest correlation with frequency of reproduction were also those most highly correlated with fecundity (Table LI). of these, perennial stem elongation was most strongly correlated with fecundity. This vegetational parameter probably best indicated overall standing crop of vegetation. These results indicated that climatically imposed variation in fecundity was largely due to changes in percentage of breeding individuals for each age class since it has been shown that annual changes in clutch size for a given SVL did not differ significantly from each other (Ch. 4 - Clutch Size). This is consistent with 
TABLE LI

LINEAR REGRESSION ANALYSIS SHOWING THE CORRELATION OF FECUNDITY WITH 3 IMPORTANT CLIMATIC AND VEGETATION PARAMETERS. ALL REGRESSIONS WERE HIGHLY

SIGNIFICANT $(P<0.001)$. UNITS AS IN CHAPTER 1

\begin{tabular}{lcccc}
\hline \multicolumn{1}{c}{ Parameter } & $\mathrm{N}$ & Slope & Intercept & $\mathrm{r}^{2}$ \\
\hline Perennial Stem Elongation & 40 & 4.74 & 19.05 & 0.67 \\
$\begin{array}{l}\text { October Through January } \\
\text { Precipitation }\end{array}$ & 40 & 1.53 & 7.29 & 0.56 \\
Spring Growing Season & 40 & 10.46 & 62.30 & 0.54 \\
\hline
\end{tabular}


the "boom or bust" iteroparity hypothesis (Case, 1982).

Reproductive rates of lizards have been viewed as adaptations to adult mortality (Tinkle and Ballinger, 1972). High mortality can be caused by either a relative abundance of predators or a long activity season during which lizards are exposed to predation. While the relative abundance of predators for populations of $\underline{S}$. obesus are not known, the results of this study indicate that individuals in the Colorado Desert have a longer activity season than their Mojave Desert counterparts. The extent of exposure to predation will be considered (Ch. 5 Predation Intensity). While predation intensity influences demographic characteristics, other explanations for reproductive rate, such as ecological feed back, might be equally plausible (Ricklefs, 1977). Regardless of predation pressure, certain ecological conditions, especially climate, seem to have an impact on growth and fecundity of Colo-

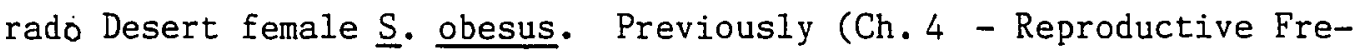
quency), it was shown that growth and fecundity were highly correlated for this species. In general, Colorado Desert $\underline{S}$. obesus have a longer activity season, due in part to the milder winter and wetter summers. Consequently, this population may be better able to take advantage of of whatever food supply exists. In turn, this may be responsible for life history attributes such a rapid pre-reproductive growth. Therefore, the reproductive rate, which is higher than that reported in other studies of $\underline{\mathrm{S}}$. obesus (Johnson, 1965; Nagy, 1973; Berry, 1974), probably was due to the increased predictability of climatic conditions and hence available food, rather than to lessened predation.

The 5-year average age-specific fecundity for Colorado Desert 
female $\underline{S}$. obesus was considerably lower than that of noniguanines, but was higher than that of one other iguanine (Table LII). These results, demonstrating an inverse relationship with longevity, are in agreement with the demographic characteristics of these populations. Examination of the reproductive parameters listed in Table XXXXVII suggests the cause of the difference in fecundity between $\underline{S}$. obesus and the other iguanine, Cyclura carinata (Iverson, 1979). The relative clutch mass (RCM) of adult female $\underline{C}$. carinata was only $70 \%$ of adult female $\underline{S}$. obesus even though the former had a body and egg size 3 times that of the latter. Female $\underline{C}$. carinata have a mean clutch size about two-thirds that of female $\underline{S}$. obesus. Therefore, the difference in RCM can largely be attributed to difference in clutch size. Data presented showed that the lower RCM of many island iguanines probably reflected adaptations to minimize the costs of locomotion associate with foraging and nesting patterns (Vitt and Price, 1982). While the RCM appeared to be different, the expenditure per progeny (EPP) was similar for $\underline{C}$. carinata and $\underline{S}$. obesus. Since these EPP values were relatively high for iguanines it appeared that reproductive success in $\underline{S}$. obesus and $\underline{C}$. carinata were dependent upon increased egg mass, which in turn reflects increased individual offspring fitness. Age-specific fecundity is the product of the mean clutch size and frequency of reproduction. Therefore, dissimilar age-specific fecundities can be explained by differences in one or both of these parameters. A comparison of the various age classes for female $\underline{S}$. obesus and female $\underline{C}$. carinata showed that the difference in fecundity between the 2 species increased with age (Table LII). It was shown above 
TABLE LII

AGE SPECIFIC FECUNDITY FOR 5 SPECIES OF IGUANID LIZARDS

\begin{tabular}{|c|c|c|c|c|c|}
\hline Age (Years) & $\frac{\text { Sceloporus }}{\text { undulatus }}$ & $\frac{\text { Sceloporus }}{\text { graciosus }}$ & $\frac{\text { Crotaphytus }}{\text { collaris }}$ & $\frac{\text { Cyclura }}{\text { carinata }}$ & $\frac{\text { Sauromalus }}{\text { obesus }}$ \\
\hline 1 & 0.25 & - & 0.70 & - & - \\
\hline 2 & 9.30 & 2.90 & 2.43 & - & - \\
\hline 3 & 10.20 & 3.90 & 5.20 & - & 0.72 \\
\hline 4 & 10.20 & 4.40 & 5.20 & - & 1.39 \\
\hline 5 & 10.20 & 4.40 & 5.20 & - & 1.39 \\
\hline 6 & - & 4.40 & - & 1.23 & 2.00 \\
\hline 7 & - & 4.40 & - & 1.37 & 2.30 \\
\hline 8 & - & 4.40 & - & 1.51 & 2.52 \\
\hline 9 & - & 4.40 & - & 1.65 & 2.71 \\
\hline 10 & - & - & - & 1.78 & 2.84 \\
\hline 11 & - & - & - & 1.92 & 3.25 \\
\hline 12 & - & - & - & 2.06 & 3.47 \\
\hline 13 & - & - & - & 2.20 & 4.40 \\
\hline 14 & - & - & - & 2.34 & 5.10 \\
\hline
\end{tabular}


TABLE LII (Con' $t$ )

\begin{tabular}{lccccc} 
Age (Years) & $\frac{\text { Sceloporus }}{\text { undulatus }}$ & $\frac{\text { Sceloporus }}{\text { graciosus }}$ & $\frac{\text { Crotaphytus }}{\text { collaris }}$ & $\frac{\text { Cyclura }}{\text { carinata }}$ & $\frac{\text { Sauromalus }}{\text { obesus }}$ \\
\hline 15 & - & - & - & 2.48 & 5.75 \\
Reference & $\begin{array}{l}\text { Tinkle } \\
(1972)\end{array}$ & $\begin{array}{c}\text { Tinkle } \\
(1973)\end{array}$ & $\begin{array}{c}\text { Fitch } \\
(1956)\end{array}$ & $\begin{array}{c}\text { Iverson } \\
(1979)\end{array}$ & this study
\end{tabular}


(Ch. 4 - Clutch Size) that clutch size increased with body size for female $\underline{S}$. obesus. However, this relationship was less apparent for C. carinata because the mean clutch size is relatively small (Iverson, 1979). Consequently, much of the difference in age specific fecundity for the 2 species can be explained by the lower mean clutch size of all age classes of $\underline{C}$. carinata. However, age specific fecundity represents only half the equation for net reproductive rate $\left(R_{0}\right)$. In addition, $\mathrm{R}_{\mathrm{o}}$ is only half of the equation for calculating population growth rate. In order to determine these 2 population characteristics one must determine juvenile survivorship, adult survivorship and mean generation time. These parameters are considered below (Ch. 5 - Survivorship and Ch. 5 - Life Tables). 
CHAPTER V

LIFE HISTORY: POPULATION DYNAMICS

SURVIVORSHIP

\section{Egg and Hatchling Survivorship}

Any thorough life history investigation should consider the ecology of both the egg stage and the posthatching stages. While demographers have examined the posthatching stages for a number of species (see review in Turner, 1977; Wiewandt, 1982) they have shown little concern for eggs (Muth, 1980). Nonetheless, the interdependence of the 2 stages is considerable. Suitable temperatures for incubation determine the timing of reproduction (Rand and Greene, 1982). Variation in egg mortality has both a spatial and temporal effect on population density (Andrews, 1982b). Finally, suitable edaphic conditions for incubation can limit the geographic distribution of a species (Muth, 1980). I addressed the following questions regarding these early life history stages: 1) What variability occurs in egg and hatchling survivorship? 2) What factors affect egg and hatchling survivorship? and 3) How does survivorship of these 2 stages differ betipen populations of $\underline{s}$. obesus?

The number of eggs produced by adult female $\underline{s}$. obesus in my study area was determined from age-specific fecundity schedules. Density of yearlings was estimated using the method of Schumacher and Eschmeyer (1943). Egg survivorship was indexed from number of hatchlings sighted 
per man hour of effort. Reproductive output showed an 8-fold variation for years in which reproduction occurred (Table LIII), being lowest in 1977 and highest in 1979. The second highest reproductive output occurred in 1978 ; at $67 \%$ of the maximum, it was 5 times greater than for 1977. Consequently, I expected to see far more hatchlings in 1978 and 1979. However, it appeared that hatchlings were as abundant in 1977 (0.16 per man hour) as in 1978 ( 0.18 per man hour) while sightings of hatchlings were greatest in 1979 (0.38 per man hour). Thus, egg mortality was about 5 times greater in 1978 than in 1977, assuming these observed frequencies were proportional to actual density.

Estimates of first-year survivorship (Table LIII) showed an 8-fold variation, being highest (about $80 \%$ ) in the 1979 cohort and lowest (about 10\%) in the 1978 cohort. While the second highest reproductive output occurred in 1978 , very few yearlings were encountered during the following year. If these observations were accurate, then for the periods 1976 - 1977 and 1978 - 1979 there was a considerable difference in first-year survivorship.

There was a strong positive correlation between egg and hatchling survivorship of Colorado Desert $\underline{\mathrm{s}}$. obesus and the amount of precipitation for July through September. From egg to yearling, survivorship was considerably greater in years of abundant precipitation $(\bar{x}=0.14 ; N=3)$ than in years when precipitation was scarce $(\bar{x}=0.14 ; N=2)$. Most S. obesus laid their eggs during the first 2 weeks of July and the summer precipitation period usually began around mid-July. Egg-laying synchrony probably reflected an adaptation to take advantage of summer precipitation which in some way--perhaps through increased water 
TABLE LIII

AGE CLASS 0 TO AGE CLASS 1 SURVIVORSHIP FOR $S$. obesUS AT THE RED CLOUD ROAD STUDY SITE.

REPRODUCTIVE OUTPUT DETERMINED FROM THE SUM OF AGE SPECIFIC FECUNDITIES

(CLUTCH SIZE X REPRODUCTIVE FREQUENCY); NUMBER OF YEARLINGS =

DENSITY ESTIMATE (SCHUMACHER AND ESCHMEYER, 1943)

\begin{tabular}{cccc}
\hline Year & $\begin{array}{c}\text { Reproductive } \\
\text { Output }\end{array}$ & Yearlings \pm 2 s. e. $)$ & Survivorship \\
\hline $1976-77$ & 106 & $84 \pm 10$ & 0.79 \\
$1977-78$ & 59 & $21 \pm 16$ & 0.38 \\
$1978-79$ & 277 & $30 \pm 27$ & 0.11 \\
$1979-80$ & 414 & $178 \pm 78$ & 0.43 \\
$1980-81$ & 90 & $15 \pm 27$ & 0.17 \\
$1981-82$ & 0 & - & - \\
\hline
\end{tabular}


potential of soil-improved the hatching success. In addition, summer precipitation promoted the availability of food in the early fall. Consequently, both eggs and hatchlings appeared to benefit from summer precipitation. Linear regression analysis was performed to see if intraspecific competition among hatchlings played a role in first year survivorship. The correlation between reproductive output (i.e., number of eggs) and first year survivorship was not significant $\left(r^{2}=0.02\right.$; $N=5 ; P>0.50)$. From the data it appears that summer precipitation has a density-independent effect on egg and hatchling survivorship. Reproductive frequency for a Mojave Desert population of adult female s. obesus (Berry, 1974) was considerably lower than that in this study. Nonetheless, even with minimum reproductive output it appeared that recruitment was further limited by low egg and/or hatchling survivorship. Density estimates of adult female $\underline{\mathrm{s}}$. obesus from her 1969 data, using the method of Schumacher and Eschmeyer (1943) totaled 23 individuals. Since most of these individuals were large ( $\bar{x}$ SVL $=$ 177.26; S.E. \pm 4.55$)$ a corresponding mean clutch size of 10 eggs (according to regression equation in Ch. 5 - Clutch Size) yielded a maximum number of 230 eggs. If one assumes a reproductive frequency of $40 \%$, a value suggested for other Mojave Desert populations (Johnson, 1965; Case, 1982), then the total number of eggs laid was about 92. Approximately 8 of Berry's 1970 population $(\mathrm{N}=100)$ were of age class one. Consequently, first year survivorship was about 0.09 . Based on similar yearling recruitment in the other 3 years of her study, I estimate an average first year survivorship of about 0.10 . This is about one-fourth of the first year survivorship of the present study 
$(\bar{x}=0.38 ;$ S.E. \pm 0.12$)$. Over the past 30 years summer precipitation in the Colorado Desert study area has been about twice that for several Mojave Desert locations. Consequently, this climatic parameter probably was a major factor for the considerable difference in egg/hatchling survivorship between Mojave and Colorado Desert s. obesus. In addition, colder winters in the Mojave Desert may also reduce hatchling survivorship. Surface active hatchlings of Mojave Desert $\underline{s}$. obesus from the same mountain range as those studied by Berry appeared to succumb to cold winter temperatures (Smits and Yorke, 1980). Dead $(N=6)$ or severely cold-stressed $(N=7)$ individuals were found in a small canyon segment. These investigators found 22 hatchlings during a 3 day search; this number indicates a relatively high density of hatchlings. Precipitation in much of the Mojave Desert was 4 times greater than normal during the previous summer (National Weather Service). High densities of hatchlings following elevated summer precipitation were common in the same year for this study (Table LIII). This supports the importance of summer precipitation for egg and hatchling survivorship in S. obesus.

\section{Postyearling Survivorship}

Usually, extant populations neither grow indefinitely nor decline to extinction. This is largely due to the fact that rates of reproduction and mortality rates evolve together. Changes in one affect the other and the trend is toward some kind of balance. According to Pianka (1978) there are 3 conditions that exemplify this relationship: 1) a species with high mortality must also possess a correspondingly 
high fecundity in order to persist; 2) a very fecund species must on the average suffer equivalent heavy mortality since the population will increase until some balance is reached and 3) species of low fecundities show low rates of mortality and those with high survivorship have low fecundities. This inverse relationship between survivorship and fecundity has been demonstrated for a number of insectivorous lizards (Tinkle, 1969).

Williams (1966a and b) has pointed out that natural selection should favor organisms that respond as though they are weighing their short-term against their long-term expectation of successful reproduction. If there is little chance of surviving long enough to reproduce again, the optimal reproductive effort is high; if survivorship is higher, immediate reproductive effort may be reduced or breeding postponed in order to enhance survivorship further, thereby maximizing an organism's lifelong overall contribution to the next generation. Two major selection factors have been implicated in the choice of reproductive strategy of an organism. One, referred to as $r$ and $\mathrm{K}$-selection, is based on resource availability (MacArthur and Wilson, 1967); the other, referred to as demographic environment, is based on survivorship (Murphy, 1968). Since neither factor alone adequately explains a lizard's reproductive strategy (Dunham, 1982), it is possible that the 2 factors are inseparable. For female $\underline{s}$. obesus, this consideration is supported by the apparent link of fecundity with body growth and the practice of "boom or bust" iteroparity.

While there are several methods for estimating survivorship of lizards, those that handle fluctuations in numbers and changes in 
schedules of age-specific survivorship have a broader application in studies on population ecology (Turner, 1977). For the present study, survivorship of $\underline{\mathrm{s}}$. obesus was estimated by the sequential sampling of marked cohorts of individuals with employment of the stochastic method of Jolly (1965). According to Turner (1977) there are at least 4 aspects of survivorship for lizards: 1) body size; 2) sex; 3) geography (latitude and altitude) and 4) annual variation. In addition, annual variation has 2 classes of influence on survivorship. One, extrinsic factors, operates independently of the state of the population (e.g., effects of varying weather). The other, regulating factors, are mediated by the state of the population. Previous investigations of S. obesus did not report on survivorship. For this Colorado Desert

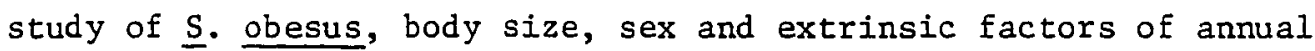
variation were determined. For the geographic aspect, the present study was compared with that of a northern Mojave Desert population of $\underline{S}$. obesus (Berry, 1974). Specific questions asked regarding postyearling survivorship were: 1) What changes occur in age-specific survivorship? 2) Is there annual variation in survivorship? 3) Does survivorship differ between sexes? and 4) How does survivorship for $\underline{\text { S. obesus }}$ compare with other iguanid and iguanine species and with conspecifics in different geographical locations?

Annual survivorship of the $\underline{s}$. obesus I studied was determined for 2 cohorts as well as for the entire population from 1978 through 1981. At the start of the study, one cohort consisted of individuals in their first year (i.e., yearlings) and the other of individuals in their fourth year. Combined, these 2 cohorts represented over one-half of the 
individuals in the population at the start of the study. Cohort and population survivorship will be presented for both sexes. Age-specific survivorship for female $\underline{S}$. obesus appeared similar for age classes in each of the 4 years (Table LIV). The Jolly analysis for data from 1980 and 1981 proved unreliable. This error can probably be attributed to the limited time spent at the study site in 1981 and 1982, which provided insufficient recapture data for the statistical method to deal with the variable activity pattern of the species. To compensate for this dilemma, survivorship for the period 1980 to 1981 was also calculated from density estimates (Schumacher and Eschmeyer, 1943). These minimal survival estimates are probably more appropriate for this particular time period (Table LIV). Treated in this manner, the results showed that annual survivorship for 8 age classes ( 1 through 8 years) ranged from about 37 to $97 \%$. The survivorship values for one age class ( 4 years) in 2 different years were 0.86 and 0.37 . This variability is considered below (see annual variation).

Table LIV shows for female $\underline{S}$. obesus the mean 4-year survivorship for 2 cohorts ( 1 and 4 years old in 1977) and the total number of individuals in the population. These results showed that female survivorship ranged from 0.70 , S.E. \pm 0.05 to 0.74 , S.E. \pm 0.05 . In addition, the average for the 4 year means was 0.73 , S.E. \pm 0.01 . Consequently, the results seemed to indicate that all female $\underline{S}$. obesus greater than I year showed an annual survivorship close to $75 \%$. While these values were determined during a period dominated by favorable climatic conditions, adult female survivorship appeared not to decline greatly except perhaps during drought. Therefore, this annual 
TABLE LIV

ANNUAL SURVIVORSHIP OF FEMALE S. obesus AT RED CLOUD ROAD STUDY SITE. VALUES DETERMINED FROM STOCHASTIC ESTIMATE OF JOLLY (1965) EXCEPT FOR THOSE STARRED WHICH WERE DETERMINED FROM DENSITY ESTIMATES (SCHUMACHER AND ESCHMEYER, 1943). COHORT-1 AND COHORT-2 = 1 AND 4 YEAR OLDS IN 1977, RESPECTIVELY; NUMBERS IN BRACKETS = 1 STANDARD DEVIATION

\begin{tabular}{cccc}
\hline \multicolumn{4}{c}{ Category } \\
\hline Year & Cohort-1 & Cohort-2 & A1199 $\geq 1$ Year \\
\hline $1977-78$ & $0.85(0.10)$ & $0.86(0.10)$ & $0.80(0.06)$ \\
$1978-79$ & $0.69(0.10)$ & $0.78(0.09)$ & $0.74(0.06)$ \\
$1979-80$ & $0.97(0.27)$ & $0.63(0.11)$ & $0.69(0.07)$ \\
$1980-81$ & $0.37(0.27)$ & $0.63 *$ & $0.58 *$ \\
4-Year Mean \pm 1 s. e. & $0.74 \pm 0.12$ & $0.74 \pm 0.05$ & $0.70 \pm 0.05$ \\
\hline
\end{tabular}


survivorship estimate was probably typical for Colorado Desert female S. obesus.

From the results in Table LIV it appears there was some annual variability in survivorship for female $\underline{s}$. obesus. Closer inspection of juvenile, adult and total female populations showed 3 basic trends in survivorship: 1) survivorship of younger age classes was directly correlated with summer precipitation; 2) adult survivorship was positively correlated with both summer and early winter precipitation (this trend was especially true when the 2 precipitation amounts were summed) and 3) survivorship was inversely related to the previous years' reproductive frequency.

It appears that adequate summer precipitation was critical for younger age classes of females. Perhaps because their smaller size renders them less resistant to dehydration and starvation (Wiewand, 1982). Nonetheless, compared to $\underline{S}$. obesus elsewhere (Johnson, 1965; Nagy, 1973; Berry, 1974) females in this study showed earliest reproductive maturity. I believe this reflected the predictability of a longer activity season and summer precipitation pattern lowering the risk of reproduction in this Colorado Desert area.

Regarding the fact that for adult female $\underline{s}$. obesus neither precipitation parameter nor frequency of reproduction alone showed good correlation probably indicated that both kinds of parameters were integral to survivorship. This can be further illustrated by noting that while the second highest survivorship followed a year of high reproductive frequency, it also followed a summer-winter precipitation total that was very high. In addition, lowest adult survivorship 
occurred in a year of optimal reproduction followed by high summer precipitation amounts. However, winter precipitation, though substantial, occurred late in the season, thus causing a dry fall and early winter. Therefore, for Colorado Desert adult female $\underline{s}$. obesus, survivorship was highest following years of low reproductive frequency coupled with high summer and early winter precipitation and lowest following years of high reproductive frequency or low summer and early winter precipitation. This situation, showing the risk involved with reproduction, can be clarified by the fact that in all reproductive years, frequency of reproduction increased with body size (Ch. 4 Reproductive Frequency). Larger body size apparently enabled individuals to be more physiologically resistant to the harsh desert environment (Wiewandt, 1982).

Age-specific survivorship of male $\underline{s}$. obesus appeared to be similar for age classes in each of the 4 years (Table LV). For 2 cohorts ( 1 and 4 years old in 1977) while the first 3 years showed uniform high age-specific survivorship, the final year, overlapping a period of drought, showed greatly reduced age-specific survivorship. Table LV shows the mean 4-year annual survivorship for the 2 cohorts and the total number of individuals in the population. These results showed that male survivorship ranged between 0.72 , S.E. \pm 0.14 and 0.77 , S.E. \pm 0.13 . In addition, the average for the 4 year means was 0.74 , S.E. \pm 0.01. Some of these values probably exceeded the long-term average, because the period was dominated by better than average climatic conditions. Perhaps annual survivorship of male $\underline{\mathbf{S}}$ obesus is typically close to that of the females, about $75 \%$. 
TABLE LV

ANNUAL SURVIVORSHIP OF MALE S. obesus AT RED CLOUD ROAD STUDY SITE. VALUE DETERMINATIONS AND DESCRIPTIONS AS IN TABLE LIV

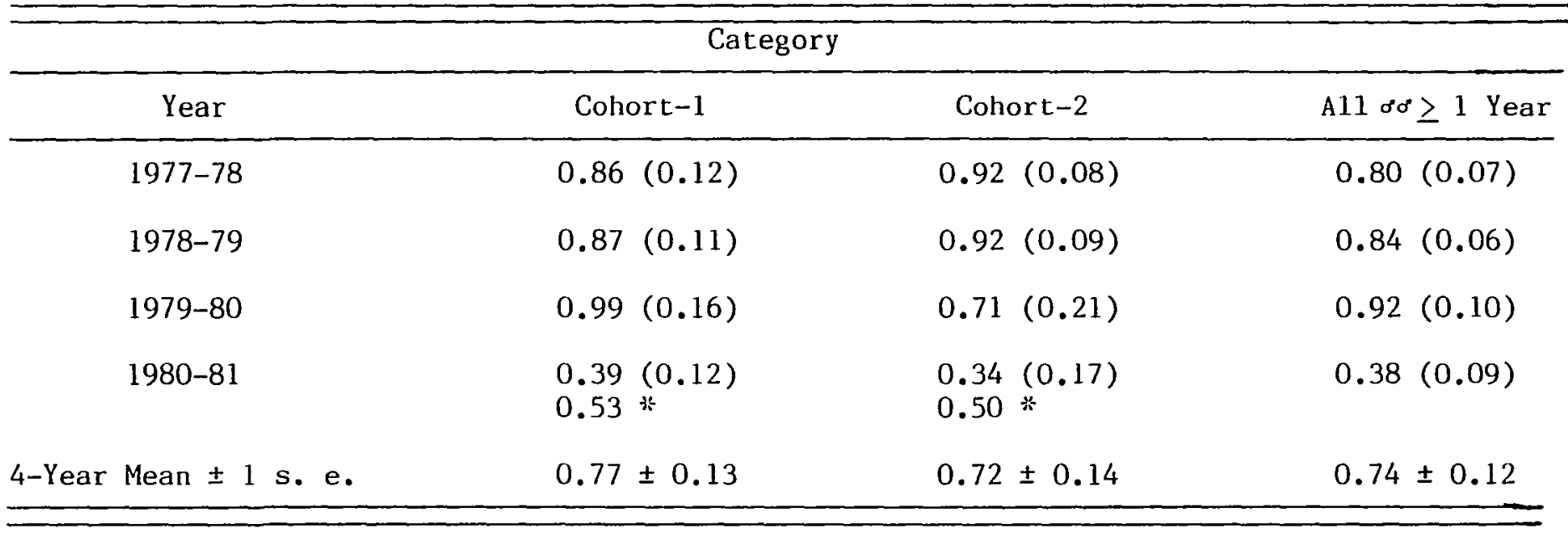


There is some annual variability in survivorship for Colorado Desert male $\underline{\mathrm{S}}$. obesus (Table LV). Closer inspection of juvenile, adult and total male populations showed 2 basic trends. First, survivorship of younger age classes was positively correlated with the summer precipitation. Second, survivorship of adult age classes was directly correlated with early winter precipitation.

It appears that adequate summer precipitation was highly important for annual survivorship of the younger age classes of Colorado Desert male s. obesus. Smaller size may render them less resistant to dehydration and starvation (Wiewand $t$, 1982). However, the correlation was not as strong for younger males. Two aspects of behavior that might affect male survivorship were pointed out in earlier chapters. First, some younger males appeared to be nomadic ( $\mathrm{Ch}$. 2 - Movement and Spacing Patterns). Two, some younger males spent considerable time attempting to court adult females (Ch. 2 - Social Behavior). Both of these behaviors carry physiological and ecological risks. Nonetheless, because annual survivorship was at a similar high level in all but the drought year, perhaps for this period these behaviors were of limited importance in determining annual survivorship of younger age classes. It should be pointed out that there was year to year variability in the most abundant age class for this group. The year of lowest annual survivorship was one in which the major contingent of the younger group was the 1 year age class. Consequently, this age class, consisting of smaller individuals, was probably most vulnerable to ecological conditions such as prevailing drought and predator pressure. 
In contrast to the situation for adult females annual survivorship of adult $\underline{\mathrm{s}}$. obesus in the Colorado Desert appeared not to be strongly correlated with summer precipitation. This was probably because adult male $\underline{S}$. obesus were not as burdened by the costs of reproduction as their female counterparts. This hypothesis is supported by the fact that according to the criteria indicative of male reproductive effort (Shrank and Ballinger, 1973; Newlin, 1976; Vitt and Ohmart, 1977b; Trauth, 1979) reproductive effort for male $\underline{S}$. obesus in this study was very low (Ch. 3 - Male Reproductive Cycle). However, substantial early winter precipitation appeared to be critical. In the Colorado Desert S. obesus were known to feed the year round (Ch. 2 - Feeding Habits). Apparently, lowered winter precipitation which severely limited available food, was a factor in causing low annual survivorship of adult males. Examination of the correlation of annual survivorship with reproductive frequency further illustrates the importance of winter precipitation. The data indicated that annual adult male survivorship can be high in years following high reproductive frequency (1978-1979) and low in years following low reproductive frequency (1980-1981). While 1978-1979 early winter precipitation was the highest observed during my study that for 1980-1981 was the lowest for this period. Consequently, it appeared that early winter precipitation was highly important for survival of both sexes.

A comparison of Tables LIV and LV indicates that annual survivorship patterns of male and female $\underline{s}$. obesus were quite different. Two general trends were indicated from the results. First, in years when climatic conditions were average to favorable (1978 through 1980), 
annual survivorship of most age classes was higher for males. Second, when climatic conditions were below average (1981) annual survivorship was higher in adult females than in adult males. While these differences might be due to unequal costs associated with reproduction (Wiewandt, 1982), perhaps they only reflected differences in behavior. Male activity was considerably increased in years when reproduction was highly successful (Ch. 2 - Movement and Spacing Patterns and Social Behavior), which made their location easier. In 1981 , when reproduction appeared nonexistent (Ch. 4 - Reproductive Frequency), surface-active males were rarely encountered. Since female movement and sites of retreat were more predictable (Ch. 2 - Movement and Spacing Patterns), perhaps they were relatively more easily detected in years of drought. At any rate, the 4-year mean annual survivorship of male and female S. obesus were very similar $(0.74 ;$ S.E. \pm 0.01 and 0.73 ; S.E. \pm 0.01 , respectively). Female survivorship was suggested to be considerably lower in Berry's (1974) Mojave Desert population. According to Wiewandt (1982), female survivorship should be lower than for males because limited food resources in late summer greatly diminish the chances of spent females surviving over the winter. However, in my study, summer precipitation made food more available to females. Perhaps, the greater predictability of sumer precipitation was responsible for similar annuals survivorship between the sexes.

Annual adult survivorship of lizards in the family Iguanidae shows a range of greater than 15-fold (Turner, 1977; Iverson, 1979). Generally, survivorship of iguanines is considerably higher than for noniguanines (Table LVI). Survivorship in $\underline{\mathrm{S}}$. obesus is 2 to 3 times 
TABLE LVI

COMPARISON OF ANNUAL SURVIVORSHIP FOR IGUANID LIZARDS. FOR NORTH AMERICAN IGUANIDS \pm 1 s. e. AND BRACKETS = NUMBER OF SPECIES

\begin{tabular}{lll}
\hline North American Insectivorous Iguanids & $0.34 \pm 0.05(11)$ & Turner (1977) \\
$\underline{S}$. obesus (Mojave Desert) & 0.90 & Berry (1974) \\
$\underline{\text { S. } \text { obesus (Colorado Desert) }}$ & 0.75 & Present Study \\
Cyclura carinata & 0.90 & Iverson (1977) \\
\hline
\end{tabular}


higher than the mean for other North American iguanid species but equal to or slightly less than that for one other iguanine species.

Natural selection should favor organisms that make some compromise between short-term and long-term reproductive expenditures (Williams, $1966 \mathrm{a}$ and b). In general, lizard species demonstrating higher reproductive effort have lower survivorship (Tinkle, 1969). For insectivorous lizard species, reproductive effort has been shown to be a function of body mass (RCM) and appears selected for as the result of several coevolved phenomena such as foraging tactics, predator escape, and habitat specificity (Vitt and Price, 1982). Basically, relative clutch mass is influenced by differential mortality and the energetic costs of locomotion for gravid females. Attempts to see how herbivorous lizard species fit the model of Vitt and Price have not been forth coming. Herbivory in lizard species requires large body size (Pough, 1973). Large body size may promote survivorship by lowering the risk of predation (Case, 1982) and/or rendering individuals more physiologically resistant to prevailing environmental conditions (Wiewandt, 1982). Iguanine species are large and long-lived lizards. However, there is considerable variation in iguanine RCM (Ch. 4 - Comparison of Iguanine Reproduction). It appears that variation in RCM among iguanines is related to selection factors for survivorship that are similar to those for iguanid insectivores, but as Iverson (1977) also noted, survivorship estimates for iguanines are limited.

Annual survivorship of 2 species of iguanines, including 2 allopatric populations of $\underline{\mathrm{s}}$. obesus, showed overlapping relatively high survival rates (Table LVI). However, Colorado Desert $\underline{s}$. obesus on the 
average had a lower annual survivorship than either Mojave Desert S. obesus (Berry, 1974) or Cyclura carinata (Iverson, 1979). According to Berry, her population experienced an annual turnover rate between 5 and $25 \%$. She also suggested that individuals in her population frequently live 20 years. It appears that egg and hatchling survival during the 4 years of her study probably did not exceed $10 \%$. From this coupled with density estimates for the study (Ch. 5 - Density) it appears that if individual $\underline{\mathrm{S}}$. obesus were to live 20 years, they would have to experience an average annual survivorship of $90-95 \%$. Iverson (1979) estimated a similar survivorship rate for $\underline{\mathrm{C}}$. carinata. This is opposed to a mean annual survivorship for $\underline{S}$. obesus in this study of 75\%. The egg and hatchling survivorship was low for the 2 studies demonstrating high adult survivorship. It appeared that for $\underline{C}$. carinata adequate nesting locations were severely limited. Adult females undertook long migrations to find suitable nest sites. This, according to the hypothesis of Vitt and Price (1982) results in a reduced RCM. While reproductive frequency was uniformly high, annual adult survivorship was probably enhanced by equable climate and reduced predation pressure. It appears that RCM was not variable between populations of S. obesus and was also relatively high for iguanines in general. This probably reflected this species' sedentary habits and therefore was consistent with the hypothesis of Vitt and Price. However, reproductive frequency of the Mojave Desert population is suspected to be low. In any given year, only a small portion of adult females reproduced. Lowered reproductive frequency was probably due to shortened spring growing season which limited availability of annuals and lack of summer 
precipitation which made food unavailable in late summer. This situation might enhance annual survivorship. Low egg and hatchling survivorship in the Mojave Desert population was attributed to near absence of summer precipitation and possibly extended cool winter conditions. From the present study, it was shown that reproductive frequency was higher than for other populations of $\underline{s}$. obesus (Johnson, 1965; Nagy, 1973; Berry, 1974). This situation would probably explain the observation of lowered adult annual survivorship. The higher reproductive frequency was largely attributed to a longer spring growing season and summer precipitation which might have made food more frequently available. Survivorship of eggs and hatchlings was considerably higher than for the other 2 studies. Frequent summer precipitation appeared to enhance such survivorship. Consequently, the difference in annual survivorship for the 3 studies can be explained largely by corresponding differences in fecundity. The decision to reduce incidence of reproduction and extend longevity has been called "bet-hedging" by some life historians (Schaffer, 1974; Stearns, 1976, 1977). It is thought that this compensates for high juvenile mortality in fluctuating environments. When juvenile mortality was relatively low (this study) then decreased adult survivorship was not so disadvantageous. Therefore, these iguanines seemed to comply with the inverse relationship of fecundity and survivorship shown for insectivorous lizards (Tinkle, 1969). 
SEX RATIO

Sex ratio is usually defined as the proportion of males in the population (Pianka, 1978). For natural populations, sex ratios often approach equality $(1: 1)$ and examination of genetic theory illustrates why this tendency persists. Fitness is a measure of the reproductive success of individuals relative to the reproductive success of other individuals since evolution operates by way of selection on individuals. Fitness can be improved if individuals produce offspring of the rarer sex because there will be less competition among individuals of this sex during reproduction. This "frequency dependent" selection will eventually result in a sex ratio of 1 : 1 because it is this ratio that provides the most stable genetic equilibrium. This theory is frequently referred to as the "Fisher Principle" after Fisher (1930) and it has often been implicated as the major cause of existing sex ratios encountered in populations of organisms (Edwards, 1960; Kolman, 1960). However, Fisher's argument works best under the following assumptions: 1) that progeny of each sex are of equal cost to produce; 2) that the population growth is in or near equilibrium; and 3) that all males and all females have the same probability of mating--i.e., all individuals have equal fitness. These assumptions are seldom fully realized in natural populations because of various ecological factors. Prevailing ecological factors regulate intensity of intra- and intersexual selection.

Sexual selection resulting in sexual dimorphisms, is of paramount importance in any discussion of sex ratio (Pianka, 1978). The intensity 
of sexual selection will play a major role in determining the sex ratio of a population. In the past, investigators have reported the sex ratio of a population from the total number of individuals or number of adults. However, to understand the intensity of sexual selection and therefore the significance of sex ratio, these overall ratios offer limited assistance. A better means of understanding sex ratio and its ultimate impact on the mating system is what Emlen and Oring (1977) term the "operational sex ratio (OSR)" which is defined as the average ratio of fertilizable females to sexually active males at any given time.

Sex ratios of lizard populations have usually been reported as close to $1: 1$ (see references in Turner, 1977). However, according to Turner, one sex may be favored because of higher survivorship when a cohort is followed for an entire life span. In addition, the number of females in a population may be considerably less than the number of males during unfavorable breeding years. For this situation, Turner cautioned against assuming that the sex ratio favored males, suggesting that repeated observations were necessary to determine if the sex ratio estimate was reliable or in error because of a seasonal decline in female activity brought about by deviation from optimal climatic conditions. The following questions were asked regarding the sex ratio of Colorado Desert $\underline{S}$. obesus at the Red Cloud Road study site: 1) What is the population sex ratio ( $\left.0^{\circ} / q q\right)$ ? 2) Does sex ratio change when the entire life span is considered? 3) What is the operational sex ratio (OSR)? and 4) How does sex ratio of the Red Cloud Road population compare with other conspecific populations? 
The population sex ratio for $\underline{S}$. obesus at Red Cloud Road was estimated by 3 methods (Table LVII). For the most part, the 3 methods illustrated a similar trend. The sex ratio ranged from near equality to highly in favor of males in years when reproductive success was average or less $(1977,1980,1981$, and 1982). Males were favored significantly according to a Schumacher-Eschmeyer population size estimate in $1980\left(x^{2}=14.12 ; 0.001>P>0.0001\right)$. The sex ratio strongly favored females in years when reproductive success was high (1978 and 1979). Females were favored significantly during these years for Schumacher-Eschmeyer estimates--i.e., for 1978, $x^{2}=6.35$; $0.03>\mathrm{P}>0.01$ and for $1979, \mathrm{x}^{2}=8.42 ; 0.005>\mathrm{P}>0.001$. This variation appeared to be largely due to an annual fluctuation in female activity (Ch. 2 - Annual Activity Cycle). Adult female $\underline{s}$. obesus were more numerous when environmental conditions promoted reproduction. Use of the Jolly method produced one obvious departure from the above trends--sex ratio significantly favored females $\left(\mathrm{x}^{2}=4.94 ; 0.05>\mathrm{P}>\right.$ 0.25 ) in 1981 , a year in which there was no reproduction. As was mentioned above, however, the Jolly method may produce an invalid estimate if the sample sizes are minimal, as occurred in 1981 and 1982. In any case, over the 6-year period 1977-1982, the mean sex ratios estimated by these 3 methods (the final year for Jolly ignored) all approached equality and therefore complied with the estimates for many other lizard species (Turner, 1977).

To my knowledge, reports on variation in sex ratio over the entire life span are limited to just a few lizard species (Blair, 1960; Tinkle, 1967; Turner et al., 1969). At the Red Cloud Road study site, the sex 
TABLE LVII

THE POPULATION SEX RATIO ( $\left.\sigma^{\circ}: q\right)$ FOR RED CLOUD ROAD $\underline{S}$. obesuS FROM 3 METHODS OF ANALYSIS. 6-YEAR MEAN FOR THE 3 METHODS SHOWN BELOW ( \pm 1 s. e.)

\begin{tabular}{lccc}
\hline & & $\begin{array}{c}\text { Schumacher } \\
\text { Eschmeyer } \\
(1943)\end{array}$ & $\begin{array}{c}\text { Capture- } \\
\text { Recapture }\end{array}$ \\
\hline 1977 & Jo11y $(1965)$ & $1.25: 1$ & $0.97: 1$ \\
1978 & - & $0.62: 1$ & $0.84: 1$ \\
1979 & $0.91: 1$ & $0.60: 1$ & $0.83: 1$ \\
1980 & $0.81: 1$ & $1.54: 1$ & $0.90: 1$ \\
1981 & $1.35: 1$ & - & $1.27: 1$ \\
1982 & $0.64: 1$ & -- & $1.06: 1$ \\
Mean & $1.02 \pm 0.17$ & $1.00 \pm 0.23$ & $0.98 \pm 0.07$ \\
\hline
\end{tabular}


ratios of 2 cohorts of $\underline{\mathrm{s}}$. obesus were determined over a 6 year period (1977-1982). The 2 cohorts were the same as reported in Ch. 5 Survivorship. Cohort 1 , was followed for 1 through 6 years of age and cohort 2 was followed from 4 through 9 years of age. These sex ratios cover the ages for a typical $\underline{\mathrm{s}}$. obesus life expectancy at Red Cloud Road (Ch. 5 - Longevity). Annual cohort sex ratios were determined by 2 methods (Table LVIII). In general, the 2 methods indicated that the sex ratio appraoched 1: 1 (variation due to reproductive activity of females). The time period in which females were predominant seemed to be related to extent of participation in reproduction ( $\mathrm{Ch} .4-$ Reproductive Frequency). When environmental conditions were optimal a significant number of females reproduced as young as 3 years of age (Ch. 4 - Age at First Reproduction). Under average environmental conditions, females were not likely to reproduce until at least 5 years of age. As early as 4 years but in all cases by 6 years of age, cohort sex ratios of $\underline{S}$. obesus showed a trend toward equality.

While operational sex ratio (OSR) is believed to be of paramount importance in determining the mating systems of various populations of S. obesus (Ryan, 1982), to date there are no reports on OSR for this species. For $\underline{S}$. obesus at Red Cloud Road, OSR was determined assuming all adult males were sexually active (Ch. 3 - Male Reproductive Cycle) and for females using the product of adult female density and annual frequency of reproduction (Ch. 4 - Reproductive Frequency). The OSR of Red Cloud Road S. obesus from 1978-1982 ranged from 0.86 : 1 to 2.6 : 1 in reproductive years (note: no reproduction occurred in 1981). The mean OSR for this period was 1.58 ; S.E. $\pm 0.39: 1$. The OSR 
TABLE LVIII

THE SEX RATIO ( $\sigma^{\circ}:$ ) FOR 2 COHORTS OF RED CLOUD ROAD $\underline{S}$. obesus. COHORTS $=$ SAME AS FOR SURVIVORSHIP IN CH. 3

\begin{tabular}{llccc}
\hline & \multicolumn{2}{c}{ Recapture-Capture } & \multicolumn{2}{c}{ Jo11y } \\
Year & Cohort-1 & Cohort-2 & Cohort-1 & Cohort-2 \\
\hline 1977 & $0.81: 1$ & $0.76: 1$ & - & - \\
1978 & $0.72: 1$ & $0.75: 1$ & $0.88: 1$ & $0.74: 1$ \\
1979 & $0.74: 1$ & $0.94: 1$ & $0.83: 1$ & $0.83: 1$ \\
1980 & $0.94: 1$ & $1.22: 1$ & $0.89: 1$ & $0.92: 1$ \\
1981 & $1.00: 1$ & $1.00: 1$ & $0.96: 1$ & $0.57: 1$ \\
1982 & $0.86: 1$ & $0.80: 1$ & - & - \\
\hline
\end{tabular}


distinctly favored males in all but one of the years. Only during the optimal reproductive year (1979) did it favor females. This tendency of OSR to be skewed toward males might favor mate monopolization. However, the fact that adult females at Red Cloud Road exhibited highly synchronous reproductive habits (Ch. 3 - Breeding Synchrony) and that adult males of relatively large size were few (Ch. 5 - Predation Intensity and Longevity) probably was responsible for diminished episodes of mate monopolization. While the results of the present study showed adult males to be more evident, such year to year instability of the OSR was largely an indication of extreme variability in aduit female acitivity. The fact that there was a significant negative correlation between OSR and population reproductive frequency $(r=-0.95 ; N=5$; $P<0.05)$ probably reflects annual variation in adult female activity. The suspected higher OSR for Mojave Desert studies (Nagy, 1973; Berry, 1974; Case, 1976) probably was largely the result of relatively fewer and/or less active adult females. Relatively fewer adult female $\underline{\text { S. }}$ obesus at most Mojave Desert locations may indicate lowered survivorship form reproduction (Wiewand, 1982), but since reproduction appeared to be infrequent, reduced female activity may be as important as female number in establishing existing OSRs.

The sex ratios of 5 Mojave Desert populations of $\underline{s}$. obesus are compared with those for the Red Cloud Road population in Table IIX. Three of the Mojave Desert populations had sex ratios highly skewed toward males (Nagy, 1971; Berry, 1974; Case, 1976). The 2 remaining populations had sex ratios very similar to the 7-year average at Red Cloud Road (Johnson, 1965; Case, 1976) and therefore close to equality. 


\section{LIX}

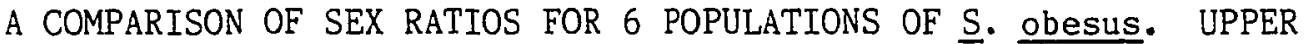
DECILE = LARGEST $10 \%$ OF THE POPULATION; NUMBERS

IN BRACKETS = SAMPLE SIZE

\begin{tabular}{llcl}
\hline \multicolumn{1}{c}{ Location } & Sex Ratio & $\begin{array}{c}\text { Upper Decile } \\
\text { (SVL) }\end{array}$ & Reference \\
\hline China Lake & $1.61: 1$ & $207.0(117)$ & Berry (1974) \\
Little Lake & $1.70: 1$ & $218.0(20)$ & Case (1976) \\
Red Rock & $0.91: 1$ & $191.2(95)$ & Johnson (1965) \\
Barstow & $1.40: 1$ & $195.2(57)$ & Nagy (1971) \\
Amboy & $0.97: 1$ & $175.0(110)$ & Case (1976) \\
Red Cloud Road & $0.98: 1$ & $189.3(326)$ & this study \\
\hline
\end{tabular}


In addition, comparison of adult sex ratios for one Mojave Desert population of $\underline{\mathrm{S}}$. obesus (Berry, 1974) and for $\underline{\mathrm{S}}$. obesus in the present study are shown in Table LX. While the former shows significant male bias $\left(x^{2} ; P<0.05\right)$ in 3 of 4 years, the latter always approaches equality. The study period means for Berry and the present were 1.88 (S.E. \pm 0.13$): 1$ and 0.88 (S.E. \pm 0.03$): 1$, respectively. The sex ratio of the Mojave Desert population was significantly greater than for the Red Cloud Road population ( $t=9.09$; df $=8 ; P<0.001$ ).

There is an interesting and significant correlation between sex ratio and one body size parameter, upper decile length (UDL), for the 6 populations $(r=0.90, N=6, P<0.05)$. UDL is the mean value for that portion of the population representing the upper $10 \%$ SVLs. Initially, fluctuations in UDL might be interpreted as reflecting different proportions of adult male $\underline{s}$. obesus in the population--i.e., the greater the UDL, the more it is composed of males. However, at the Red Cloud Road study site, a location that showed a low UDL, the annual female complement of the UDL ranged only between $10-25 \%$ (Ch. 5 - Predation Intensity). This range was not different than for the population studied by Berry (1974). Therefore, the variation in UDL probably reflected a difference in maximum male body sizes--i.e., with regard to largest males, Little Lake and Amboy had the largest and smallest, respectively.

The reason for this relative difference in number of males and corresponding male size can be discerned by looking at differences in reproductive strategy. In the northern Mojave Desert individual $S$. obesus have a relatively long life expectancy (Berry, 1974 and pers. 
TABLE LX

A COMPARISON OF ADULT SEX RATIOS FOR 2 POPULATIONS OF $\underline{S}$. obesus. SEX RATIO WAS DETERMINED BY CAPTURE-RECAPTURE METHOD

MEANS \pm 1 s. e.

\begin{tabular}{lccccc}
\hline & $\begin{array}{c}\text { Mojave Desert } \\
\text { (Berry, 1974) }\end{array}$ & \multicolumn{3}{c}{ Red Cloud Road } \\
\hline Year & Sex Ratio & Number & Year & Sex Ratio & Number \\
\hline 1968 & $1.58: 1$ & 42 & 1977 & $0.83: 1$ & 64 \\
1969 & $2.12: 1$ & 43 & 1978 & $0.87: 1$ & 71 \\
1970 & $1.75: 1$ & 73 & 1979 & $0.83: 1$ & 126 \\
1971 & $2.07: 1$ & 72 & 1980 & $1.02: 1$ & 93 \\
& & & 1981 & $0.93: 1$ & 29 \\
& & & 1982 & $0.80: 1$ & 31 \\
& & & & $0.88 \pm 0.03: 1$ & \\
\hline
\end{tabular}


comm.). The climatic conditions of the Mojave Desert are not as conducive to reproduction as at Red Cloud Road but there appears to be less predation pressure in the Mojave Desert (Ch. 5 - Predation Intensity). Assessment of Berry's data indicated that males were favored in all size classes. This seems to indicate that there were more males than females in various cohorts. Since reproduction appeared to occur much less frequently at a number of Mojave Desert locations (Johnson, 1965; Nagy, 1973; Berry, 1974), the reproductive strategy may have favored the production of males. With infrequent reproduction it would be necessary to ensure maximum success when one of the few optimal years arrived. With relatively less predation, because of lower densities and/or shorter activity season, perhaps Mojave Desert sites have experienced sexual selection that has enabled these $\underline{s}$. obesus to overcome unfavorable reproductive conditions. Selection has operated in the form of greatly increased size of adult males. Greatly outnumbering adult females, males of large size best demonstrated the competitive edge necessary to maintain territories optimal for female use and ultimately to ensure high reproductive success. The fact that some investigators have noted the clumped nature of adult females further supports the selective advantage of larger male body size (see references in Ryan, 1982).

Better climatic conditions in the Colorado Desert have promoted higher levels of reproduction (Ch. 4 - Reproductive Frequency) but this has also led to higher predation intensity (Ch. 5 - Predation Intensity). At the Red Cloud Road study site the sex ratio approached equality. In optimal years such as 1979, the OSR actually favored 
females. This situation probably enabled $\underline{S}$. obesus to take advantage of prevailing reproductive conditions and thus maintain a balance with predation. Selection appeared not to favor large body size because, with relatively more adult females available, large body size was not necessary to ensure successful matings.

These differences in sex ratio ultimately has led to quite different mating systems between Mojave and Colorado Desert localities. According to Emlen and Oring (1977) mate monopolization is most successful when adult females demonstrate moderate breeding asynchrony (degree of temporal availability) and clumped distribution (degree of spatial availability). While the breeding synchrony for Mojave Desert S. obesus is not well understood it appears not to be as synchronous as at the Red Cloud Road study site. While the home range sizes of Berry's Mojave Desert adult females were considerably larger than those at the Red Cloud Road study site (Ch. 2 - Movement and Spacing Patterns) it appears that the relative distribution of adult females at the former locality was more clumped i.e., they were more inclined to move, but frequently returned to favorite locations. Consequently, such conditions probably were responsible for the more intense territorial behavior and distinct social organization demonstrated by some Mojave Desert $\underline{\text { s. }}$ obesus (Ryan, 1982). The collection of data concerned with detailed time budgets and environmental conditions such as measurement of density and distribution of food resources would elucidate these observations. 


\section{RECRUITMENT AND PREDATION INTENSITY}

Significant annual changes in density of lizard populations (in some environments as much as $50 \%$ ) has been well documented (see references in Turner, 1977). However, most lizard populations demonstrate a certain amount of stability over a long period of time (they do not approach extinction or infinite size). Maintenance of a constant density by lizard populations is the result of a number of factors usually assigned to density-independent factors (which operate on populations without regard to density) and density-dependent factors (the effects of which are apparently moderated by or dependent upon population size). Together, they bring about regulation of population size by promoting an increase in density when numbers are sparse and a decrease in density when numbers are high. Meteorological factors (weather) operate in a regulatory manner, only by chance. The level of fecundity of desert lizards shows a strong positive correlation with extent of drought, hence reduced food (Ballinger, 1977), thus implying that winter precipitation is a basic regulator of numbers. This does not contradict the general theory if viewed from the standpoint that in the face of prevailing summer conditions (usually dry) hatchling survival has frequently shown a strong density-dependent correlation (Blair, 1960).

However, this approach pays most attention to the posthatchling stage of the life history and largely ignores the egg stage. The environmental conditions for incubation can have a great impact on hatching success (Muth, 1980) and for some lizard species may play as 
big a role as competition among hatchlings in regulating population density. If a climatic factor such as summer precipitation is highly predictable, then weather might indeed show routine regulatory capacity. The balance between population density and resources such as space, food and shelter has been shown, both in the field (Blair, 1960) and experimentally (Bustard, 1970), to be influenced strongly by social behavior. For $\underline{\mathrm{S}}$. obesus, social behavior varies according to body size (Ryan, 1982). In general, larger individuals demonstrate increased activity and aggression. In turn, this leads to greater demand on resources and susceptibility to predation. This investigation will show that for $\underline{S}$. obesus at Red Cloud Road regulation of numbers was strongly controlled by the effect of weather (egg and hatchling survival) in a manner independent of population density and by predation on adults which becomes a density dependent factor only after a certain adult body size is attained.

Densities of lizard populations increase due to recruitment, the sum of reproduction and immigration (Ricklefs, 1979). A decrease in lizard population densities is the result of mortality and emigration. Attributes of reproduction have already been considered. Immigration, emigration and predation will be dealt with here. Estimates of predation are from frequency of tail-breaks (Pianka, 1970. The following questions were addressed regarding recruitment and predation

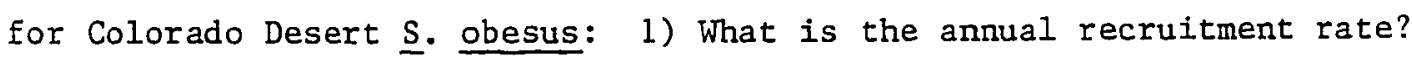
2) What recruitment factor (reproduction or immigration) is most important? 3) How does recruitment in the Colorado Desert compare with conspecific populations throughout the geographic range? 4) What factor 
(predation or emigration) is most important in decreasing population density? 5) What is the population tail-break frequency? 6) How does tail-break frequency differ between sexes and cohorts? 7) What parameters show the strongest correlation with tail-break frequency? and 8 ) How does tail-break frequency in this population compare with that in populations of conspecifics?

The annual recruitment rate for Red Cloud Road $\underline{\mathrm{S}}$. obesus was estimated in part from analyses of capture-recapture data using the method of Jolly (1965). Application of this method for the 4-year period 1978 - 1981 revealed that annual recruitment was variable (Table LXI). Mean annual recruitment was 42.5 (S.E. \pm 14.4) lizards. If 1982, a year following no reproduction, is added to the 4-year period, then the mean annual recruitment rate dropped to 33.9 (S.E. \pm 14.0). These findings indicate that a considerable number of new individuals were added to the population in most years. In fact, the

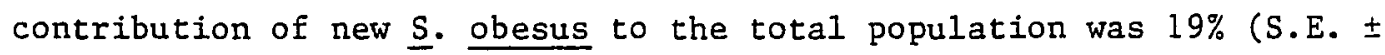
$7 \%$ ) for 1978 - 1982. In other words, about one-fifth of the population each year consisted of new lizards.

Closer examination of the data (Table IXII) revealed that nearly

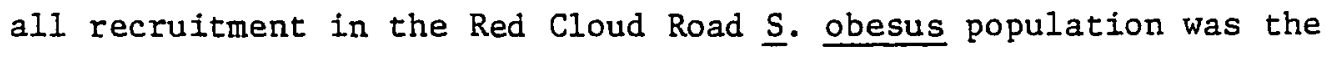
result of reproduction. Individuals in their first year, while highly variable in abundance, made the greatest age-specific contribution. The mean percentage of yearlings in the total number of marked lizards during 6 years was 30 (S.E. \pm 11 ). Therefore, on the average, annual recruitment of yearlings was almost one-third of the total. For the same 6 year period $\underline{\text { s. obesus }} 2$ and 3 years of age (largely subadult) 
TABLE LXI

THE ANNUAL RECRUITMENT RATE FOR S. obesus AT THE RED CLOUD ROAD STUDY SITE. DETERMINED FROM JOLLY (1965)

\begin{tabular}{lcc}
\hline Year & Number & $\begin{array}{l}\text { Standard } \\
\text { Deviation }\end{array}$ \\
\hline 1978 & 51.48 & - \\
1979 & 32.30 & 6.89 \\
1980 & 77.08 & 9.03 \\
1981 & 8.99 & 8.16 \\
\hline
\end{tabular}


TABLE LXII

ANNUAL RECRUITMENT OF $\underline{S}$. obesus AT THE RED CLOUD ROAD STUDY SITE. $*=$ SITE EXPANSION

\begin{tabular}{lcc}
\hline Year & $\begin{array}{c}\text { Number of } \\
\text { Yearlings }\end{array}$ & $\begin{array}{c}\text { Number }> \\
1 \text { Year }\end{array}$ \\
\hline 1978 & 21 & $30 *$ \\
1979 & 30 & 15 \\
1980 & 178 & 0 \\
1981 & 15 & 0 \\
\hline
\end{tabular}


showed a mean percentage of the total recruitment to be 48 (S.E. \pm 12 ). Consequently, individuals in their first 3 years of life constituted nearly $80 \%$ of the annual recruitment. While some of the $2-3$ year old individuals appeared nomadic, thus enhancing the possibility of immigration, since most individuals in this age group were highly secretive and moved much less than the adults (Ch. 2 - Movemient and Spacing Patterns), many had probably been residents since hatching. The large increase in number of lizards > 1 year in 1978 was because I extended a portion of the study site eastward (to include an additional rock outcrop). The increase in 1979 was the result of an optimal breeding year (Ch. 4 - Reproductive Frequency). In 1979, thirteen of the 15 adults ( $>3$ years) were females. Since females $\underline{S}$. obesus were much more sedentary than their male counterparts, it seems likely that most of them had spent their entire lives within the study site perimeter. In addition, though adult male $\underline{S}$. obesus showed considerably greater movement and hence were more likely to immigrate, for the 6-year period, their mean annual recruitment among adults was only 0.2 (S.E. \pm 0.1 ).

Some immigration probably occurred because of "nomadic" juvenile and subordinate adult male $\underline{S}$. obesus. However, 2 additional points seem to minimize its significance. First, in 1977 about 50 individuals, mostly adults, were marked in a canyon adjacent to the study site's western margin. Some were captured within $25 \mathrm{~m}$ of the site. Not one of those individuals however, has been sighted on the site, even though several have been captured repeatedly off the site near their original capture locations. Second, examination of emigration showed a similar 
pattern (see below). Apparently, extensive movements were limited to a few male $\underline{s}$. obesus, and the vast majority of the population remained in a smaller and/or permanent location. This tendency of restricted movement further supports reproduction as the main factor in recruitment

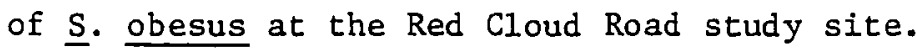

Recruitment of $\underline{S}$. obesus has been reported only for a northern Mojave Desert population (Berry, 1974). Mean annual recruitment of yearlings (percent of total new individuals) was $8 \pm 2$. This value was about one-fifth of that for yearling recruitment at the Red Cloud Road study site. The maximum number of yearlings captured in one year was 5 compared to 61 for this study. Berry's data showed annual recruitment was low for all age classes.

Previously, it was shown that summer precipitation enhanced survival of eggs and hatchlings at the Red Cloud Road site (Ch. 5 Survivorship) and that summer precipitation is usually much less in the northern Mojave Desert than in the Colorado Desert study area (Ch. 1 Climate and Vegetation). During Berry's study (1968-1971), most Mojave Desert weather stations experienced average amounts of summer and winter precipitation (National Weather Service). Therefore, as Berry's data suggested, annual frequency of reproduction and survivorship of eggs and hatchlings were probably low. When juvenile survivorship is low, demographic theory predicts infrequent reproduction and high adult survivorship (Hirschfield and Tinkle, 1975; Murphy, 1968; Stearns, 1976, 1977; Williams, 1966 a and b). Since observations indicated low reproduction (alternate years) and $90-95 \%$ annual adult survivorship, Berry's data seemed to support the theory. For much of the time, 
recruitment of yearlings in the northern Mojave Desert appears greatly limited.

Berry's research protocol did not enable her to measure immigration of $\underline{\text { S. }}$ obesus. However, her animals displayed a different social organization than those in the present study (Ch. 2 - Social Behavior) which may have led to a corresponding difference in this recruitment factor. According to Ryan (1982), male size distribution and operational sex ratio (OSR) are important factors in the mating

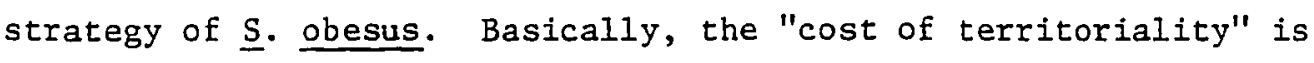
directly proportional to the number of females and inversely proportional to male body size. At Berry's northern Mojave Desert study site, the sex ratio for $\underline{S}$. obesus was strongly biased toward adult males and many of them were relatively large. In contrast, at the Red Cloud Road study site, the sex ratio frequently favored females (Ch. 5 - Sex Ratio) and adult males were relatively small. The social organization of Berry's population, perhaps reflecting lower costs of territoriality, was typically tyrant-subordinate. On the other hand, with higher costs, the social structure of the Red Cloud Road population appeared less organized or completely lacking. As will be shown below (Ch. 5 Predation Intensity), predation pressure appeared greater at the Red Cloud Road study site. Because of higher predator pressure, Red Cloud Road $\underline{S}$. obesus remained relatively small. At small body sizes, individuals faced elevated costs in maintaining territories and therefore abandoned this behavior. Relative to this study, increased body size (with lowered predation) in the northern Mojave Desert might have promoted immigration tendencies in some subordinate males. 
In comparison to predation, emigration was probably not a major factor in the regulation of density of $\underline{s}$. obesus in the Colorado Desert study area. For the period 1977-1982 areas adjacent to the perimeter of the 8 ha site were frequently and intensely searched for approximately 400 hours. For this effort, only one marked individual from the study site was found, about $25 \mathrm{~m}$ west of the site. In addition, of $50 \underline{\mathrm{s}}$. obesus marked early in 1977 in a canyon adjacent to the site's west boundary, none were found on the study site. Nonetheless, under certain conditions a few individuals, mostly immature and subordinate males, were suspected of emigrating. The one small adult found off site, lizards 7, was a $165 \mathrm{~mm}$ SVL male known to exhibit nomadic behavior (Ch. 2 - Movement and Spacing Patterns). This individual was found in 1979, a year when social organization appeared most structured. This lizard had occupied a distinct rocky east facing slope for 2 years previously. In 1979 the dominant male in this area, lizard 2, was about 185 ImL and noticeably assertive. Perhaps a confrontation with the larger territorial lizard 2 led to lizard 7 leaving the area. Still, while such male-male confrontations were common at the study site in 1979 and subordinate males made extensive movements, this is the only off-site record of a marked $\underline{S}$. obesus.

Measuring predation in natural populations, or even determining that the disappearance of an individual from the population is, in fact, due to predation, poses a difficult technical problem (Ricklefs, 1979). This problem stems from the fact that: 1) there are a number of causes of apparent death besides predation--starvation, disease, exposure to the elements and emigration ("ecological death"); 2) predators are 
rarely caught in the act (some of the predator-prey interactions reported here were from local residents who have spent years in the desert); and 3) most predator-prey relationships represent a very complex and ever changing interaction--e.g., few predators restrict their feeding to one kind of prey, few prey species are eaten by only a single species of predator, and predators do not remove individuals from prey populations at random. According to Holling (1959) an increase in prey density is frequently followed by a corresponding increase in predation, first by a functional response (increase in individual predator's rate of food consumption) and second by a numerical response (increase in number of predators). Due to increased intraspecific competition among individual predators functional and numerical responses are usually inversely related. The selectivity by a predator, regimented by a time restriction, dictates that they choose prey that are the easiest to catch--the individual with a relatively small chance of escape (Errington, 1946 and 1963). Prey populations are most vulnerable to predators when they exhibit relatively high rates of reproduction, inhabit relatively homogeneous environments, and appear to lack an established social order (Ricklefs, 1979).

The incidence of broken tails in lizard populations serves as an indirect estimate of predation intensity (Pianka, $1970 \mathrm{~b}$ and Rand, 1954) if tail breaks are not the resuit of intraspecific agonistic behavior. During the past decade, the frequency of broken or regenerated tails has been determined for a number of different lizard species (see Vitt et al., 1977) and various populations of conspecifics (Ballinger and Tinkle, 1979; Case, 1976, 1982). Two general strategies of tail 
adaptations have been recognized in lizards (Vitt et al., 1977). Either tail loss or autotomy is self-induced and followed by regeneration, or tail loss occurs with great difficulty and there is little or no regeneration following loss. It appears that autotomy is the primitive condition and that tail retention has evolved to accomodate a number of functions (Etheridge, 1967). Some of the more obvious and widespread functions include: swimming, climbing, stabilization, balance, social activities, defense, and fat storage. For lizard species whose tails are employed for one or a combination of these functions, tail retention is critical to maintaining individual fitness. However, if predation is high, then reduced fitness from autotomy, perhaps reducing growth which might lead to smaller clutch size or longer time to reach maturity, is still preferable to loss of fitness from predation, which results in mortality. Consequently, the evolution of the autotomy-regeneration adaptive complex is the result of the interplay of predation pressure and retention adaptations that improve individual fitness (Ballinger and Tinkle, 1979).

Considering both Berry's (1974) study and this one, several hundred intraspecific confrontations have not brought about one incidence of a tail break. Consequently, $\underline{s}$. obesus appears to demonstrate a tail retention adaptation that undoubtedly accomodates most of the above functions. For the 7-year period (1977-1983) tail break frequency of the Red Cloud Road population showed an almost 3-fold annual variation (Table LXIII). At least $20 \%$ of the population had broken tails in all years. For this time period frequency of tail breaks was lowest in the initial year, much higher but fairly constant 


\section{TABLE LXIII}

THE RELATIONSHIP OF TAIL BREAK FREQUENCY WITH CERTAIN PARAMETERS FOR RED CLOUD ROAD $\underline{\text { s. obesus }}$ STANDARD ERRORS ARE \pm 1

\begin{tabular}{lrccccccc}
\hline Year & $\mathrm{N}$ & $\begin{array}{c}\text { Upper } \\
\text { Decile }\end{array}$ & $\begin{array}{c}\text { Lower } \\
\text { Quartile }\end{array}$ & $\begin{array}{c}\text { Median } \\
\text { SVL }(\mathrm{mm})\end{array}$ & $\begin{array}{c}\text { Mean } \\
\text { SVL }(\mathrm{mm})\end{array}$ & $\begin{array}{c}\text { Modal } \\
\text { SVL (mm) }\end{array}$ & $\begin{array}{c}\text { Mean Age } \\
\text { (Years) }\end{array}$ & $\begin{array}{c}\% \text { Tai1 } \\
\text { Breaks }\end{array}$ \\
\hline 1977 & 130 & $181.7 \pm 2.6$ & $83.5 \pm 1.9$ & 128 & $124.1 \pm 3.6$ & 146 & 3.3 & 19 \\
1978 & 123 & $190.0 \pm 1.6$ & $116.7 \pm 1.9$ & 147 & $149.9 \pm 2.5$ & 152 & 4.2 & 28 \\
1979 & 135 & $191.9 \pm 2.2$ & $132.3 \pm 2.6$ & 160 & $157.7 \pm 2.5$ & 158 & 4.4 & 33 \\
1980 & 146 & $191.5 \pm 2.2$ & $89.2 \pm 1.3$ & 153 & $136.7 \pm 3.4$ & 161 & 3.7 & 28 \\
1981 & 36 & $187.7 \pm 3.4$ & $113.3 \pm 6.8$ & 164 & $153.4 \pm 4.8$ & 174 & 5.6 & 34 \\
1982 & 36 & $193.3 \pm 3.5$ & $130.9 \pm 2.8$ & 160 & $158.9 \pm 3.7$ & 173 & 6.4 & 31 \\
1983 & 15 & $186.0 \pm 9.0$ & $138.5 \pm 0.7$ & 166 & $161.5 \pm 4.5$ & 175 & 7.3 & 53 \\
\hline
\end{tabular}


over the next 5 years $(\bar{x}=30.8, \pm 1.2 \%$ and, increasing by about $60 \%$, highest in 1983 when over $50 \%$ of the population had broken tails. As expected, tail break frequency for $\underline{\mathrm{S}}$. obesus was higher in adults, but the comparison between adult sexes showed great dissimilar variability (Table LXIV). For the 6-year period 1977 - 1982, tail break frequency was greater for adult males in 4 years, greater for adult females in 1 year and roughly equal in the 1 remaining year. Increased activity associated with territoriality no doubt contributed to usually higher incidences among adult males. Nonetheless, different behavior patterns for the sexes did not fully explain the trends that were observed. For instance, the year of lowest tail break frequency for adult males (1979) was also a year in which territoriality was most intense. In 1981, when there was no reproduction and adult females were relatively inactive, tail break frequency was much higher for females than for adult males over half of which had broken tails. As will be shown below, such parameters as age and body size distribution have a great deal to do with tail break frequency. Perhaps, the significnace of tail break frequency can best be illustrated by observing trends in various cohorts. For the 6-year period 1977 - 1982 tail break frequency was monitored for 2 cohorts of S. obesus (Ch. 5 - Survivorship). These two groups were treated according to sex as well as age (Figs. 44 and 45). For cohort-1, which consisted of yearlings in 1977, during ages 1 through 4 years, tail break frequency increased gradually and was similar for male and females. However, at age 5 (1981), tail break frequency in males nearly doubled while showing no increase in females. Consequently, for this 
TABLE LXIV

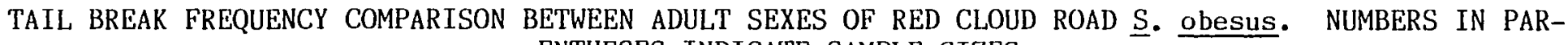
ENTHESES INDICATE SAMPLE SIZES

\begin{tabular}{lcccccc}
\hline & \multicolumn{1}{c}{1977} & 1978 & 1979 & 1980 & 1981 & 1982 \\
\hline Adult Males & $0.41(29)$ & $0.49(33)$ & $0.40(57)$ & $0.47(47)$ & $0.43(14)$ & $0.57(14)$ \\
Adult Females & $0.20(35)$ & $0.35(38)$ & $0.32(69)$ & $0.48(46)$ & $0.53(15)$ & $0.29(17)$ \\
\hline
\end{tabular}


Figure 44. Annual tail break frequency of a cohort of Red Cloud Road S. obesus (yearlings in 1977). clear = females; shaded = males; numbers $=$ sample sizes. 


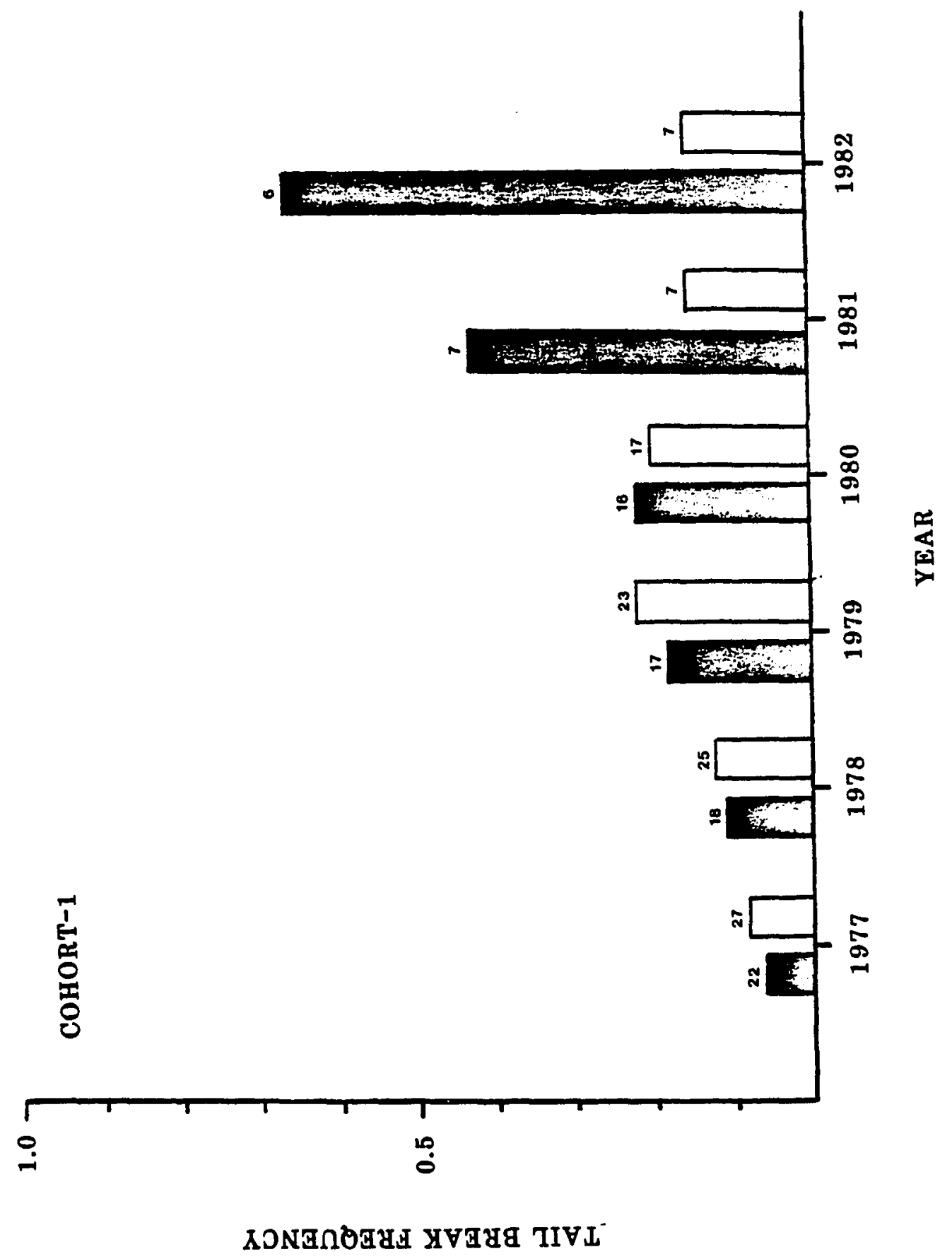


Figure 45. Annual tail break frequency of a cohort of Red Cloud Road $\underline{\text { S. }}$ obesus ( 4 years old in 1977). clear = females; shaded = males; numbers $=$ sample sizes. 


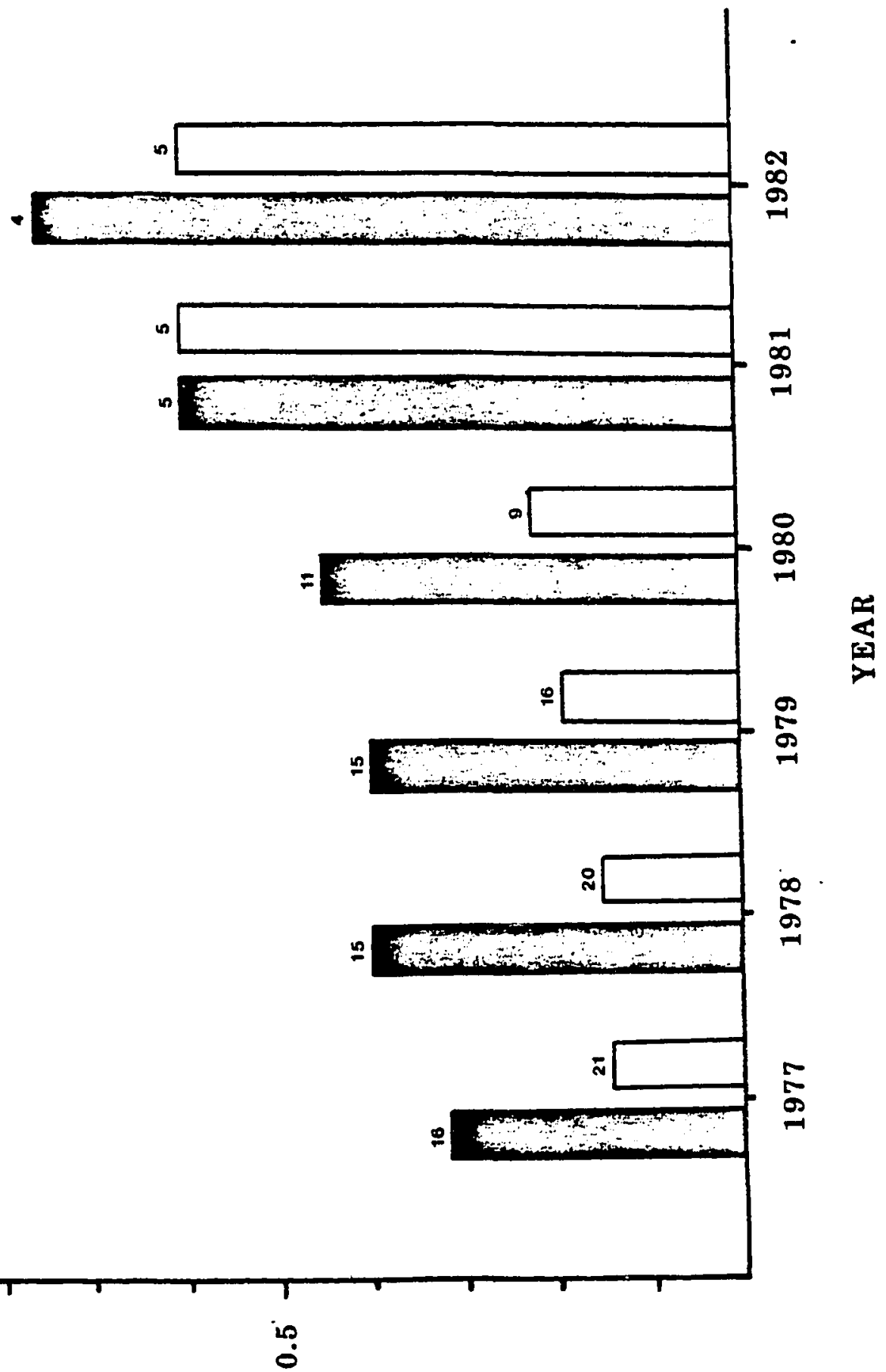

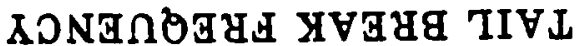


age the tail break frequency for males was about 3 times greater than for females. At age 6, tail breaks in males continued to increase but remained about the same level in females. This resulted in 6 year old males showing a tail break frequency about 5 times that of females for the same age.

For cohort-2, which consisted of 4 year olds in 1977 , during ages 4 through 7 years tail break frequency was roughly twice as high in male s. obesus. At about 4 years all males and most females were reproductively mature (Ch. 4 Age at Reproductive Maturity). Consequently, during the entire 6 years these individuals were considered adults. Nonetheless, not until 8 years of age did females have a tail break frequency similar to that of males. By age 9 (1982) the vast majority of cohort-2 had broken tails.

Tail break data of both cohorts was available for the ages $4-6$ years and consequently, a comparison of these ages for different years was possible (Fig. 46). For both sexes, similarities in rail break frequency existed in most of the ages. Regarding 2 male cohorts, divergence of similaricy was greatest at 6 years of age. At this age, males of cohort-1 showed a tail break frequency that was 1.67 times that of cohort-2. Because of the small sample size of cohort-1, this difference may be exaggerated, but if accurate it probably corresponded to marked changes in population density and age distribution at this time (see below). The similarity was close for 2 female cohorts in all 3 years. From 4 to 6 years, tail break frequency appeared to have remained consistently low. The reason for lack of substantial increase in tail break frequency can be attributed to the trend in female body 
Figure 46. Tail break frequency of specific ages of Red Cloud Road S. obesus. stippled $=$ cohort $-1 ;$ clear $=$ cohort -2 ; numbers $=$ sample sizes. 


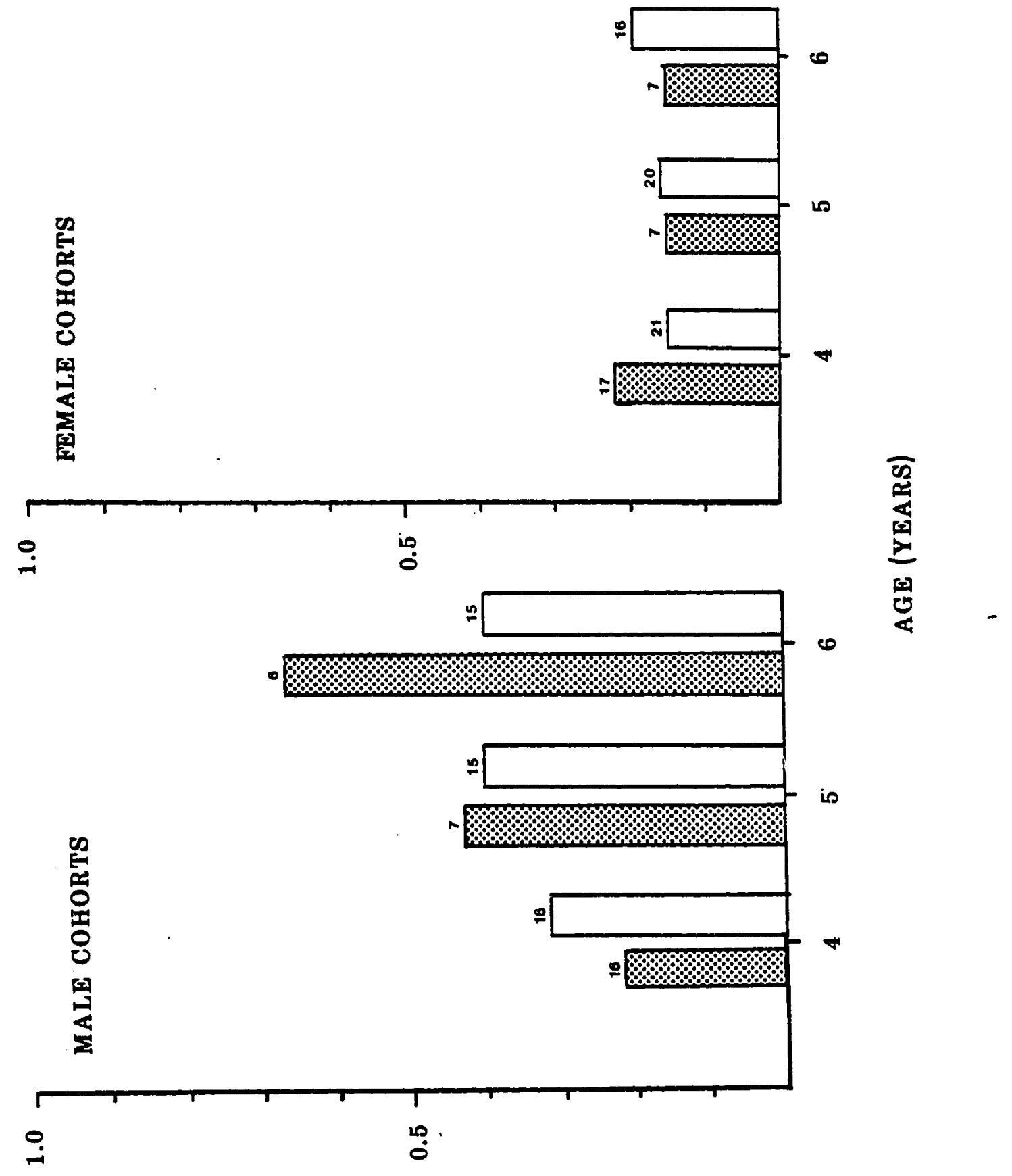

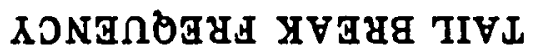


size distribution over this age span (i.e., slower growth rates kept

them relatively small).

This examination of annual changes in tail break frequency for $\underline{s}$. obesus revealed one consistent trend. When individuals attained an SVL of about $165 \mathrm{~mm}$, regardless of sex, they appeared more susceptible to tail breaks. Males achieved this body size at $4-5$ years. For cohort2 females, $165 \mathrm{~mm}$ SVL was attained by $7-8$ years, resulting in a tripling of the tail break frequency. In 1982, all cohort-1 females ( 6 years) were still less than $165 \mathrm{~mm}$ SVL (maximum about $160 \mathrm{~mm}$ ) and for them tail break frequency, only $14 \%$, had not appreciably increased. Consequently, this marked increase in tail break frequency for all groups that surpassed the $165 \mathrm{~mm}$ SVI limit seemed to emphasize that this minimum threshold is a critical aspect of predation intensity for $\underline{\mathrm{s}}$. obesus. This claim is supported by the fact that for 1977 - 1983 much larger individuals were not consistently abundant. The limited rise in tail break frequency of cohort-2 males for a few years after attaining $165 \mathrm{~mm}$ SVL was probably due to the fact that there are relatively fewer large S. obesus present during a period when food was frequently abundant. In 1981 when tail break frequency greatly increased, the SVL of all cohort2 males exceeded $180 \mathrm{~mm}$ and at this time tail break frequency increased by $25 \%$. Therefore, this large increase in tail break frequency in 1981 for most adults can be attributed to the combination of a large number of individuals exceeding a critical body size when drought made food resources particularly scarce (see below--correlation with density). The presence of a considerable number of larger individuals at a time other prey might not have been as relatively abundant rendered $\underline{s}$. obesus 
a prime candidate for a shift in predator preference with a corresponding increase of the numerical response.

A number of population parameters were compared with tail break

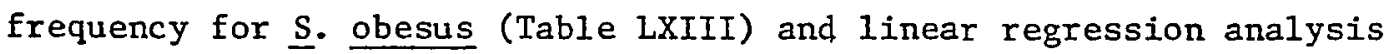
showed that several were significantly correlated with this parameter. Five body size parameters were regressed with tail break frequency. Median and modal values were chosen because they might better reflect the body sizes most likely encountered by a predator. The upper decile length (UDL) and lower quartile length (LQL) were size categories em-.? ployed by Case (1976) in a study of body size relationships of populations of $\underline{S}$. obesus. Both UDL and LQL were included in the analysis for comparative purposes and because the variance of both measurements further served to depict the age structure of the population. The median SVL showed the highest body size correlation with tail break frequency. Changes in mean SVL were closely paralleled by modal SVL changes and both showed significant correlation. Because of limited sensitivity to changes in age structure, UDL showed little correlation with tail break frequency. However, because LQL showed considerable sensitivity to age structure it was significantly correlated with tail break frequency. Therefore, with the exception of UDL, all body size parameters showed correlationwith tail break frequency. Of these, all but mean SVL provided a clue to age structure of the Red Cloud Road population.

Regression analysis showed mean age of the population and density were correlated with tail break frequency (Table LXV). Consequently, parameters other than body size also contributed to susceptibility to predation. Regarding density, when just numbers of adults for 1977 
TABLE LXV

LINEAR REGRESSION ANALYSIS OF TAIL BREAK FREQUENCY AND SELECTED POPULATION PARAMETERS. * INDICATES $\mathrm{P}<0.05$

\begin{tabular}{lcccc}
\hline \multicolumn{1}{c}{ Parameter } & N & Slope & Intercept & $\mathrm{r}$ \\
\hline Upper Decile SVL & 7 & 0.10 & 14.19 & 0.04 \\
Lower Quartile SVL & 7 & 0.36 & -9.16 & $0.75 *$ \\
Mean SVL & 7 & 0.57 & -52.51 & $0.75 *$ \\
Median SVL & 7 & 0.62 & -62.60 & $0.78 *$ \\
Modal SVL & 7 & 0.66 & -75.57 & $0.75 *$ \\
Mean Age & 7 & 0.06 & 0.02 & $0.85 *$ \\
Density & 7 & -0.20 & 53.49 & $-0.72 *$ \\
\hline
\end{tabular}


through 1980 were regressed with tail break frequency the result was highly significant $(x=0.99 ; P<0.001)$. The higher tail break frequencies (at lower adult densities) in 1981-1983 probably indicated that predation pressure was very high after 1980 and because adult recruitment was low, increased tail break frequencies at lower adult densities would have been predicted. Reproduction appeared not to be a factor; maximum increases in tail break frequencies for males and females of cohort-2 (33.3\% and $172.7 \%$, respectively) and males of cohort-1 (95\%) occurred in the year in which no reproduction occurred. Therefore, at least for adults, density appeared an important parameter affecting tail break frequency.

Tail break frequencies have been reported for populations throughout much of the geographic range of $\underline{S}$. obesus (Case, 1976). These compilations (Table LXVI) were for northern populations (mostly Mojave Desert). While some of the data was from discrete studies of single populations (Johnson, 1965; Nagy, 1971; Berry, 1974; Case, 1976) a large contribution was from a survey of museum specimens that for some localities were collected over a 50-year period. The latter source of data, because of considerable temporal and perhaps spatial ramifications, does not necessarily depict a common age structure of a population. In addition, though the tremendous variation in tail break frequency has been assumed to indicate differences in intensity of predation (Case, 1982), until age structure, at least size distribution, of the populations is analyzed the actual significance of predation remain to be clarified. 
TABLE LXVI

THE RELATIONSHIP BETWEEN TAIL BREAK FREQUENCY AND 2 BODY SIZE PARA-

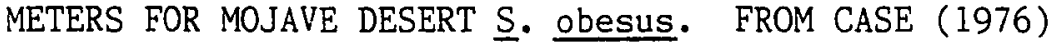

\begin{tabular}{lcccc}
\hline Location & $\begin{array}{l}\text { Upper } \\
\text { Decile }\end{array}$ & $\begin{array}{c}\text { Lower } \\
\text { Quartile }\end{array}$ & $\mathrm{N}$ & $\begin{array}{c}\% \text { Tail } \\
\text { Breaks }\end{array}$ \\
\hline E. Utah & 175.5 & 112.0 & 24 & 29 \\
W. Utah & 209.5 & 137.3 & 16 & 8 \\
Nevada & 183.1 & 117.5 & 36 & 22 \\
China Lake & 207.0 & 101.0 & 117 & 22 \\
Little Lake & 218.0 & 179.5 & 20 & 44 \\
Amboy & 175.0 & 133.0 & 110 & 24 \\
\hline
\end{tabular}


Since the growth rates of young $\underline{S}$. obesus for at least some Mojave Desert localities (Berry, 1974) were very similar to those for Red Cloud Road and because of the similar slow growth rates of the very large individuals, a partial comparison of age structure of the population was possible. For 5 of the 6 northern desert localities listed in Table LXVI the LQLs of the populations most likely consisted largely of individuals less than or equal to 3 years. The LQL of the one exception (Little Lake) probably consisted largely of individuals over 8 years. Therefore, at least for LQL, 5 of the 6 populations showed age structures within the range of what was observed for this study (Table LXIII). Three of the 6 northern desert populations showed UDLs considerably greater than recorded anywhere in the Colorado Desert (Abts, unpublished data). Since adult growth rates of this study were at least equal to those for Berry (1974) the populations with higher UDLs probably represent ones with considerably older individuals. It is very doubtful that the UDLs of these northern desert populations and the study site share many individuals similar in age. Only the Amboy population (Case, 1976) showed a UDL lower than that of the study site. According to Case this population has "stunted" body sizes because of severely limited food diversity; i.e., while they are smaller, they are not necessarily younger at Amboy.

The mean tail break frequencies of northern (mostly Mojave Desert) and Red Cloud Road study site were 24.8 (S.E. $\pm 4.8 \%$ ) and 32.2 (S.E. \pm $3.9 \%)$, respectively. However, since these values were computed from samples showing considerably diversity in age structure, especially LQL, they perhaps say very little about intensity of predation. On the other 
hand, if populations were selected that showed similarity of size distribution (i.e., possibly similarity of age distribution), then maybe a more accurate illustration of predation can be presented. Employing only populations of greater LQL, and hence diminishing the contribution of yearlings, may best depict predation intensity. Adopting this procedure and comparing the mean of 4 desert localities (W. Utah, Nevada, E. Utah and Amboy $=20.8$; S.E. $\pm 4.5 \%$ ) with that of 4 Red Cloud Road years $(1979,1981-1983=37.8$; S.E. $\pm 5.1 \%$ ) revealed that the lizards in this study had a highly significantly greater tail break frequency than did the others $(t=3.53 ; \mathrm{df}=6 ; \mathrm{P}<0.01)$. This situation indicated that predation intensity at the Red Cloud Road study site was much greater and 2 additional factors might further enhance this condition. First, undoubtedly the greater UDLs of some Mojave Desert populations probably indicated the presence of much odler $\underline{s}$. obesus. Second, at Red Cloud Road, predation intensity markedly increased as individuals grew greater than $165 \mathrm{~mm}$ SVL. Several of the Mojave Desert populations were dominated by lizards much larger than this (Berry, 1974; Case, 1976). Nonetheless, tail break frequency was often very low ( $8 \%$ for $W$. Utah). Even the $44 \%$ at Little Lake was not necessarily indicative of high predation intensity since nearly the entire population exceeded the $165 \mathrm{~mm}$ SVL threshold at Red Cloud Road and the LQL of this Mojave Desert locality was over $50 \mathrm{~mm}$ greater than the maximum recorded at Red Cloud Road during a 7-year period. For the highest LQL at Red Cloud Road $(138.5 \mathrm{~mm})$ the tail break frequency was 53\%. This means over half ot eh entire population had an encounter with predator. With this kind of intensity I doubt if a population 
consisting of individuals as large as at Little Lake could ever flourish at Red Cloud Road.

The heightened predation intensity for $\underline{S}$. obesus at Red Cloud Road study site could be the result of a higher predator density (numerical response) or increased opportunities for predator-prey encounters (functional response). While predators, mostly coyotes, were frequently sighted at the study site, especially during years when vegetation was lush, little is known about their activities and it would have been difficult to make comparison with Mojave Desert localities. However, there were some obvious differences in reproductive tactics between Mojave Desert populations and the Red Cloud Raod study site (Ch. 4 Reproductive Frequency) which might have brought about differences in exposure to predators. Climatic conditions in the latter location appeared more favorable for reproduction and this has resulted in occasional periods of annual reproduction, versus alternate years in the Mojave Desert. The summer precipiration pattern favored the survivorship of eggs and hatchlings (Ch. 5 - Survivorship). The combination of these tendencies has led to frequent episodes of relatively high population densities. Consistent, predictable periods of high population density probably have made Red Cloud Road $\underline{\mathrm{s}}$. obesus more obvious to predators. The result of such exposure appeared to be near elimination of the large individauls ( $>165 \mathrm{~mm}$ SVL) of both sexes from the population. 
DENSITY

According to the general theory of population regulation, population growth is the result of the interaction of density-dependent and density-independent factors. The relative roles of densitydependent (stabilizing) and density-independent (nonstabilizing) factors in regulating densities of populations has been the subject of considerable debate (Nicholson, 1933; Andrewartha and Birch, 1954; Lack, 1954). Most likely, various factors have an impact on population equilibrium (Ricklefs, 1979).

Traditionally, the 4 methods for estimating the densities of lizard populations (Turner, 1977) are: 1) direct counts, which are most frequently used (Fitch, 1956; Blair, 1960; Tinkle, 1967; Turner et al., 1970); the investigator simply attempts to count every individual occupying the study area; 2) capture-recapture analysis, which is frequently employed in lizard studies (Bustard, 1969; Turner et al., 1969; Bradshaw, 1971); subsequent samples of marked individauls are taken and various statistical methods are employed to estimate total population size from incomplete samples; 3) removal methods, which is infrequently used in lizard studies (Turner, 1960); individuals are removed from a population during a series of censuses; and 4) indices, which are used by a few investigators (Degenhardt, 1966; Medica et al., 1971 and Ruibal and Philibosian, 1974); total population size is inferred from a standardized incomplete count.

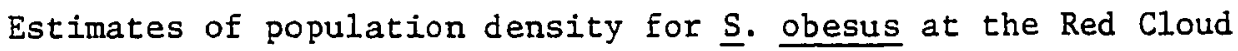
Road study site were achieved primarily by capture-recapture analysis. 
The study site population was repeatedly sampled numerous times during the activity season for 1977-1980. The 2 statistical methods employed to estimate population densities were the stochastic method of Jolly (1965) and the "weighted least squares" method of Schumacher and Eschmeyer (1943). The results from these 2 methods are compared below. I posed the following questions regarding population densitie; for Colorado Desert $\underline{\text { s. obesus: }}$ 1) What is the annual population density and how does it vary from year to year? 2) What factors determine population density? and 3 ) How do the population densities observed at the Red Cloud Road study site compare with those of Mojave Desert $\underline{\text { S. }}$ obesus populations?

The density of $\underline{S}$. obesus at the 8 hectare Red Cloud Road study site showed considerable annual variation. Both Jolly and SchumacherEschmeyer methods showed a 2-fold variation during the 4 year periods they were employed (Table LXVII). Both methods showed that maximum density occurred in 1980 following the best breeding year of the study. Mimimum densities appeared to occur following 1980. The Jolly method estimated a decline of nearly $50 \%$ of the population by 1981 . However, using the method of Bailey (1952) for 2 samples. densities of $\underline{\text { s. obesus }}$ in 1981 and 1982 showed a marked decline to 83 and 56, respectively. If Baileys' method was accurate, then the annual density showed a 6-fold variation for 1977 through 1982. However, the results of the 2 primary methods of estimating population density were not as convincing toward the latter years of the study. The Jolly method requires substantial sample sizes; the high standard deviation for 1981 reflects limited visits (hence recaptures) to the study site in 1981 and 1982 . Both 
TABLE LXVII

ANNUAL POPULATION DENSITY OF $S$. obesus AT THE RED CLOUD ROAD STUDY SITE. NUMBERS IN PARENTHESES $=1$ STANDARD DEVIATION

\begin{tabular}{|c|c|c|c|c|c|c|c|}
\hline \multirow[t]{2}{*}{ Year } & \multicolumn{3}{|c|}{ Jolly (1965) } & \multicolumn{2}{|c|}{$\begin{array}{c}\text { Schumacher- } \\
\text { Eschmeyer (1943) }\end{array}$} & \multicolumn{2}{|c|}{$\begin{array}{l}\text { Direct } \\
\text { Count }\end{array}$} \\
\hline & & Total & \#/ha & Total & \#/ha & Tota1 & $\# /$ he \\
\hline 1977 & & - & - & $144 \pm 8.5$ & 18 & 130 & 16 \\
\hline 1978 & 181 & $(11.6)$ & 23 & $133 \pm 8.1$ & 17 & 123 & 15 \\
\hline 1979 & 165 & ; $\quad(9.0)$ & 21 & $154 \pm 3.5$ & 19 & 135 & 17 \\
\hline 1980 & 201 & $(18.6)$ & 25 & $290 \pm 15.7$ & 36 & 148 & 18 \\
\hline 1981 & 107 & $(24.8)$ & 13 & - & - & - & - \\
\hline Mean \#/ha & & & $2.8 \pm 0.1$ & & $4.0 \pm 6.2$ & & $16.8=$ \\
\hline
\end{tabular}


Schumacher-Eschmeyer and Jolly methods yielded high standard errors and standard deviations even in 1980 the year of maximum density, when most of the lizards were yearlings. Since the behavior of yearlings differed considerably from that of adults, perhaps neither method adequately describes density when there is a preponderance of yearlings in the population. While not shown, estimates of annual densities for $\underline{s}$. obesus using Bailey's method were always 25 - 50\% less than the other 2 methods; e.g., the Bailey density estimate for 1980 was 140 . Consequently, the decline in density of $\underline{\mathrm{S}}$. obesus for 1981 and 1982 , as shown by 2 statistical procedures, probably was excessive. Nonetheless, as previously shown, reproductive success was greatly reduced for the period 1980 through 1982 (Ch. 4 - Reproductive Frequency) and during this time, with the shift in age distribution to favor older and larger individuals, predation grew more intense (Ch. 5 - Predation Intensity). Therefore, it appears that a marked decline in density of the population occurred for the period.

To further clarify this determination, when there are years of low reproductive success and/or dry summers, such as was the case prior to 1977, annual recruitment of yearlings is low. During such times, the population consists largely of small adult lizards at low density since larger individauls are preyed upon. Annual recruitment of yearlings is high when reproductive success is average to high and followed by abundant sumer precipitation as in 1976 and 1977. There was a marked population increase, largely due to yearling recruitment, in 1977 when initial population density was low. Density remained at a similar level until 1980, when annual recruitment of yearlings was again relatively 
high. However, with a dense population now dominated by larger $\underline{S}$. obesus, and with an ensuing period of low reproductive success (none in 1981), vulnerability to predation was not offset by recruitment and the population density rapidly declined.

Another rough method of estimating population density is to

index 1981 and 1982 sampling efforts with those of the previous years. Comparison of the number of $\underline{s}$. obesus sighted per man hour of effort for June of 1980 (Ch. 2 - Annual Activity cycle of chuckwallas) with numbers for 1981 and $1982--1.24$ and 1.38 , respectively--shows that numbers for 1982 and 1982 were about 70 to $80 \%$ of those for 1980 . The 2-year period of 1981 through 1982 was environmentally poor to average for Colorado Desert $\underline{\text { S. }}$ obesus, and there was no recruitment of yearlings in 1982 . Nonetheless, the number of lizards sighted per man hour of effort in June was approximately $80 \%$ of those for the same month in 1980 . One should not infer that the same difference can be applied to density, but it suggests that the actual density was higher than predicted by the statistical procedures that were used. Therefore, I feel that annual variation in density of $\underline{s}$. obesus at the Red Cloud Road study site can be as much as 2-fold, and density is most affected by annual recruitment of yearlings.

Density is meaningful only in the context of resource availability (Ricklefs, 1979). Estimates of food resource availability were determined (Ch. 1 - Climate and Vegetation). A convenient way of showing density for comparison with resource availability is the number of individuals per hectare (Table LXVII). These values clearly demonstrate the density per given area. Such a measurement will be very 
helpful when densities are compared with biomass, and when density and biomass are compared for several locations (see below). Table LXVII also shows mean estimates of population density for $\underline{s}$. obesus for 3 consecutive years. It appears that in any one year only about $75 \%$ of the entire population was captured. This will have some bearing on the comparison of densities between Mojave and Colorado Desert populations of $\underline{\text { S. obesus. }}$

The density of $\underline{\mathrm{s}}$. obesus at the Red Cloud Road study site was compared with density estimates of 3 Mojave Desert populations (Table LXVIII). The values for the 3 Mojave Desert populations were from direct counts; only Berry's (1974) study spans more than one year. Density values for the Red Cloud Road population represent the 4-year mean for 1977 through 1980. Density estimates from direct counts were only slightly greater for the Red Cloud Road population. Berry's estimate at China Lake was for a 3.4 ha area during 1970 and 1971 . She thought nearly all the lizards in this area were marked and thus provided reliable values for density. In the present study, if the capture-recapture statistics were reliable, then the direct count density reflected only about $75 \%$ of the actual population. Therefore, density estimates for the time span of my study suggest that Red Cloud Road $\underline{\text { s. }}$ obesus were about $50 \%$ more numerous per hectare than at China Lake. The limited data for the other 2 Mojave Desert populations (Johnson, 1965; Nagy, 1971) showed a similar trend.

It has been shown that $\underline{s}$. obesus in many Mojave Desert locations were considerably larger than at the Red Cloud Road study site (Ch. 5 Sex Ratio). It is well-established that larger lizards have a higher 
TABLE LXVIII

COMPARISON OF DENSITY AND BIOMASS BETWEEN MOJAVE DESERT AND RED CLOUD ROAD $\underline{\text { S. obesus }}$

\begin{tabular}{lccc}
\hline \multicolumn{1}{c}{ Location } & $\begin{array}{c}\text { Number } \\
\text { Per Hectare }\end{array}$ & $\begin{array}{c}\text { Biomass } \\
(\mathrm{Kg} / \mathrm{ha})\end{array}$ & Reference \\
\hline China Lake & 13.8 & 1.7 & Berry (1974) \\
Red Rock & 7.1 & 0.8 & Johnson (1965) \\
Black Mountain & 10.0 & 1.6 & Nagy (1971) \\
Red Cloud Road & & & present study \\
Direct Count & 16.7 & 1.9 & \\
Schumacher- & & & \\
Eschmeyer & & 2.5 & \\
$1977-80$ & 22.5 & 3.0 & \\
$1978-80$ & 24.1 & 2.8 & \\
Jolly & & 2.6 & \\
$1978-80$ & 20.4 & 2.6 & \\
$1978-81$ & & & \\
\hline
\end{tabular}


metabolism than small ones (Nagy, 1982), and being an herbivore requires ingesting great quantities of food material because plants are energetically of lower quality than insects (Pough, 1973). Thus, other factors being equal, a population of $\underline{\mathrm{s}}$. obesus consisting of larger individuals should require more food. Though there was a higher density of $\underline{S}$. obesus at the Red Cloud Road study site than has been reported elsewhere, perhaps the former, being smaller lizards represented no more total biomass than the latter. The estimates of biomass for 2 of the Mojave Desert $\underline{S}$. obesus populations were from Case (1982). It was not clear how he determined the biomass values. I determined biomass as the sum of the products of density times mean spring individual weights for the sexes, as did Nagy (1971). One must be careful in deciding which masses should be used because of extreme seasonal and year-to-year variation in body mass. I chose spring mass because it best reflected the response to the year's peak standing crop. The relationship of the values determined by this procedure and the values presented by Case appeared similar (Table LXVIII). Therefore, although the Red Cloud Road population consisted of a larger proportion of smaller lizards, the mean biomass of $\underline{s}$. obesus per hectare was also about $60 \%$ greater than that for $\underline{S}$. obesus at China Lake (Berry, 1974). Unfortunately, during the times that the Mojave Desert data was collected reproductive success was often low, so the masses recorded for these 1izards may reflect their exposure to sub-optimal conditions. The Red Cloud Road population may have been less food-limited than the Mojave Desert populations, at least when the investigations were undertaken. There is some indication that Mojave Desert $\underline{s}$. obesus rely 
more on perennial vegetation than annual vegetation (Stebbins, 1966; Nagy, 1973; Hansen, 1975). At the Red Cloud Road study site annuals were frequently abundant and strongly preferred by $\underline{\mathrm{s}}$. obesus (Ch. 2 Feeding Habits). It would be instructive to compare diversity, distribution and density of annual plants at a Mojave Desert locality such as China Lake with that at the Red Cloud Road study site. Such data is presently lacking for the former. It has been suggested that annuals may be largely responsible for a number of the reproductive attributes of $\underline{S}$. obesus (Berry, 1974; Ryan, 1982). Relatively frequent periods of reproduction owing to availability of annuals and relatively high recruitment rates because of summer precipitation have resulted in a higher density of $\underline{s}$. obesus at the Red Cloud Road study site. Probably because of different vegetational and climatic conditions, Mojave Desert $\underline{\text { s. }}$ obesus showed relatively infrequent periods of reproduction and lowered recruitment and simply did not have many opportunities to support higher densities even given lower predation intensity.

\section{LONGEVITY}

How long individuals of a population live depends upon the association of traits that constitute a species' reproductive strategy. If environmental conditions frequently provide a high risk to reproduction (i.e., annual survivorship is low) then the choice should be to lower energy allotment and/or reproduce infrequently. Individuals might postpone reproduction in favor of extending the period of growth in localities where the environment renders reproduction typically a risk. 
Female iguanine lizards experinece no less than 5 benefits from an emphasis on body growth (Wiewandt, 1982). Naturally, because of variation in environmental conditions, the significance of any of these benefits will vary between species and within a species showing wide geographic distribtuion. Large body size may also be an essential male trait necessary for mating. This is especially true when adult females of a population exhibit slight asynchronous breeding and/or the operational sex ratio is strongly skewed in favor of adult males (Emlen and Oring, 1977). Different adult sizes do not necessarily reflect differences in age for iguanine lizards (Case, 1976) although large body size usually indicates a relatively long life span and certain iguanines live from 10 to 40 years (see references in Dugan and Wiewandt, 1982). To deal with different environmental conditions, for example, the Colorado Desert frequently receives substantial summer precipitation and the northern Mojave Desert does not, large body size represents not only a trait of the reproductive strategy but also may vary in response to environmental conditions (i.e., winter rainfall, summer precipitation, etc.). Populations of $\underline{\mathrm{s}}$. obesus show considerable variation in adult body size without a corresponding difference in age (Case, 1976), presumably owing to differences in amount and quality of available food. The following questions are addressed here regarding the longevity of

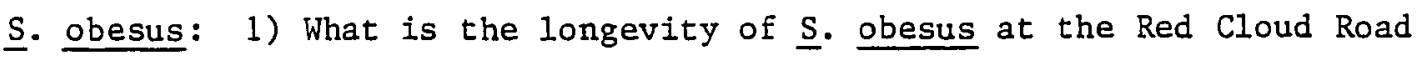
study site? 2) How does longevity of $\underline{s}$. obesus at Red Cloud Road compare with that for a northern Mojave Desert population? 3) Does variation in body size between populations reflect difference in ages? and 4) How do factors other than available food (e.g., predation) affect 
longevity?

Longevity of $\underline{\mathrm{S}}$. obesus at the Red Cloud Road study site was best determined by monitoring known-age lizards in the population for up to 10 years of age and then comparing the body sizes of these individuals with the percent of the total population equal to or exceeding these sizes (Table LXIX). Male and female S. obesus known to be 10 years old attained body sizes of about 195 and $175 \mathrm{~mm}$, respectively. Between 1977 and 1983, males and females of these sizes constituted only $7-8 \%$ of the annual populationdensity. Consequently, I considered $\underline{s}$. obesus older than 10 years of age to be rare. Moreover, since the period of study was dominated by unusually mesic climatic conditions that greatly enhanced the growth of the desert flora, $\underline{\mathrm{s}}$. obesus at Red Cloud Road may be smaller under more typical conditions. Annual growth rates vary widely from year to year for both male and female $\underline{s}$. obesus (Tables LXX and LXXI). Regression analysis of annual growth rates and precipitation from October through January showed a significantly positive correlation in the case of males less than $180 \mathrm{~mm}$ SVL $(r=0.68 ; \mathrm{N}=13 ; \mathrm{P}<0.01)$. The lack of this correlation in the case of lizards larger than $180 \mathrm{~mm}$ SVL may be due in part to small sample sizes. Regression analysis of the same parameters for female $\underline{s}$. obesus showed no significant correlation $(r=0.39 ; N=14 ; P>0.50)$. However, examination of Table LXXI shows that the females of most body size categories grew the most during years when winter precipitation was plentiful. The weak correlation probably reflects an emphasis on reproduction in wet years, yielding growth rates that were less than predicted (Ch. 4 Reproductive Frequency). 
TABLE LXIX

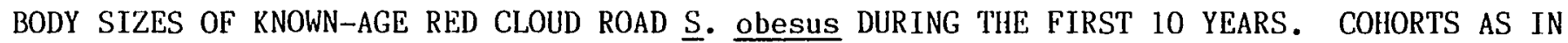
CH. 3 - SURVIVORSHIP. NUMBERS IN BRACKETS = SAMPLE SIZES

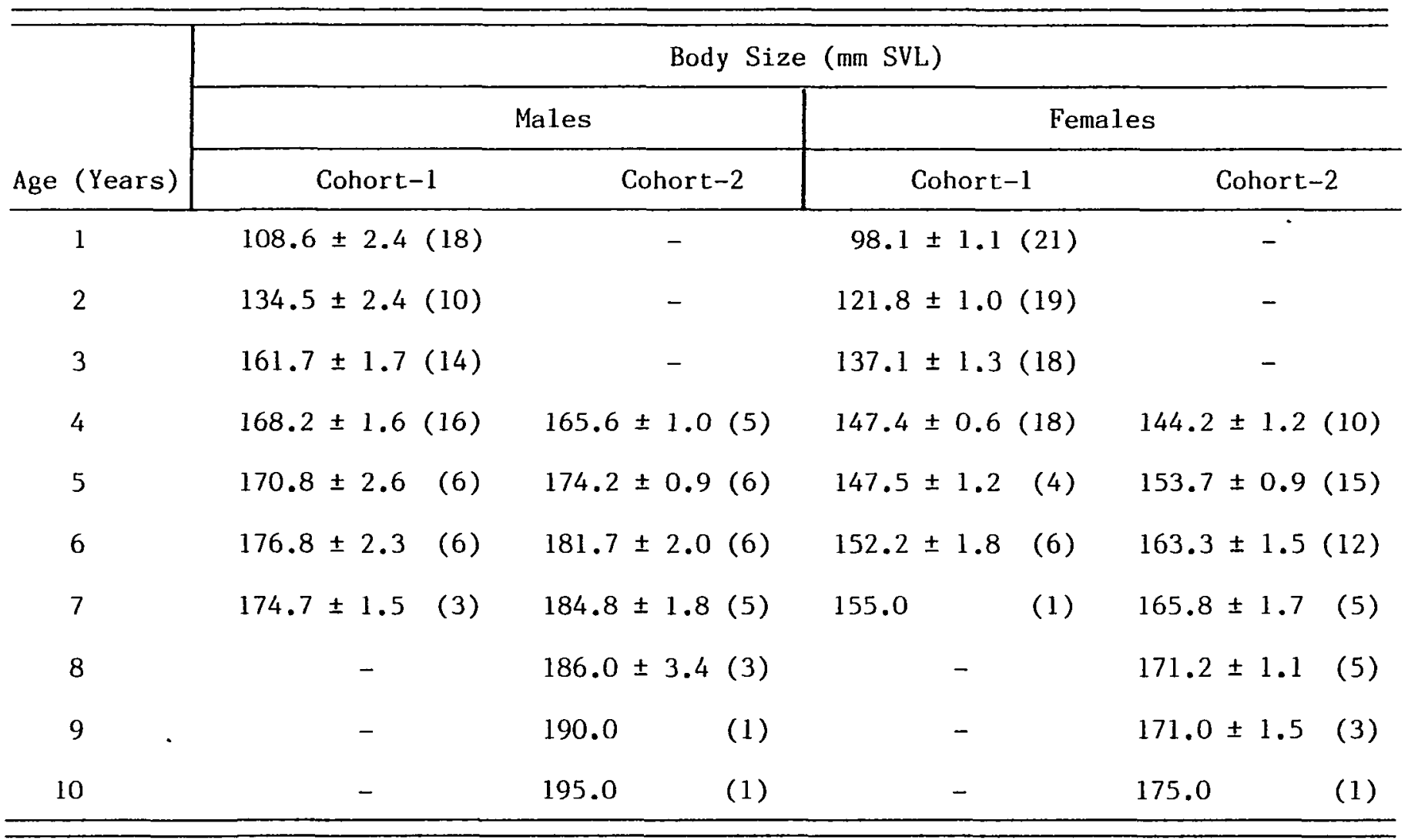


TABLE LXX

ANNUAL GROWTH RATES FOR DIFFERENT BODY SIZE CATEGORIES OF MALE $\underline{S}$. obesUS AT RED CLOUD ROAD. NUMBERS IN BRACKETS $= \pm 1$ STANDARD ERROR

\begin{tabular}{|c|c|c|c|c|c|c|c|c|}
\hline \multirow{3}{*}{$\begin{array}{l}\text { Body Size } \\
\text { Category }\end{array}$} & \multicolumn{8}{|c|}{ Mean Annual Growth Rate } \\
\hline & \multicolumn{2}{|r|}{1977} & \multicolumn{2}{|l|}{1978} & 1979 & \multicolumn{2}{|l|}{1980} & 1981 \\
\hline & 4.0 & (1) & - & & $19.8 \pm 1.6(6)$ & 11.0 & (1) & - \\
\hline $141-150$ & $5.7 \pm$ & $1.6(7)$ & $20.7 \pm 4.1$ & (3) & $24.0 \pm 0.0$ & 15.0 & (1) & - \\
\hline $151-160$ & $2.3 \pm$ & $1.6(6)$ & $10.0 \pm 1.2$ & (9) & $12.5 \pm 3.5(2)$ & $7.5 \pm 1.3$ & (10) & $3.0 \pm 2.0$ \\
\hline $161-170$ & $3.0 \pm$ & 0.6 & $7.8 \pm 1.8$ & (4) & $11.4 \pm 1.8(7)$ & $5.6 \pm 1.6$ & (7) & $3.5 \pm 0.7(4)$ \\
\hline $171-180$ & $4.5 \pm$ & $2.5(2)$ & $10.7 \pm 1.3$ & (3) & $7.8 \pm 0.0(2)$ & $5.1 \pm 0.8$ & (9) & $0.3 \pm 0.3(6)$ \\
\hline $181-190$ & & - & $2.0 \pm 1.0$ & (2) & $6.0 \pm 0.0(2)$ & $3.0 \pm 1.4$ & (5) & $0.0 \pm 0.0$ \\
\hline $191-200$ & & - & 1.0 & (1) & $2.0 \pm 2.0(2)$ & 2.0 & (1) & 0.0 \\
\hline $201-210$ & & - & 4.0 & (1) & $0.5 \pm 0.5$ (2) & - & & 0.0 \\
\hline
\end{tabular}


TABLE LXXI

ANNUAL GROWTH RATES FOR DIFFERENT BODY SIZE CATEGORIES OF FEMALE $\underline{S}$. obesUS AT RED CLOUD ROAD. NUMBERS IN BRACKETS = SAMPLE SIZES. \pm 1 STANDARD ERROR

\begin{tabular}{|c|c|c|c|c|c|c|c|}
\hline \multirow{2}{*}{$\begin{array}{l}\text { Body Size } \\
\text { Category }\end{array}$} & \multicolumn{7}{|c|}{ Mean Annual Growth Rate } \\
\hline & & 1977 & 1978 & & 1979 & 1980 & 1981 \\
\hline $121-130$ & $5.0 \pm$ & $3.0(2)$ & $12.5 \pm 1.5$ & $(2)$ & $17.1 \pm 1.2(9)$ & - & - \\
\hline $131-140$ & $10.5 \pm$ & $2.5(2)$ & $12.0 \pm 3.0$ & $(2)$ & - & $9.6 \pm 0.9$ & - \\
\hline $141-150$ & $1.5 \pm$ & $1.5(2)$ & $10.8 \pm 1.3$ & (10) & $11.0 \pm 1.5(3)$ & $8.0 \pm 1.0(5)$ & $0.2 \pm 0.2(5)$ \\
\hline $151-160$ & 1.0 & $(1)$ & $10.5 \pm 2.3$ & $(4)$ & $7.9 \pm 0.8$ & $4.7 \pm 0.9$ & $0.3 \pm 0.3$ \\
\hline $161-170$ & & - & - & & $9.0 \pm 2.3(3)$ & $6.0 \pm 1.6(6)$ & $1.7 \pm 1.2(3)$ \\
\hline $171-180$ & & - & - & & 3.0 & $0.7 \pm 0.7$ & $0.8 \pm 0.9(4)$ \\
\hline $181-190$ & 0.0 & (1) & $8.0 \pm 1.0$ & (2) & $8.5 \pm 4.5(2)$ & - & - \\
\hline $191-200$ & & - & - & & 2.0 & 1.0 & - \\
\hline
\end{tabular}


Berry (1974) estimated longevity from annual growth rates of lizards of unknown age. In my study, 1980 was considered to approximate an average year for environmental conditions. If this is true, then employing the growth rates for different size classes of lizards that developed under these conditions shows that after 10 years adult male and female SVLs would be similar to those shown for the known-age lizards.

Therefore, adult males and females of body sizes greater than shown above are typically rare. Both males and females older than 10 years of age were consequently an insignificant part of most populations, since the sex ratio of older $\underline{s}$. obesus at Red Cloud Road study site was approximately 1 : 1 (Ch. 5 - Sex Ratio). This is the shortest longevity so far reported for $\underline{S}$. obesus, and according to references in wiewand (1982) it is one of the shortest reported for any iguanine.

S. obesus over $200 \mathrm{~mm}$ SVL were extremely rare throughout the study region. Only $15(1 \%)$ of approximately 1500 different individuals captured were larger than $200 \mathrm{~mm}$ SVL. The largest male and female to be captured were 214 and $209 \mathrm{~mm}$, respectively. These large males and females possibly were $15-25$ and $15-45$ years old, respectively. I suspect a life span of 15 years to be more typical for males since some individuals grew rapidly from $190-210 \mathrm{~mm}$. Only 4 females exceeded $200 \mathrm{~mm}$ SVL. Some females grew relatively rapidly from 180 $200 \mathrm{~mm}$ SVL. Consequently, I suspect a life span for females to be no longer than 20 years. 
Longevity has previously been estimated only for one northern Mojave Desert population (Berry, 1974). Males and females at her Lone Butte study site averaged 15 and 20 years of age, respectively, for estimates from annual growth rates. This is 50 to 100 greater average longevity than I observed at the Red Cloud Road study site. In fact, about $71 \%$ of the Lone Butte population appear to be 10 years of age or more. Growth rates of different body size categories for Lone Butte and Red Cloud Road males are similar (Tables LXX and LXXII), but females at Red Cloud Road grew considerably faster (Tables LXXI and LXXII). Female growth rates and reproductive frequency were highly correlated at the Red Cloud study site (Ch. 4 - Reproductive Frequency). This may be interpreted as maximizing present reproductive success with limited detriment to future reproductive prospects (Pianka, 1976). For any given year, the tendency to channel energy into growth first may have reflected an adaptation to ensure future prospects in the face of the harsh and uncertain environmental conditions typical of arid regions. As low adult female growth rates and infrequent reproductions seemed to indicate, prevailing environmental conditions at Lone Butte in the Mojave Desert might have made the propsects of future reproduction almost as uncertain as those for the present. Whatever limited reproductive success was possible for Mojave Desert female

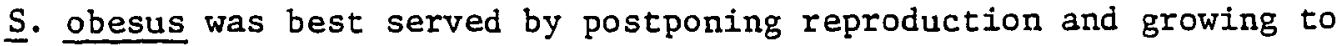
maximum body size.

Earlier investigators did not measure vegetational parameters and comparable information to this study is sorely needed. Berry (1974) observed that an abundance of winter annuals greatly enhanced 
TABLE LXXII

MEAN ANNUAL GROWTH RATES (mm/year) FOR DIFFERENT BODY SIZE

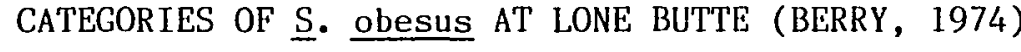

\begin{tabular}{ccc}
\hline Body Size (mm SVL) & Females & Males \\
\hline 150 & 10.8 & 23.0 \\
$150-169$ & 1.8 & 11.4 \\
$>170$ & 0.2 & 4.4 \\
\hline
\end{tabular}


reproductive success. Nonetheless, perennials seemed to be a major constituent of the diet throughout much of the range of $\underline{S}$. obesus (Hansen, 1974; Nagy, 1973; Case, 1982). Annuals were always preferred, and perennials became a primary food item at the Red Cloud Road study site only after the annual standing crop had significantly diminished (Ch. 2 - Feeding Habits). I suspect that the diversity and perhaps the density of annuals was typically greater at Red Cloud Road than at Lone Butte. If so, the low reproductive rates and corresponding greater longevity observed in the Mojave Desert might reflect predominantly less than optimal diet (Ryan, 1982).

There are several reasons why large body size might promote

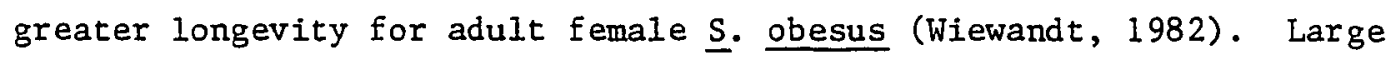
females at Red Cloud Road were more fecund, adding 1.2 eggs for every $10 \mathrm{~mm}$ increase in SVL, and they consistently reproduced more clutches and at shorter intervals. Body size and frequency of reproduction were strongly correlated $(r=0.78 ; N-22 ; P<0.001)$. While larger females perhaps were more resistant to starvation and dehydration (Ch. 5 Survivorship) they were more intensely preyed upon (Ch. 5 - Predation Intensity). All in all, smaller females survived about as well as larger ones. This is not to say the last 2 benefits have no more importance in other populations. At Lone Butte in the Mojave Desert, where there was a lower incidence of tail breaks, perhaps large size offered some protection from predation. With low recruitment of young, because of infrequent summer precipitation, perhaps larger reproductive females gained some advantage in coping with the limited amounts of food and water. 
The status of male $\underline{s}$. obesus in any population is largely influenced by the availability of females (Ryank 1982). At Lone Butte, where reproductive success appeared minimal, fitness might be improved if the production of males were favored (Ch. 5 - Sex Ratio). With operational sex ratios strongly favoring males, and with the possibility that females demonstrate asynchronous breeding habits, the competition between males for mates would be strongly intensified (Emlen and Oring, 1977). An outcome of heightened competition would be increased male size, which was observed at Lone Butte. Since male growth rates at Lone Butte were similar to those observed at Red Cloud Road, it appears that while adult female $\underline{S}$. obesus were sometimes food-limited, adult males were not. Consequently, for females body size and longevity appeared inversely correlated with food availability. For males, these values were inversely correlated with the number of available females. Both phenomena are integral to the structure of a mating system and overall reproductive strategy (Ryan, 1982). At Red Cloud Road relatively large numbers of females probably indicated frequent reproductions. Since adult females were abundnat, not only were large adult males unnecesary, but they also appeared more vulnerable (Ch. 5 - Predation Intensity). Perhaps greater numbers of $\underline{s}$. obesus at Red Cloud Road elicited a greater functional response from predators than was observed at Lone Butte and probably most other Mojave Desert locations. If one assumes lifetime reproductive output of individuals were similar between Lone Butte and Red Cloud Road populations, then females of the former population must exhibit twice the longevity. 
Environmental conditions may have been so severe at Amboy that older males as well as females demonstrated retarded body growth (Case, 1976). The predominant food item available at Amboy was creosote bush (Larrea tridentata), a perennial; alternative food plants were few. If smaller lizards at Amboy were as old as larger individuals in the northern Mojave Desert, then Amboy perhaps represents the harshest environmental conditions so far reported for habitats of $\underline{s}$. obesus. Unfortunately, during the time of the Amboy study, environmental conditions for reproduction by $\underline{S}$. obesus were poor. It has already been. stated that suboptimal food supplies in the Mojave Desert were responsible for low reproductive rates and increased longevity. I see no reason to exclude the Amboy population from this group. However, I disagree with Case that body size differences between populations of S. obesus necessarily indicates genetic divergence. It seems that if future studies of this species were to consider simultaneously such environmental parameters as density of winter annuals that a model of reproductive strategy that includes body size and longevity could be devised. This is an obejctive of future investigations.

\section{LIFE TABLES}

Life tables summarize information on survival and fecundity of females in each age class in a population. Though difficult to obtain, these data are needed to calculate the growth performance of a population (Deevey, 1947; Birch, 1948).

Age-specific sruvival is normally estimated for natural populations from the survival of individuals marked at birth or from the 
deaths of individuals of known age (Farner, 1955). However, both methods have serious limitations. The first requires that individuals not emigrate from the area in which they were marked, since emigration may not be distinguished from death. The second method requires that large numbers of individuals be marked to obtain sufficeint recoveries of dead individuals (Ricklegs, 1979).

Age-specific fecundity has been estimated by numerous techniques to count embryos or eggs directly (see Ricklegs, 1979). Age-specific fecundity values reflect the mean number of eggs of a reproductive female of a specific age reduced to compensate for the portion of females of that age that do not reproduce.

A life table enables the estimation of parameters associated with population growth rates and their age-specific contributions from specific demographic statistics. Noteworthy parameters include: 1) net reproductive rate $\left(\underline{R}_{0}\right)$ - the overall expected lifetime production of females by an age class zero female - this is sometimes referred to as the replacement rate; 2) mean generation time (T ) - the average age at which a female lays eggs or gives birth to her offspring, or the average time (I) for a population to increase by a factor equal to the net reproductive rate; 3 ) expectation of life $\left(\underline{E_{X}}\right)$ - the average life span remaining for an individual of age $x$; and 4 ) reproductive value ( $\left(v_{x}\right)$ the expected reproductive output of an individual at a particular age relative to that of a newborn individual at the same age. In a stable population $v_{x}$ is often defined as the age-specific expectation of future offspring. 
Two population growth rates can be obtained from $R_{0}$ and $\underline{T}$. Geometric growth rate $(\underline{\lambda})$, is an empirically determined rate calculated from change in population size. Exponential or intrinsic rate of increase $(\underline{r})$, is determined by survival and fecundity schedules. These life table estimates of population growth rates, being mathematically equivalent but having different biological interpretation, are generally of most use when a population has attained stable age distribution (Ricklefs, 1979).

Life tables have been constructed for many lizard populations (Fitch, 1966; Tinkle, 1967; Brooks, 1967; Turner et al., 1970; Tinkle, 1972; Tinkle and Ballinger, 1972; Tinkle, 1973; Iverson, 1979). Every life table depicts 3 important population conditions: 1) age at first reproduction; 2) survivorship schedule; and 3) fecundity schedule. Most of the above investigators failed to represent accurately one or more of these conditions, resulting in life table information that was not consistent with the histories of the populations (Turner, et al., 1970).

Investigators often miscalculated age at first reproduction because they underestimated the contribution of reproductive output or neglected to determine how minimum age of reproduction varied because of changing environmental conditions. Errors in survivorship often stemmed from lack of attention to seasonal, annual and sexual variation in adults and/or inaccurate estimates for eggs and hatchlings. Errors in fecundity were either due to variation in clutch size of individauls or the inability to assess the number of clutches per active season (clutch frequency). In addition, some of the previous studies presented 
life tables constructed from one or a few years; this brief amount of time may be inadequate for revealing important trends in population growth.

Age-specific fecundity was estimated for female $\underline{s}$. obesus from 1978 through 1982 from dissection of females collected off my study site and from mark and recapture of specific cohorts of females at the Red Cloud Road site. Survivorship was estimated for female $\underline{\text { s. obesus }}$ from mark and recapture of specific cohorts of females at the Red Cloud Road site. These procedures revealed the following: 1) clutch size showed little year to year variation for a given body size; 2) there was little variation in seasonal survivorship; 3) annual survivorship rates were similar for all age classes greater than 1 year (at about $75 \%$ ); 4) annual age-specific reproductive frequency showed considerable variation (i.e., 11 to $79 \%$ ) and 5) age at reproductive maturity varied from about 3 to 5 years. The significance of these findings in affecting population growth will be considered below.

Life table information for $\underline{s}$. obesus is presented for a variety of time periods to show the capabilities of population performance in the face of changing environmental conditions and how these temporary capabilities distort a more general underlying trend in population growth. While survivorship was not constant, especially for eggs and hatchlings, it has been maintained on a specific schedule because from the apparent year to year uniformity among age classes $\geq 1$ this schedule best reflected the observed population trends. The following questions were addressed regarding life tables for $\underline{s}$. obesus: 1) What kind of life tables can be constructed and which best reflect the 
populations history? 2) What basic population trends are revealed by the life table information and how do they compare with other lizard species? 3) What environmental parameters have the most influence on population growth potential?

Table IXXIII depicts optimal fecundity as I observed it in 1979, the best year during the 7-year study. Changes in fecundity largely reflected variation in annual age-specific reproductive frequency. In 1979 nearly all younger adult age classes achieved 100\% reproductive frequency. Consequently, age-specific fecundities were $2-3$ times those of the average for 1978 - 1982. In 1979, the combined 3 through 6 year old age classes contributed more than $60 \%$ of the replacement rate $\left(\mathrm{R}_{\mathrm{O}}\right)$. The prevailing environmental conditions at this time were perhaps the most suitable for successful reproduction in at least a quarter century (Ch. 1 - Climate and Vegetation, and Ch. 4 - Reproductive Frequency and Annual Reproductive Output and Fecundity). An $\underline{R}_{0}$ of 1 indicates a stable population. The $R_{0}$ of 2.8 for 1979 indicates large potential increase in population density. Associated with this high $R_{0}$ was the lowest mean generation time $(\underline{T})$ in all tables constructed. If the conditions contributing to this life table became constant, then the population would have the capacity to double every $51 / 2$ years. The fecundity schedule for 1980 (Table LXXIV) is probably more typical for $\underline{\mathrm{s}}$. obesus at Red Cloud Road. The younger age classes exhibited fecundities ranging from 3 times below the 5-year average to slightly above it. The lower values reflected the lack of participation in reproduction by the youngest adult females. For this life table, the combined 3 through 6 year old age classes contributed only about 35\% of 
TABLE LXXIII

LIFE TABLE FOR RED CLOUD ROAD $\underline{\mathrm{S}}$. obesus, BASED ON OPTIMAL FECUNDITY SCHEDULE (1979). $x=A G E$ IN YEARS; $l_{x}=$ PROPORTION OF ORIGIN-

AL POPULATION SURVIVING TO AGE $\mathrm{x} ; \mathrm{m}_{\mathrm{x}}=$ AGE-SPECIFIC FECUNDITY; $1_{\mathrm{x}} \mathrm{m}_{\mathrm{x}}=$ CONTRIBUTION TO REPRODUCTIVE RATE

BY ANIMALS OF AGE $x ; x 1_{x} m_{x}=$ WEIGHT AGE; $R_{0}$

$=$ NET REPRODUCTIVE RATE; $T=$ MEAN GENERATION TIME; $r=$ INSTANTANEOUS

RATE OF POPULATION GROWTH

\begin{tabular}{|c|c|c|c|c|}
\hline$x$ & ${ }^{1} x$ & $\mathrm{~m}_{\mathrm{x}}$ & $1_{x} m_{x}$ & ${ }^{x l} x^{m} x$ \\
\hline 0 & 1.00 & 0.0 & 0.0 & 0.0 \\
\hline 1 & 0.40 & 0.0 & 0.0 & 0.0 \\
\hline 2 & 0.30 & 0.0 & 0.0 & 0.0 \\
\hline 3 & 0.23 & 2.24 & 0.52 & 1.55 \\
\hline 4 & 0.17 & 3.0 & 0.51 & 2.04 \\
\hline 5 & 0.13 & 3.0 & 0.39 & 1.95 \\
\hline 6 & 0.09 & 3.33 & 3.30 & 1.80 \\
\hline 7 & 0.07 & 3.63 & 0.25 & 1.75 \\
\hline 8 & 0.05 & 3.80 & 0.19 & 1.52 \\
\hline 9 & 0.04 & 4.08 & 0.16 & 1.47 \\
\hline 10 & 0.03 & 4.23 & 0.13 & 1.27 \\
\hline 11 & 0.023 & 4.32 & 0.10 & 1.10 \\
\hline 12 & 0.017 & 4.62 & 0.08 & 0.96 \\
\hline 13 & 0.013 & 5.85 & 0.08 & 1.04 \\
\hline 14 & 0.009 & 6.78 & 0.06 & 0.84 \\
\hline \multirow[t]{3}{*}{15} & 0.007 & 7.65 & 0.05 & 0.75 \\
\hline & & & $\mathrm{R}_{\mathrm{o}}=2.82$ & 18.04 \\
\hline & & & $\mathrm{T}=6.4 \quad \mathrm{r}=0.16$ & \\
\hline
\end{tabular}


TABLE LXXIV

LIFE TABLE FOR RED CLOUD ROAD $\underline{S}$. obesus, BASED ON AVERAGE FECUNDITY SCHEDULE (1980). SYMBOLS AS IN TABLE LXXIII

\begin{tabular}{|c|c|c|c|c|}
\hline $\mathrm{x}$ & $1_{x}$ & $\mathrm{~m}_{\mathrm{x}}$ & ${ }^{1} x_{x}$ & ${ }^{x 1} x^{m} x$ \\
\hline 0 & 1.00 & 0.0 & 0.0 & 0.0 \\
\hline 1 & 0.40 & 0.0 & 0.0 & 0.0 \\
\hline 2 & 0.30 & 0.0 & 0.0 & 0.0 \\
\hline 3 & 0.23 & 0.0 & 0.0 & 0.0 \\
\hline 4 & 0.17 & 0.53 & 0.09 & 0.36 \\
\hline 5 & 0.13 & 0.70 & 0.09 & 0.45 \\
\hline 6 & 0.09 & 2.17 & 0.20 & 1.20 \\
\hline 7 & 0.07 & 2.30 & 0.16 & 1.12 \\
\hline 8 & 0.05 & 2.44 & 0.12 & 0.96 \\
\hline 9 & 0.04 & 2.53 & 0.10 & 0.90 \\
\hline 10 & 0.03 & 2.63 & 0.08 & 0.80 \\
\hline 11 & 0.023 & 3.02 & 0.07 & 0.77 \\
\hline 12 & 0.017 & 3.23 & 0.05 & 0.60 \\
\hline 13 & 0.013 & 4.09 & 0.05 & 0.65 \\
\hline 14 & 0.009 & 4.74 & 0.04 & 0.56 \\
\hline \multirow[t]{4}{*}{15} & 0.007 & 5.35 & 0.04 & 0.56 \\
\hline & & & $R_{0}=1.09$ & 8.93 \\
\hline & & & $\mathrm{T}=8.19$ & \\
\hline & & & $r=0.01$ & \\
\hline
\end{tabular}


$\underline{R_{0}}$. I suspected, before I constructed the life table, the environmental conditions of 1980 indicated an average year. $\underline{R}_{0}$ approached unity, indicating a stable population. Associated with this $\underline{R}_{0}$ was the highest I for any of the life tables constructed from field data. An age-specific fecundity schedule could not be constructed for 1981 in which there was no reproduction. Consequently, $\underline{R_{0}}$, $\underline{T}$, and $\underline{r}$ were unobtainable. Clearly, a population lacking replacement but with a typical age-specific survivorship schedule would decline. The geometric growth rate would show about a $25 \%$ annual decline and the population half-life (the projected time for the population size to be reduced by $1 / 2$ ) would be about 3 years.

Long-term studies allow the construction of more reliable life tables (Turner et al., 1970). Table LXXV depicts one that averages fecundity of female $\underline{S}$. obesus over 5 consecutive years (1978 - 1982). The $\underline{R}_{0}$ for this period still indicates a growing population. The population showed considerable growth both in 1977 and in 1980. These gains overshadow the population decline of 1982 (Ch. 5 - Density). The youngest breeders, ages 3 through 6 , contributed to $50 \%$ of the $\mathrm{R}_{0}$ during the 5 years. The mean generation time ( $\underline{T}$ ) was intermediate between 1979 (optimal year) and 1980 (average year). If the conditions for this life table were constant then the population would require 16.67 years to double in size.

A stable life table was constructed for $\underline{s}$. obesus from the 5-year average (Table XXXXIX) by reducing age-specific fecundities by a constant (Table LXXVI). Consequently, $\underline{R_{0}}$, and $\underline{I}$ were no different from the values obtained for the stable population in 1980 but there is one 
TABLE LXXV

LIFE TABLE FOR RED CLOUD ROAD $S$. obesus, BASED ON A 5-YEAR AVERAGE (1978-1982) FECUNDITY SCHEDULE. SYMBOLS AS IN TABLE LXXIII

\begin{tabular}{|c|c|c|c|c|}
\hline$x$ & $1_{x}$ & $m_{x}$ & $I x_{x} m_{x}$ & ${ }^{x} x_{x}{ }^{m}$ \\
\hline 0 & 1.00 & 0.0 & 0.0 & 0.0 \\
\hline 1 & 0.40 & 0.0 & 0.0 & 0.0 \\
\hline 2 & 0.30 & 0.0 & 0.0 & 0.0 \\
\hline 3 & 0.23 & 0.72 & 0.17 & 0.51 \\
\hline 4 & 0.17 & 1.39 & 0.24 & 0.96 \\
\hline 5 & 0.13 & 1.40 & 0.18 & 0.90 \\
\hline 6 & 0.09 & 2.0 & 0.18 & 1.08 \\
\hline 7 & 0.07 & 2.30 & 0.16 & 1.12 \\
\hline 8 & 0.05 & 2.52 & 0.13 & 1.04 \\
\hline 9 & 0.04 & 2.71 & 0.11 & 0.99 \\
\hline 10 & 0.03 & 2.84 & 0.09 & 0.90 \\
\hline 11 & 0.023 & 3.25 & 0.07 & 0.77 \\
\hline 12 & 0.017 & 3.47 & 0.06 & 0.72 \\
\hline 13 & 0.013 & 4.40 & 0.06 & 0.78 \\
\hline 14 & 0.009 & 5.10 & 0.05 & 0.70 \\
\hline \multirow[t]{4}{*}{15} & 0.007 & 5.75 & 0.04 & 0.60 \\
\hline & & & $R_{0}=1.54$ & 11.07 \\
\hline & & & $T=7.19$ & \\
\hline & & & $r=0.06$ & \\
\hline
\end{tabular}


TABLE LXXVI

LIFE TABLE FOR RED CLOUD ROAD S. obesus, DEPICTING A STABLE POPULATION $\mathrm{E}_{\mathrm{x}}=$ EXPECTION OF LIFE; $\mathrm{v}_{\mathrm{x}}=$ REPRODUCTIVE VALUE OTHER SYMBOLS AS IN TABLE LXXIII

\begin{tabular}{|c|c|c|c|c|c|c|}
\hline $\mathrm{x}$ & $1 \mathrm{x}$ & $\mathrm{mx}$ & $1_{x} m_{x}$ & $x I_{x} m_{x}$ & $E_{X}$ & $v_{x}$ \\
\hline 0 & 1.00 & 0.0 & 0.0 & 0.0 & 2.58 & 1.00 \\
\hline 1 & 0.40 & 0.0 & 0.0 & 0.0 & 3.95 & 2.50 \\
\hline 2 & 0.30 & 0.0 & 0.0 & 0.0 & 3.93 & 3.34 \\
\hline 3 & 0.23 & 0.48 & 0.11 & 0.33 & 3.83 & 4.30 \\
\hline 4 & 0.17 & 0.88 & 0.15 & 0.60 & 3.82 & 5.23 \\
\hline 5 & 0.13 & 0.92 & 0.12 & 0.60 & 3.69 & 5.71 \\
\hline 6 & 0.09 & 1.33 & 0.12 & 0.72 & 3.67 & 6.92 \\
\hline 7 & 0.07 & 1.43 & 0.10 & 0.70 & 3.71 & 7.37 \\
\hline 8 & 0.05 & 1.60 & 0.08 & 0.64 & 3.80 & 7.92 \\
\hline 9 & 0.04 & 1.75 & 0.07 & 0.63 & 3.50 & 8.06 \\
\hline 10 & 0.03 & 2.00 & 0.06 & 0.60 & 3.33 & 8.41 \\
\hline 11 & 0.023 & 2.22 & 0.05 & 0.53 & 3.04 & 8.37 \\
\hline 12 & 0.017 & 2.38 & 0.04 & 0.48 & 2.76 & 8.32 \\
\hline 13 & 0.013 & 3.17 & 0.04 & 0.52 & 2.31 & 7.76 \\
\hline 14 & 0.009 & 3.30 & 0.03 & 0.42 & 1.89 & 6.64 \\
\hline \multirow[t]{3}{*}{15} & 0.007 & 4.29 & 0.03 & 0.45 & 1.14 & 4.29 \\
\hline & & & 1.0 & 8.23 & & \\
\hline & & & $\left(R_{0}\right)$ & $(\mathrm{T})$ & & \\
\hline
\end{tabular}


important difference. The stable population life table showed that 3 year olds and combined $3-6$ year old age classes contributed 11 and $50 \%$ of the $R_{0}$, respectively, whereas 3 year old female $\underline{S}$. obesus in 1980 failed to reproduce and that the younger age classes $(4-6)$ contributed to only $38 \%$ of the $R_{0}$. Based on prevailing environmental conditions over the past 3 decades, the $1_{x} m_{X}$ schedule of the stable population might be more realistic for the period.

A life table which best reflects the typical survivorship and reproductive performance of Colorado Desert $\underline{S}$. obesus was made by maintaining age-specific survival as in the previous table, but I listed age-specific fecundity according to values determined from regression models based on fecundity as a function of various segments of winter precipitation (Table LXXVII). The importance of early winter precipitation for growth of vegetation and reproduction was stressed. The precipitation segments that appeared most important to reproduction were October through January and December. Using the regression equations for precipitation and age-specific fecundity, over the period 1978 - 1982 age-specific fecundities were estimated for every year between 1961 and 1977. For this earlier period, if age-specific annual survivorship approximated the values determined during the study then these equations for fecundity have practical application (Ch. 5 Leslie Matrix Analysis). Inspection of the table reveals that mean agespecific fecundity values for the 16 year period were remarkably similar to those of the 5-year stable population. $R_{0}$ for this period was very close to unity. Younger age classes ( 3 - 6 years) of female $\underline{S}$. obesus contributed to $45 \%$ of the $\underline{R_{0}}$, intermediate between those for 1980 and 
TABLE LXXVII

LIFE TABLE FOR RED CLOUD ROAD $\underline{S}$. obesus PREDICTED FOR 1961-1977 FROM FECUNDITY-PRECIPITATION REGRESSION EQUATIONS

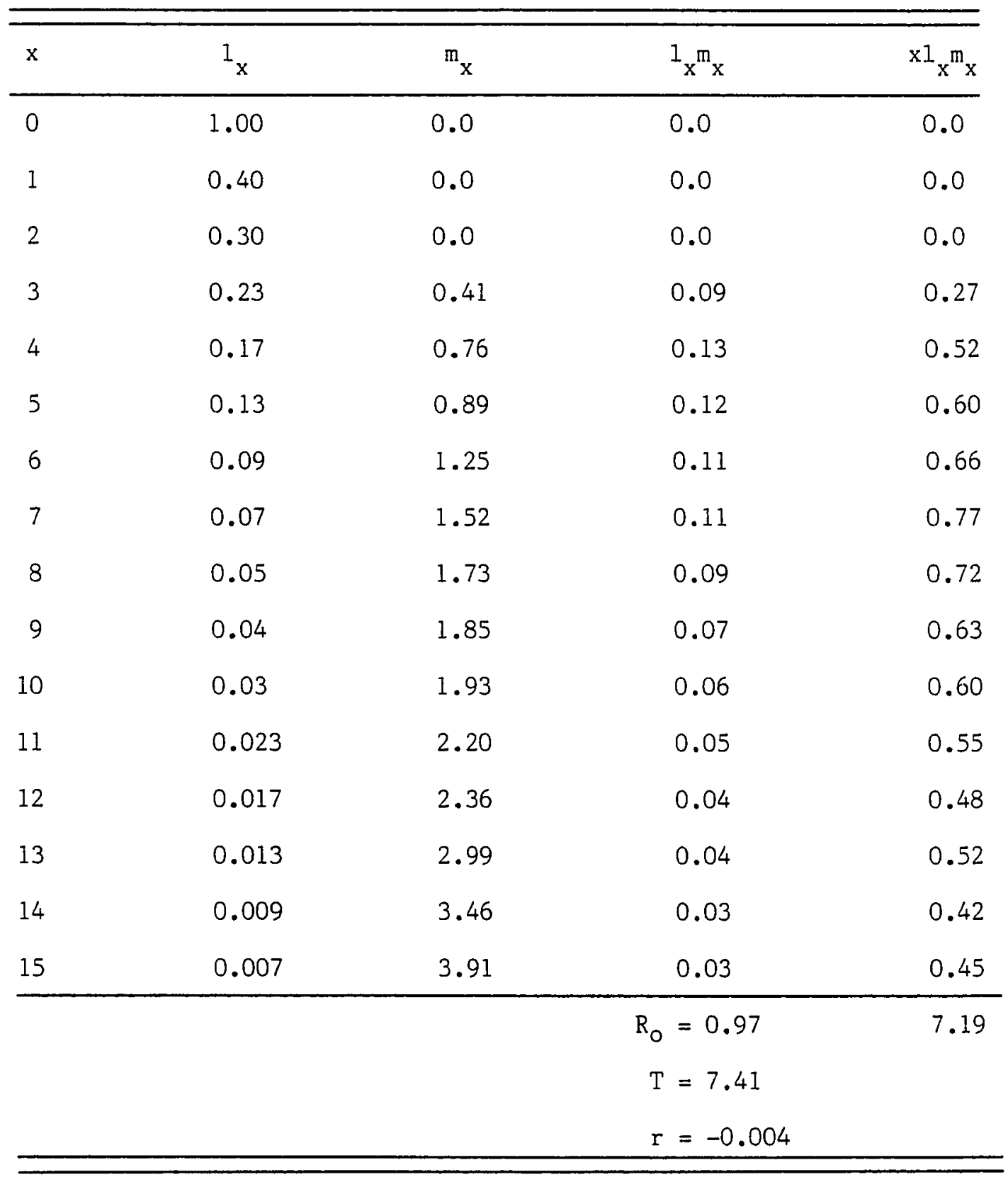


the 5-year average. If this life table approximates the history of $\underline{\text { S. }}$ obesus during the period--there was no apparent data to the contrary--then this population of $\underline{s}$. obesus has shown no growth from 1961 to the present.

Expectation of future life and reproductive values are illustrated in Table LXXVI. If the data are valid, then the life span is 15 years for female $\underline{S}$. obesus, which reinforces an earlier conclusion (Ch. 5 Longevity). Species exhibiting a lack of senescent decline in fecundity and survival rates tend to maintain a $\underline{v x}$ for an extended period of adult life (Leslie, 1966; MacArthur and Wilson, 1969; Mertz, 1971; Ricklegs, 1971) while reproductive value frequently is largest around the onset of reproduction (Pianka, 1978). Such appeared to be the case for adult female S. obesus. While individuals of the older age classes were rare, the limited data indicated that fecundity increased steadily with age while survivorship was constant at the annual value of 0.75 . These findings probably apply to most iguanines which are of indeterminant growth and have great longevity.

Several trends affecting population performance were apprent from the data, many of which can serve as comparison with other lizard species or conspecifics. The mean annual survival of eggs and hatchlings was one of the highest so far reported. It is at least double that of some long-lived iguanid species (Tinkle, 1972, 1973).

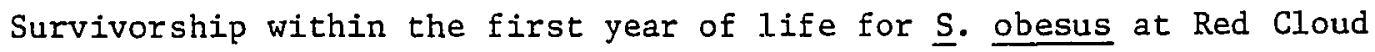
Road ranged from 2 to 5 times that for some mainland populations of

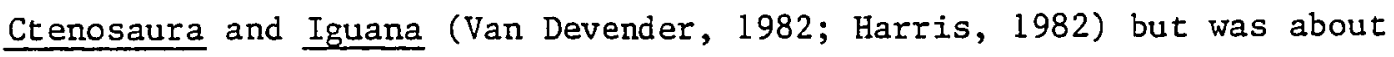
equal to that of the island-inhabiting iguanine Cyclura cornuta 
(Iverson, 1977). As stated previously (Ch. 5 - Survivorship), first

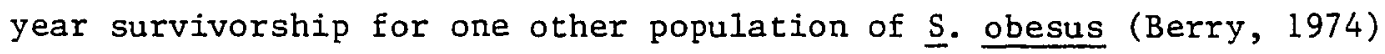
was probably about one-fourth of that for this study. Annual survivorship of Red Cloud Road $\underline{\mathrm{S}}$. obesus $\geq 1$ year, which appeared relatively constant at 0.75 , was considerably less than for $\underline{\mathrm{c}}$. cornuta (Iverson, 1979) and for $\underline{S}$. obesus at Lone Butte (Berry, 1974). These 2 investigators reported annual adult survivorship to be around 0.90 . Keeping in mind that first year survivorship at Red Cloud Road was quite variable $(0.10-0.80)$, survivorship schedules oscillated between Type II and Type III curves (Deevey, 1947).

Younger adult female $\underline{S}$. obesus made a significant contribution to reproduction in most years, in some years exceeding $50 \%$ of the replacement rate. This situation is common for most iguanids (Blair, 1960; Tinkle, 1972, 1973), but not for iguanines (Berry, 1974; Iverson, 1979). Frequent involvement of younger females in reproduction may be indicative of a life history strategy for a predictable environment (see below).

Reproduction was relatively frequent at the Red Cloud Road study site (Ch. 4 - Reproductive Frequency), yet population growth was basically static. Replacement rate values $\left(R_{0}\right)$ values shown to be in excess of 1 were slowed by a moderately long mean generation time of about 7 to 8 years. Nonetheless, given favorable conditions for population growth, the population at Red Cloud Road would probably respond much more quickly than did either Cyclura cornuta (Iverson, 1979 ) or $\underline{\mathrm{S}}$. obesus at Lone Butte (Berry, 1974). Iverson calculated a $\underline{T}$ of 14 years for Cyclura. He stated this was the longest generation time 
reported for a lizard species. From preliminary investigation of Berry's data I suspect a $\underline{T}$ of $10-12$ years for $\underline{S}$. obesus at Lone Butte if the conditions during her 4-year study period were typical.

While the long term trend of population growth for Red Cloud Road S. obesus approached unity, the life tables presented above indicated large oscillations in growth potential. These oscillations could be attributed to variation in age-specific fecundity and survivorship of individuals from age class zero (eggs) to age class one. Environmental conditions have been poor enough since 1961 to discourage reproduction in 6 years and egg survivorship in 9 years, based on the regression equation for 1977 through 1983. The 7 years in which reproduction appeared curtailed (1965, 1968,1970 - 1972 and 1981) were not directly associated with the 9 for expected low egg survival (1962 - 1964, 1972 - 1973, 1975, 1978 and 1980). This is not surprising because reproduction and egg survival were most affected by winter and summer precipitation, respectively. For the past 23 years reproduction and egg survival were probably curtailed 26 and $39 \%$ of the time, respectively. This situation probably made egg survival the primary factor in annual population density oscillations (Ch. 5 - Density). Nonetheless, while changing environmental conditions promoted egg survivorship, the fact that when reproduction occurred during 1977

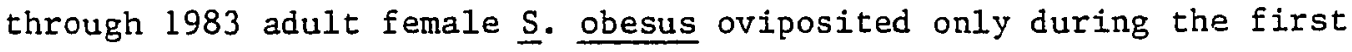
half of July (Ch. 3 - Synchrony of Breeding) probably is indication of a highly predictive environment suitable for egg survivorship (see below). Seven years of data plus an additional 16 years in which the population appeared stable seemed to indicate that relative to other 
S. obesus populations (Johnson, 1965; Nagy, 1973; Berry, 1974; Case, 1975 and 1982) the Red Cloud Road population exhibited high fecundity rates, high first year survival, low reproductive life span, and consequently, low adult survival. While deserts demonstrate considerable climatic fluctuation, perhaps some of the parameters were relatively predictable. Two climatic parameters that appeared important for population growthwere annual growing season and summer precipitation. The fact that relative clutch mass remained constant from year to year in the face of variable resource levels (Ch. 4 Reproductive Effort) supports the claim for importance of the growing season. Also, as mentioned above, the highly synchronous oviposition of adult females during a time when ambient temperatures were extremely high and food was nonexistent can only be of benefit because of the predictable summer precipitation. As discussed above (Ch. 5 Survivorship), summer precipitation may be critical to successful hatching. Great numbers of hatchling $\underline{S}$. obesus have also been observed following extensive summer precipitation in the northern Mojave Desert of California (Smits and Yorke, 1980) and in southwestern Arizona (Abts, unpublished data). While the Colorado Desert receives less summer precipitation than occurs in Arizona deserts, it receives significantly greater amounts than in the northern Mojave where other studies were undertaken (Johnson, 1965; Berry, 1974; Case, 1975). High amounts of summer precipitation frequently occurred in consecutive years. For the 5-year period 1967 through 1971, summer precipitation exceeded average levels. Such potentially predictable conditions support the life history pattern observed (Murphy, 1968; Schaffer, 
1974). Unpredictable environmental conditions such as have been implicated in the strong selection pressure for high adult survival rates and long reproductive life span in the Everglade kite (Nichols et al, 1980). Possibly the same can be said for a similar life history pattern observed in $\underline{\mathrm{S}}$. obesus in the northern Mojave Desert (Berry, 1974). Certain predictable environmental conditions appeared beneficial

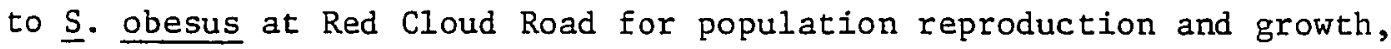
yet the population density has probably remained fairly stable for at least the last 23 years. The lack of steady growth was probably the result of an interaction of density independent and density dependent factors. While early winter precipitation may be integral to reproductive success, the degree of hatching success was dependent on summer precipitation. Unfortunately, abundant amounts of precipitation for these periods occurred in the same year only infrequently. The fact that high reproductive success did not always culminate in high hatching success can be illustrated by recalling that while reproductive output in 1978 was considerably above average the number of hatchlings observed in the fall was greatly reduced ( $\mathrm{Ch} .5$ - Survivorship). In addition, relatively large, therefore older, $\underline{\mathrm{s}}$. obesus approaching a threshold body size were reduced by increased predation intensity (Ch. 5 - Predation Intensity). Perhaps such density dependent regulation occurs periodically. Though the density of $\underline{s}$. obesus at the Red Cloud Road study site attained levels exceeding those previously reported (Ch. 5 - Density) various population characteristics did not seem to indicate that this population was frequently food limited. Perhaps, if winter and summer rainfall patterns were more synchronous, 
the Red Cloud Road population would support a greater number of individuals. Predictable climatic parameters are frequently typical of tropical or subtropical locations. The fact that Red Cloud Road S. obesus responded positively to such conditions may indicate that this species' life history evolved in a tropical or subtropical environment. While all previous studies depicted $\underline{S}$ obesus as having infrequent reproduction and high adult survival, these life history characteristics may be a futile attempt to resist extinction over the long term. Any persisting climatic changes such as increased frequency or lengths of summer drought, that further diminish the quality of the egg incubation environment might support this trend.

The life history pattern of $\underline{s}$. obesus can be further examined by directing attention to the specific life table components of the replacement rate formula:

$$
R_{0}=\sum_{x=0}^{\infty} \ell_{\chi} m_{x}=\operatorname{abpypa}^{2} /(1-\text { pa })
$$

The term $\underline{a}$ is an estimate of the number of females per clutch. The term b represents the average proportion of adults which reproduce (i.e., reproductive frequency). The $1 \mathrm{x}$ values of the life tables presented previously are subdivided using 2 terms py and pa which represent annual survival probabilities for first year and older individuals, respectively. In shaping the life history pattern of $\underline{s}$. obesus it is important to know which of these terms is least variable and which is most variable. Previously, it was shown that for a given body size, clutch size does not vary from year to year (Ch. 4 - Clutch Size). 
Also, young adult females tend to always be predominant (Ch. 5 Predation Intensity). Therefore, the a term was relatively static and annual survivorship rate in ages $\geq 1$ was 0.75 (Ch. 5 - Survivorship). However, the remaining 2 terms, $\underline{b}$ and $\underline{p y}$, appeared to show considerable variation, ranging from 0 to 0.95 and 0.11 to 0.79 , respectively. Consequently, it is these last 2 terms that have received considerable attention so far. To better understand the relationship of these terms in affecting population short term growth (or decline) formula 1 can be rewritten:

$$
R_{0}=\sum_{x=0}^{\infty} \ell_{\chi} m_{x}=3.53 \text { b py } 0.75^{2} /(1-0.75)
$$

If the 5-year mean py $(0.38)$ is accurate, a stable populationis achieved when $\underline{b}=0.34$. Such $a$ value for $\underline{b}$ is lower than any recorded for the Red Cloud Road population in years when reproduction occurred (Ch. 4 Reproductive Frequency). However, knowing there were years when no reproduction occurred, perhaps this value is not too divergent from the mean overall annual reproductive frequency. Over the 22-year period from 1961 through 1983 it appeared that reproduction occurred in about two-thirds of the years. If reproduction failed in the remaining onethird of the years, then to average a reproductive frequency of 0.34 , the mean frequency in years when reproduction occurred must have been 0.51. During the study, this value was exceeded in 2 of the 4 reproductive years. It was 0.13 less than the 4 year mean, but it must be recalled that from the climatic data this 4 -year period was a better than normal time for reproduction. Therefore, it all of these values 
were realistic, the replacement formula for a stable population of S. obesus can be written as:

$$
\mathrm{R}_{\mathrm{o}}=\sum_{x=0}^{\infty} \ell_{\chi} m_{x}=(3.53)(.34)(.38)\left(.75^{2}\right) /(1-.75)=1
$$

Figure 47 depicts stable population conditions $\left(\underline{R_{0}}=1\right)$ for

S. obesus from several possible annual proportions of breeding adult females and combinations of survival rates. In order to have a mean annual reproductive frequency of 0.34 at Red Cloud Road, roughly half of the adult female population must have reproduced in 2 or 3 years. While it seemed plausible that mean annual py and pa were about 0.38 and 0.75 respectively, other combinations of possible survival rates are shown along an isopleth. For the population to remain stable if the py annual survival rate ranged from 0.10 to 0.80 , corresponding pa annual survival rates must have ranged from 0.90 to 0.62 . The latter values were observed for various age classes during the course of the study (Ch. 5 - Survivorship). If the Red Cloud Road $\underline{s}$. obesus population were to reproduce every year, the annual reproductive frequency would be 0.51. For this reproductive frequency, if a and pa remain constant, then py annual survival rates can be as low as about 0.24 and population will remain stable. From 1977 through 1981, reproduction occurred in 4 of 5 years and thsu approached this value. However, during this time py annual survival rates were about average $(0.38)$ which resulted in an increase in population size (Table LXXV).

If over the long term $\underline{S}$. obesus in the Colorado Desert reproduced only every other year, as was suggested for Mojave Desert populations by 
Figure 47. An estimate of stable population conditions (Ro $=1$ ) for Red Cloud Road $\underline{S}$. obesus from several possible annual reproductive frequencies (b) and combinations of survival rates (py and pa). Population estimate of females per clutch (a) are assumed to be constant. 


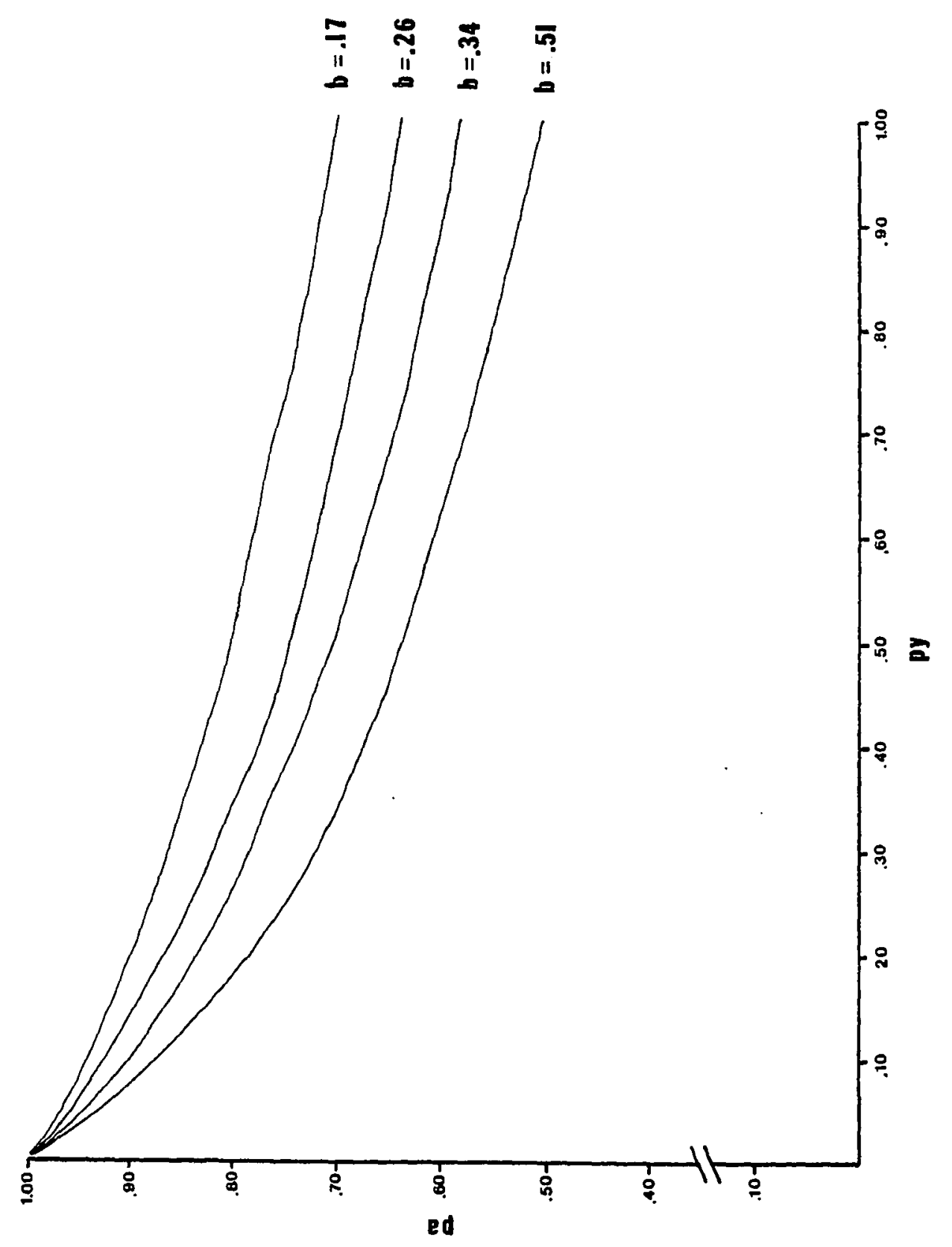


Johnson, 1965; Nagy, 1973; Berry, 1974, then the mean annual

reproductive frequency would be 0.26 . Under such conditions, if pa remained at 0.75 nearly half of the zero age class must survive to age I $(\underline{p y}=0.49)$. While the reproductive data $(\underline{a}$ and $\underline{b})$ were not available for Mojave Desert $\underline{s}$. obesus, if my reproductive schedule is applicable then it agrees with py and pa survival rates observed for the data of Berry (1974). From her data, annual recruitment rates were around 0.10 and adult survival about 0.90 . These values were very closely predicted by the $\underline{b}=0.26$ isopleth.

Drought has been common over much of the desert southwest in this centruy (Ch. 1 - Climate; Berry, 1974). Consequently, for some periods it is possible that some populations of $\underline{S}$. obesus reproduced only every third year. At Red Cloud Road this would give a mean annual reproductive frequency of just 0.17 . At this level of reproductive frequency, if pa annual survival rates remained at 0.75 , then py survival rates would have to be nearly as high $(0.74)$. Even at the Red Cloud Road study site, where summer precipitation is far more predictable than in the Mojave Desert, the annual mean py was only about half this level (0.38). Therefore the mean annual survival of 3 out of every 4 first year individuals seems unlikely for most, if not all desert areas. Most likely, population densities declined during such conditions.

So far, interest has centered on the survival of first year (py) S. obesus. However, from examination of the slopes of the various isopleths in Figure 47 which probably cover most realistic population possibilities, it is apparent that pa survival is considerably 
important. To maintain a stable population $\left(\underline{R_{0}}=1\right)$, even when the annual reproductive frequency approaches the likely maximum and py $=$ 1.0 , the pa annual survival rate must still be around 0.50 . Of course, as part of the life history strategy of $\underline{\mathrm{S}}$. obesus, the pa of essentially all desert areas consistently exceeds this value. Consequently, any management decision regarding the habitat of $\underline{S}$. obesus should reflect the importance of changes on adult survival.

To illustrate further the stability of the cluth size contribution to the fecundity part of the replacement rate formula, if from Berry's data on increased adult female size (1974) mean clutch size is elevated to 4.5 (from regression equation and only females considered) and py and pa remain as above 0.10 and 0.90 , respectively, annual reproductive frequency raises only one percent $(0.27)$. Therefore, this model for the maintenance of population stability (Fig. 47) may have application for other populations of $\underline{S}$. obesus.

Mortality from predation probably lowered pa annual survival rate of the Red Cloud Road population and was brought about by longer periods of annual activity in response to the longer Colorado Desert growing season (Ch. 5 - Predation Intensity). The higher pa survival rates of northern Mojave Desert $\underline{s}$. obesus are probably the result of diminished duration of annual activity because the growing season is reduced. However, extended longevity of these individuals would be further favored because of strong selection pressures to live long enough to ensure successful reproduction in the face of uncertain first year survival (Murphy, 1968; Schaffer, 1974). 
LESLIE MATRIX ANALYSIS

To my knowledge the age structure of lizard populations has not been predicted from correlations with environmental parameters. In this investigation I found that: 1) first year annual survivorship, directly correlated with summer precipitation, was about $40 \%$;2) annual survivorship in age classes > 1 year was consistently close to $75 \%$; 3) mean clutch size showed little annual variation; and 4) affected by an extended growing season, annual reproductive frequency was directly correlated with early winter precipitation. From this information, age

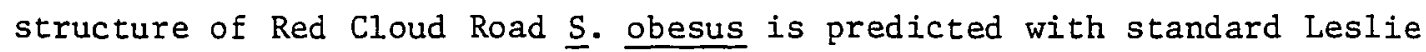
matrix methodology (Leslie, 1952) using age-specific fecundityprecipitation regression models.

Breifly, age specific survivorship and fecundity rates were determined as previously described for Red Cloud Road $\underline{S}$. obesus. Various hypothetical populations of specific numbers of the different ages typical for this population were set up in a Leslie Matrix. These populations were analyzed continuously for the period 1961 through 1980 based on annual age-specific fecundities from the fecundity - winter precipitation regression models and constant age specific survival of $40 \%$ in the first year and $75 \%$ each year thereafter. Following this format, for each year 1977 through 1980 the predicted age class distribution from the Leslie analysis was compared with what appeared to be the actual Red Cloud Road age class distribution (Figs. 48-51). For each of the 4 years there was considerable overlap between observed and predicted age distribtuions of $\underline{s}$. obesus. Both clearly 
Figure 48. Age class distribution of Red Cloud Road $\underline{S}$. obesus. Shading indicates prediction from Leslie Analysis. 


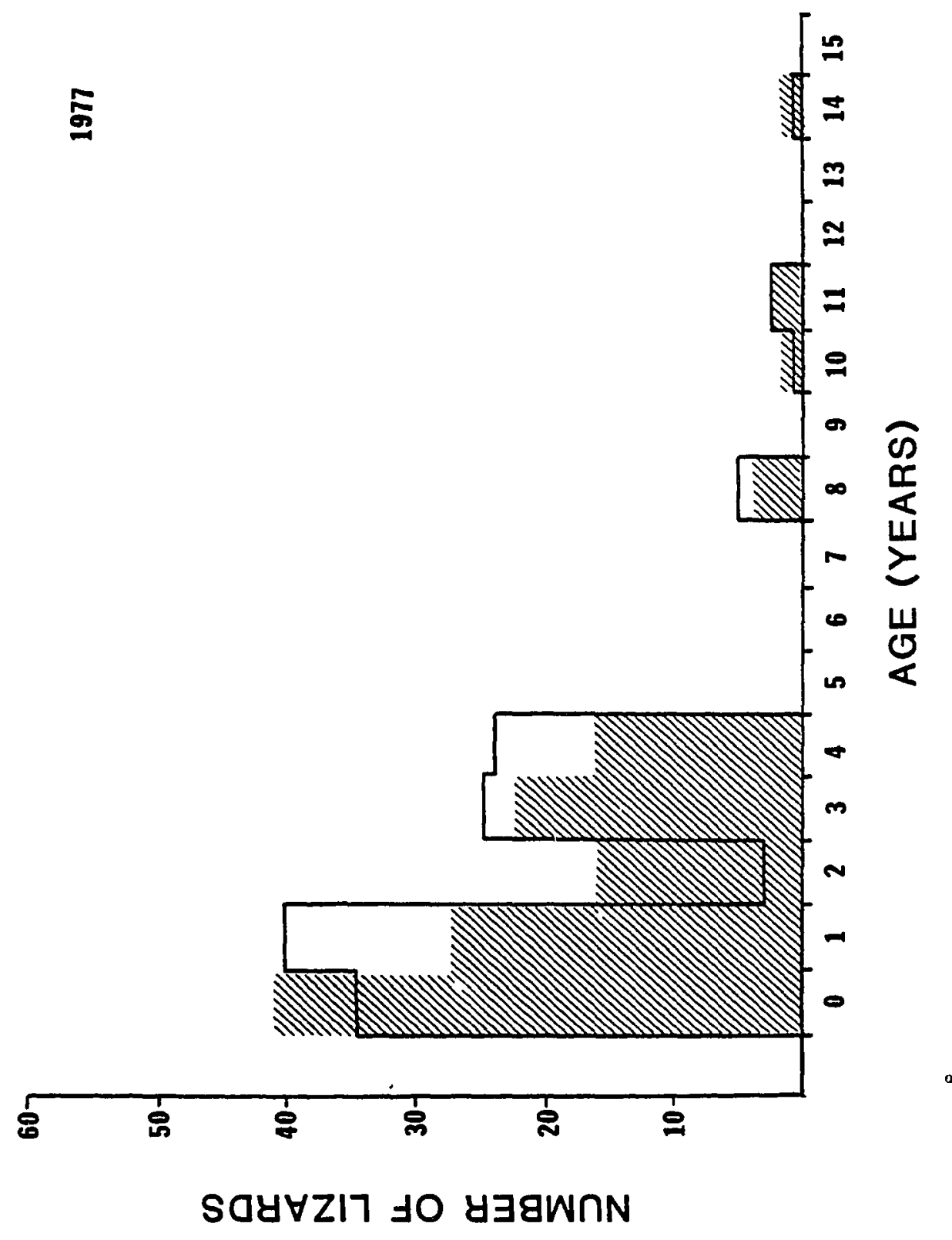


Figure 49. Age class distribution of Red Cloud Road $\underline{S}$. obesus. Shading indicates prediction from Leslie Analysis. 


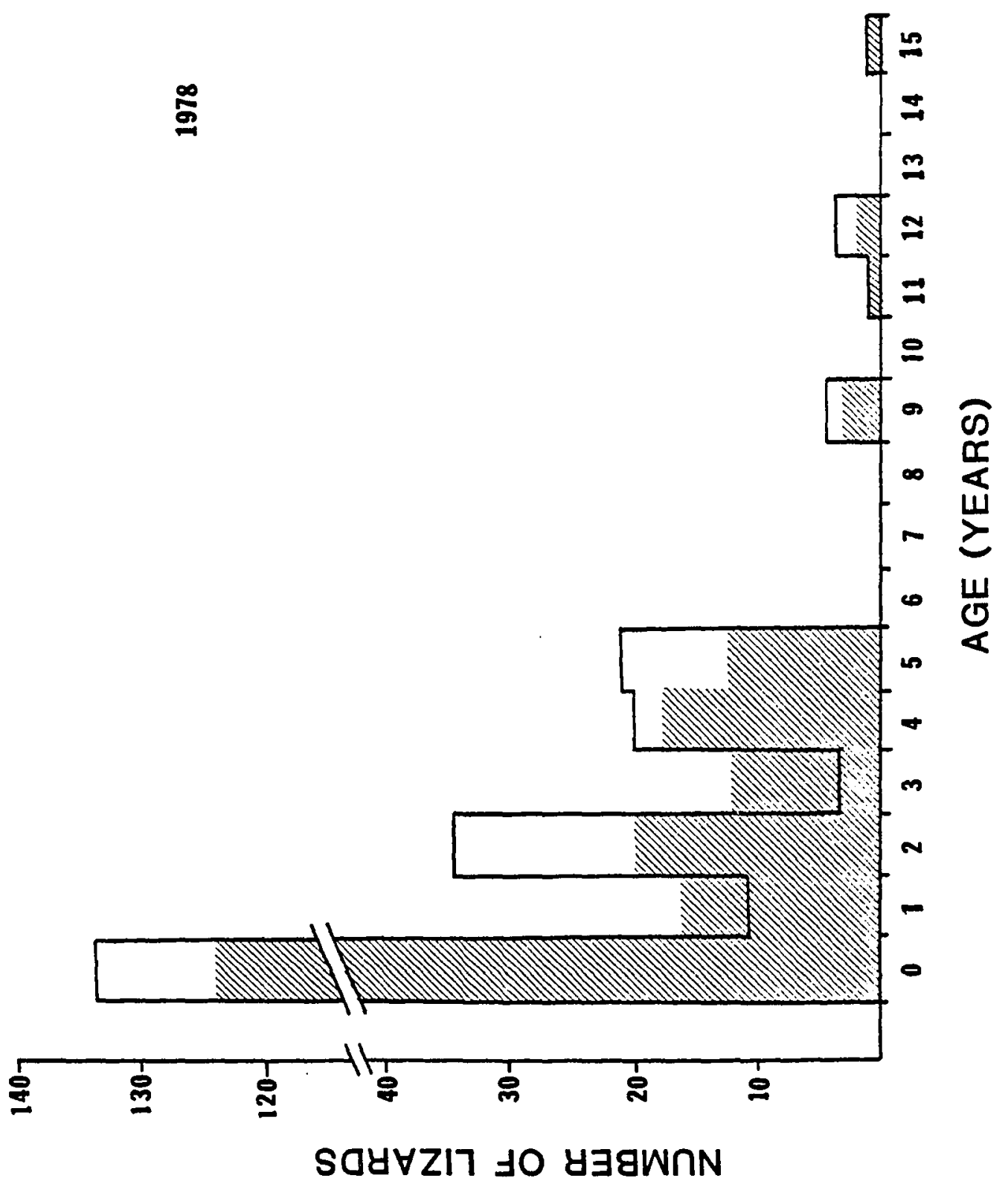


Figure 50. Age class distribution of Red Cloud Road $\underline{S}$. obesus. Shading indicates prediction from Leslie Analysis. 


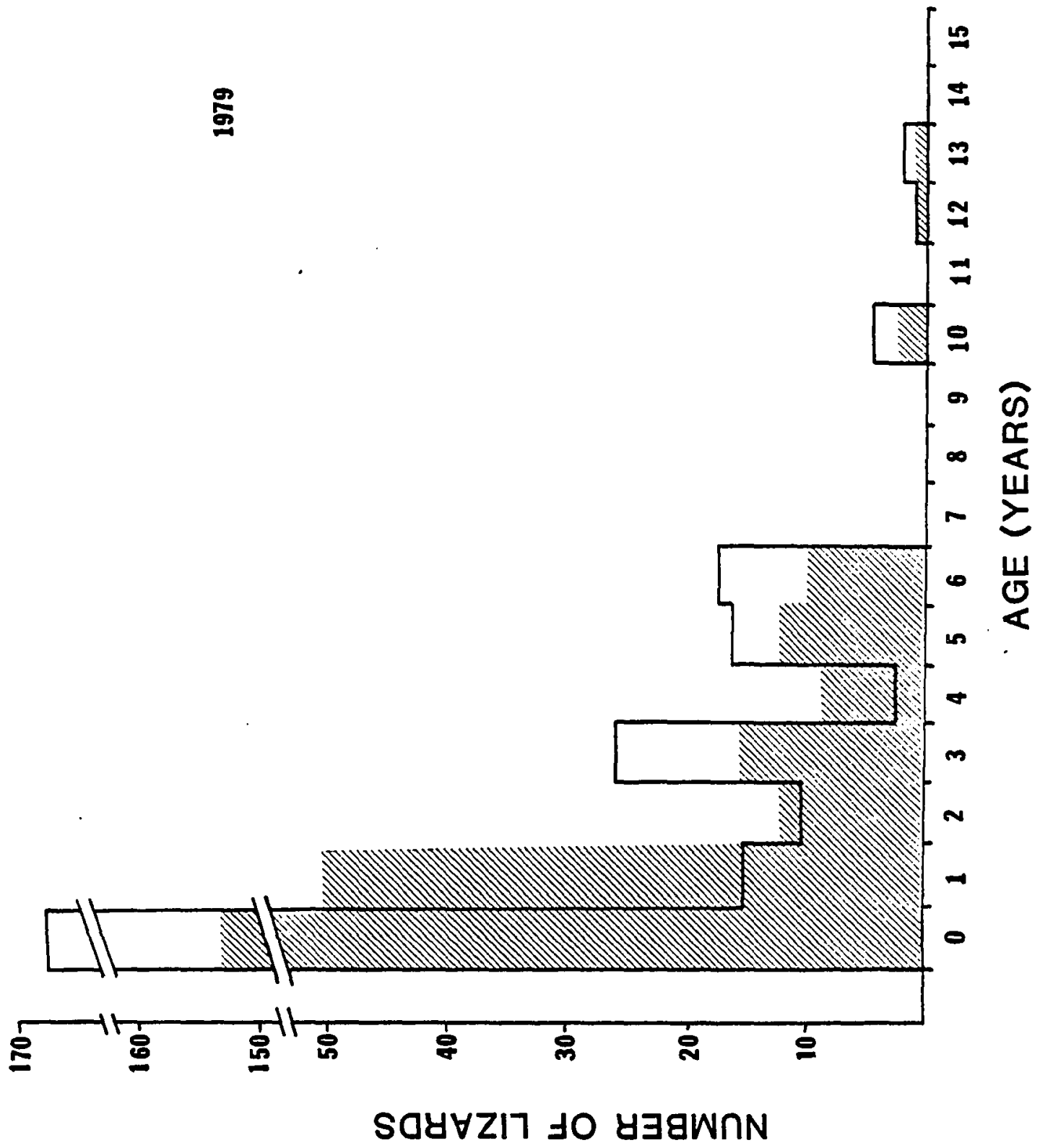


Figure 51. Age class distribution of Red Cloud Road $\underline{S}$. obesus. Shading indicates prediction from Leslie Analysis. 


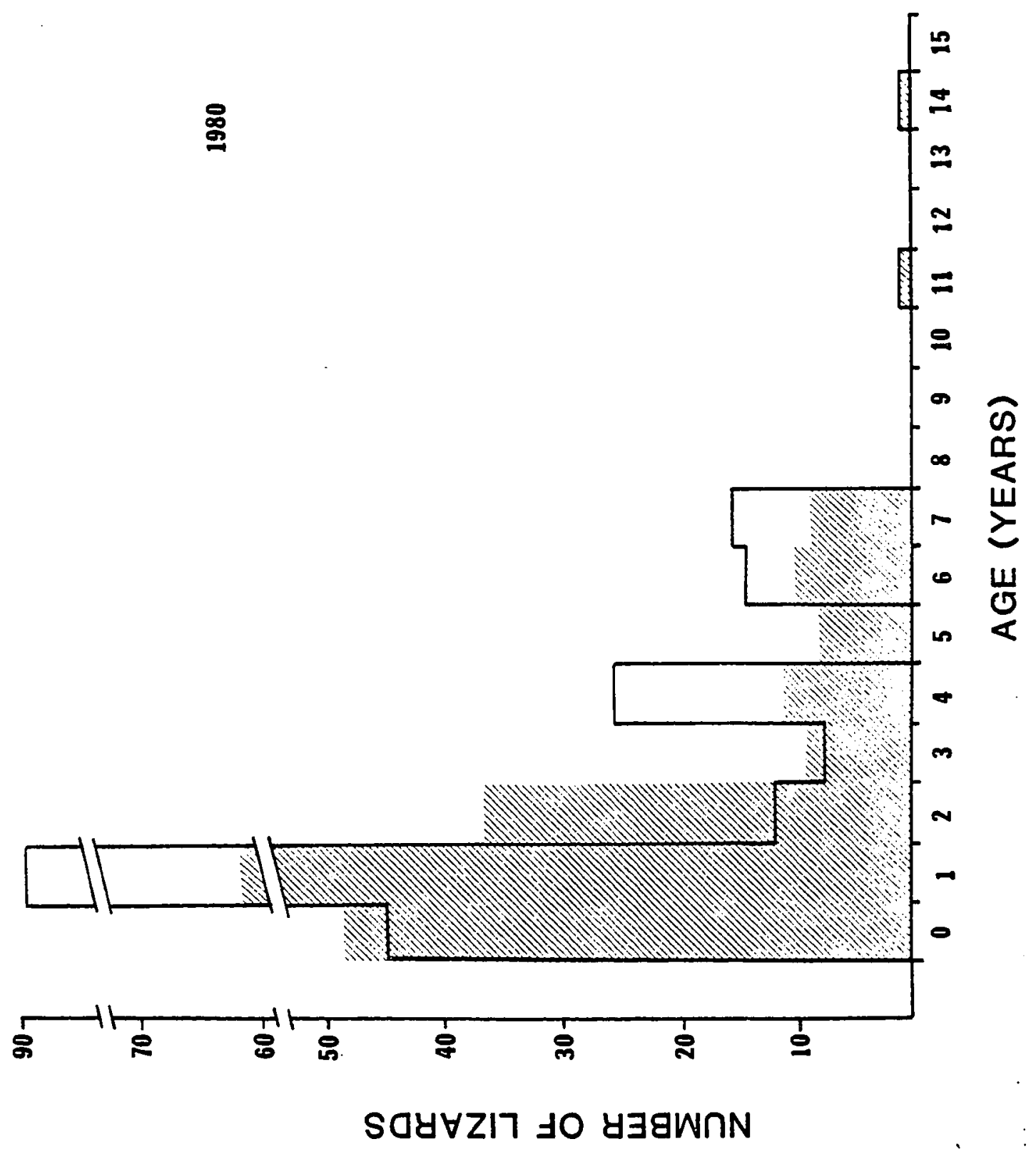


demonstrated the apparent frequent reproduction and short reproductive life span life history tactics of this population. The absence of individuals for certain age classes in observed and predicted distributions were identical. While the total number of individuals in both were not significantly different there were significant differences in the frequency distributions (Table LXXVIII). However, predicted values from the regression models deviated considerably less from the observed than employing a fixed fecundity rate. Differing values for observed and predicted age class frequencies can be attributed to: 1) variability in annual survivorship of first year individuals; 2) higher survivorship ( $>0.75$ ) of the younger age classes ( $1-8$ years); and 3) lower survivorship $(<0.75)$ of the older age classes $(>8$ years) .

In 1976, 1977 and 1979 precipitation from July through August greatly exceeded the average for this period (Ch. 1 - Climate and Vegetation). A correspondingly greater than average egg survivorship can be especially illustrated for 1976 and 1979 (Ch. 5 - Survivorship). In 1978 , reproductive success was second highest for the study and well above average (Ch. 4 - Reproductive Frequency). Nonetheless, the number of $\underline{s}$. obesus surviving to one year of age was less than one-third of the predicted number, thus indicating very low first year survival. Another case for low first year survival when there was little summer precipitation is illustrated by the puacity of 2 year olds in the 1977 population. While reproductive success for 1975 was probably average, only $0.03 \mathrm{~cm}$ of summer precipitation fell that year, leading to low first year survival. As mentioned previously, adequate summer 


\section{TABLE LXXVIII}

CHI-SQUARE TEST FOR GOODNESS OF FIT FOR OBSERVED AND PREDICTED (LESLIE MATRIX) POPULATION CHARACTERISTICS OF RED CLOUD ROAD $\underline{\text {. }}$ obesus

\begin{tabular}{lll}
\hline Year & \multicolumn{1}{c}{$\mathrm{X}^{2}$} & Probability of $\mathrm{X}^{2}$ \\
\hline 1977 & 0.38 & $0.75>\mathrm{P}>0.50$ \\
1978 & 3.23 & $0.10>\mathrm{P}>0.05$ \\
1979 & 0.31 & $0.75>\mathrm{P}>0.50$ \\
1980 & 1.13 & $0.25>\mathrm{P}>0.10$ \\
$\overline{\mathrm{X}}$ 5-Year & 201.45 & $0.001>\mathrm{P}$ \\
Fecundity & & \\
& Age Class Distribution & \\
1977 & 21.04 & $0.005>\mathrm{P}>0.001$ \\
1978 & 20.94 & $0.005>\mathrm{P}>0.001$ \\
1979 & 56.98 & $0.001>\mathrm{P}$ \\
1980 & 41.15 & $0.001>\mathrm{P}$ \\
$\overline{\mathrm{X}}$ 5-Year & 86.32 & $0.001>\mathrm{P}$ \\
\hline Fecundity & & \\
\hline
\end{tabular}


precipitation is neccessary for the maintenance of a proper environment for incubation (Muth, 1980).

The number of $\underline{s}$. obesus in the age classes $1-7$ frequently exceeded the number predicted by the Leslie Matrix analysis. Higher numbers of these individuals, especially illustrated by following the 1,3 , and 4 year olds of 1977 , perhaps reflected a higher than average annual survivorship rate, perhaps because these individuals were smaller than a critical size (Ch. 5 - Predation Intensity). In addition to size, density may also play a role in the situation presented in Fig. 48. Age classes 3 and 4 years in 1977 may show a greater number of individuals than predicted because they have lived to this time under low population density conditions. Supporting this impression is the fact that prior to 1973, when the 4 year olds were of age class zeros, there were 3 consecutive years of poor reproductive conditions as determined from the fecundity-Winter rainfall regression models. This period, 1970 - 1972, coincides with the time of poor reproduction observed in other $\underline{\text { S. }}$ obesus populations (Nagy, 1973; Berry, 1974). Apparently, drought was widespread in the desert at this time. Therefore, because of drought conditions, lowered numbers of younger S. obesus might have enjoyed heightened survivorship rates because of reduced predation intensity.

The number of $\underline{\mathrm{S}}$. obesus in age classes $>8$ years were usually equal to or less than the predictions from the Leslie Matrix analysis. If the conclusions about higher than average survivorship rates in younger individuals are reasonable, then the status of the older individuals might indicate slightly lower than average annual 
survivorship rates. At about $165 \mathrm{~mm}$ SVL, tail break frequencies showed marked increase (Ch. 5 - Predation Intensity). Females of $165 \mathrm{~mm}$ SVL were generally $7-8$ years of age. Unfortunately, field efforts were greatly reduced after 1980, when this concern could have been determined. Nonetheless, perhaps in agreement with heightened incidences of tail breaks, a drop in survivorship estimates for 1980 1981, when a large number of females approached 8 years (Ch. 4 Survivorship), might have indicated a lower than average survivorship rate for older $\underline{S}$. obesus. However, while such a trend was observed at a high population density, it may not be the same at lower densities.

There is a strong similarity for the years 1977, 1978 and 1980 between the Leslie Matrix predictions and actual reproductive output. While values for 1979 were high on both accounts, the actual count was $33 \%$ higher. This discrepancy probably was attributable to underestimating the fecundity of the older $\underline{s}$. obesus (because few were available to allow estimation of this parameter) and to the great number of third year adult females, almost twice as many as predicted by the Leslie Matrix analysis. Because nearly all third year females were reproductively active in 1979 (Ch. 4 - Reproductive Frequency) the latter condition accounted for over $50 \%$ of the difference in fecundity. From the above, the employment of specific survivorship and reproductive data in Leslie Matrix analysis has proved useful in predicting the age class structure of Red Cloud Road $\underline{S}$. obesus. While variation in first year and older class survival was the result of quantity of summer precipitation and predation intensity, respectively, only the former showed enough variation to occasionally be in 
disagreement with statistical predictions. On the other hand, application of the fecundity-winter precipitation regression model appeared to be highly successful in predicting population reproductive output. Consequently, this fecundity model may have important application for management of $\underline{\mathrm{S}}$. obesus and perhaps other desert animals. A step toward discerning the usefulness of such a procedure will involve attempts to construct similar fecundity models for other populations of this species in the near future. 
SUMMARY

Climate greatly affected the population dynamics of $\underline{s}$. obesus in this 7-year study in the Colorado Desert. Overall, approximately twothirds of the annual precipitation falls in winter (October through March). Most of the remaining third falls in summer (July through September). Mean winter and summer precipitation amounts were below normal (largely due to lengthy periods of drought) during the 25 year period (1951 - 1976) prior to this study. However, mean winter and summer precipitation amounts during this investigation were the wettest in over 30 years, and summer precipitation constituted almost half of the annual amount.

There was a relatively extensive annual season in the Colorado Desert influenced by milder winters and more frequent precipitation. Growth of perennials always occurred after substantial precipitation. Growth of annuals occurred largely after winter and summer precipitation. The peak standing crops of winter and summer annuals during the study occurred in mid-April and mid-August, respectively. The peak standing crop of winter annuals showed a 73-fold variation during the study .

The timing of precipitation was especially critical to the condition of vegetation. Early winter precipitation (October through January) was clearly the most important climatic parameter for increasing perennial stem elongation, for increasing peak winter annual standing crop and for extending the winter growing season.

In comparing Colorado and Mojave Deserts, the former had a longer winter growing season and greater frequency of summer precipitation. 
The extent to which these two parameters were responsible for observed differences in life history traits of $\underline{S}$. obesus was a major concern of this investigation.

The annual activity cycle for Colorado Desert $\underline{S}$. obesus varied according to food availability and level of reproductive activity. The maximum activity period for any year was about eight months (February through September). Peak activity (corresponding to the breeding season) occurred over a six-week period from May through the first half of June.

Episodes of feeding in Colorado Desert $\underline{\text { S. }}$ obesus occurred throughout the year. Feeding was most intense in early spring (when winter annuals were abundant) and late summer (when perennials responded to summer precipitation). In years when winter annuals were abundant they constituted two-thirds of the food items selected. Throughout the year an opportunistic feeding behavior was exhibited with no plant species contributing to more than $10 \%$ of the diet.

Several snake species were known or suspected of feeding on hatchling $\underline{S}$. obesus. Large birds of prey and carnivorous mammals preyed on adults. Coyotes (Canis latrans) were probably responsible for the majority of tail breaks and thus considered the primary predator. While the Colorado Desert study region supported numerous lizard species it appeared that interspecific competition for food and retreats were minimal. Consequently, predation was considered more important than competition in determining the life history traits of $\underline{\mathrm{S}}$. Obesus in this area.

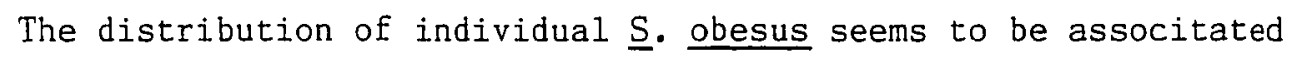


with the quality of the rock outcrop habitat (i.e., retreats and available food). Typically, a rock outcrop was occupied by one tyrant adult male and several adult females and subordinate males. Most tyrant males had large home ranges, but some wide-ranging subordinate males had the largest ranges. Home range size for adult males and females was correlated with adult female activity and nutrient requirements, respectively.

Episodes of territorial behavior for $\underline{S}$. obesus were common in adult males but infrequent in adult females. Territorial behavior was exhibited throughout the activity season but was most intense during the peak for the breeding season. High level aggressive behavior was rare, contributing to only $3 \%$ of the overall social encounters. Adult males courted adult females March through June but episodes of courtship were most intense in early June. While males of SVL $<140 \mathrm{~mm}$ were observed in courtship activities, most episodes involved tyrant males. Females of SVL 120 - $150 \mathrm{~mm}$ were frequently observed in courtship activities in years when food was abundant, but courtship was largely limited to females whose SVLs were greater than $150 \mathrm{~mm}$ in years when food levels were no better than average. Not all adult females participated in courtship (did not reproduce) even in years when food was abundant. Some aspects of social activity (crevice-sharing) appeared not to be associated with present reproduction (e.g., subordinate male-adult female and adult male-immature female interactions). Crevice-sharing was especially obvious during the breeding season and in late summer and probably solidified pair-bonding for potential future matings. While the social behavior of adult males was well-documented prior to 
this study the same cannot be stated for adult females. Adult female S. obesus in the Colorado Desert exhibited several complex stereotyped behavior patterns which were mostly influenced by the time of the activity season and particular male involved (e. g., avoidance, enticement. submission and rejection).

Previous reports on aspects of the reproductive cycle of female

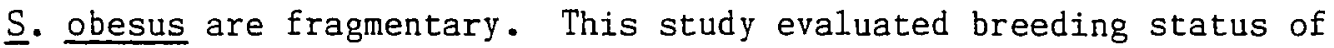
female lizards by discerning four types of ovarian follicles: 1) previtellogenic; 2) vitellogenic; 3) atretic and 4) pre-ovulatory. Previtellogenic follicles were present throughout the year. Vitellogenic follicles were most numerous from a month after the onset of activity season to June, although they were found in some individuals throughout the year. The latter observation is unusual among temperate region iguanids. Follicular atresia occurred from April through August, but most commonly in June and July, at the end of the reproductive season. Corpora atretica were more common in smaller adult females $(<150 \mathrm{~mm}$ SVL), as expected for a long-1ived species, in less than optimal reproductive years. Preovulatory follicles ( $\geq 10 \mathrm{~mm}$ diameter) were present for about a 6-week period (mid-May through June). They rarely became atretic, and thus provide one way of dterming the clutch size.

Corpora lutea were readily observed in adult females, from the time of ovulation to about 2 weeks post-oviposition (late June through July). The histological organization of the corpora lutea was similar to that of mammals. Corpora lutea were especially robust while females possessed oviductal eggs, suggesting a function associated with egg development. Counts of corpora lutea provided another means of determin- 
ing clutch size.

The ovaries of immature female $\underline{S}$. obesus contained considerably fewer follicles than adults. Some vitellogenic follicles were found in individuals from April through August (none exceeded $5 \mathrm{~mm}$ diameter) although most follicles were previtellogenic. Follicular atresia, was observed only in femlaes approaching minimum adult size (125 $130 \mathrm{~mm}$ SVL) from June through July. The role of vitellogenesis in smaller females (SVL $125 \mathrm{~mm}$ ) remains unsolved. The ovarian size of breeding adults changed 100-fold over the course of the activity season. However, the ovarian size of immature (non-breeding)individuals changed very little during the course of the activity season.

Gross inspection of the oviducts of adult female $\underline{S}$. obesus showed them to be opaque and highly convoluted the year round. Histological inspection revealed that $75 \%$ of the oviductal length was uterus. The peak thickness of the branched tubular gland epithelium occurred in mid-June, just prior to ovulation. There was a holocrine secretion to provide albumin and materials for production of shell membranes. The regeneration of the uterine gland epithelium began in August, about a month after oviposition, but progressed slowly until mid-spring of the following year.

Eggs were found in the oviducts of adult female $\underline{S}$. obesus from late June through mid-July. The eggs were white, parchment-like and ellipsoidal in shape. The eggs increased in size while in the oviducts and at the time of oviposition were roughly $75 \%$ longer than wide (i.e., about $35 \times 20 \mathrm{~mm}$ ). Oviductal eggs provided the best means of estimating clutch size. 
The oviducts of immature $\underline{S}$. obesus were reproductively quiescent. The oviducts were transparent, thin and straight prior to first reproduction. The uterine gland epithelium of immature individuals did not hypertrophy during the activity season.

The corpora adiposa of adult female $\underline{S}$. obesus were largest in late spring (May through mid-June) and for breeding individuals, rapidly declined in size in late June. The corpora adiposa of nonbreeding individuals varied little in size. Corpora adiposa were smallest in late summer and early spring. They showed little change in size over winter and only grew slowly during the first half of spring. Consequently, the primary function of corpora adiposa for adult females appears to be to provide energy for developing follicles (reproduction) and not for other physiological requirements (such as resource for winter dormancy).

Previous reports on the reproductive cycle of male $\underline{S}$. obesus are fragmentary. The evaluation of breeding status in this study involved discerning three reproductive parameters: 1) testis volume; 2) motile sperm in the terminal vas deferens and 3) spermatogenic activity. Peak testis volumes were not variable from year to year. However, the timing of peak volume showed slight variation (mid-May through late May). In general, testis volumes were maximum at the height of the breeding season. Testis volumes were minimum either in late summer (August) or early spring (March). Consequently, testis volume showed little change over winter. Motile sperm were found in terminal portions of the vas deferens from late April until mid-July. Spermatogenic activity was assessed according to eight seminiferous epithelial stages. 
Immature males never progressed beyond stage 1 . Stage 6 , indicating the the presence of mature sperm at the seminiferous tubule margin, persisted from mid-April through June. An individual was considered to be in breeding condition if observed to have maximum testis volume, motile sperm at the terminal end of the vas deferens, or stage 6 spermatogenic activity. Motile sperm in the terminal vas deferens or stage 6 spermatogenic activity were observed in all males > $125 \mathrm{~mm}$ SVL in most years. The widely-reported correlation of seasonal change in testis size with spermatogenesis has lead to the elucidation of 3 major types of testicular cycles. Adult male $\underline{S}$. obesus clearly have type II testicular cycle (testes are of maximum size in late spring or early summer). The type II testicular cycle is associated with the least amount of energy devoted to spermatogenesis, but this does not imply a low male reproductive effort.

The levels of secretory activity in the interstitial cells $\underline{S}$. obesus were best indicated by cell size and the nature of cytoplasmic granules. The cytoplasmic granules were richly eosinophilic through the spring (March through June). These cellular phenomena, representing peak levels of androgen synthesis, coincided with morphological and behavioral changes associated with reproductive activities. The seasonal changes in interstitial cells of immature $\underline{S}$. obesus were similar to those for adults. This probably illustrated the wide-ranging importance of androgens to male development.

Reports on the testicular accessory ducts of male $\underline{S}$. obesus are lacking. There was a four-fold change in height of the epididymal epithelium during the course of the activity season. The maximum heght of 
the epididymal epithelium (with a definite brush border) occurred during the peak of the breeding season (mid-May through mid-June). At this time, epididymal lumina were packed with sperm and secretory granules. In early summer (late June) seminiferous debris was also found in the lumina of the epididymis. Consequently, it appeared that the epididymis of adult males was capable of secretion and reabsorption. The epididymal epithelium of immature males showed no significant change in height throughout the activity season.

The epithelial height of the vas deferens was greatest (with a definite brush border) for adult male $\underline{S}$. obesus in late spring, but showed considerable individual variation. This might be attributable to different levels of secretory activity. Mature sperm were present in the Iumina of the vas deferens from mid-April through July. At this time, there was a highly organized ring of dense connective tissue external to the epithelium. Consequently, the vas deferens of adult males appears to serve as an ejaculatory duct as well as being capable of secretion and reabsorption. The vas deferens epithelium of immature males showed no significant change in height throughout the activity season.

The sexual segment of the kidney of male $\underline{S}$. obesus included terminal segments of nephronic tubules, collecting ducts and proximal portions of the ureter. The epithelial height showed a four-fold change during the course of the activity season. Maximum epithelial heights occurred during the peak of the breeding season (mid-May through midJune). At this time cells were packed with eosinophilic secretory granules. Since the secretory granules of adults were most obvious 
when sperm were present in the vas deferens, perhaps secretions contribute to the formation of a primitive seminal fluid. The renal kidney sexual segment epithelium of immature male $\underline{S}$. obesus showed no significant change in height or function throughout the activity season.

The abdominal fat bodies (corpora adiposa) of adult male $\underline{S}$. obesus were largest from late spring (late May through June) and in late summer. Corpora adiposa were smallest at the time of spring emergence (March). This pattern is greatly different from that for temperate region insectivorous lizard species, in which corpora adiposa were smallest at the peak of the breeding season. This energy resource for $\underline{S}$. obesus was largely apportioned to reproduction; development of reproductive tissues (seminiferous tubules and interstitial cells) and/or social activities (territorial maintenance) seem possible.

The male and female reproductive cycles were affected by a number of interrelated environmental factors. For the most part, these environmental factors were responsible for determing the. onset and duration of certain reproductive cycle events. In particular, extended periods in which food was available seemed to prolong spermiation in males and cool conditions and limited food delayed the onset of vitellogenesis in females. Nevertheless, the events culminating in reproduction showed restricted temporal variation during the study. Spermiation occurred in May and June for adult males. The sequence of events from preovulatory follicles to oviposition occurred from mid-May through mid-July for adult females. Adult females oviposited during the first half of July. While adherence to this schedule might have been potentially detrimental to adult females, since oviposition occurred during the 
warmest time of the year, it was highly advantageous to egg survival, since summer precipitation appeared to improve incubation conditions. Previous studies reported hatchling $\underline{S}$. obesus in fall, but none indicated the duration of the incubation period. The earliest sighting of hatchlings in this study was during the last week of September, althought sightings were infrequent through October. Maximum frequency of sightings occurred in November. Most recent hatchlings had completely healed abdominal yolk scars by December. Consequently, duration of incubation for $\underline{S}$. obesus was about $4(2.5$ - 5) months. This is considerably longer than incubation periods reported for most temperate region lizard species. The reason for an extended incubation period might be due to the larger egg size of $\underline{S}$. obesus. The variability in hatching time probably reflected differing microhabitat structure and physical factors.

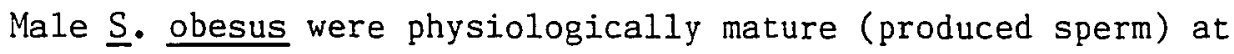
$125 \mathrm{~mm}$ SVL during most years of the study. However, behavioral maturity (successful defense of territories and acceptance by adult females) usually did not occur until about $165 \mathrm{~mm}$ SVL. Both SVLs were much smaller than reported elsewhere for breeding male $\underline{S}$. obesus.

Female $\underline{S}$. obesus were reporductively mature at $150 \mathrm{~mm}$ SVL during most years of the study. However, some individuals attained maturity at about $125 \mathrm{~mm}$ SVL in years when food was abundant. The former size was similar to earlier reports, but the latter was considerably smaller. The small adult size of Colorao Desert $\underline{S}$. obesus was consistant with other life history traits observed.

S. obesus marked during their first year provided information on 
age at maturity. All males attained physiological maturity (125 mm SVL) in their second year. Behavioral maturity varied according to the number of relatively large individuals present (> $165 \mathrm{~mm} \mathrm{SVL}$ ), but in general occurred at about 4 years.

Most female $\underline{S}$. obesus attained reproductive maturity (i.e., 150 $\mathrm{mm}$ SVL) at about 5 years during periods of average environmental conditions. However, many individuals attained maturity (i.e., $125 \mathrm{~mm}$ SVL) in their second or third year in years when food was abundant. The small size (and early age) at reproductive maturity for $\underline{\text { S. }}$ obesus in this study represents a unique situation in comparison with reports for Mojave Desert populations. Apparently, this different life history trait, along with several others (see below), reflects the somewhat different Colorado Desert environment.

Clutch size for female $\underline{S}$. obesus was determined by 3 methods: 1) number of enlarged ovarian follicles ( $\geq 10 \mathrm{~mm})$; 2) number of oviductal eggs and 3) number of corpora lutea. The mean and range for clutch size was $6.91 \pm 0.22$ and $2-15$, respectively for 115 lizards. Annual variation in clutch size was attributed to a corresponding variation in body size since clutch size did not vary from year to year for a given SVL. A similar clutch size/body size relationship appears to exist throughout the geographic range of $\underline{S}$. obesus. Consequently, female $\underline{S}$. obesus demonstrate "boom or bust" iteroparity. Such a reproductive adaptation may be expected to evolve in a predictable environment. Reproduction was detected for Colorado Desert $\underline{S}$. obesus in all but one year during this study. The annual population frequency of reproduction ranged from 0 to $95 \%$. Smaller adult females ( $<150 \mathrm{~mm}$ SVL) 
had the lowest frequency of reproduction. Adult female $\underline{S}$. obesus frequently maintained an annual breeding schedule despite the alternate year pattern described by other studies.

The variable climate was responsible for adult female $\underline{S}$. obesus demonstrating different levels of reproductive frequency. Reproductive success was apparently influenced both by foraging conditions prior to reproduction and by extent of energy reserves built up from the previous year. The lower frequency of reproduction in Mojave Desert studies (usually less than 40\%) reflected less favorable climate. Several climatic factors (less prevalent in the Mojave Desert) seemed important to reproduction in the Colorado Desert. Summer precipitation enabled individuals to replenish energy reserves prior to the onset of winter. Early winter precipitation (October through January) was critical to the standing crop of winter annuals, and milder winter temperatures enabled individuals to get an earlier start at assimilating available food. prior to turning attention to reproduction. Specific parameters like perennial stem elongation and length of growing season (period in which winter annuals were available) served as indicators of overall standing crop and were highly correlated with annual frequency of reproduction. Much of the Mojave Desert experienced frequent summer drought and winter cold. Subjected to these less than optimal climatic conditions, perhaps Mojave Desert adult female $\underline{S}$. obesus attaining large body size, were . better able to cope with the risks of reproduction. The fact that smaller Colorado Desert females (SVL 125 - $150 \mathrm{~mm}$ ) did not participate in reproduction when climatic conditions were suboptimal reinforces this impression. 
Egg size in lizards has been known to vary between populations because of different selection presssures and within populations because of year to year fluctuating resources. Prior to this study, little quantitative data was available for egg size in $\underline{S}$. obesus. Previous studies estimated wet egg masses to be $8-10 \mathrm{~g}$. From 15 clutches, mean wet egg mass and standard error for this study was 8.4 $\pm 0.3 \mathrm{~g}$. This suggested considerable geographic consistency in wet egg mass. Egg mass was not positively correlated with body size, nor was it negatively correlated with clutch size. Egg mass showed no year to year variation associated with climatic variation. Apparently, egg mass was a fixed parameter that probably optimized hatchling survival.

The total energy devoted to reproduction is apparently under different selection pressures than egg mass. The reproductive effort of female $\underline{S}$. obesus was estimated as ratios of the following: 1) wet egg mass/wet total mass; 2) dry egg mass/dry total mass and 3) egg calories to body calories. Wet clutch mass/wet total mass ratios were sometimes referred to as the relative clutch mass (RCM). The RCM for $\underline{S}$. obesus, previously estimated from 2 clutches, was between 35 and 45 . The mean RCM for this study was $34.3 \pm 0.0,(N=15)$, with several values within the range for previous estimates. This suggests geographic consistency in RCM. The mean dry clutch mass/dry total mass ratio for female $\underline{S}$. obesus was $50.0 \pm 1.4(N=4)$ and the mean caloric ratio was $54.0 \pm$ 1.0 $(N=4)$. These estimates of reproductive effort were considerably greater than previously reported for many single-clutched insectivorous iguanid species. The deviation presented here should encourage future 
investigators to evaluate the selective factors that influence this life history trait in herbivorous lizard species.

There was considerable stability of energy devoted to reproduction in the face of changing environmental and ontogenetic parameters. RCM showed little year to year variation for a given body size. In addition, RCM appeared not to be positively correlated with body size. RCM showed no systematic variation with different climatic conditions. Consequently, RCM, a measure of reproductive effort, appeared to be a very stable parameter. A relatively consistant reproductive effort may be indicative of minimal energetic costs of locomotion for gravid females of this species.

One selective factor apparently affecting reproductive effort in lizards is body shape. Some insectivorous lizard species have sacrificed reproductive effort in favor of a flattened shape that enables them to slip into narrow rock crevices and escape predation. $\underline{S}$. obesus is a flattened herbivore, but has a relatively high reproductive effort. The reason for this exception to body shape has to do with a number of morphological and behavioral traits exhibited by this species. A number of other iguanine species also exhibit a relatively high RCM.

Expenditure per progeny (EPP), frequently represented as the wet egg mass/total mass ratio, is associated with advantages of size for the offspring. Previous estimates of EPP for female $\underline{S}$. obesus, from 2 clutches ranged from 4.5 to 5.5 . The mean EPP for this study was 5.3 (S.E. $\pm 0.4, N=15$ clutches). This suggests geographic consistency in EPP for this species.

The stability of EPP in the face of ontogenetic parameters was 
determined for $\underline{\mathrm{S}}$ obesus. EPP was highly negatively correlated with both SVL and body mass. Since egg mass was not variable it followed that larger females would have lower EPP. EPP was highly negatively correlated with clutch size. Again, since egg mass was stable, the larger the clutch the less significant the mass of individual eggs. Lastly, since absolute egg mass, clutch size and RCM were stable reproductive parameters over 7 years for female $\underline{S}$. obesus (hence little affected by climatic factors) the same can be said for EPP. Selection for relatively consistant and high EPP probably was indicative of large egg mass being benefical in the face of harsh environmental conditions.

One means of having greater reproductive success is to increase reproductive output. Annual reproductive output was determined for adult female $\underline{S}$. obesus as the product of the mean clutch size and population frequency of reproduction. Variation in annual reproductive output was attributable to variation in body size, which affected mean clutch size, or to variation in climatic factors, which affected frequency of reproduction. The annual reproductive output of adult female $\underline{\text { S. obesus }}$ was considerably less than for many other iguanine lizard species. Reproductive success can also be improved by increasing the average individual fitness. In the face of a highly variable desert environment, reproductive output may be reduced in favor of a large egg mass.

Female $\underline{S}$. obesus were aged according annual increments and agespecific fecundity was determined as the product of the age-specific mean clutch size and frequency of reproduction. To date, very little data is available for age-specific fecundity in iguanine lizard species. 
For female $\underline{S}$. obesus, fecundity was highly correlated with age. Thus older females, being larger, produced larger clutches and reproduced more frequently.

Annual variability in fecundity was largely a consequence of climate. For all age classes, reproduction was curtailed during periods of drought and optimal during periods of wet conditions. However, during average climatic conditions, the older age classes had high fecundity levels, whereas the younger age classes had reduced fecundity levels.

Annual changes in fecundity largely reflected variation in reproductive frequency since clutch size appeared fairly stable for a given body size. Therefore, it was not surprising that the same climatic and vegetation parameters that were most highly correlated with reproductive frequency were also highly correlated with fecundity. Such a situation, portraying a "boom or bust" iteroparity, has been documented for island gigantic Sauromalus and may be a common adaptation for the genus.

Reproductive rates fluctuate according to both the level of adult mortality and ecological conditions, especially climate. The fact that annual reproductive output appeared greater for Colorado Desert $\underline{s}$. obesus than their Mojave Desert counterparts probably reflected a longer activity season for the former which allowed individuals greater access to food resources but also made them more susceptable to precation. To date, demographers have paid limited attention to survivorship of the egg stage. Egg survivorship was estimated for Colorado Desert S. obesus indirectly from hatchling densities. Egg survivorship showed 
an 8-fold variation between 1977 and 1982. Egg survivorship was highly dependent upon summer precipitation, as indicated by values of 0.53 and 0.14 for wet and dry summers, respectively. The precise annual timing of oviposition no doubt optimizes egg survivorship. The postulated low recruitment of young $\underline{S}$. obesus into Mojave Desert populations may largeIy be due to low egg survival, since much of the Mojave Desert experiences consistently dry summers.

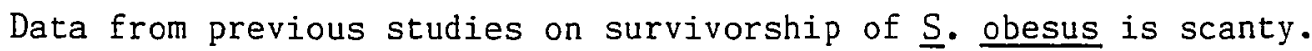
Four factors contributing to survivorship were considered for this species: 1) body size; 2) sex; 3) geography and 4) annual variation (i.e., effects of varying climate). Age-specific survivorship was determined by observing:two cohorts.

The mean annual survivorship of female $\underline{S}$. obesus older than one year was $0.74 \pm 0.01$ during the study period. Year to year variation in annual survivorship ranged from 0.60 to 0.90 . Variation in climate and reproductive activity contributed to variability in annual survivorship of females. The survivorship of younger ages appeared correlated with combined summer and winter precipitation and previous years' reproductive frequency. The maximum annual survivorship of adult female $\underline{\text { S. }}$ obesus occurred in years following low reproductive frequency coupled with high summer and early winter precipitation. The single most important climatic parameter for adult female survival was early winter precipitation (October through January). No doubt this parameter greatly affected the amount of time females went without food. While young (i.e., small) female $\underline{\text { S. }}$ obesus were more susceptable to starvation and desiccation, their tendency to achieve early reproductive maturity may 
have been due to lowered risks of reproduction (relative to Mojave Desert populations) because of predictability of certain climatic parameters (i.e., longer activity season and summer precipitation).

The mean annual survivorship of male $\underline{S}$. obesus older than one year was $0.74 \pm 0.01$ during the study period. Year to year variation in annual survivorship ranged 0.60 to 0.90 . Therefore, male and female annual survivorship may be similar. Variability in climate contributed to variability in annual survivorship of male $\underline{S}$. obesus. The survivorship of younger age classes appeared correlated with summer precipitation. The survivorship of adults appeared correlated with early winter precipitation. That annual survivorship was not strongly correlated with summer precipitation and reproduction was not surprising in light of the fact that in late summer adult male $\underline{S}$. obesus appeared to have maintained higher lipid reserves than their female counterparts.

Annual adult survivorship for $\underline{S}$. obesus in the Colorado Desert was considerably higher than reported for other iguanids, but it was markedly lower than postulated for a conspecific Mojave Desert population. Increased frequency of reproduction contributed to lowered adult female survivorship in this study. Since the same Mojave Desert population exhibited a substantially lower frequency of reproduction, perhaps this phenomenon improved annual survivorship.

Previous investigations of sex ratios in lizard populations have rarely been concerned with how these ratios evolved and operated within the mating system. Two related phenomena critical to the understanding of sex ratio are the intensity of sexual selection and operational sex ratio. For $\underline{S}$. obesus, both under the influence of ecological con- 
straints, tended to show considerable interpopulation variation.

The population sex ratio clearly favored females only in optimal reproductive years at the Colorado Desert study site. The mean six year population sex ratio approached unity. Cohort sex ratio slightly favored females in the younger age classes. After about 5 years of age, cohort sex ratios approached unity. Operational sex ratio (OSR), defined as the average ratio of fertilizable females to sexually active males at any given time strongly favored males (six year mean $=1.58: 1)$. However, as expected it approached unity in optinal reproductive years.

The sex ratio of Mojave Desert $\underline{S}$. obesus was previously reported to range from unity to nearly twice as many males as females. In addition, males of these populations were often relatively large. If keen sexual selection in the Mojave Desert results in a greatly increased number of large males, it may be an adaptation to ensure that infrequent reproductions are successful. The near absence of large males in the Colorado Desert study, perhaps showing reduced sexual selection, may be an indication of improved reproductive conditions.

The operational sex ratio (OSR) had a tremendous impact on the structure of the mating system of $\underline{S}$. obesus. The frequency of reproduction of adult females was largely influenced by prevailing climate. Understandably, frequency of reproduction and OSR were inversely related. In the Mojave Desert, climate did not favor reproduction. Not only was the number of reproductive females reduced but 'it appeared the synchrony of attaining breeding condition was also diminished. Such conditions probably indicated that each reproduction involved consider- 
able risk. Therefore, at any given time, the number of adult females (relative to adult males) appeared to be markedly less. However, breeding asynchrony by adult females made monopolization of mates more feasible for adult males. Hence the tyrant-subordinate mating system prevailed for Mojave Desert $\underline{S}$. obesus. In the Colorado Desert, climate favored reproduction and breeding was highly synchronous. Apparently, the risk associated with reproduction was minimal. For any given time, this resulted in the number of adult females usually being similar to number of adult males. This situation made monopolization of mates not only impractical but unnecessary. Consequently, the mating system of Colorado Desert $\underline{\mathrm{S}}$. obesus was relatively more loosely organized.

Little is known about annual recruitment (the sum of reproduction and immigration) for $\underline{S}$. obesus. In the Colorado Desert, annually about one-fifth of the population consisted of new individuals. One year old lizards and those less than three years old contributed one-third and four-fifths of the new individuals, respectively. In addition, adult females were extremely sedentary and no new adult males were captured in the last three years of the project. Consequently, reproduction (not immigration) was the chief means of annual recruitment in this study.

Annual recruitment was reported for one previous Mojave Desert study to be about one-fourth of that estimated for this study. If reproduction was as important to annual recruitment, then lowered frequency of reproduction and lowered egg survivorship would account for this difference. However, since asymmetrical body size in males was more typical at this Mojave Desert location (hence increased episodes 
of male-male aggression), perhaps immigration by subordinate males was common. If so, then the impact of reproduction on annual recruitment (relative to this Colorado Desert study) would have been further diminished.

The migration of individuals away from an area might be an important factor in the regulation of population density of some lizard species, but apparently not for $\underline{S}$. obesus in this study. Only one marked individual was observed off site (for 2 marked populations) during a 7-year period. While data is presently unavailable for Mojave Desert populations, the persistance of a more structured social organization might have led to increased episodes of emigration.

The observation of several hundred intraspecific confrontations of $\underline{S}$. obesus resulted in no broken tails. This tail-retention adaptation allowed the incidence of broken tails to serve as an indirect estimate of predation intensity.

The population frequency of broken tails of $\underline{S}$. obesus at the Red Cloud Road study site showed nearly a 3-fold annual variation (1953\%). Annual tail-break frequencies of adult males and females showed considerable variation. In general, frequencies were higher for adult males. Tail-break frequency for males increased gradually in the first 4 years of life then markedly afterward. Tail-break frequency for females increased gradually for about the first 7 years of 1 ife, then markedly afterward. Body sizes were similar for these different ages of the sexes (about $165 \mathrm{~mm}$ SVL). Therefore, in this popultion of $\underline{S}$. obesus a specific body size appeared crucial to predation intensity. A number of population parameters were compared with tail break 
frequency for this Colorado Desert $\underline{S}$. obesus. Those parameters most highly correlated with tail break frequency were median body size, mean age and previous years density. Greater median body size and density probably were indicative of more individuals being obvious to predators. Frequency of reproduction was not correlated with tailbreak frequency. In fact, maximum tail break frequency occurred in the years of lowest reproduction frequency. This is not to say mortality was lower in optimal reproductive years. Relative to males, greater numbers of adult females at younger ages but not older ages was indicative of mortality associated with the "risks" of reproduction.

Previous attempts to compare tail-break frequencies of various S. obesus populations were futile because they did not consider variation in age class structure. In this study, a comparison of Colorado and Mojave Desert populations of similar age structure revealed the former to have twice the tail-break frequency of latter (i.e., $37.8 \pm 5.1 \%$ and $20.8 \pm 4.5 \%$, respectively). Therefore, predation intensity on $\underline{S}$. obesus appeared considerably greater in the Colorado Desert. Increased predation intensity for this area was probably due to the improved reproductive conditions and incubation environment leading to increased population densities that made individulas more obvious to predators.

The regulation of numbers of $\underline{S}$. obesus in the Colorado Desert area was an interaction of density-dependent and density-independent stabilizing factors. From capture-recapture data, annual population density showed a 2-fold annual variation at the Red Cloud Road study site. It was maximum a year following optimal reproductive success $(N=25 / h a)$ and minimum following a year of no reproduction when rela- 
tively large individuals ( $>165 \mathrm{~mm}$ SVL) were numerous (13.4/ha). Recruitment of yearlings, regulated by density-independent factors (i.e., summer precipitation) had the greatest impact on population density. The number of large adults, regulated by density-dependent factors (i.e., predation) was usually maintained at a relatively consistent low level.

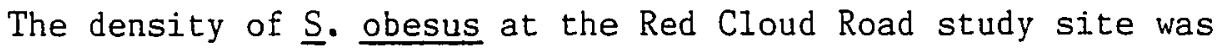
compared with densities of 3 Mojave Desert populations. In general, the density at the Red Cloud Road study site was 2 to 3 times greater than for the Mojave Desert localities. With regard to biomass, the Red Cloud Road population consisted of smaller lizards than at the Mojave Desert localities. However, it supported a $60 \%$ higher biomass. Therefore, under most conditions the Red Cloud Road population appeared less food-limited. Posessing smaller and more stable home ranges and being able to feed the year round provided spatial and temporal evidence, respectively, to reinforce this impression. Such a situation culminated in higher frequency of reproduction and along with higher egg survivorship resulted in frequent periods of high density.

The association of traits that constitute a species' reproductive strategy determines how long individuals of a population live. For iteroparous species maximal reproductive success is achieved by balancing the immediate prospects of reproduction with those that are long-term. Previous studies on $\underline{S}$. obesus have occurred in environments that typically impart a great deal of risk in reproduction. Under such conditions, both males and females lowered the risk of reproduction by postponing it in favor of extended periods of growth. Apparently, the 
risk of reproduction in this Colorado Desert study was considerably less. Consequently, individuals matured earlier and experienced reduced longevity. From capture-recapture data, 10 year old male and female S. obesus were typically $195 \mathrm{~mm}$ and $175 \mathrm{~mm}$ SVL, respectively. Throughout the study area, these body sizes contributed to only about $8 \%$ of the total male and female populations. Consequently, most individuals in this area do not live longer than 10 years, which was about one-half to two-thirds the longevity reported for Mojave Desert

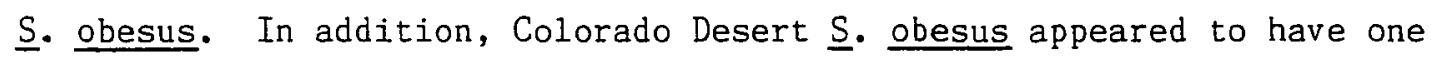
of the shortest longevities reported for iguanine lizard species.

The relationship between risk of reproduction and growth was illustrated for $\underline{S}$. obesus by comparing Mojave and Colorado Desert populations. Males from both regions appeared to have similar growth rates but for females, those from the Colorado Desert grew considerably faster. It was shown that annual growth rates and frequency of reproduction were highly correlated for adult female $\underline{S}$. obesus in the Colorado Desert. This adaptation enabled females to maximize both present and future reproduction. However, probably due to frequently limited and/or suboptimal food resources, reproduction was usually a great risk for Mojave Desert adult females. It appeared only the largest individuals were able to risk reproduction, but because of the prevailing nutrient defiency it took considerable time (about 12 years') to achieve the critical size. In other words, the stunted growth rates of Mojave Desert female $\underline{S}$. obesus made not only present reproduction but that of the near future risky. In order for Mojave Desert counterparts, they must have extended longevity . 
A summary of demographic information in the form of a life table has yet to be presented for $\underline{S}$. obesus. Previously, most life tables for lizards were not consistent with population histories, largely due to inadequate estimation of age at first reproduction, survivorship schedule and fecundity schedule. These inadequacies were avoided here by monitoring known-aged individuals. Various life tables were constructed for Colorado Desert $\underline{S}$. obesus to predict population parameters in the face of changing environmental conditions and establish which suite of demographic characteristics best depicted the overall history of the population.

The population of $\underline{\underline{S}}$. obesus was analyzed by constructing various life tables for annual periods (optimal reproduction and no reproduction) and longer (5-year average, stable population 16-year fecundity/ winter precipitation regression model). These life tables used a 5-year average survival for all age classes. First year survival is quite variable, as this parameter would be under or overestinated for various years. However, since it was the 5-year average value, it was realistic for long time period models. These predicted life tables illustrated the inconsistency of relying on limited (one year) data to depict a population's history. The 5-year life table indicated a period of population growth $\left(R_{0}=1.54\right)$. The 16-year life table indicated a period of population stability $\left(R_{0}=0.97\right)$. If the last 25 years were typical, then oscillations between population growth and decline in several year increments were probably indicative of the population history for Colorado Desert $\underline{S}$. obesus.

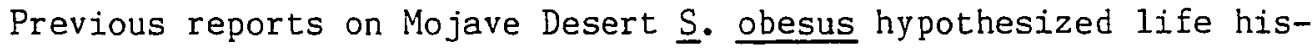


tory traits indicative of a species faced with low resource supply/ demand ratio (K-selection) and/or low recruitment of yearlings (low juvenile survivorship). Such traits for Mojave Desert $\underline{\text { S. obesus }}$ included: 1) delayed female maturity (minimum $=5$ years and $\mathrm{T}_{\mathrm{c}}=$ 10 years); 2) infrequent reproduction ( $440 \%$ annual frequency); 3 ) long reproductive 1ife span (typically 10 - 15 years) and 4) long life expectancy (typically 15 - 20 years). In this Colorado Desert study, two trends for life history traits were indicated by various life tables. First, life history traits of $\underline{S}$. obesus were indicative of high supply/demand ratios (r-selection) and high recruitment of yearlings (high juvenile survivorship) for periods when reproduction was favored. Such traits included: 1) early female maturity (minimum = 2 years; $\mathrm{T}_{\mathrm{c}}=6-8$ years and young adult females contributed to between one-third and two-thirds of the annual reproduction); 2) frequent reproduction (sometimes nearly $100 \%$ annual frequency and greater than $40 \%$ in 5 of 7 consecutive years); 3 ) short reproductive life span (typically $5-7$ years) and 4) short life expectancy (less than 10 years for most individuals). Second, the life history traits approached those predicted for Mojave Desert populations of $\underline{S}$. obesus for periods when reproduction was not favored. Such traits were: 1) female maturity requiring about 5 years and $T_{C}>8$ years); 2) frequency of reproduction being $<40 \%$; 3) reproductive life span approaching 10 years and 4) life expectancy approaching 15 years.

The above trends for Colorado Desert $\underline{\text { S. obesus }}$ indicated tremendous flexibility in life history traits which were necessary to adjust to variable environmental conditions. Nonetheless, the data seemed to 
indicate that the climate of the Colorado Desert was highly predictable. Consistently warmer winter conditions enabled $\underline{S}$. obesus to take advantage of winter precipitation by having a longer activity season (they were known to feed the year round). Frequent summer precipitation a1lowed individuals to feed in late summer and was essential to the egg incubation environment. Therefore, mild winters and summer precipitation allowed $\underline{\mathrm{S}}$. obesus to have a higher frequency of reproduction and summer precipitation enhanced egg survivorship. Analysis of climatic conditions over a 25-year period revealed reproduction and egg incubation would have been favored in $75 \%$ and $60 \%$ of the years, respectively. The probability of reproduction and high egg survival occurring in the same year would have been 0.45 . For these climatic phenomena, a probability of 0.2 was suspected for northern Mojave Desert S. obesus. Consequently, while climatic conditons in the Colorado Desert study area were variable they appeared more stable and conducive to reproduction than those prevailing in the northern Mojave Desert.

Stable population life history analyses $\left(R_{0}=1\right)$ reflected the different reproductive strategies of Colorado and Mojave Desert $\underline{S}$. obesus. For the former, relatively high reproductive frequencies and egg survival were crucial. For the latter, high adult survival (with corresponding increased clutch size) was crucial. However, even the Colorado Desert region required high adult survival to counter periods of poor climatic conditions. The tendency of Colorado Desert $\underline{S}$. obesus to have life history traits approaching those of the Mojave Desert lizards when climatic conditions were poor would argue against strong geno- 
typic differences between populations. Perhaps the life histories

of all populations of $\underline{S}$. obesus can be explained primarily by climatic effects on demographic parameters. In addition, it seens likely that the resource supply and demand theory may explain some of the life history variation of $\underline{S}$. obesus, but measurement of resources in the Mojave Desert are sorely needed.

This study of $\underline{S}$. obesus is the first to attempt to predict the age class structure of a lizard population. Data from the 16-year fecundity/winter precipitation regression model and 5-year survivorship schedule was analyzed according to standard Leslie Matrix methodology. The age class distributions from the Leslie analysis were compared with those of the Colorado Desert population for 1977 through 1980. The discrepencies between the two estimates were largely due to: 1) annual variation in first year survival; 2) higher survival rates of younger age classes (SVL $<165 \mathrm{~mm}$ ) during years of low density and 3) lower survival of older age classes (SVL $>165 \mathrm{~mm}$ ) during years of high density. The similarity of the actual and predicted age class structures for this population of $\underline{S}$. obesus makes a fecundity/winter precipitation model highly benefical to future studies of this species and perhaps other desert animals and a valuable employment tool for future management practices. 


\section{REFERENCES}

Abrahamson, W. G. and M. D. Gadgil. 1973. Growth form and reproductive effort in goldenrods (Soligaga, Compositae). Amer. Natur. $107: 651-661$.

Andrewartha, H. G. and L. C. Birch. 1954. The Distribution and Abundance of Animals. Chicago, Univ. of Chicago Press. 782 pp.

Andrews, R. M. 1982a. Patterns of growth in reptiles. Pp. 273-320. In C. Gans and F. H. Pough (Eds.). Biology of the Reptilia, Vol. XIII. Academic Press, New York.

- 1982b. Spatial variation in egg mortality of the lizard Anolis limifrons. Herpetologica 38:165-171.

Andrews, S. R. and A. S. Rand. 1974. Reproductive effort in Anoline lizards. Ecology 55: 1317-1327.

Atland, P. D. 1941. Annual reproductive cycle of the male fence lizard. J. Elisha Mitchell Scient. Soc. 57:73-83.

Bailey, N. T. J. 1952. Improvements in the interpretation of recapture data. J. Anim. Ecol. 21:120-127.

Ballinger, R. E. 1973. Comparative demography of two viviparous iguanid lizards (Sceloporus jarrovi and Sceolporus poinsetti). Ecology 54:269-283.

- 1976. Evolution of life history strategies: implications of recruitment in a lizard population following density manipulations. S. W. Natur. 21:203-208.

- 1977. Reproductive strategies: food availability as a source of proximal variation in a lizard. Ecology 58:628-635.

- 1979. Intraspecific variation in demography and life history of the lizard Sceloporus jarrovi along an altitudinal gradient in southeastern Arizona. Ecology 60:901-909.

- 1983. On the nature of life history variation in lizards. Pp. 241-260 in R. B. Huey, E. R. Pianka and T. A. Schoener (Eds.), Lizard Ecology; Studies of a Model Organism. Harvard Univ. Press, Cambridge, Massechusetts.

., E. D. Tyler and D. W. Tinkle. 1972. Reproductive ecology of a west Texas population of the greater earless lizard, Cophosaurus texanus. Am. Midl. Nat. 88:419-428. 
Ballinger, R. E. and G. D. Schrank. 1972. Reproductive potential of female whiptail lizards, Cnemidophorus gularis gularis. Herpetologica 28:217-222.

- and D. W. Tinkle. 1979. On the cost of tail regeneraton to body growth in lizards. J. Herpetol. 13:374-375.

Bartholomew, G. A., A. F. Bennet and W. R. Dawson. 1976. Swimming, diving, and lactate production of the marine iguana, Amblyrhnchus cristatus. Copeia 1976:709-720.

Bellairs, A. d'A. 1970. The Life of Reptiles, Vol. I, II. Universe Books, New York.

Berry, K. H. 1974. The ecology and social behavior of the chuckwalla, Sauromalus obesus. Univ. Calif. Publ. Berkely.

- 1978. Livestock Grazing and the Desert Tortoise. California Desert Plan Program. Bureau of Land Management. Riverside, $\mathrm{Ca}$.

Birch, L. C. 1948. The intrinsic rate of natural increase of an insect population. J. Anim. Ecol. 17:15-26.

Bishop, J. E. 1959. A histological and histochemical study of the kidney tubule of the common garter snake Thamnophis sirtalis, with special reference to the sexual segment in the male. J. Morph. 104:307-357.

Blair, W. F. 1960. The Rusty Lizard. University of Texas Press, Austin. $185 \mathrm{pp}$.

Bloom, W. and D. W. Fawcett. 1975. A Textbook of Histology $10^{\text {th }}$ ed. W. B. Saunders Company, Philadelphia. 1033 pp.

Blount, R. F. 1929. Seasonal cycles of the interstitial cells in the testis of the horned toad, Phrynosoma solare. J. Morph. 48:317343.

Bostic, D. L. 1966. A preliminary report of reproduction in the teiid lizard, Cnemidophorus hyperthyrus beldingi. Herpetologica. 22:8190 .

Boyd, M. M. 1940. The structure of the ovary and the formation of the corpus luteum in Hoplodactylus maculatus Gray. 0. F1. Micrsc. Sci. 82:337-376.

Bradshaw, S. D. 1971. Growth and mortality in a field population of Amphibolurus lizards exposed to seasonal cold and aridity. J. Zoo1. Lond. 165:1-25. 
Brooks, G. R. 1967. Population ecology of the ground skink, Lygosoma laterale Say. Ecol. Mongr. 37:71-87

Bustard, H. R. 1969. The population ecology of the gekkonid lizard Gehyra variegata Dumeril and Bibron in exploited forests in northern New South Wales. J. Anim. Eco1. 38:35-51

- 1970. The role of behavior in the natural regualtion of numbers in the gekkonid lizard Gehyra variegata. Ecology 51:724728.

Carpenter, C. C. 1966. The marine iguana of the Galapagos Islands, its behavior and ecology. Proc. Calif. Acad. Sci. 34:329-376.

- and G. W. Ferguson. 1977. Variations and evolution of stereotyped behavior in reptiles. Pp. 335-508 in C. Gans and D. W. Tinkle (Eds.), Biology of the Reptilia Vo1. VII. Academic Press, New York.

Case, T. J. 1976. Body size differences between populations of the chuckwalla, Sauromalus obesus. Ecology 57:313-323.

- 1982. Ecology and evolution of the insular gigantic chuckwallas, Sauromalus hispidus and Sauromalus varius. Pp. 184-211 in G. M. Burghardt and A. S. Rand, (Eds.), Iguanas of the World: their behavior, ecology and conservation. Noyes, Park Ridge, N. J.

Christiansen, J. L. 1971. Reproduction of Cnemidophorus inornatus and Cnemidophorus neomexicanus (Sauria, Teiidae) in northern New Mexico. Am. Mus. Novit. (2442), 1-48.

Church, G. 1962. The reproductive cycle of the Javanese house geckos Cosymbotus platyurus, Hemidactylus frenatus, Peropus mutilatus. Copeia 1962:262-269.

Cole, L. C. 1954. The population consequences of life history phenomena. Quart. Rev. Biol. 29:103-137.

Cuellar, 0. 1966. Oviductal anatomy and sperm storage in lizards. J. Morph. 119: 7-20.

., J. J. Roth, J. D. Fawcett and R. E. Jones. 1972. Evidence for sperm sustance by secretions of the renal sexual segment of male lizards, Anolis carolinensis. Herpetologica 28:53-57.

Deevey, E. S., Jr. 1947. Life tables for natural populations of animals. Quart. rev. Biol. 22:283-314.

Degenhardt, W. G. 1966. A method of counting some diurnal ground lizards of the genera Holbrookia and Cnemidophorus with results from the Big Bend National Park. Am. Midl. Nat. 75:61-100. 
Derickson, W. K. 1976. Lipid storage and utilization in reptiles. Am. Zool. 16:711-723.

Dessauer, H. C. 1955. Seasonal changes in the gross organ composition of the lizard Anolis carolinensis. J. Exp. Zool. 128:1-12.

Droge, D. L., S. M. Jones and R. E. Ballinger. 1982. Reproduction of Holbrookia maculata in western Nebraska. Copeia 1982:356-362.

Duda, P. L. and O. Koul. 1977. Ovarian cycle in high altitude lizards from Kashmir Part II Scincela himalayanum Boulenger. Herpetologica 33:427-433.

Dugan, B. and T. A. Wiewandt. 1982. Socio-Ecological determinants of mating strategies in iguanine lizards. Pp. 303-317 in G. M. Burghardt and A. S. Rand (Eds.), Iguanas of the World: their behavior, ecology and conservation. Noyes, Park Ridge, N. J.

Dunham, A. E. 1978. Food availability as a proximate factor in influencing individual growth rates in the iguanid lizard Sceloporus merriami. Ecology 59:770-778.

- 1982. Demographic and life-history variation among populations of the iguanid lizard Urosaurus ornatus: implications for the study of life history phenomena in lizards. Herpetologica $38: 208-221$.

Edwards, A. F. W. 1960. Natural selection and the sex ratio. Nature 188:960-961.

Emlen, S. T. and L. W. Oring. 1977. Ecology, sexual selection and the evolution of mating systems. Science 197: 215-223.

Errington, P. L. 1946. Predation and vertebrate populations. Quart. Rev. Biol. 21:144-177, 221-245.

- 1963. The phenomenon of predation. Amer. Sci. 51:180-192.

Etheridge, R. 1967. Lizard caudal vertebrae. Copeia 1967:699-721. - 1982. Checklist of the iguanine and Malagasy iguanid: 1izards. Pp. 7-37, in G. M. Burghardt and A. S. Rand (Eds.), Igaunas of the World; their behavior, ecology and conservation. Noyes, Park Ridge, N. J.

Farner, D. S. 1955. Bird banding in the study of population dynamics. In A. Wolfson (Ed.), Recent studies in Avian Biology. Urbana, Univ. of Illinois Press.

Ferguson, G. W., C. H. Bohlen, and H. P. Woolley. 1980. Sceloporus undulatus: compariative life history and regulation of a Kansas population. Ecology $61: 313-322$. 
Fisher, R. A. 1930. The genetical theory of natural selection. London, Oxford Univ. Press. 272 pp.

Fitch, H. S. 1956. An ecological study of the collared lizard, Crotaphytus collaris. Univ. Kans. Publ. Mus. Nat. Hist.

- 1970. Reproductive cycles in lizards and snakes. Univ.

Kans. Nat. Hist. Misc. Publ. No. 52. 247 pp.

Forbes, T. R. 1961. Endocrinology of reproduction in cold-blooded vertebrates, in W. C. Young (Ed.), Sex and Internal Secretions. 2:1035-1087. Balliere, Tindall and Cox.

Fox, H. 1977. The Urinogenital System of Reptiles. Pp. 1-158, in C. Gans (Ed.), Biology of the Reptilia, Vol. VI. Academic Press, New York.

Fox, W. 1952. Seasonal variation in the male reproductive system of Pacific coast garter snakes. J. Morph. 90:481-554.

- and Dessauer, H. C. 1958. Response of the male reproductive system of lizards (Anolis carolinensis) to unnatural day lengths in different seasons. Biol. Bull. Mar. Biol. Lab., Woods Hole $115: 421-439$.

Gadgil, M. and W. Bossert. 1970. Life history consequences of natural selection. Amer. Natur. 104:1-24.

- and O. T. Solbrig. 1972. The concept of " $r$ " and " $K "$ selection: evidence from wildflowers and some theoretical considerations. Amer. Natur. 106:14-31.

Gaffney, F. C. and L. C. Fitzpatrik. 1973. Energetics and lipid cycles in the lizard, Cnemidophorus tigris. Copeia 1973:446-452.

Gennaro, A. L. 1974. Growth, size and age at sexual maturity of the lesser earless lizard, Holbrookia maculata maculata, in eastern New Mexico. Herpetologica 30:85-90.

Gilbert, N. and A. P. Gutierrez. 1973. A plant-aphid parasite relationship. J. Anim. Ecol. 42:323-340.

Gleeson, T. T. 1979. Foraging and transport costs in the Galapagos marine iguana, amblyrhynchus cristatus. Physiol. Zool. 52:549-557.

Goldberg, S. R. 1970. Seasonal ovarian histology of the ovoviviparous lizard Sceloporus jarrovi Cope. J. Morph. 132:255-276.

- 1971a. Reproductive cycle of the ovoviviparous iguanid lizard Sceloporus jarrovi Cope. Herpetologica 27:123-131. 
Goldberg, S. R. 1971b. Reproduction in the short-horned lizard Phry nosoma douglassi in Arizona. Herpetologica 27:311-314.

- 1972a. Seasonal weight and cytological changes in the fat bodies and liver of the iguanid lizard Sceloporus jarrovi Cope. Copeia. 1972:227-232.

- 1972b. Reproduction in the southern alligator lizard Gerrhonotus multicarinatus. Herpetologica 28:267-273.

- 1973. Ovarian cycle of the western fence lizard Sceloporus occidentalis. Herpetologica 29:284-289.

- 1974. Reproduction in mountain and lowland populations of the lizard Sceloporus occidentalis. Copeia 1974:176-182.

- 1975a. Reproduction in the sagebrush lizard, Sceloporus graciosus. Amer. Mid1. Nat. 93:177-187.

- 1975b. Yearly variations in the ovarian cycle of the lizard sceloporus occidentalis. J. Herpetol. 9:187-189.

- 1976. Reproduction in a mountain population of the coastal whiptail lizard, Cnemidophorus tigris multiscutatus. Copeia 1976: 260-266.

- and C. H. Lowe. 1966. The reproductive cycle of the western whiptail lizard, Cnemidophorus tigris in southern Arizona. J. Morph. 118:543-548.

- and R. L. Bezy. 1974. Reproduction in the island night lizard, Xantusia riversiana. Herpetologica 30:350-360.

- and W. S. Parker. 1975. Seasonal testicular histology of the colubrid snakes, Masticophus taeniatus and Pituophis meanoleucus. Herpetologica $31: 317-322$.

Gorman, G. C. and P. Licht. 1974. Seasonality in ovarian cycles among tropical Anolis lizards. Ecology 55:360-369.

Hahn, W. E. 1964. Seasonal changes in the testicular and epididymal histology and spermatogenic rate in the lizard Uta stansburiana stejnegeri. J. Morph. 115:447-460.

1967. Estradiol-induced vitellinogenesis and concomitant fat mobilization in the lizard Uta stansburiana. Comp. Biochem. Physiol. 23:83-93.

- and D. W. Tinkle. 1965. Fat body cycling and experimental evidence for its adaptive significance to ovarian follicle development in the lizard Uta stansburiana. J. Exp. Zool. 158:79-86. 
Hairston, N. G., D. W. Tinkle and H. M. Wilbur. 1970. Natural selection and the parameters of population growth. J. Wild. Manage. 34:681-690.

Hansen, R. M. 1974. Dietary of the chuckwalla, Sauromalus obesus, determined by dung analysis. Herpetologica 30:120-123.

Harris, D. M. 1982. The phenology, growth and survival of the green iguana, in northern Columbia. Pp. 150-161, in G. M. Burghardt and A. S. Rand (Eds.), Iguanas of the world : their behavior, ecology and conservation. Noyes, Park Ridge, N. J.

Hastings, J. R. and R. M. Turner. 1965 The Changing Mile. The University of Arizona Press. Tucson, Arizona. 317 pp.

Hirshfield, M. F. and D. W. Tinkle. 1975. Natural selection and the evolution of reproductive effort. Proc. Nat. Acad. Sci. 72:22272231 .

Hoddenbach, G. 1966. Reproduction in western Texas Cnemidophorus sexlineatus (Sauria, Teiidae). Copeia 1966:110-113.

- and F. B. Turner. 1968. Clutch size of the lizard Uta stansburiana in southern Nevada. Amer. Midl. Nat. 80:262-265.

Holling, C. S. 1959. The components of predation as revealed by a study of small mammal predation of the European pine sawfly. Cand. Entomo1. 91:293-320.

Humason, G. L. 1979. Animal Tissue Techniques, $4^{\text {th }}$ ed. W. H. Freeman and Company. San Francisco. 661 pp.

Iverson, J. B. 1979. Behavior and ecology of the rock iguana, Cyclura carinata. Bull. Florida State Mus. Biol. Sci. 24:175-358.

Jacob, D. and L. S. Ramaswami. 1976. The female reproductive cycle of the indian monitor lizard, Varanus monitor. Copeia 1976:256-260.

Jameson, E. W., Jr. 1974. Fat and breeding cycles in a montane population of Sceloporus graciosus. J. Herpetol. 8:331-322.

- and A. Allison. 1976. Fat and breeding cycles in two montane populations of Sceloporus occidentalis. J. Herpetol. 10: 211-220.

Johnson, C. 1960. Reproductive cycle in females of the earless lizard, Holbrookia texana. Copeia 1960:297-300.

Johnson, S. R. 1965. An ecological study of the chuckwalla, Sauromalus obesus Baird, in the western Mojave desert. Am. Midl. Nat. 73:1-29. 
Jolly, G. M. 1965. Explicit estimates for capture-recapture data with both death and emigration - stochastic model. Biometrika $52: 225-247$.

Kolman, W. A. 1960. The mechanism for natural selection for the sex ratio. Amer. Natur. 94:373-377.

Koul, 0. and P. L. Duda. 1977. Ovarian cycle in high altitude lizards from Kashmir. Copeia 1977:751-754.

Lack, D. 1954. The Natural Regulation of Animal Numbers. London, Oxford Univ. Press. 343 pp.

Leslie, P. H. 1952. The estimation of population parameters from data obtained by means of the capture-recapture method II. The estimation of total numbers. Biometrika 39:363-388.

Licht, P. 1970. Effects of mammalian gonadotropins (ovine FSH and LH) in female lizards. Gen. Endocr. 14:98-106.

- and G. C. Gorman. 1970. Reproduction and fat bodies in Caribbean Anolis lizards. Univ. Calif. Publ. Zool. 95:1-12.

- 1975. Altitudinal effects on the seasonal testis cycles of tropical Anolis lizards. Copeia 1975:496-504.

Lowe, C. H. and S. R. Goldberg. 1966. Variation in the circumtesticular Leydig cell tissue of teiid lizards (Cnemidophorus and Ameiva). J. Morph. 119:277-281.

MacArthur, R. H. and E. O. Wilson. 1967. Theory of Island Biogegraphy. Princeton Univ. Press, Princeton. 203 pp.

Marion, K. R. and O. J. Sexton. 1971. The reproductive cycle of the lizard Sceloporus malachiticus in Costa Rica. copeia 1971:517526.

Martin, R. F. 1973. Reproduction in the tree lizard, Urosaurus ornatus in central Texas: drought conditions. Herpetologica 29: $\overline{27-32}$.

- 1977. Variation in reproductive productivity of range margin tree lizards, Urosaurus ornatus. Coipeia 1977:83-92.

Mayhew, W. W. 1961. Photoperiodic response of female fringe-toed lizards. Science 134:2104-2105.

- 1963. Reproduction in the granite spiny lizard, Sceloporus orcutti. Copeia 1963:144-152.

$\therefore$ 1964. Photoperiodic response in three species of the lizgenus Uma. Herpetologica 20:95-113. 
Mayhew, W. W. 1965. Reproduction in the sand-dwelling lizard Uma inornata. Herpetologica 21:39-55.

- 1966a. Reproduction in the arenicolous lizard Uma notata. Ecology $47: 9-18$.

- 1966b. Reproduction in the psammophilous lizard Uma scoparia. Copeia 1966:114-122.

1968. Biology of desert amphibian and reptiles. Pp. 195-356, in G. W. Brown Jr. (Ed.). Vol I Desert Biology. Academic Press.

- 1971. Reproduction in the desert lizard Dipsosaurus dorsalis. Herpetologica $27: 57-77$.

- and S. J. Wright. 1970. Seasonal changes in testicualr histology of three species of the lizard genus Uma. J. Morph. 130: 163-186.

McCoy, C. J. and G. A. Hoddenbach. 1966. Geographic variation in ovarian cycles and clutch size in Cnemidophorus tigris (Teiidae). Science 154:1671-1672.

Medica, P. A., G. A. Hoddenbach and J. R. Lannom Jr. 1971. Lizard sampling techniques. Rock Valley Misc. Publ. No. 1, 55 pp.

- and F. B. Turner. 1976. Reproduction by Uta stansburiana (Reptilia, Lacertilia, Iguanidae) in southern Nevada. J. Herpetol. $10: 123-128$.

Miller, M. R. 1948. The seasonal histological changes occurring in the ovary, corpus luteum and testis of the viviparous lizard, Xantusia vigilis. Univ. of Calif. Publ. Zool. 47:197-224.

- 1951. Some aspects of the life history of the yucca lizard, Xantusia vigilis. Copeia 1951:114-120.

- 1959. The endocrine basis for reproductive adaptations in reptiles. Pp. 499-516 in A. Gorman (Ed.), Comparative Endocrinology. John Wiley, New York.

- 1963. The histogenesis of the endocrine organs of the vivia parous lizard Xantusia vigilis. Gen. Comp. Endocr. 3:579-605.

Minnich, J. E. 1971. Seasonal variation in weight-length relationships and fat body size in the desert iguana, Dipsosaurus dorsalis. Copeia $1971: 359-362$.

Mountford, M. D. 1968. The significance of litter size. J. anim. Ecol. 37:75-79. 
Mulaik, D. 1946. A comparative study of the urogenital systems of a oviparous and two ovoviviparous species of the lizard genus Sceloporus. Bu11. Univ. Utah Biol. Ser. 37:3-24.

Munz, P. 1968. A California Flora. Berkeiey and Los Angeles: Univ. Calif. Press. 1681 pp.

Murphy, G. I. 1968. Pattern in life history and the environment. Amer. Natur. 102:390-404.

Muth, A. 1977. Eggs and hatchlings of captive Dipsosaurus dorsalis. Copeia 1977:189-190.

- 1980. Physiological ecology of the desert iguana, Dipsosaurus dorsalis eggs: temperature and water relations. Ecology $61: 1335-1343$.

Nagy, K. A. 1971. Seasonal metabolism of water, energy and electrolytes in a field populationof desert lizards, Sauromalus obesus. Ph.D. Thesis. Univ. of Calif., Riverside.

- 1973. Behavior, diet and reproduction in a desert lizard, Sauromalus obesus. Copeia 1973:171-184.

- 1983. Ecological energetics. Pp. 24-54, in R. B. Huey, E. R. Pianka and T. W. Schoener (Eds.), Lizard Ecology: Studies of a model Organism. Harvard Univ. Press, Cambridge, Mass.

Newlin, M. E. 1976. Reproduction in the bunch grass lizard, Sceloporus scalaris. Herpetologica 32:171-184.

Nichols, J. D., G. L. Hansler and P. W. Sykes, Jr. 1980. Demography of the Everglade Kite: implications for population management. Ecol. Mode1. 9:215-232.

Nicholson, A. J. 1933. The balance of animal populations. J. Anim. Ecol. 2:132-178.

Parker, W. S. and E. R. Pianka. 1975. Comparative ecology of populations of the lizard Uta stansburiana. Copeia 1975:615-632.

- and E. R. Pianka. 1976. Ecological observation on the leopard lizard, Crotaphytus wislizeni, in different parts of its range. Herpetologica 32:95-114.

Pianka, E. R. 1970a. On r- and K-selection. Amer. Natur. 104:592-597.

- 1970b. Comparative autecology of the lizard Cnemidophorus tigris in different parts of its geographic range. Ecology 51: 703-720. 
Pianka, E. R. 1972. $r$ and K-selection or $b$ and $d$ selection. Amer.Natur. 106:581-588.

- 1976. Natural selection of optimal reproductive tactics. Am. Zool. 16:775-784.

- 1978. Evolutionary Ecology 2 $\frac{\text { nd }}{2}$ ed. Harper \& Row, Publishers N. Y. 397 pp.

- and W. S. Parker. 1976. Age-specific reproductive tactics. Amer. Natur. 109:453-464.

Porter, H. R. 1972. Herpetology. W. B. Saunders Co. Phila. 524 pp.

Pough, H. R. 1973. Lizard energetics and diet. Ecology 54:837-844.

Prieto, A. A. 1977. Reproduction in the Arizona chuckwalla, Sauromalus obesus tumidus Shaw. Amer. Midl. Nat. 98:463-469.

- and M. J. Ryan. 1978. Some observations on the social behavior of the Arizona chuckwalla, Sauromalus obesus tumidus

(Reptilia, Lacertilia, Iguanidae). J. Herpetol. 12:260-262.

Rahn, H. 1938. The corpus luteum of reptiles. Anat. Rec. 72:55 Supp1.

Rand, A. S. 1954. Variation and predator pressure in an island and a mainland population of lizards. Copeia 1954:260-262.

- and H. Greene. 1982. Latitude and climate in the phenology in the green iguana, Iguana iguana. Pp. 142-149, in G. M. Burghardt and A. S. Rand (Eds.), Iguanas of the world: their behavior ecology and conservation. Noyes, Park Ridge, N. J.

Ricklefs, R. E. 1977. On the evolution of reproductive strategies in birds: reproductive effort. Amer. Natur. 11:453-478.

- 1979. Ecology $3^{\text {rd }}$ ed. Chiron Press., Inc. New York. 966 pp.

Roughgarden, J. 1971. Density-dependent natural selection. Ecology $52: 453-468$.

Ruibal, R., R. Philibosian and J. L. Atkins. 1972. Reproductive cycle and growth in the lizard Anolis acutus. Copeia 1972:509-518.

- and R. Philibosian, 1974. The populaiton ecology of the lizard Anolis acutus. Ecology 55:525-537.

Ryan, M. J. 1982. Variation in iguanine social organization: mating systems in chuckwallas (Sauromalus). Pp. 380-390, in G. M. Burghardt and A. S. Rand (Eds.), Iguanas of the world: their behavior, ecology and conssrvation. Noyes, Park Ridge, N. J. 
Sanyal, M. K. and M. R. N. Prasad. 1966. Sexual segment of the kidney of the Indian house lizard Hemidactylus flaviviridis Ruppel. J. Morph. 118:627-633.

Schaffer, W. M. 1972. Evolution of optimal reproductive strategies. Ph.D. Thesis. Princeton Univ. Princeton.

- 1974. Selection for optimal life histories. The effects of age. Ecology 55:291-303.

Schal1, J. J. 1978. Reproductive strategies in sympatric whiptail lizards (Cnemidophorus): 2 parthenogenic and 3 bisexual species. Copeia 1978:108-116.

Schumacher, F. X. and R. W. Eschmeyer. 1943. The estimate of fish population in lakes or ponds. J. Tenn. Acad. Sci. 228-249.

Sexton, O. J., E. P. Ortleb, L. M. Hathaway, R. E. Ballinger, and P. Licht. 1971. Reproductive cycles of three species of anoline lizards from the isthmus of Panama. Ecology 52:201-215.

Shaw, C. E. 1945. The chuckwallas, genus Sauromalus. San Diego Soc. Nat. Hist. Trans. 10:269-305.

Shine, R. 1980. Costs of reproduction in reptiles. Oecologia (Berlin) 46:92-100.

Shrank, G. D. and Ballinger, R. E. 1973. Male reproductive cycles in two species of lizards (Cophosaurus texanus and Cnemidophorus gularis). Herpetologica 29:289-293.

Smith, D. C. 1977. Interspecific competition and the demography of tree lizards. Ph.D. Dissertation, Univ. Mich.

- 1981. Comparative interactions of the striped plateau lizard, Sceloporus virgatus and the three lizard, Urosaurus ornatus. Ecology 62:679-687.

Smith, R. E. 1968. Experimental evidence for gonadal fat body relationship in two teiid lizards (Ameiva festiva, Ameiva quadrilineata). Biol. Bull. mar. biol. lab., Woods Hole 134:325-331.

Sokal, R. R. and F. J. Rohlf. 1969. Biometry. W. H. Freeman and Company, San Francisco. 776 pp.

Southwood, T. R. E., P. M. May, M. P. Hassell, and G. P. Conway. 1974. Ecological strategies and population parameters. Amer. Natur. $108: 791-804$.

Stearns, S. C. 1976. Life history tactics: a review of the ideas. Q. Rev. Biol. 51:3-47. 
1977. The evolution of life history traits: a critique of the theory and a review of the data. Ann. Rev. Ecol. Syst. $8: 145-171$.

Stebbins, R. C. 1966. A Field Guide to Western Reptiles and Amphibians. Houghton Mifflin, Boston. 279 pp.

Telford, S. R., Jr. 1969. The ovarian cycle, reproductive potential, and structure in a population of the Japanese lacertid Tachydromus techydromoides. Copeia 1969:548-567.

- 1970. Seasonal fluctuations in liver and kidney weights of the Japanese lacertid Takydromus tachydromoides. Copeia 1970: 681-689.

Tinkle, D. W. 1961. Population structure and reproduction in the lizard Uta stansburiana stejnegeri. Am. Midl. Natur. 66:206-234.

- 1967. The life history and demography of the side-blotched lizard, Uta stansburiana, Misc. Publ. Mus. Zool. Univ. Michigan $132: 1-182$.

- 1969. The concept of reproductive effort and its relation to the evolution of life histories in lizards. Amer. Natur. 103: $501-516$.

- 1972. The dynamics of a Utah population of Sceloporus undulatus. Herpetologica 28:351-359.

- 1973. A population analysis of the sagebrush lizard, Sceloporus graciosus, in southern Utah. Copeia 1973:284-295.

., H. M. Wilbur, and S. T. Tilley. 1970. Evolutionary strategies in lizard reproduction. Evolution 24:55-74.

- and R. E. Ballinger. 1972. Sceloporus undulatus: a study of the intraspecific comparative demography of a lizard. Ecology $53: 570-584$.

- and N. F. Hadley. 1973. Reproductive effort and winter activity in the viviparous montane lizard Sceloporus jarrovi. Copeia 1973:272-276.

- 1975. Lizard reproductive effort: caloric estimates and comments on its evolution. Ecology 56:427-434.

Trauth, S. E. 1979. Testicular cycle and timing of reproduction in the collared lizard, Crotaphytus collaris in Arkansas. Herpetologica 35:184-192.

Trivers, R. L. 1972. Parental investment and sexual selection. Pp 52-114 in T. H. Clutton-Brock and P. H. Harvey (Eds.): Readings in Sociobiology. 1978. Freeman, San Francisco. 
Turner, F. B. 1960. Estimation of a Louisiana population of the skink, Lygosoma laterale. Ecology 41:574-577.

- 1977. The dynamics of populations of squamates, crocodilians, and rhynchocephalians. Pp. 157-264 in C. Gans and D. W. Tinkle (Eds.). Biology of the Reptilia, Vol. VII. Academic Press, London.

Turner, F. G., J. R. Lannom Jr., P. A. Medica and G. A. Hoddenbach. 1969. Density and composition of fenced populations of leopard lizards, Crotaphytus wislizenii, in southern Nevada. Herpetologica $25: 247-257$.

., G. A. Hoddenbach, P. A. Medica, and J. R. Lannom Jr. 1970. The demography of the lizard, Uta stansburiana Baird and Girard, in southern Nevada. J. Anim. Ecol. 39:505-519.

Van Deventer, R. W. 1982a. Comparative demography of the lizard Basiliscus basiliscus. Herpetologica 38:189-208.

- 1982b. Growth and ecology of sping-tailed and green iguanas in Costa Rica, with comments on the evolution of herbivory and large body size. Pp. 162-182, in G. M. Burgehardt and A. S. Rand (Eds.), Iguanas of the world: their behavior, ecology and conservation. Noyes, Park Ridge, N. J.

Vinegar, M. B. 1975. Demography of the striped plateau lizard, Sceloporus virgatus. Ecology 56:172-182.

Vitt, L. J. 1973. Reproductive biology of the anguid lizard Gerrhonotus coerules principis. Herpetologica 29:176-184.

- 1974. Reproductive effort and energy comparisons of adults, eggs and neonates of Gerrhonotus coeruleus principis. J. Herpetol $8: 165-168$.

- 1977. Observations on clutch and egg size and evidence for multiple clutches in some lizards of southwestern United States. Herpetologica 33:333-338.

- 1978. Caloric content of lizard and snake (Reptilia) eggs and bodies and the conversion of weight to cąloric data. J. Herpetol: $12: 65-72$.

- 1981. Lizard reproduction: habitat specificity and constraints on relative clutch mass. Amer. Natur. 117:506-514.

- and R. D. Ohmart. 1974. Reproduction and ecology of Colorado River population Sceloporus magister (Sauria, Iguanidae). Herpetologica 30:410-417. 
- 1975. Ecology, reproduction and reproductive effort of the iguanid lizard Urosaurus graciosus on the lower Colorado River. Herpetologica 31:56-65.

- 1977a. Ecology and reproduction of the lower Colorado River lizards: I Callisaurus draconoides (Iguanidae) Herpetologica $33: 214-222$.

- 1977b. Ecology and reproduction of the lower Colorado River lizards: II Cnemidophorus tigris (Teiidae), with comparisons. Herpetologica 33:223-234.

., J. D. Congdon and N. A. Dickson. 1977. Adaptive strategies and energetics of tail autotomy in lizards. Ecology 58:326337 .

Vitt, L. J. and J. D. Congdon. 1978. Body shape, reproductive effort and relative clutch mass in lizards: resolution of the paradox. Amer. Natur. 112:595-608.

- H. J. Price. 1982. Ecological and evolutionary determinants of relative clutch mass in lizards. Herpetologica 38:237-255.

Werner, D. I. 1983. Reproduction in the iguana Conolophus subcristatus on Fernandina island, Galapagos: clutch size and migration costs. Amer. Natur. 121:757-775.

Wiewandt, T. A. 1977. Ecology, behavior and management of the Mona Island ground iguanas, Cyclura stejnegeri. Ph.D. diss. Cornell University, Ithaca, N. Y.

- 1982. Evolution of nesting patterns in iguanine lizards. Pp. 119-141, in G. M. Burghardt and A. S. Rand (Eds.), Iguanas of the World: their behavior, ecology and conservation. Noyes, Park Ridge, N. J.

Wilbur, H. M., D. W. Tinkle, and J. P. Collins. 1974. Environmental certainty, trophic level, and resource availability in life history evolution. Amer. Natur. 108:805-817.

Wilhoft, D. C. 1963. Gonadal histology and seasonal changes in the tropical Australian 1izard, Leiolopisma rhomboidalis. J. Morph. 113:185-204.

- and W. B. Quay. 1961. Testicular histology and seasonal changes in the lizard Sceloporus occidentalis. J. Morph. 108:95106.

Williams, G. C. 1966a. Adaptation and natural selection. Princeton University Press, Princeton. 307 pp. 
1966b. Natural selection, the costs of reproduction and a refinement of Lack's principle. Amer. Natur. 100:687-690.

Zar, J. H. 1984. Biostatistical Analysis 2nd ed. Prentice-Hal1, Inc. Englewood Cliffs, N. J. 718 pp.

Zweifel, R. G. and C. H. Lowe. 1966. The ecology of a population of Xantusia vigilis, the desert night lizard. Am. Mus. Novit. 2247:157. 